\title{
Population genetics of the teleost orange roughy, Hoplostethus atlanticus, and insights into their visual adaptations to the deep-sea environment
}

By

\section{Andrea Isabel Varela Nayar}

\author{
A thesis \\ submitted to Victoria University of Wellington \\ in fulfilment of the requirements for the degree of \\ Doctor of Philosophy in Conservation Biology
}

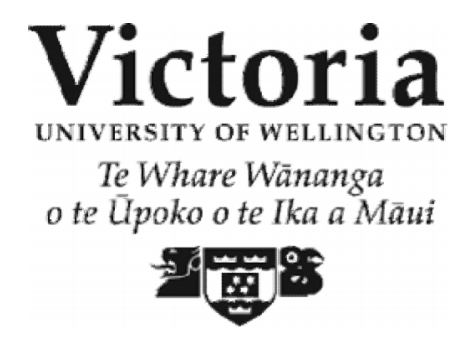

Victoria University of Wellington

Te Whare Wānanga o te Ūpoko o te Ika a Māui 

This thesis was conducted under the supervision of:

Dr. Peter A. Ritchie (Primary Supervisor)

Victoria University of Wellington

Wellington, New Zealand

and

Dr. Peter J. Smith (Secondary Supervisor)

Museum Victoria

Melbourne, Australia 



\begin{abstract}
The orange roughy, Hoplostethus atlanticus, has been one of the main targeted species in deep-sea fisheries worldwide. It occurs at depths of $450-1800 \mathrm{~m}$ and is abundant off the coasts of New Zealand, Australia, Namibia, Chile, and in the Northeast Atlantic Ocean. Like many other deep-sea fishes, orange roughy is vulnerable to over exploitation because they grow slow reaching maturity at about 30 years and live for more than 100 years. Their fecundity is low, which means they have low productivity. The individuals form predictable and dense spawning aggregations close to seamounts, plateaus and canyons. The trawl fishery for orange roughy started in seamounts around New Zealand in the late 1970s and progressively expanded off the coast of other countries and to the high seas (out of any Economic Exclusive Zone). Most stocks have been fished down to or below $30 \%$ pre-exploitation levels; as a consequence, fisheries have been closed or catches largely reduced. Currently, the only large scale fisheries operate off New Zealand.
\end{abstract}

For effective fisheries management it is essential to define real biological units or "stocks". There has been considerable research into the levels of population differentiation of orange roughy using a range of techniques at different geographic scales to attempt to differentiated stocks. However, there is no consensus about the level of connectivity among populations. In the present study, I investigated the levels of population differentiation in orange roughy using two types of neutral molecular markers at a global and fine-scales. Both markers revealed high levels of genetic diversity which is likely related with historically large population sizes. The analyses of 546 cytochrome $c$ oxidase subunit I (COI) sequences revealed a lack of global genetic differentiation among samples from New Zealand, Australia, Namibia, and Chile. However, low but significant differentiation was found between the Southern hemisphere sites and two Northeast Atlantic sites. Mismatch distribution and Bayesian analyses indicated the occurrence of expansion events in orange roughy during the Pleistocene period. A data set of nine microsatellite DNA loci genotyped from 812 individuals, showed a predominant lack of significant genetic differentiation across the Tasman Sea and at a fine-scale around New Zealand. At a global scale, differentiation was low but significant across the Southern hemisphere; and the highest values of differentiation were detected between the Southern hemisphere sites and the Northeast 
Atlantic Ocean. The predominant lack of differentiation at the regional and fine-scale and the low differentiation within the Southern hemisphere is probably the result of stepping-stone dispersal of long-lived adults that are able to spawn many times in their life.

Most orange roughy studies have been oriented to fisheries aspects, but other kind of studies as the genetic divergence and phylogenetic relationships among Hoplostethus species are lacking. Using available COI sequences, I conducted a phylogenetic study including $H$. atlanticus, $H$. crassispinus, $H$. gigas, $H$. japonicus $H$. latus, and $H$. mediterraneus. As expected, the inter species divergence was much higher than the intra species divergence. Phylogenetics analyses showed that $H$. latus, $H$. crassispinus, $H$. japonicus, and $H$. mediterraneus form a separate clade from $H$. atlanticus and $H$. gigas. The position of $H$. gigas was not well defined with the nucleotide data. However, at the amino acid level, non-synonymous substitutions differentiated $H$. atlanticus from all the other species. This was correlated with morphological characteristics presented elsewhere.

A candidate gene approach was attemped using the rhodopsin gene; however, there was almost no variation among partial sequences of individuals from distant sites. Instead, this gene was used to investigate the molecular basis for visual adaptations in orange roughy to the bathypelagic light environment. It is known that certain amino acid replacements in the rhodopsin gene of vertebrates shift the $\lambda_{\max }$ value of the pigment to perceive different light conditions. To compare and identify critical amino acid sites that are known to be involved in spectral tuning, I obtained partial rhodopsin sequences of other 18 marine teleost habiting at different depths $(1-1,175 \mathrm{~m})$ and, thus, different light environments. A phylogenetic analysis was conducted to determine whether particular rhodopsin gene sequences correlate with the depths occupied by the species. I identified four critical amino acid replacements that have been involved in the spectral tuning of rod pigments. Orange roughy presented the same amino acid combination at two critical sites already reported for the deep-sea congener silver roughy, which was not found in any of the other species. This likely reflects an adaptation to the light available (i.e. bioluminescence) in the bathypelagic environment. The phylogeny was weakly related to the maximum depth of the species, probably because there are selectively neutral (i.e. inherited by ancestry) and non-neutral changes (i.e. influenced by natual selection) among the rhodopsin sequences of the species being considered. 


\section{Acknowledgements}

I most thank to my primary supervisor Dr. Peter Ritchie who welcomed me to come to New Zealand to conduct my $\mathrm{PhD}$ studies under his guidance. I am grateful for his support and help over all the development of this project and for his positive feedback and advice. I am also deeply grateful for the support and feedback of my secondary supervisor Dr. Peter Smith. His expertise in marine fish genetics was an invaluable input for the study of genetic structure in orange roughy.

I would like to thank to Milan Barbarich and Khush Mistry from Anton's Seafoods Ltd, and Jim Fitzgerald from Sanford Ltd for their financial support and assisting with sample collection in Northern New Zealand. I express my gratitude to Dave Banks and the New Zealand Seafood Industry Council Ltd. for their assistance and help during the first stage of this project. Also to Kris Ramm, Ministry of Fisheries Observer, for collection of samples in Northern New Zealand. I am most grateful for all the persons and institutions that made possible to extent this study across the Southern hemisphere and to the Northeast Atlantic Ocean resulting in a valuable global-scale study. Dr. Peter Smith and NIWA (National Institute of Water and Atmospheric Research, New Zealand) gave all the facilities to obtain samples from around central and southern New Zealand, South Australia and from Namibia that were from a frozen tissue collection held at NIWA. I thank to Edwin Niklitschek, Universidad Austral de Chile for samples from the Juan Fernández Archipelago, Chile; and to Jamie Coughlan, University College Cork, Ireland and Sergio Stefanni, University of the Azores, Portugal who provided samples from the Northeast Atlantic Ocean.

Thanks to all former and current persons in Peter's lab group that I have luckily met. I especially thank Elizabeth Hegg, Sebastien Rioux Paquette and Monica Gruber for their help in laboratory stuff and analyses at the beginning of my $\mathrm{PhD}$. Sebastien was of most help in my introduction to the microsatellite DNA world. Many thanks to the lab partners who let me used some of their fish samples to develop the comparative rhodopsin gene study, to Hayden (who provided most of the samples), Heather, Sebastien, Jack, Henry, David and Brenton. 
CONICYT (Comisión Nacional de Investigación Científica y Tecnológica, Gobierno de Chile) and Victoria University of Wellington (VUW) Scholarships made possible to carry out my $\mathrm{PhD}$ studies in Wellington. Thanks also to Faculty Strategic Research Grants (VUW) and to the First Overseas Conference Travel Fund (New Zealand Marine Sciences Society), for their financial support to attend and present my $\mathrm{PhD}$ project in the Australian Society for Fish Biology Conference 2011, Australia.

This journey would not been possible without the company of my husband Sergio. His love, partnership and support have made this time in New Zealand a great and unforgettable experience. His dedication to marine sciences and the constant day by day sharing of difficulties and achievements were a great motivation and help to develop my project.

I also thanks to all my office mates with whom I have shared space and experiences during the past four years; particularly to Roz for being such a nice, easy-going and supportive person. Thanks to the big group of Chilean (and other Latin Americans!) friends for all the friendship, help and for make this a unique experience. To Daniela, Ursula, Sebastián, Erasmo, Alejandro, Enrique, Alejandra, Benjamín, Marcela, Cristian, Marisol, Gelant, Mariana, Mauro, Fernanda, and Alfonso.

Last but not less, my most lovely thanks goes to mum Aileen and to my sister and brothers Claudia, Pepe and Carlitos. Their infinitive support and love have been fundamentals pillars to be here and to live this experience far from them. 


\section{Publications from this Thesis ${ }^{1}$}

\section{Published Articles}

Varela AI, Ritchie PA, Smith PJ (2012) Low levels of global genetic differentiation and population expansion in the deep-sea teleost Hoplostethus atlanticus revealed by mitochondrial DNA sequences. Marine Biology 159:1049-1060.

Author contribution: AI Varela, PA Ritchie and PJ Smith developed the theoretical framework of the project. AI Varela conducted the laboratory work, analyzed the data and wrote the manuscript. PA Ritchie and PJ Smith gave comments and edited the manuscript.

Varela AI, Ritchie PA, Smith PJ (2013) Global genetic population structure in the commercially exploited deep-sea teleost orange roughy (Hoplostethus atlanticus) based on microsatellite DNA analyses. Fisheries Research 140:83-90

Author contribution: AI Varela, PA Ritchie and PJ Smith developed the theoretical framework of the project. AI Varela conducted the laboratory work, analyzed the data and wrote the manuscript. PA Ritchie and PJ Smith gave comments and edited the manuscript.

${ }^{1}$ As of $25^{\text {th }}$ January 2013 


\section{Article in Preparation}

Varela AI, Ritchie PA, Smith PJ (In Preparation) Critical amino acid replacements in the rhodopsin gene of the deep-sea teleost orange roughy (Hoplostethus atlanticus): comparison with other teleost species occupying different light environments. Intended for submission to New Zealand Journal of Marine and Freshwater Research

Author contribution: AI Varela and PA Ritchie developed the theoretical framework of the project. AI Varela conducted the laboratory work, analyzed the data and wrote the manuscript. PA Ritchie and PJ Smith gave comments and edited the manuscript. 


\section{Table of Contents}

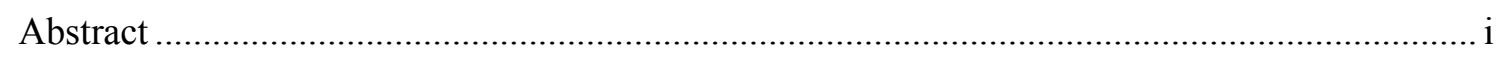

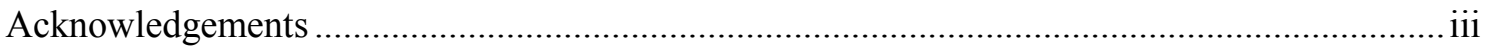

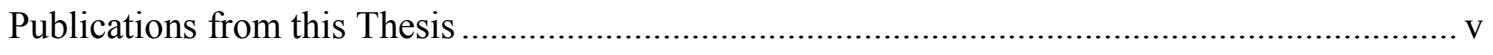

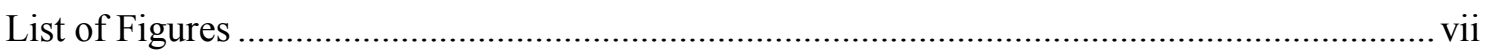

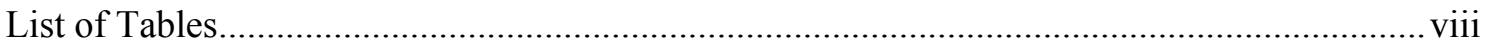

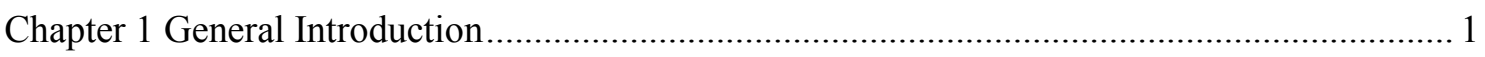

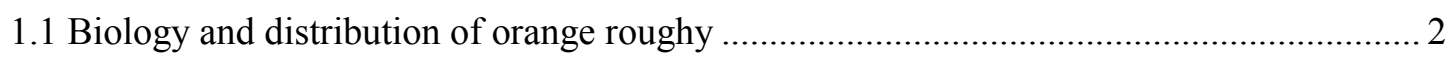

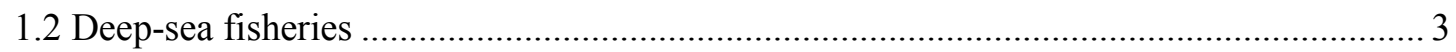

1.3 Fisheries management and population genetics ............................................................. 4

1.4 Population differentiation studies in orange roughy ......................................................... 6

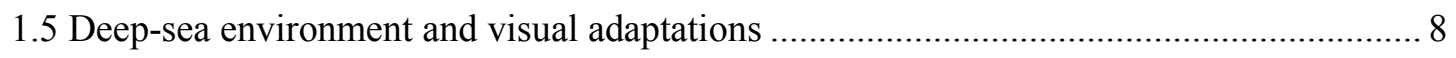

1.6 Demographic history and DNA sequence analyses ..................................................... 9

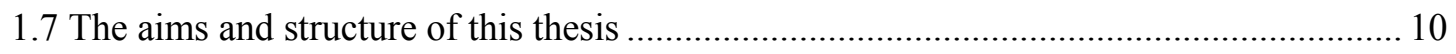

Chapter 2 Low levels of global genetic differentiation and population expansion in the deep-sea teleost Hoplostethus atlanticus revealed by mitochondrial DNA sequences .............................. 11

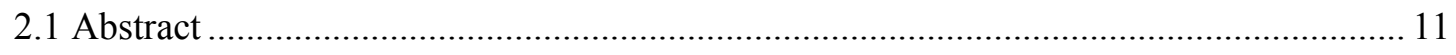

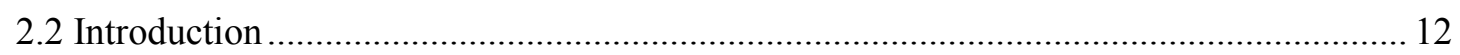

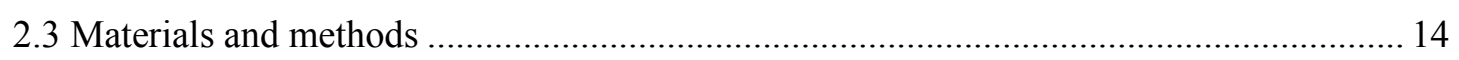

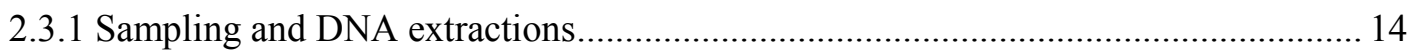

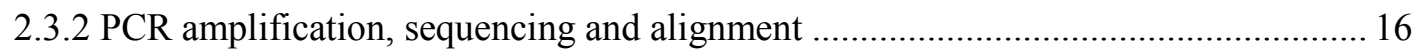

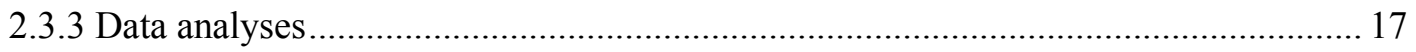

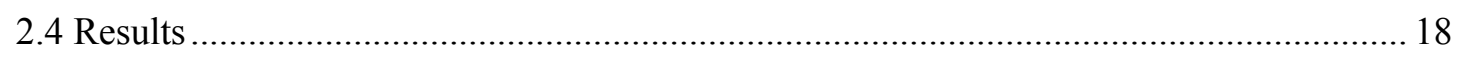

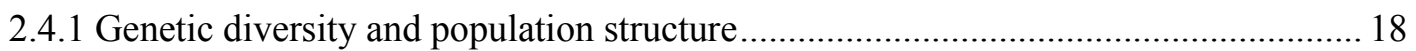

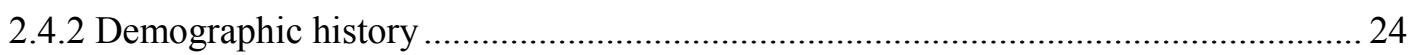

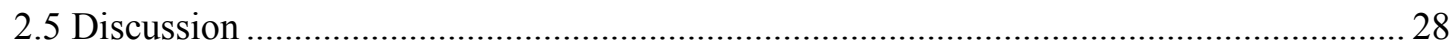

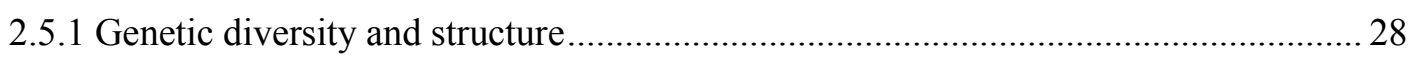

2.5.2 Implications for fisheries management in New Zealand ............................................ 30

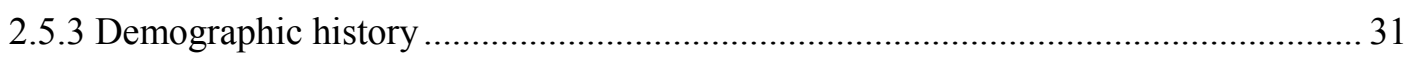

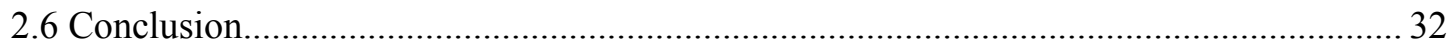


Chapter 3 Global and fine-scale population structure in the commercially exploited deep-sea

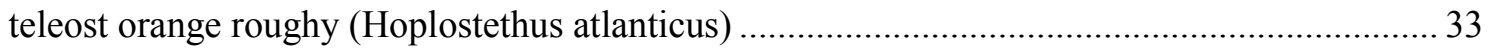

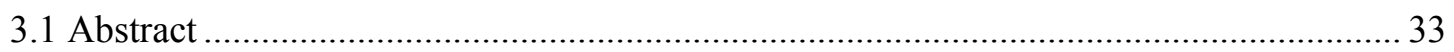

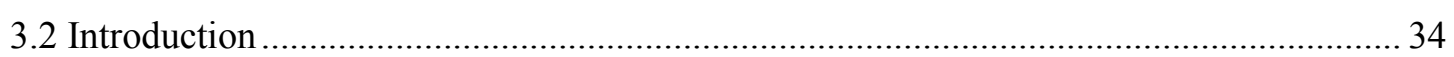

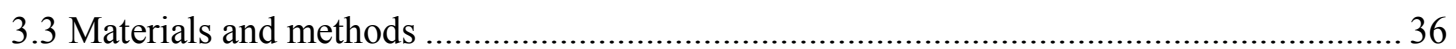

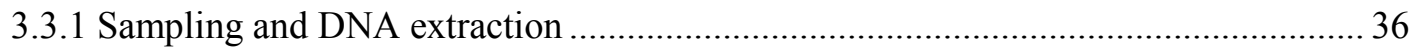

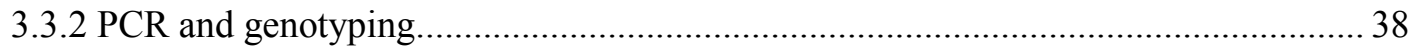

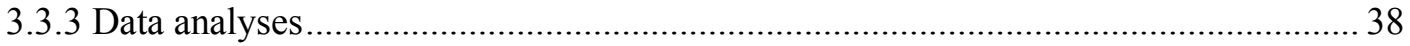

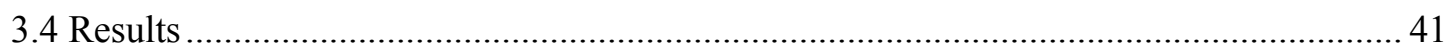

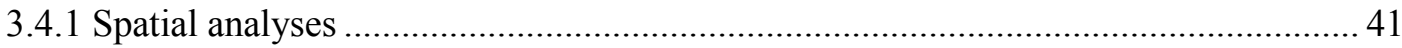

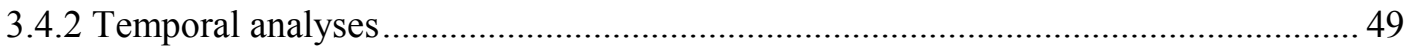

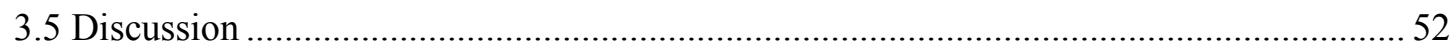

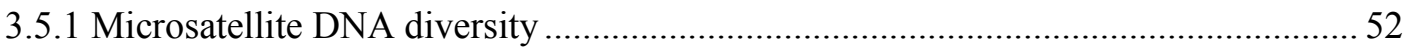

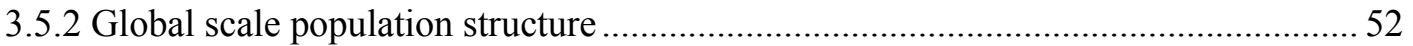

3.5.3 Fine-scale population structure and implications for fisheries management in New

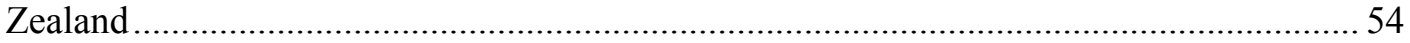

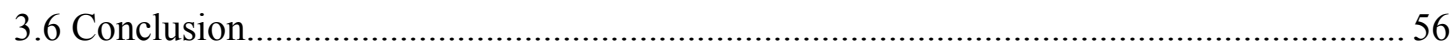

Chapter 4 Genetic divergence and phylogenetic relationships of six species of the genus Hoplostethus based on Cytochrome $c$ Oxidase I (COI) sequences ........................................... 57

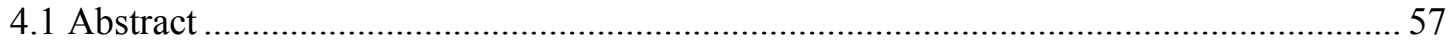

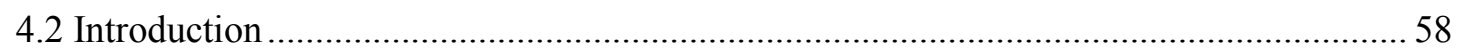

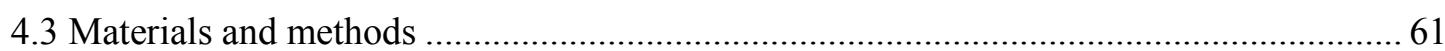

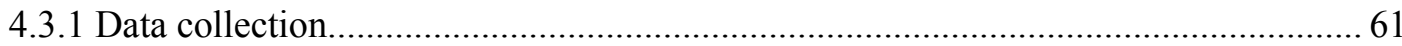

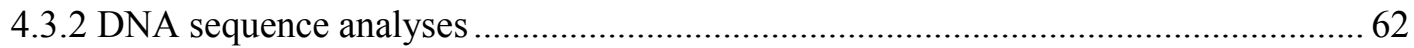

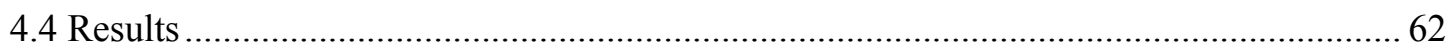

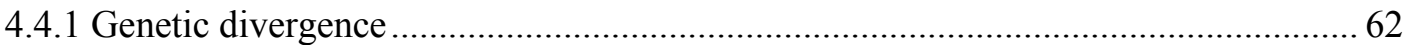

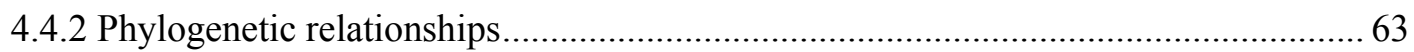

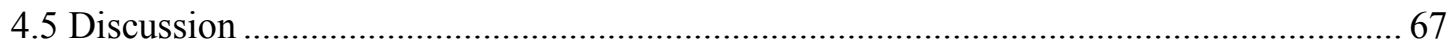

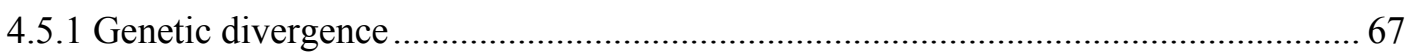

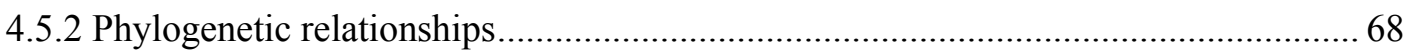

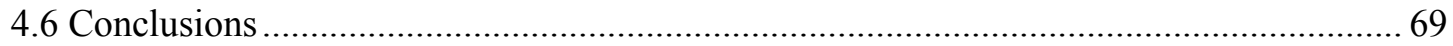


Chapter 5 Critical amino acid replacements in the rhodopsin gene of the deep-sea teleost orange roughy (Hoplostethus atlanticus): comparison with other teleost species occupying different

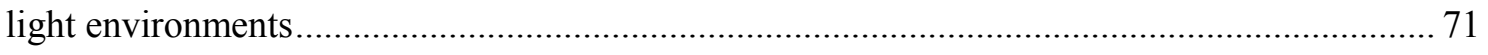

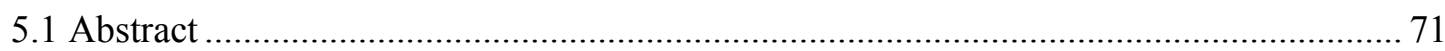

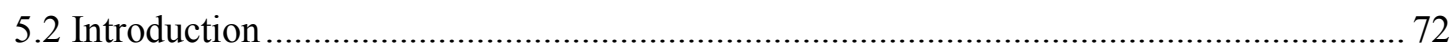

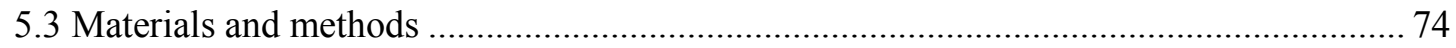

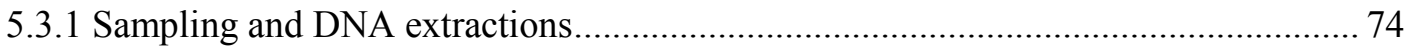

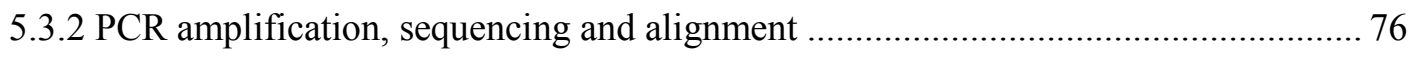

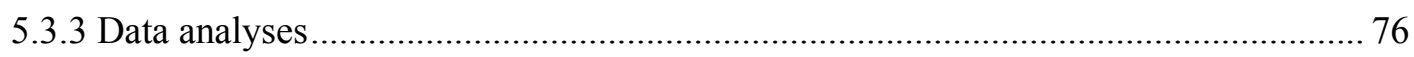

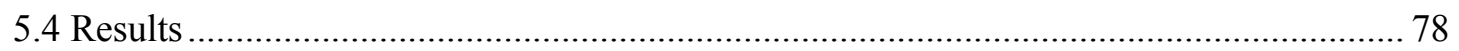

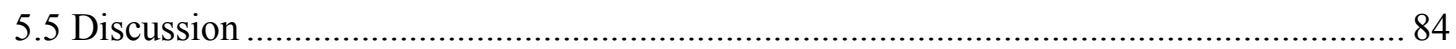

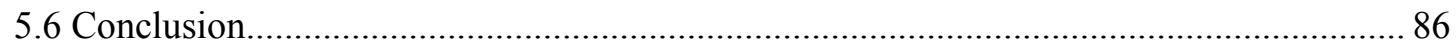

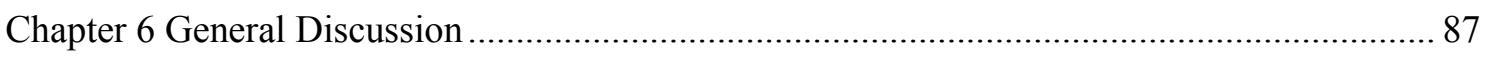

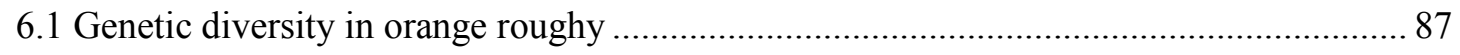

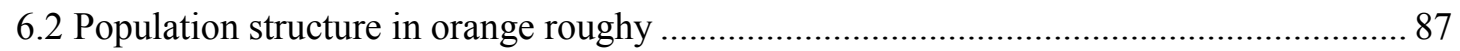

6.3 Implications for fisheries management in New Zealand .................................................. 91

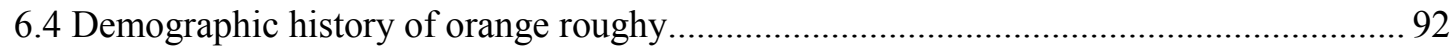

6.5 Genetic divergence and phylogenetic relationships of Hoplostethus spp......................... 95

6.6 Visual adaptations of orange roughy to the bathypelagic light environment .................... 95

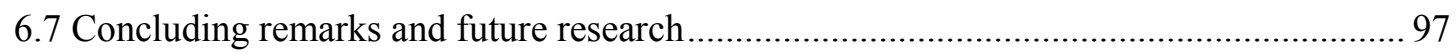

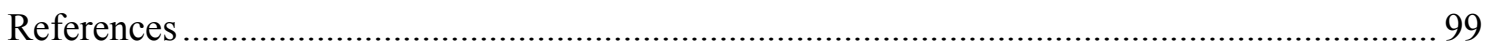

Appendix A COI haplotype frequencies in each sampling site............................................... 119

Appendix B Cyt $b$ haplotype frequencies in each area ........................................................... 122

Appendix C Genotypes of each individual for the spatial analyses ......................................... 123

Appendix D Genotypes of each individual for eight sampling sites from the ORH1 area sampled

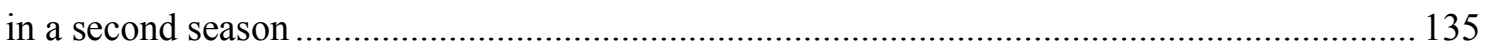

Appendix E Genetic statistics for each microsatellite DNA locus in all sampling sites ........... 139 Appendix F Cover page of articles published in Marine Biology (Chapter 2) and in Fisheries

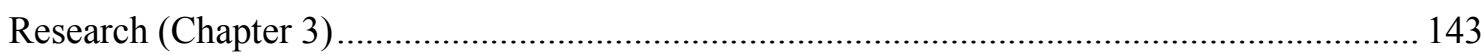




\section{List of Figures}

Fig. 2.1 Map showing the sampling sites surveyed for orange roughy using Cytochome $c$ Oxidase I (COI) sequences

Fig. 2.2 Haplotype genealogy from Maximum Likelihood (ML) tree of the COI sequences performed in the software Haploviewer

Fig. 2.3 Mismatch distribution graphic of the COI sequences 25

Fig. 2.4 Bayesian skyline plot of the COI sequences

Fig. 3.1 Map showing the sampling sites surveyed for orange roughy using microsatellite DNA

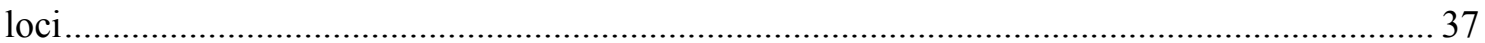

Fig. 3.2 Plot of the first two principal components axes of microsatellite DNA variation 46

Fig. 3.3 Graphic obtained from STRUCTURE HARVESTER indicating the best numbers of $K$ groups from STRUCTURE analyses

Fig. 3.4 Population structure plot inferred by STRUCTURE 48

Fig. 4.1 Kimura 2-Parameter distance neighbour-joining phylogram of COI sequences from six Hoplostethus species and representatives from other three genera. 64

Fig. 4.2 Maximum Likelihood phylogram of COI sequences from six Hoplostethus species and representatives from other three genera

Fig. 5.1 Bayesian phylogram of rhodopsin gene sequences from 19 teleost species using amino acidic data and the bovine sequence as outgroup

Fig. 6.1 Relationship between haplotype diversity $(h)$ and nucleotide diversity $(\pi)$ for marine fishes. Reconstructed following Grant and Waples (2000) 94 


\section{List of Tables}

Table 2.1 Sample sizes for each site surveyed for orange roughy and genetic diversity indices of the Cytochome $c$ Oxidase I (COI) gene

Table 2.2 Sample sizes for the five regions and genetic diversity indices of the cytochrome $b$ (cyt $b$ ) gene.

Table 2.3 Pairwise $\Phi_{\mathrm{ST}}$ values for the COI gene between sampling sites

Table 2.4 Pairwise $\Phi_{\mathrm{ST}}$ values for the COI gene between regions

Table 2.5 Values and probabilities of Tajima's $D$ and Fu's $F$ s for COI sequences for all the sampling sites

Table 2.6 Mismatch distribution values for COI sequences for all the sampling sites 26

Table 3.1 Summary statistics for the levels of genetic variation across nine microsatellite DNA loci for all the sampling sites sampled on one season

Table 3.2 Pairwise $F_{\mathrm{ST}}$ and $D_{\text {est }}$ values for microsatellite DNA loci between sampling sites sampled on one season.

Table 3.3 Pairwise $F_{\mathrm{ST}}$ and $D_{\text {est }}$ values for microsatellite DNA loci between regions 45

Table 3.4 Summary statistics for the levels of genetic variation across nine microsatellite DNA loci for eight sampling sites from Northern New Zealand sampled in a second season 50

Table 3.5 Pairwise $F_{\mathrm{ST}}$ and $D_{\text {est }}$ values between sites sampled in two seasons 51

Table 4.1 Maximum length, depth range and distribution of valid Hoplostethus species 60

Table 4.2 K2P (\%) distances within and among Hoplostethus species 63

Table 5.1 Sample size and sampling area of 19 teleots species used for partial amplification of the rhodopsin gene 
Table 5.2 Depth range and geographic distribution of the 19 teleost species used for partial amplification of the rhodopsin gene

Table 5.3 Heterozygote positions in the rhodopsin nucleotide fragment

Table 5.4 Variable amino acid sites among the 19 teleost species analysed using the bovine rhodopsin sequence as a reference

Table 5.5 Grouping of the species according to the combination of two critical sites. .83 


\section{Chapter 1}

\section{General Introduction}

The orange roughy, Hoplostethus atlanticus Collet 1889 (Teleostei: Trachichthyidae), has been one of the main targeted species in deep-sea fisheries worldwide (Pitcher 2010). Its biological characteristics and their aggregating behaviour, makes orange roughy vulnerable to over exploitation (Clark 1996; Branch 2001; Baker et al. 2009). The fishery for orange roughy started around New Zealand in the late 1970s (Clark 1996) and progressively expanded off the coast of other countries and to the high seas (out of any Economic Exclusive Zone) (reviewed by Branch 2001). Many stocks have been over-fished; consequently, fisheries have been closed or catches largely reduced (see Clark 2009; Niklitscheck et al. 2010; Foley et al. 2011). Currently, the only large scale fisheries operate off New Zealand (Clark 2009; Dunn and Forman 2011).

There are 28 valid species within the genus Hoplostethus, one of them has been recently described (Moore and Dodd 2010). The orange roughy is the only Hoplostethus species with commercial value. The silver roughy, $H$. mediterraneus is caught as bycatch in bathyal trawling and has low commercial value (Madurell and Cartes 2005). While there has been extensive research on orange roughy, less attention has been given to the other Hoplostethus species, with the only exception of the silver roughy, $H$. mediterraneus. Studies on this species have been mainly focused in the diet, feeding habits and bathymetric distribution (e.g. Madurell and Cartes 2005; Jones 2009; Katsanevakis and Maravelias 2009; Fanelli and Cartes 2010). There are no studies about the molecular phylogeny of Hoplostethus species (Moore and Dodd 2010). Kotlyar (1986) proposed a phylogenetic tree for the subgenera of Hoplostethus, but this was based on geographic distribution and morphology only.

Most studies of orange roughy have been orientated to fisheries aspects. There are no studies about their adaptation to the light environment of the deep-sea, except by Pankhurst (1987), who studied the retinal morphology of orange roughy and other mesopelagic and demeresal teleost. It has been reported that orange roughy have a pronounced lateral line (Paulin 1979) and functional eyes with highly specialized retina 
(Pankhurst 1987), these characteristics may allow them to detect movement of conspecifics in aggregations in almost complete darkness to respond quickly, displaying avoidance behaviour to predators and fishing gear (Koslow 1996; Branch 2001). The high degree of retinal specialization of orange roughy has been correlated with a visual adaptation to dim-light (Pankhurst 1987). However, the molecular basis for this visual adaptation to the light environment of the deep-sea has never been studied.

\subsection{Biology and distribution of orange roughy}

The orange roughy is a widely distributed deep-sea fish. The species is found along continental slopes and seamounts at depths of $450-1,800 \mathrm{~m}$ across the Southern hemisphere and in the Northeast Atlantic Ocean (Horn et al. 1998; Branch 2001). They form dense aggregations on seamounts for spawning and feeding (Clark et al. 2000). It has been suggested that dense aggregations may also form adjacent to the bottom in areas with low currents acting as "resting sites" (Lorance et al. 2002). Orange roughy are opportunistic feeders, juveniles fed mainly on bentho and meso-pelagic crustaceans and mature individuals consume predominately fish and squid (Bulman and Koslow 1992). Rates of food consumption are high in orange roughy and their metabolism is substantially higher than the typical non-migratory deepwater fishes, and similar to mesopelagic migratory species (Bulman and Koslow 1992; Koslow 1996). The bodily composition is also similar to that of active mesopelagic fishes, high in lipid and protein and low in water (Koslow 1996). The high metabolic costs for orange roughy have been related to its exceptionally slow growth (Bulman and Koslow 1992) and with its strong locomotory performance to maintain position around seamounts; an environment characterized by strong and variable currents (Koslow 1996).

As other deep-sea fishes, the orange roughy is a " $K$-selected" species (Koslow 1996). They grow slowly, reaching maturity at about 30 years (Fenton et al. 1991; Francis and Horn 1997) and living for more than 100 years (Mace et al. 1990; Fenton et al. 1991). The fecundity is low, and therefore, they have low productivity (Pankhurst and Conroy 1987). Because of its long life span, orange roughy individuals may spawn many times; however, intermittent spawning in females has been reported related to low food availability coupled with the cost of participating in spawning migrations and 
aggregations around seamounts (Bell et al. 1992). Egg development takes $\sim 10$ days and they sink at the end of their development hatching near the bottom (Zeldis et al. 1995; Zeldis et al. 1998), which likely results in low passive dispersal.

\subsection{Deep-sea fisheries}

The collapse and depletion of many inshore and shelf fish stocks in the 1900s and the increasing technology over the past decades increased the development of deep-sea fisheries, targeting, in particular, seamount-associated teleost species (Morato et al. 2006; Pitcher et al. 2010). The most widely used method to catch fishes on seamounts is bottom trawling, where a net with heavy rollers is dragged along certain areas of the seamounts having a major effect over the seafloor and its fauna (see Clark 2010). Fisheries for teleosts mainly occur on and around seamounts in the North Pacific Ocean along the Emperor and Hawaiian Ridges, in the Southwest Pacific around New Zealand, New Caledonia and Australia, in the Southeast Pacific off Chile, in the Northeast Atlantic Ocean around the Azores and on the Mid Atlantic Ridge, and in the South Atlantic (Smith 2007). Recently, Pitcher (2010) identified eight major targeted seamount fish species worldwide. One of the first and most exploited deep-sea fishes is the orange roughy. The others are the alfonsino Beryx splendens, the cardinalfish Epigonus telescopus, the oilfish Ruvettus pretiosus, the black scabbard fish Aphanopus carbo, the armorhead Pseudopentaceros wheeleri, the abyssal grenadier Coryphaenoides armatus and the smooth oreo Pseudocyttus maculatus. Other exploited seamount-associated fishes include the roundnose grenadier Coryphaenoides rupestris, the black oreo Allocyttus niger, the spiky oreo Neocyttus rhomboidalis, the toothfish Dissostichus spp. and Sebastes spp. (Smith 2007).

The extraction of seamount fish species by large-scale fisheries increased rapidly reaching a peak on catches of about 1.2 million tonnes per year in the mid 1990s, then catches decreased sharply showing a key feature of deep-sea fisheries termed "boomand-bust" (reviewed by Pitcher et al. 2010). The un-sustainability and risk of depletion of most deep-sea fisheries is explained by the general characteristics of exploited deepsea species. They are usually " $K$-selected” exhibiting slow grow, extreme longevity, late maturity and low fecundity; which coupled with their aggregating behaviour around 
seamounts, explain their lack of resiliency and vulnerability to overexploitation (Koslow et al. 2000; Watson and Morato 2004; Morato et al. 2006; Smith 2007). The management of fish resources should ensure the preservation of genetic diversity as this is the basis for all the others levels of diversity and it is essential for the evolutionary adaptation of the species to environmental changes and other pressures (Laikre et al. 2005). This is particularly relevant for deep-sea exploited species as they are less resilient than shelf species (Smith et al. 2007).

\subsection{Fisheries management and population genetics}

For fisheries management and conservation plans it is crucial to determine the connectivity among populations to attempt to differentiate stocks (Begg et al. 1999; Grant and Waples 2000). There are several definitions of the term "stock" in fisheries management, but it usually refers to biological units large enough to be self-recruiting (Hilborn and Walters 1992). Several techniques have been used to study the connectivity among marine fish populations such as tag-recapture studies (e.g. Hurst et al. 1999), morphometrics (e.g. Mamuris et al. 1998), parasites (e.g. Moore et al. 2011), otoliths (e.g. Correia et al. 2011), and population genetics analyses using neutral molecular markers (e.g. Broderick et al. 2011). Laikre et al. (2005) stressed the importance of determining the genetic population structure of exploited fish species; this is the distribution of genetic variation within and between populations. According to these authors, knowledge of this structure may reduce the risk of depletion of genetic resources by considering groups of genetically homogenous individuals as the basic units for management. Based on the amount of genetically effective migration (gene flow) Laikre et al. (2005) defined three types of genetic structure for the identification of biological (genetics) units for fisheries management, 1) distinct populations: gene flow is small enough to generate genetic divergence among geographically close populations; 2) continuous change: genetic composition change over space. Gene flow is larger among geographically close populations resulting in an isolation by distance (IBD) pattern; and 3) no differentiation: gene flow is extensive and the species behaves as a single panmictic unit over the geographic region under consideration. Some species may present a combination of these three types of genetic structure. 
Most studies to determine the genetic structure of marine (and terrestrial) species have been conducted using selectively neutral molecular markers, since they have a great potential to estimate gene flow (see Holderegger et al. 2006). More recent studies have also incorporated or used loci under selection to estimate differentiation due to local adaptation (e.g. Fevolden and Pogson 1997; Hemmer-Hansen et al. 2007; André et al. 2011). To date, the most commonly employed neutral markers have been mitochondrial DNA (mtDNA) sequences and microsatellite DNA loci (Hellberg 2009). Since mitochondrial DNA is usually transmitted maternally, does not recombine and evolves faster than nuclear (encoding) DNA, mtDNA sequences have been widely used in phylogenetic and phylogeographic studies (Avise 1998a). For population genetics analyses, one advantage of mtDNA over microsatellite DNA analyses is that the population size of mtDNA is about one quarter of the nuclear DNA, and therefore, it is expected to be more sensitive to genetic drift. On the other hand, microsatellite DNA loci have a higher resolution and power to detect genetic differentiation than others multilocus markers (i.e. AFLPs, RAPDs, allozymes); the main advantages of microsatellites respect to mtDNA sequences is that they are multiple independent loci and have a higher mutation rate allowing estimations of levels of genetic structure on ecological/contemporary time scales (reviewed by Selkoe and Toonen 2006).

Marine fish species typically exhibit higher genetic diversity than freshwater and anadromous fish species as measured with molecular markers; a pattern that has been related to larger evolutionarily effective population sizes of marine fishes and to the existence of fewer barriers to dispersal in the marine realm compared to freshwater systems (Ward et al. 1994; DeWoody and Avise 2000; McCusker and Bentzen 2010). However, the general pattern of high genetic diversity in many marine fish species does not imply that fishing has not affected the levels of genetic variation of populations since changes in this measure will be apparent only after several generations for species with large population sizes. This is particularly relevant for long-lived species, because they would have slow genetic drift and any reductions in genetic diversity are unlikely to be detected yet. For example, Chapman et al. (2011) suggested that one of the main hypotheses to explain the absence of genetic bottleneck in the critically endangered smalltooth sawfish Pristis pectinata is the longevity of this elasmobranch.

Genetic techniques provide an indirect measure of population connectivity and have been widely used because it is difficult to measure dispersal directly, particularly in the marine environment (Avise 1998b; Lowe and Allendorf 2010). The limitation of genetic 
approaches is that genetic connectivity does not necessarily reflect demographic connectivity, and the later is of most interest for fisheries management. As defined by Lowe and Allendorf (2010), genetic connectivity is "the degree to which gene flow affects evolutionary processes within populations" and demographic connectivity is "the degree to which population growth and vital rates are affected by dispersal". Therefore, genetic estimates should be combined with inferences from other techniques, especially with tag-recapture studies (Lowe and Allendorf 2010). However, tag-recapture studies are very difficult to conduct for deep-sea species and a holistic approach using available techniques should be applied to effectively define stocks (Begg and Waldman 1999) as performed for the pelagic horse mackerel Trachurus trachurus (Abaunza et al. 2008). Dunn and Devine (2010) followed a holistic approach to determine the stock structure of orange roughy on the Chatham Rise, a complex topographic system located off the east coast of New Zealand. Using catch data, differences in life history characteristics and genetic data among others, Dunn and Devine (2010) determined the existence of two stocks on the Chatham Rise. The application of a holistic approach to other areas would likely results in better management for this species.

\subsection{Population differentiation studies in orange roughy}

There have been several population differentiation studies in orange roughy to attempt to differentiate management units or "stocks" using a range of techniques applied at different geographical scales. Lester et al. (1988) using parasite analyses discriminated a number of stocks among New Zealand and Australian samples. Similarly, morphometrics and otolith micro-chemistry analyses found significant differentiation among Australian populations (Elliott et al. 1995; Edmonds et al. 1991). However, genetic studies have reported contradictory results for orange roughy. The first population genetic studies for orange roughy were conducted with allozymes. Smith (1986) found high levels of genetic connectivity among samples from New Zealand and the Northeast Atlantic Ocean. Similarly, Elliott and Ward (1992) reported lack of differentiation among New Zealand and Australian samples. In contrast, using restriction enzyme analysis of mtDNA, Smolenski et al. (1993) found genetic differentiation among samples from New Zealand and Australia. Later, significant genetic structure was also reported among sites around New Zealand with RFLP and 
allozyme analyses (Smith et al. 1996; Smith and Benson 1997). Covering a higher geographical scale and using microsatellite DNA markers, Oke et al. (2002) found lack of genetic differentiation among samples from New Zealand, Australia, and the Northeast Atlantic Ocean, although there was a pattern of IBD. Genetic homogeneity has been also reported with microsatellite DNA loci at a lower geographical scale among Northeastern Atlantic samples (White et al. 2009a). However, significant differentiation was reported using microsatellite DNA loci and otolith analyses in a complex topographic system located in the Northeast Atlantic Ocean (Carlsson et al. 2011). Considering all the above, a broad study about levels of population differentiation in orange roughy at global and fine-scales using one technique and a large sampling size would be highly valuable to help to determine the levels of connectivity among populations.

Therefore, this study used two types of neutral molecular markers, mtDNA sequences and microsatellite DNA loci, to investigate the genetic structure of orange roughy using samples from most of its distribution range (global-scale) including multiple sites around New Zealand (fine-scale). A candidate gene approach (i.e. genes subject to natural selection) was also attempted to investigate adaptive population divergence in orange roughy, since there are several examples of population differentiation at candidate genes without differentiation at neutral markers in marine fishes (e.g. Pogson and Fevolden 2003; Hemmer-Hansen et al. 2007; André et al. 2011). The only candidate gene that was successfully amplified for orange roughy samples was the rhodopsin gene, which is involved in visual adaptations at inter and intra-specific levels in marine fishes (e.g. Yokoyama and Takenaka 2004; Yokoyama 2008; Larmuseau et al. 2009b, 2010, 2011). However, there was almost no variation among partial rhodopsin sequences in orange roughy (i.e. only one site presented a transition and there were no transversions), even for samples from distant regions (e.g. New Zealand and the Northeast Atlantic Ocean). Given this, partial sequences of the rhodopsin gene were instead used to study the molecular basis for visual adaptations of this species to the bathypelagic light environment. As stated before, the high degree of retinal specialization of orange roughy has been correlated with a visual adaptation to dim-light (Pankhurst 1987); however, the molecular basis for this visual adaptation has never been studied in orange roughy. This is important to understand how deep-sea species have adapted to the light available in the bathypelagic environment (Yokoyama 2008). 


\subsection{Deep-sea environment and visual adaptations}

Orange roughy habits the largest ecosystem on Earth. The deep-sea extends over the $65 \%$ of the World's surface (Sverdrup et al. 1942). It is commonly considered that the deep-sea begin at the shelf break, which occurs at a depth of $200 \mathrm{~m}$ in most of the Oceans, marking a transition between shallow to deep-sea fauna (Thistle 2003). The deep-sea ocean is characterized by extreme environmental conditions. Salinity and pressure are high, while temperature and food availability are low (Sanders et al. 1965; Thistle 2003). However, topographic features, as most seamounts, have a complex topography and are biological "hot-spots" characterized by high production due to Taylor columns (parcels of water that retain microorganisms) and upwelling of nutrient rich water (Rogers 1994). They provide habitat to support a range of epifaunal and suspension-feeding invertebrates (Ramirez-Llodra et al. 2010), attracting high abundance and diversity of top-level predators as fishes (Dower and Brodeur 2004). Early studies (e.g. Sanders 1968) considered that the deep-sea was a physically stable environment. However, over the past decades increasing technology and sampling efforts have shown that the deep-sea is a complex and dynamic environment (Stuart et al. 2003). There are gradients, habitat shifts, and high species diversity (Rex et al. 1993; Levin et al. 2001; Ramirez-Llodra et al. 2011).

One striking difference of the deep-sea environment respect to the sea surface is the lack of photosynthetically-usable light below about $250 \mathrm{~m}$, which results in lack of primary production in most deep-sea ecosystems (Thistle 2003). Light intensity decreases exponentially with depth because photons are absorbed or scattered by the water column (Levine and MacNichol 1982). Many marine organisms, therefore, have developed visual adaptations to the spectral quality of the deep-sea (reviewed by Crescitelli 1991), while others lack of vision and have evolved other senses as chemoreception and mechanoreception (Thistle 2003). To adapt to the dim-light and bioluminescence of the deep-sea, many visual fish species have lost cone photoreceptors and have only rod photoreceptors (see Hunt et al. 2001), because rods mediate vision at low light intensities (reviewed by Yokoyama 2008). Visual pigments consist of an opsin protein and a chromophore, and are characterized by the wavelengths of maximal absorption $\left(\lambda_{\max }\right)$ (Bowmaker 1995). Rhodopsin pigments $\left(\lambda_{\max }=\sim 500 \mathrm{~nm}\right)$ are usually expressed in rods (Yokoyama et al. 1999) and certain amino acid replacements in the opsin protein explain changes in the $\lambda_{\max }$ of the pigment to perceive different light 
environments, a phenomenon known as spectral tuning (reviewed by Yokoyama 2008). The molecular basis for spectral tuning has been studied in several shallow and deep-sea fish species, allowing the identification of critical amino acid sites, called "tuning sites" (e.g. Hope et al. 1997; Yokoyama et al. 1999; Hunt et al. 2001; Yokoyama and Takenaka 2004).

\subsection{Demographic history and DNA sequence analyses}

The analyses of DNA sequences are also suited to make inferences about the past demographic history of the species (Rogers and Harpending 1992; Drummond et al. 2005). The molecular clock hypothesis assumes that DNA sequences change at a near constant rate through time at intra-specific levels. Demographic events and the timeframe when they occurred can be inferred from DNA sequences analyses (Grant and Waples 2000). Glaciations events during the Pleistocene period ( 1.6 Myr to 10,000 years before present) resulted in major demographic changes, which in turn had a great influence in the intra-specific genetic diversity in many marine and freshwater species (reviewed by Grant and Waples 2000). Two measures of diversities among intraspecific DNA sequences have been used to categorize marine fishes into four groups depending on different combinations of small and large values of haplotype and nucleotide diversity (Grant and Bowen 1998). Low values for both measures are characteristic of species that have had catastrophic reductions in population's sizes (bottleneck events or founder events). Low nucleotide diversity and medium-high levels of haplotype diversity are expected for species that have suffered bottleneck events followed by sudden expansion in populations that have rapidly grown. When both measures are high it is assumed that populations have been large and stable over long periods of time or that isolated and divergent populations have become into contact. Finally, low levels of haplotype diversity and high nucleotide diversity is typical of large ancient populations, which suffered drastic reductions in size or that have become isolated. Marine fishes are usually within one the first three categories and the last group may be most common in inshore or freshwater species, since gene flow is more restricted than in coastal or oceanic environments (reviewed by Grant and Waples 2000). 


\subsection{The aims and structure of this thesis}

The aims of this thesis were to: (i) use neutral molecular markers to study the genetic diversity, differentiation and past demographic history of orange roughy populations using large sample sizes at a global and fine-scales, (ii) conduct a phylogenetic study of Hoplostethus species, and (iii) study the molecular basis for visual adaptation of orange roughy to the bathypelagic light environment.

In Chapter 2, I present my results about levels of global genetic differentiation and demographic history of orange roughy using mitochondrial DNA sequences. In Chapter 3 , I show the results of microsatellite DNA analyses that were conducted to determine the genetic structure of orange roughy at a global and fine-scales. In Chapter 4, I show the results of phylogenetic analyses of Hoplostethus species using the mitochondrial DNA sequences obtained by me for orange roughy and silver roughy $(H$. mediterraneus) and sequences of congener species available from a public data base (GenBank). In Chapter 5, I present the findings of critical amino acid sites replacements in the rhodopsin gene of orange roughy, which are known to be involved in spectral tuning. Rhodopsin sequences were also obtained for other 18 species to compare to other teleost species habiting different light environments. Each chapter has been written as independent manuscripts, and hence there is some repetition in the introductions and methodological sections. Finally, in Chapter 6, I conclude with a summary and general discussion of the main findings of this thesis. 


\section{Chapter 2}

\section{Low levels of global genetic differentiation and population expansion in the deep-sea teleost Hoplostethus atlanticus revealed by mitochondrial DNA sequences}

\subsection{Abstract}

The orange roughy Hoplostethus atlanticus is a well known commercial species with a global distribution. There is no consensus about levels of connectivity among populations despite a range of techniques having been applied. I used cytochrome $c$ oxidase subunit I (COI) and cytochrome $b$ (cyt $b$ ) sequences to study genetic connectivity at a global scale. Pairwise $\Phi_{\mathrm{ST}}$ analyses revealed a lack of significant differentiation among samples from New Zealand, Australia, Namibia, and Chile. However, low but significant differentiation $\left(\Phi_{\mathrm{ST}}=0.02-0.13 P<0.05\right)$ was found between two Northeast Atlantic sites and all the other sites with COI. AMOVA and the haplotype genealogy confirmed these results. The prevalent lack of genetic differentiation is probably due to active adult dispersal under the stepping-stone model. Demographic analyses suggested the occurrence of two expansion events during the Pleistocene period. 


\subsection{Introduction}

Deep-sea fishes (i.e. $>200 \mathrm{~m}$ ) live in the largest habitat on Earth. Many deep-sea fishes are widely distributed, and have a circumglobal distribution, e.g. the alfonsino Beryx decadactylus. Some bathyal fishes inhabit continental slopes, the slopes of oceanic islands, and seamounts that are separated by extensive areas of deep ocean. The dispersal of deep-sea fishes may be less constrained by their habitat than that of coastal fishes. However, while there are few obvious barriers in the deep-sea, migration of individuals could be limited by ocean currents and bathymetric features, as reported for the demersal fish Brosme brosme (Knutsen et al. 2009). There are several examples of genetic differentiation among deep-sea fish populations at different geographical scales, including the spikey oreo Neocyttus rhomboidalis (Elliott et al. 1998), the bluemouth Helicolenus dactylopterus (Aboim et al. 2005), the Patagonian toothfish Dissostichus eleginoides (Smith and McVeagh 2000; Rogers et al. 2006), and the Cape hake Merluccius paradoxus (von der Heyden et al. 2007). However, there are also species that exhibit panmixia at regional, oceanic, and inter-oceanic scales such as the armorhead Pseudopentaceros wheeleri, the wreckfish Polyprion americanus, the alfonsino Beryx splendens, and the oreos Allocytus niger and Pseudocyttus maculatus (Martin et al. 1992; Sedberry et al. 1996; Hoarau and Borsa 2000; Smith et al. 2002b).

The orange roughy, Hoplostethus atlanticus, has a cosmopolitan distribution (Paulin 1979). It occurs at depths of 450-1800 $\mathrm{m}$ and is locally abundant off the coasts of New Zealand, Australia, Namibia, and in the Northeast Atlantic Ocean (Horn et al. 1998; Branch 2001) and off Chile (Labbé and Arana 2001). Orange roughy aggregate near prominent topographic features such as seamounts, plateaus and canyons, especially during spawning and feeding periods (Clark et al. 2000). It is thought that adults migrate hundreds of kilometres to spawn, as mature fish are widespread, but spawning occurs in just a few specific areas (Francis and Clark 1998). Orange roughy fisheries started in 1979 around New Zealand (Clark 1996) and later developed off Australia (1980s), South Africa (Namibia), and in the Northeast Atlantic Ocean in the 1990s (Branch 2001), and in the South Indian Ocean and off Chile in 1999 (Branch 2001; Labbé and Arana 2001). Orange roughy grow slowly, live longer (100+ years) (Mace et al. 1990; Fenton et al. 1991), mature later ( 30 years) than most other marine teleosts (Fenton et al. 1991; Francis and Horn 1997; Horn et al. 1998) and has low productivity due to its low fecundity (Pankhurst and Conroy 1987). All these life history 
characteristics make orange roughy vulnerable to over-exploitation. Most orange roughy stocks have been fished down to or below 30\% of pre-exploitation levels and most fisheries have shown a pattern of rapidly decreasing catches (reviewed by Branch 2001). As part of the management for this species, which is found in several Economic Exclusive Zones and occurs in international waters, it is important to determine levels of connectivity among populations.

A range of indirect techniques have been applied to estimate connectivity among orange roughy populations, as tag-recapture studies have been unsuccessful in this deep-sea species (Branch 2001). In general, studies using morphometrics, otolith microchemistry, and parasite analyses have found differences between populations of orange roughy within ocean basins (e.g. Elliott et al. 1995; Edmonds et al. 1991; Lester et al. 1988). On the other hand, genetic studies, with different molecular markers applied at different geographical scales, have reached contrary conclusions about differentiation among populations, and wide scale connectivity among populations has not been rejected. Smith (1986) using allozyme analyses found low genetic differentiation among samples from the Tasman Sea, Southwest Pacific Ocean, and Northeast Atlantic Ocean. Similarly, Elliott and Ward (1992) showed a lack of genetic subdivision among six sites off southern Australia and one site off the eastern coast of New Zealand. Using a restriction enzyme analysis of mitochondrial DNA, Smolenski et al. (1993) surveyed samples from seven locations in Australia, New Zealand and South Africa, and found evidence for genetic separation among southeastern Australian and New Zealand samples. Genetic structure was found among different sites off the coast of New Zealand by Smith et al. (1996) using RFLP analysis and by Smith and Benson (1997) with allozyme loci. In another study based on multiple techniques, Smith et al. (2002a) also found evidence for differentiation among populations off the west coast of New Zealand with the analysis of otolith shape, fish size, and restriction digest of the whole mitochondrial genome. However, mitochondrial DNA polymorphism of the control region and two microsatellite loci revealed lack of differentiation among New Zealand sites (Smith et al. 2002a). A study by Oke et al. (2002) using microsatellite markers showed no significant differentiation within Australian waters, and no evidence of genetic differentiation between samples from Australia and New Zealand, and Australia and the Northeast Atlantic, although both regional comparisons revealed a significant pattern of isolation by distance (Oke et al. 2002). Recently, White et al. (2009a) used 14 microsatellite loci to test the hypothesis that the life-history characteristics of orange 
roughy should generate philopatry and the evolution of population genetic structure at a relatively small geographical scale. However, they found panmixia among five samples from the Northeast Atlantic, with some sampling sites separated by over $2000 \mathrm{~km}$, but significant differentiation between the pooled Northeast Atlantic samples and one sample from Namibia. Contrary to White et al. (2009a), Carlsson et al. (2011) recently reported low but significant differentiation within a complex topographic system in the Northeast Atlantic, mainly due to genetic differences between samples from a flat area and seamount sites. The authors suggested that differences in seafloor structures (seamounts and flats) may provide discrete spawning structures with limited gene flow between them.

The application of molecular markers allows not only inferences about levels of genetic connectivity among populations, but they also enable the study of the demographic history of species, in which expansion and contraction events can be related to global climatic changes (e.g. Larmuseau et al. 2009a).

The main goal of this study was to use molecular markers to determine levels of genetic variation within and differentiation among orange roughy populations at a global scale. The second goal was to determine the demographic history of the species and to relate this to past climatic events. I used DNA sequence data from the mitochondrial cytochrome $c$ oxidase subunit I (COI) and cytochrome $b$ (cyt $b$ ) genes and samples collected from New Zealand, Australia, Namibia, Chile, and the Northeast Atlantic. Large samples from multiple locations around New Zealand were used to determine within region variation.

\subsection{Materials and Methods}

\subsubsection{Sampling and DNA extractions}

Tissue samples were obtained from 546 orange roughy specimens from 13 sites in five regions: New Zealand, Australia, Namibia, Chile, and the Northeast Atlantic Ocean (Fig. 2.1). Muscle samples were collected from fresh fish and frozen at $-20^{\circ} \mathrm{C}$. Samples from northern New Zealand and from Lord Howe Rise (outside the Economic Exclusive Zone (EEZ) of New Zealand,) were taken by New Zealand Ministry of Fishery 
Observers. Samples from all other sites in New Zealand, Australia and from Namibia were from a frozen tissue collection held at NIWA (National Institute of Water \& Atmospheric Research Ltd., New Zealand). Samples from Chile and the Northeast Atlantic Ocean were supplied by researchers undertaking studies in their respective locations.

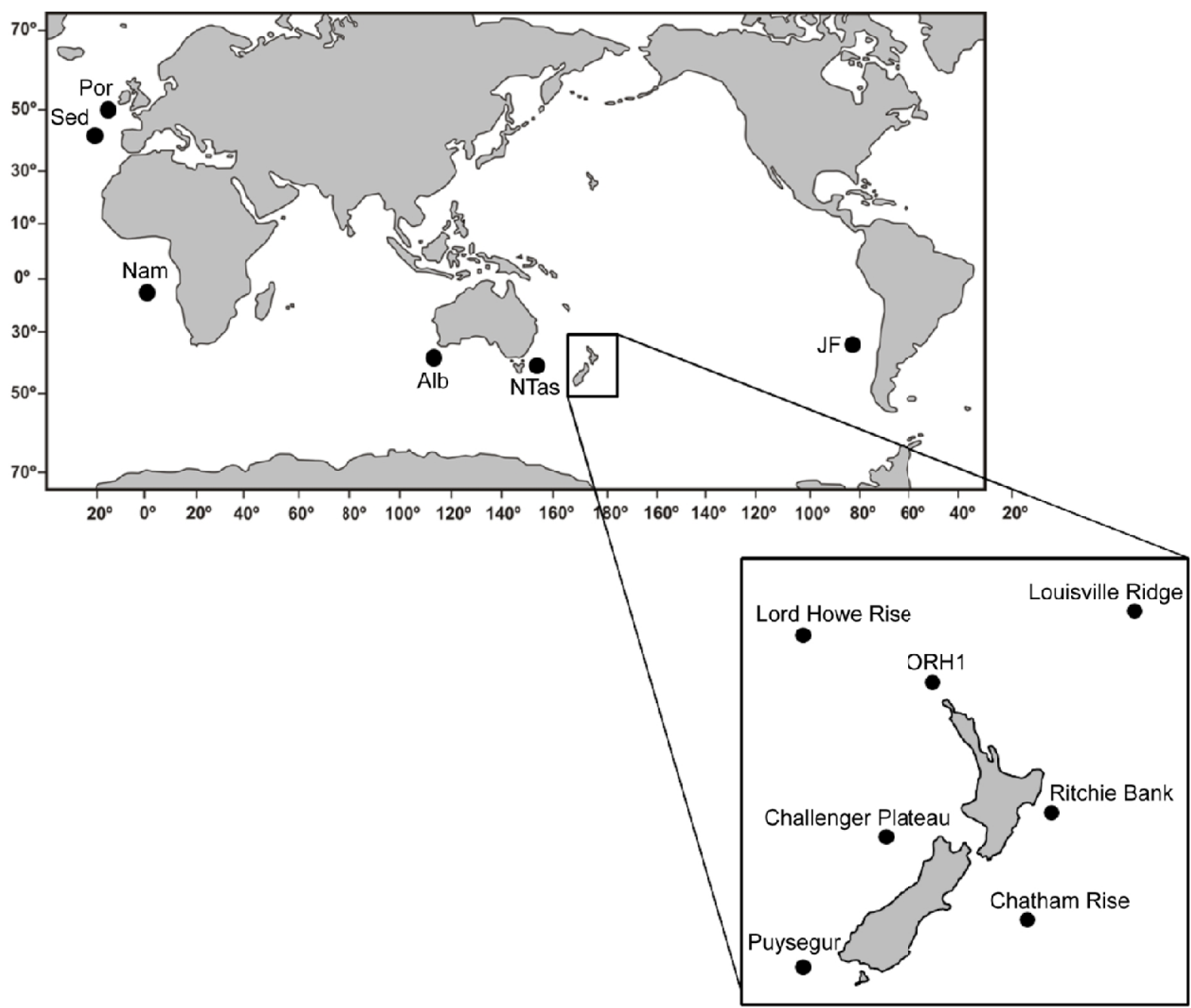

Fig. 2.1 Map showing the 13 sampling sites across the five regions surveyed for orange roughy. Codes as follow: Por $=$ Porcupine Bank, Sed $=$ Sedlo (Northeast Atlantic), Nam = Namibia, Alb $=$ Albany, NTas $=$ North Tasmania (Australia), JF = Juán Fernández Archipelago (Chile), ORH1 = Northern New Zealand 
DNA extractions were performed using proteinase $\mathrm{K}$ digestion followed by salt extraction. The remaining pellet was washed twice with ethanol and resuspended in 100 $\mu \mathrm{L}$ TE buffer. DNA samples were stored at $4^{\circ} \mathrm{C}$.

\subsubsection{PCR amplification, sequencing and alignment}

A $630 \mathrm{bp}$ fragment of the cytochrome $c$ oxidase subunit I (COI) gene was amplified by PCR using the primers developed by Ward et al. (2005) with the modification of two bases in the reverse primer based on the complete mitochondrial sequence of Hoplostethus japonicus (GenBank: AP002938.1). The primers used were: FishF1-5'TCAACCAACCACAAAGACATTGGCAC-3' and FishR1(a)-5'-TATACTTCGGGG TGGCCAAAGAATCA-3'. A 416 bp fragment of the cytochrome $b$ gene (cyt $b$ ) was amplified in 95 individuals from the five regions. The forward and reverse primers (Palumbi et al. 1991 and Kocher et al. 1989, respectively) were modified based on the complete mitochondrial sequence of $H$. japonicus. The primers used were tGludg(a)-5'TGACTTGAAAAACCACCGTTG-3' and Cyb2(a)-5'-CCCTCAAAAGGATATTTGT CCTCA-3'.

Reactions of $10 \mu \mathrm{L}$ total volume for partial amplification of both genes consisted of

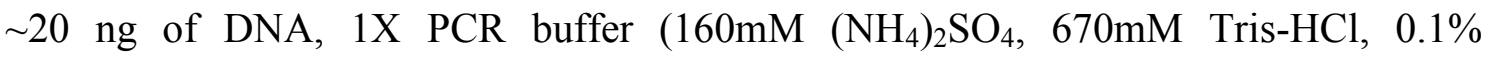
stabilizer), $2 \mathrm{mM} \mathrm{MgCl}_{2}, 0.6 \mu \mathrm{M}$ of each primer, $0.2 \mathrm{mM}$ of each dNTPs, $1.5 \mathrm{U}$ of Taq polymerase and $0.4 \mathrm{mg} \mathrm{mL}^{-1}$ of Bovine Serum Albumin (BSA). PCR cycles were performed on a Eppendorf Mastercycler ep gradient $\mathrm{S}$, as follow: $95^{\circ} \mathrm{C}$ for $2 \mathrm{~min}$, followed by 35 cycles of $94^{\circ} \mathrm{C}$ for $30 \mathrm{~s}, 57^{\circ} \mathrm{C}$ for $\mathrm{COI}$ and $48^{\circ} \mathrm{C}$ for cyt $b$ for $30 \mathrm{~s}, 72^{\circ} \mathrm{C}$ for $1 \mathrm{~min}$ and a final extension at $72^{\circ} \mathrm{C}$ for $10 \mathrm{~min}$. PCR products were purified with ExoSAP-IT following manufacturer's instructions. The DNA sequences of the purified products were determined using an ABI3730 Genetic Analyzer. Initially, DNA sequences were obtained in both directions which resulted in high quality sequences, subsequently only the forward primer direction was sequenced for both the COI and cyt $b$ genes. Sequences were aligned using the software Geneious 5.1.7 (Biomatters Ltd.) using the Geneious alignment option (Drumond et al. 2010). Alignments were verified through translation into amino acid sequences. 


\subsubsection{Data analyses}

Genetic diversity indices, the number of polymorphic (segregating) sites $(S)$, the number of haplotypes $\left(N_{\mathrm{h}}\right)$, haplotype diversity $(h)$, and nucleotide diversity $(\pi)$, were calculated in DnaSP 5.10 (Librado and Rozas 2009) for both genes. The software ARLEQUIN 3.11 (Excoffier et al. 2005) was used to estimate pairwise genetic divergence between populations using the fixation index $\Phi_{\mathrm{ST}}$. The significance of the $\Phi_{\mathrm{ST}}$ values was evaluated by 20,000 permutations. Further analyses were only performed for COI sequences. The pattern of Isolation By Distance (IBD) was evaluated for New Zealand sites using a Mantel Test with 10,000 permutations comparing linearized $\Phi_{\mathrm{ST}}$ with the shortest marine distances ( $\mathrm{ln} \mathrm{m}$ ) between sites. Geographic distances were estimated using Google Earth v.4.3. ARLEQUIN 3.11 was also used to perform an AMOVA analysis with pairwise difference as the distance method and 20,000 permutations.

A haplotype network was first constructed using the median-joining approach implemented in the NETWORK 4.6 software (Bandelt et al. 1999). The resulting network had many loops that were only resolved using both, the Frequency $>1$ criterion and the criteria based on coalescent theory (Crandall and Templeton 1993). However, only haplotypes present in two or more individuals were represented in the network. The alternative method described by Salzburger et al. (2011) was implemented to obtain a complete haplotype genealogy without reticulations. A phylogenetic reconstruction was estimated with a Maximum Likelihood (ML) approach implemented in the program PhyML 3.0 (Guindon et al. 2010) using default settings and the best fit model obtained with jModelTest (Posada 2008). The ML tree was then converted into a haplotype genealogy using the Haploviewer software (Salzburger et al. 2011).

A mismatch distribution analysis was performed in ARLEQUIN and DnaSP to infer the demographic history. A unimodal distribution is indicative of a sudden population expansion in the past whereas a multimodal curve is most typical of populations in equilibrium whose sizes have been constant over a long period of time (Rogers and Harpending 1992). The demographic parameters $\tau, \theta_{0}$ and $\theta_{1}$ were obtained from the mismatch distribution analysis. The time since the last expansion $(t)$ can be estimated from $\tau=2 u t$ where $\tau$ is an index of time since expansion expressed in units of mutational time and $u$ is the mutation rate considering $u=\mu k$ ( $\mu$ is the mutation rate per nucleotide and $k$ is the number of nucleotides obtained by PCR) (Rogers and Harpending 1992). Two mutations rates were applied for the COI sequences, the one 
proposed by Brown et al. (1979) of 2\%/Myr for the vertebrate mitochondrial genome based on mammalian data and that calibrated by Bermingham et al. (1997) of 1.2\%/Myr for the COI gene in marine fishes. The parameters $\theta_{0}$ and $\theta_{1}$ correspond to the mutation parameter before and after population growth and is defined as $2 \mathrm{Nu}$ for mitochondrial loci, where $N$ is the effective female population size and $u$ is the mutation rate per generation. ARLEQUIN was also used to obtain the sum of square deviations (SSD) between the observed and the expected distribution of pairwise differences and to calculate the Harpending's raggedness index $\left(H_{\mathrm{r}}\right)$ (Harpending 1994). Both statistics were used to test the null hypothesis of population expansion. Tajima's $(D)$ (Tajima $1989)$ and Fu's $\left(F_{S}\right)(\mathrm{Fu} 1997)$ neutrality tests were also performed in ARLEQUIN. Negative and significant $D$ and $F_{S}$ values are also indicative of population expansion.

I also performed Bayesian skyline analyses to infer changes in effective population size $(N)$ through time. This analysis allows the discovery of complex demographic signatures that are not possible to recover with simple demographic models (Drummond et al. 2005). The settings to construct the skyline plot were implemented in BEAST v1.6.1 (Drummond and Rambaut 2007). All analyses were run under the HKY+I+G model that was selected by jModelTest (Posada 2008) using both, the Bayesian and the Akaike information criterion. The analyses were run for 100,000,000 iterations sampled every 10,000 iterations with a burn-in of $10 \%$. The parameter $m$ that represents the number of grouped intervals was set to 10 . The mutation rate used was $1.2 \% / \mathrm{Myr}$ (Bermingham et al. 1997) with an uncorrelated lognormal relaxed clock model (Drummond et al. 2006). All operators were optimized automatically. Two independent runs were combined using LogCombiner v.1.6.1 (Drummond and Rambaut 2007). The skyline plot was then visualized in TRACER v1.5 (Rambaut and Drummond 2007).

\subsection{Results}

\subsubsection{Genetic diversity and population structure}

Analyses of the COI gene sequences for 546 individuals revealed very high levels of diversity. In the $630 \mathrm{bp}$ fragment, 82 sites were polymorphic and produced 114 haplotypes of which 71 were unique (recorded in one individual only). The haplotype 
and nucleotide diversities ranged from 0.810 to 0.940 and from 0.0034 to 0.0049 respectively in each site (Table 2.1). Analyses of the cyt $b$ gene sequences for 95 individuals also showed high levels of variation. In the 416 bp fragment, 37 sites were polymorphic and there were 37 haplotypes of which 24 were unique. The haplotype and nucleotide diversities ranged from 0.819 to 0.965 and from 0.0063 to 0.0099 respectively (Table 2.2). Sequences of all haplotypes were deposited in GenBank under Accession Numbers: JN580075- JN580188 for the COI gene and JN580189-JN580225 for the cyt $b$ gene. The haplotype frequencies in each sampling site/area are provided in Appendixes A and $\mathrm{B}$ for the $\mathrm{COI}$ and cyt $b$ genes, respectively.

Table 2.1 Sampling sites grouped in five regions and COI genetic diversity indices. $n$ : number of samples, $S$ : number of segregating sites, $N_{\mathrm{h}}$ : number of haplotypes, $h$ : haplotype diversity, $\pi$ : nucleotide diversity. The standard deviations of haplotype and nucleotide diversity values are given between brackets

\begin{tabular}{llcccccc}
\hline Regions & Sampling sites & Code & $n$ & $S$ & $N_{\mathrm{h}}$ & $h$ & $\Pi$ \\
\hline New Zealand & Northern New Zealand & ORH1 & 41 & 23 & 23 & $0.926(0.028)$ & $0.00430(0.00036)$ \\
& Ritchie Bank & Rit & 40 & 23 & 22 & $0.931(0.026)$ & $0.00466(0.00039)$ \\
& Chatham Rise & Chat & 46 & 31 & 24 & $0.926(0.025)$ & $0.00406(0.00044)$ \\
& Puysegur & Puy & 48 & 25 & 21 & $0.890(0.030)$ & $0.00408(0.00040)$ \\
& Challenger Plateau & Cha & 30 & 24 & 19 & $0.926(0.034)$ & $0.00494(0.00051)$ \\
& Lord Howe Rise & LHR & 40 & 27 & 23 & $0.940(0.023)$ & $0.00420(0.00044)$ \\
& Louisville Ridge & Lou & 40 & 21 & 22 & $0.933(0.022)$ & $0.00399(0.00038)$ \\
Australia & North Tasmania & NTas & 25 & 11 & 10 & $0.810(0.056)$ & $0.00342(0.00035)$ \\
& Albany & Alb & 46 & 25 & 23 & $0.916(0.024)$ & $0.00411(0.00035)$ \\
Namibia & Namibia & Nam & 45 & 19 & 16 & $0.872(0.032)$ & $0.00413(0.00038)$ \\
Chile & Juan Fernández & JF & 52 & 19 & 14 & $0.839(0.035)$ & $0.00403(0.00036)$ \\
Atlantic & Porcupine Bank & Por & 51 & 16 & 12 & $0.831(0.038)$ & $0.00466(0.00043)$ \\
& Sedlo & Sed & 42 & 19 & 13 & $0.837(0.039)$ & $0.00445(0.00049)$ \\
& Total & & 546 & 82 & 114 & $0.902(0.008)$ & $0.00433(0.00012)$ \\
\hline
\end{tabular}


Table 2.2 Samples sizes for the five regions and genetic diversity indices of the cyt $b$ gene. $n$ : number of samples, $S$ : number of segregating sites, $N_{\mathrm{h}}$ : number of haplotypes, $h$ : haplotype diversity, $\pi$ : nucleotide diversity. The standard deviations of haplotype and nucleotide diversity values are given between brackets

\begin{tabular}{lccccc}
\hline Regions & $N$ & $S$ & $N_{\mathrm{h}}$ & $H$ & $\pi$ \\
\hline New Zealand & 19 & 15 & 10 & $0.819(0.083)$ & $0.00628(0.00126)$ \\
Australia & 19 & 17 & 14 & $0.965(0.028)$ & $0.00922(0.00072)$ \\
Namibia & 18 & 15 & 9 & $0.863(0.057)$ & $0.00817(0.00111)$ \\
Chile & 19 & 15 & 12 & $0.936(0.037)$ & $0.00922(0.00099)$ \\
Northeast Atlantic & 20 & 15 & 8 & $0.821(0.072)$ & $0.00998(0.00100)$ \\
Total & 95 & 37 & 37 & $0.907(0.020)$ & $0.00863(0.00045)$ \\
\hline
\end{tabular}

None of the pairwise $\Phi_{\mathrm{ST}}$ values showed significant differentiation for the cyt $b$ gene $\left(P>0.05\right.$, data not shown). The pairwise $\Phi_{\mathrm{ST}}$ analysis of the COI sequences between sites resulted in low values revealing a lack of significant genetic differentiation for most comparisons (Table 2.3). However, $\Phi_{\mathrm{ST}}$ values were highest for comparisons between the Northeast Atlantic sites and all the other sites and all were significant $(P<$ 0.05). Significant differences after Bonferroni correction between few pairs of sites are shown in Table 2.3. Within regions, the only significant differentiation was between Chatham Rise and Puysegur in New Zealand $\left(\Phi_{\mathrm{ST}}=0.031, P=0.027\right)$ and there was an absence of IBD for New Zealand sites (Mantel test, $P=0.853$ ). In the absence of significant differentiation within the regions, sites were pooled by region to perform a new $\Phi_{\mathrm{ST}}$ analysis. The revised analysis on pooled samples showed significant differentiation (after Bonferroni correction) among the Northeast Atlantic region and all other regions (Table 2.4).

The AMOVA for the COI data revealed that almost all the variation was within sites (97.88\%) with a significant overall $\Phi_{\mathrm{ST}}$ value among sites $\left(\Phi_{\mathrm{ST}}=0.021, P=0.0003\right)$, which is influenced by the slight differentiation between the Northeast Atlantic sites and all the others sites. This was confirmed performing a new AMOVA without the Northeast Atlantic sites, which showed that the overall $\Phi_{\mathrm{ST}}$ among sites was very low and non significant $\left(\Phi_{\mathrm{ST}}=0.0003, P=0.425\right)$. 


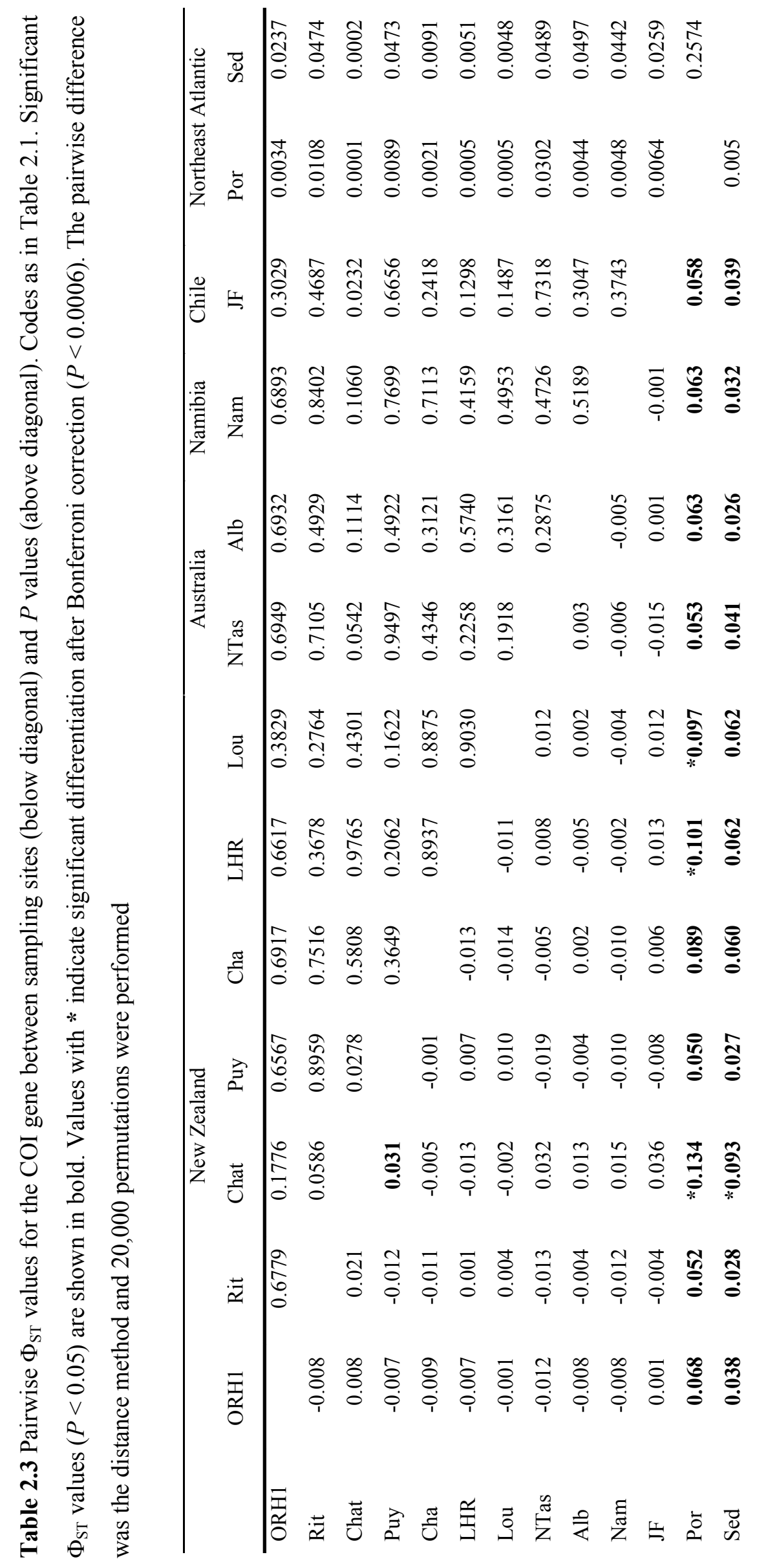


Table 2.4 Pairwise $\Phi_{\mathrm{ST}}$ values for the COI gene between regions (below diagonal) and $P$ values (above diagonal). Significant $\Phi_{\mathrm{ST}}$ values after Bonferroni correction $(P<0.005)$ are shown in bold. The pairwise difference was the distance method and 20,000 permutations were performed

\begin{tabular}{lccccc}
\hline & New Zealand & Australia & Namibia & Chile & Northeast Atlantic \\
\hline New Zealand & & 0.4534 & 0.6956 & 0.1049 & 0.0001 \\
Australia & -0.001 & & 0.6036 & 0.5508 & 0.0016 \\
Namibia & -0.004 & -0.006 & & 0.3676 & 0.0050 \\
Chile & 0.008 & -0.005 & -0.001 & & 0.0046 \\
Northeast Atlantic & $\mathbf{0 . 0 7 1}$ & $\mathbf{0 . 0 4 6}$ & $\mathbf{0 . 0 4 7}$ & $\mathbf{0 . 0 4 7}$ & \\
\hline
\end{tabular}

Haplotypes from the different sites were grouped by region to construct the haplotype genealogy. A star-like genealogy was obtained showing three main haplotypes of high frequency present in all five regions (Fig. 2.2). Most of the derived haplotypes were shared by more than one region. However, considering the haplotypes of frequency $>1$, four haplotypes were only present in the Northeast Atlantic (frequency 4-8). Five haplotypes were restricted to New Zealand (frequency 2-5), but the New Zealand region included the greatest number of sites (7) and individuals (285) compared to two sites and 93 individuals from the Northeast Atlantic. Therefore, the finding of four haplotypes restricted to the Northeast Atlantic is more meaningful than five haplotypes restricted to the New Zealand area. 


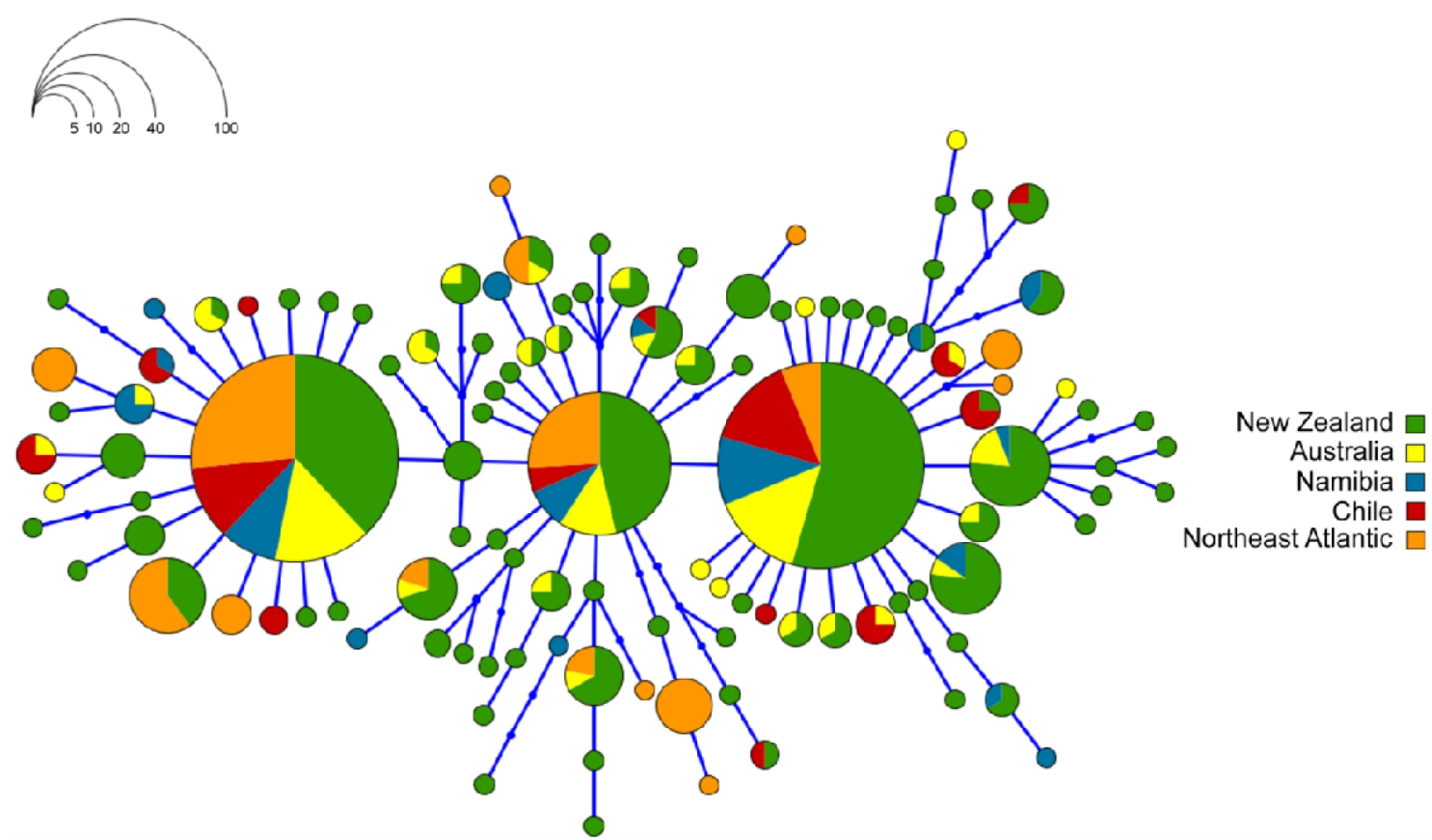

Fig. 2.2 Haplotype genealogy from Maximum Likelihood (ML) tree of the COI sequences performed in the software Haploviewer, which shows the relationship among haplotypes of the five regions. The model of nucleotide substitution for ML was HKY $+\mathrm{G}(0.744)+\mathrm{I}(0.654)$. The circles represent the haplotypes. The scale shown on the upper left side of the figure indicates the relationship between circle sizes and the frequency of the haplotypes. Lines connecting the circles indicate a mutational step and dots in the lines represent putative mutational steps between haplotypes 


\subsubsection{Demographic history}

High levels of haplotype diversity (mean 0.902 for COI and 0.907 for cyt $b$ ) and low nucleotide diversity (mean 0.0043 for COI and 0.0086 for cyt $b$ ) are indicative of a population bottleneck followed by rapid population growth and accumulation of mutations (Grant and Bowen 1998). This interpretation was supported by negative and significant Tajima's $D$ and Fu's $F$ s values in each site. Few sites showed negative but not significant values (Table 2.5). The overall Tajima's $D$ statistic was negative but not significant $(D=-1.49, P=0.078)$. However, the overall Fu's $F \mathrm{~s}$, which is more sensitive to population demographic expansion, was significantly negative $(F \mathbf{S}=-11.94$, $P=0.033)($ Table 2.5).

Table 2.5 Values and probabilities of Tajima's $D$ and Fu's $F$ s for all the sampling sites

\begin{tabular}{llcccc}
\hline Regions & Sampling sites & Tajima's $D$ & $P$ & Fu's $F \mathrm{~s}$ & $P$ \\
\hline New Zealand & Northern New Zealand & -1.66 & 0.028 & -18.58 & $<0.001$ \\
& Ritchie Bank & -1.54 & 0.034 & -15.77 & $<0.001$ \\
& Chatham Rise & -2.15 & 0.003 & -19.92 & $<0.001$ \\
& Puysegur & -1.79 & 0.022 & -13.75 & $<0.001$ \\
& Challenger Plateau & -1.73 & 0.017 & -12.98 & $<0.001$ \\
& Lord Howe Rise & -1.99 & 0.004 & -19.29 & $<0.001$ \\
& Louisville Ridge & -1.63 & 0.037 & -17.97 & $<0.001$ \\
Australia & North Tasmania & -0.87 & 0.204 & -3.39 & 0.031 \\
& Albany & -1.80 & 0.016 & -17.73 & $<0.001$ \\
Namibia & Namibia & -1.29 & 0.082 & -6.73 & 0.004 \\
Chile & Juan Fernández & -1.25 & 0.098 & -4.08 & 0.056 \\
Northeast Atlantic & Porcupine Bank & -0.54 & 0.359 & -1.73 & 0.258 \\
& Sedlo & -1.19 & 0.110 & -3.30 & 0.076 \\
& Mean & -1.49 & 0.078 & -11.94 & 0.033 \\
\hline
\end{tabular}


The mismatch analysis produced a unimodal distribution (Fig. 2.3) consistent with a population expansion event. This was also supported by the sum of square distributions values and low levels of Harpending's raggedness indexes in all sites without exceptions (mean SSD $=0.009, P=0.431$ and mean $H_{r}=0.042, P=0.503$, Table 2.6). Additional evidence for population expansion in orange roughy was the star-like shape of the haplotype genealogy (Fig. 2.2) and the values of $\theta_{0}$ and $\theta_{1}$ for all populations that ranged from zero to 0.05 and from 5.85 to 99999 respectively (Table 2.6). The values of $\theta_{0}$ and $\theta_{1}$ also suggest that there was a major reduction before the expansion. The mean value of $\tau$ was 3.19 and the time since the last expansion was estimated between 211,000 and 126,000 years ago (Middle - Late Pleistocene). Interestingly, the skyline plot revealed two expansion events (Fig. 2.4). According to the plot, a fast population growth occurred between $\sim 150,000$ and 75,000 years ago (Late Pleistocene) and a second but smaller expansion event took place less than 25,000 years ago (end of Pleistocene).

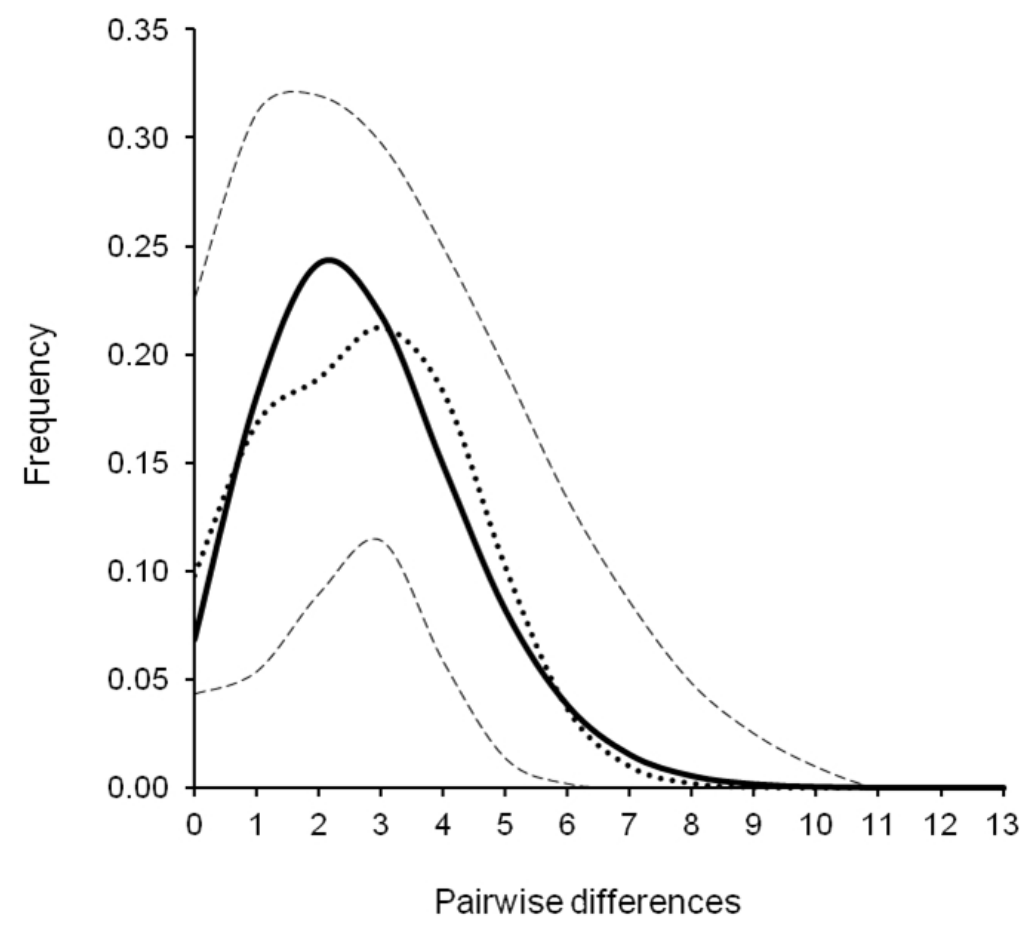

Fig. 2.3 Mismatch distribution graphic of the COI sequences. The solid line indicates the expected frequency of the pairwise differences between sequences under the sudden expansion model. The dotted line indicates the observed frequency and the dashed lines the $95 \%$ confidence intervals (CI). SSD $=0.00941, P=0.431 . F_{S}=-11.94, P=0.033$ 


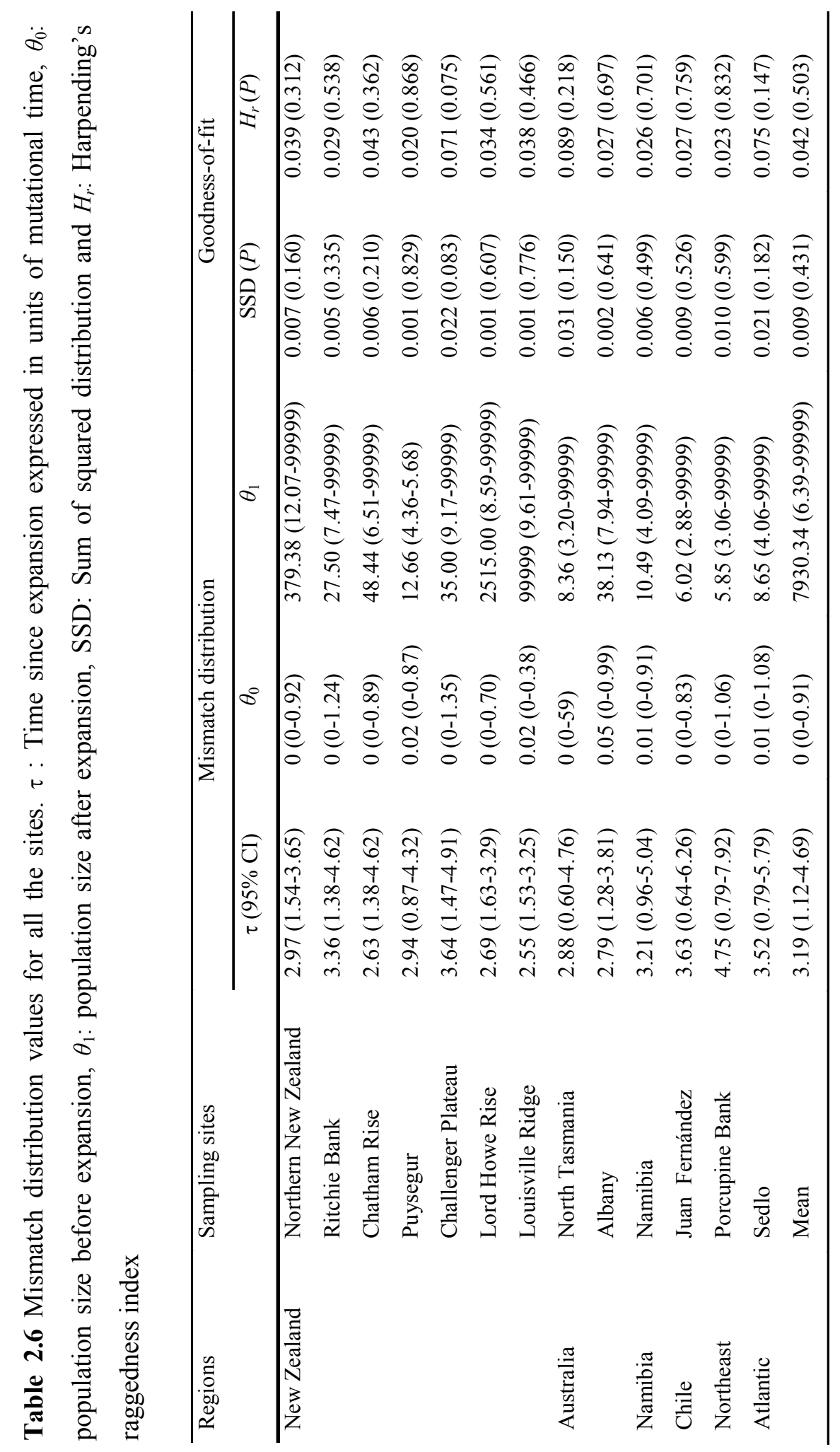




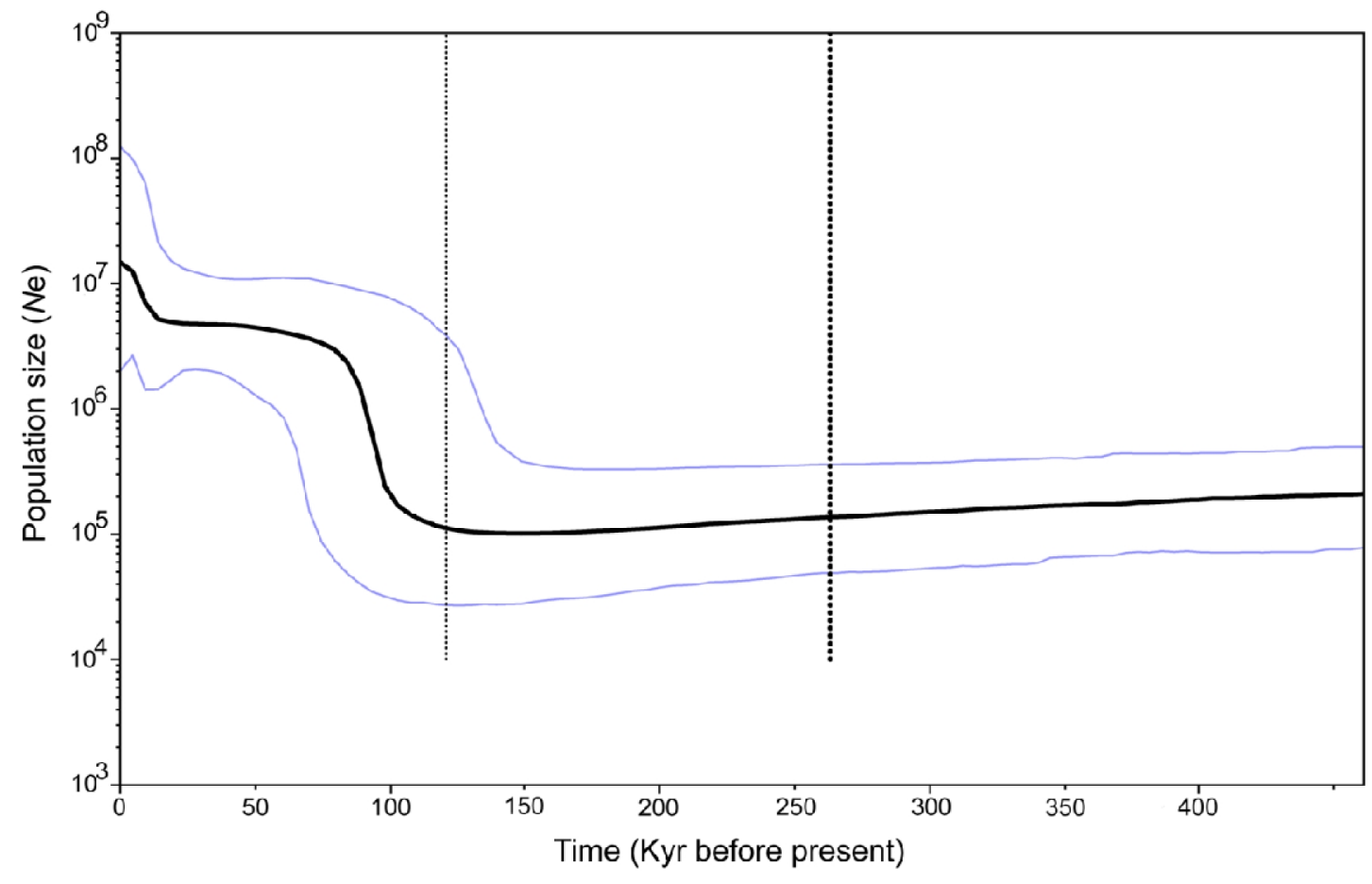

Fig. 2.4 Bayesian skyline plot showing change of population size through time using a mutation rate of 1.2\%/Myr. The thick line indicates the median estimate and the thin lines denote the $95 \%$ upper and lower confidence limits (95\% HPD). The verticals dotted lines indicate the maximum time when the root height is the lower 95\% HPD and the upper 95\% HPD 


\subsection{Discussion}

\subsubsection{Genetic diversity and structure}

Analyses of the COI and cyt $b$ sequences in orange roughy revealed high haplotype diversity which is indicative of a large historical effective population size (McCusker and Bentzen 2010). This pattern of high haplotype diversity is common in marine fishes and consistent with previous reports for cyt $b$ sequences in orange roughy by Baker et al. (1995) and in the bluemouth Helicolenus dactylopterus by Aboim et al. (2005). Similarly, high values of diversity have been reported for mtDNA d-loop sequences in other deep-sea fishes such as the thornyhead rockfishes Sebastolobus alascanus, $S$. altivelis and $S$. macrochir, the cape hake Merluccius capensis, the Alaskan Pacific halibut Hippoglossus stenolepis, and the alfonsino Beryx decadactylus (Stepien et al. 2000; von der Heyden et al. 2007; Nielsen et al. 2010; Friess and Sedberry 2011).

The lack of genetic differentiation among orange roughy populations from the South Atlantic Ocean and South Pacific Ocean is surprising given the large geographic distances between the regions surveyed in this study. Genetic homogeneity among distant orange roughy populations was also found by Smith (1986), Elliott and Ward (1992) and Oke et al. (2002) with different molecular markers. At a regional scale (i.e. within New Zealand) and between regions, our results are consistent with those reported in a study of microsatellite markers (White et al. 2009a), which found panmixia in orange roughy within the Northeast Atlantic, but significant differentiation between samples from the Northeast Atlantic and one sample from Namibia. A lack of genetic differentiation has been also reported for other deep-sea fishes, as the armorhead Pseudopentaceros wheeleri in the North Pacific Ocean (Martin et al. 1992; Yanagimoto et al. 2008). The larvae of the armorhead remain pelagic for 1.5 to 2.5 years and have a neustonic distribution with high potential for dispersion by wind-driven currents (Boehlert and Sasaki 1988; Mundy and Moser 1997). Similarly, genetic homogeneity was reported among populations of the wreckfish Polyprion americanus in the North Atlantic (Sedberry et al. 1996), which is probably related to the long period that juvenile stages spend in the pelagic environment. Several other deep-sea species show genetic homogeneity among populations and have pelagic larval and juvenile stages, that last for several months and could be passively transported by ocean currents (Hoarau and Borsa 2000; von der Heyden et al. 2007; Friess and Sedberry 2011). 
In contrast, orange roughy have a relatively short larval period of $\sim 10$ days (Zeldis et al. 1998), and coupled with spawning around seamounts, where Taylor columns (closed circulation cells) can retain eggs and larvae (Rogers 1994), long distant juvenile dispersal is unlikely. The characteristics of orange roughy that might contribute to panmixa over such large distances might relate to their longevity and active adult dispersal. It is generally recognized that some deepwater teleosts (e.g. Coryphaenoides spp., Sebastolobus altivelis) have reduced bone and musculature for neutral buoyancy and low metabolism as an adaptation to the deep-sea environment (Koslow 1996). However, the metabolism of orange roughy is substantially higher than the typical nonmigratory deepwater fishes, and similar to shallow water active species (Koslow 1997), suggesting a high capacity for active migration of adults. Based on this fact, I agree with White et al. (2009a) that there is potential for gene flow under a stepping stone model, especially considering the longevity of orange roughy and the opportunity to spawn many times in a lifetime. Rogers et al. (2006) reported that the lack of differentiation between two Southern Ocean sites in the Patagonian toothfish could be due to stepping stone links via oceanic ridge systems and seamounts. Although the geographic distance among orange roughy sites surveyed here is much larger than between the two sites considered by Rogers et al. (2006), there could be systems connecting ridges or seamounts were orange roughy is found that may promote dispersal of adults.

Nevertheless, the two Northeast Atlantic sites $\left(41^{\circ} \mathrm{N}\right.$ and $\left.50^{\circ} \mathrm{N}\right)$ showed some degree of genetic differentiation from all the other regions. Oceanographic characteristics may be important for explaining this pattern. Tsuchiya et al. (1992) reported an abrupt watermass boundary at $41^{\circ} \mathrm{N}$ at the Azores-Biscay Rise. It is possible that this oceanographic boundary restricts the north-south dispersal of orange roughy $\sim 41^{\circ} \mathrm{N}$ and may help explain our findings. Low but significant differentiation between sites in the Azores region $\left(38-39^{\circ} \mathrm{N}\right)$ and one site off Madeira $\left(33^{\circ} \mathrm{N}\right)$ was detected for the deep-sea species Pagellus bogaraveo with mitochondrial DNA sequences (Stockley et al. 2005). Further studies are needed to determine if oceanographic characteristics at the Azores-Biscay Rise around $41^{\circ} \mathrm{N}$ represent a barrier for dispersal of deep-sea teleosts.

When considering a fine scale of comparison, it is notable that Carlsson et al. (2011) using microsatellites and otolith chemistry found shallow but significant genetic differentiation in orange roughy samples within a complex topographic system in the Northeast Atlantic. The contrast between our results (lack of genetic differentiation at a regional scale, i.e within New Zealand) and the results of Carlsson et al. (2011) could be 
explained by the different signals revealed by different types of DNA markers. Although, as mentioned before, White et al (2009a) using microsatellites markers found no significant differentiation in a fine scale study in the Northeast Atlantic. It is possible that the findings of Carlsson et al. (2011) are related to differences in the particular topographic system, as the genetic differences were largely between one flat site and seamount sites.

The genetic structure of orange roughy, as measured here with mtDNA markers, suggest that homogeneity prevails over large geographic areas and there is no measurable genetic divergence among populations. However, this does not necessarily mean that populations are demographically connected. Genetic differentiation may not be detected with selectively neutral markers especially when population sizes are large, and when populations have recently diverged. Indeed the COI gene typically shows low divergence among widely distributed populations in marine fishes (Ward et al. 2009). The genetic homogeneity found in this study may result from 1) panmixia; 2) recent differentiation that is undetected with mitochondrial markers; 3) few migrants per generation that maintain genetic connectivity, but not necessarily demographic connectivity. Nevertheless, the mitochondrial DNA markers employed here have clearly shown high genetic diversity, which is related with historical large population size (McCusker and Bentzen 2010), and genetic connectivity among orange roughy populations in the past, even though more recent events may have changed these patterns.

\subsubsection{Implications for fisheries management in New Zealand}

Currently there are five areas that are treated separately for assessment and management of orange roughy in New Zealand. Each area (ORH) may consist of one or more stocks. In this study I included samples from Northern New Zealand (ORH1), Ritchie Bank (ORH2A), Chatham Rise and Puysegur (ORH3B), Challenger Plateau (ORH7A) and two sites outside the EEZ, Lord Howe Rise and Louisville Ridge. I found no significant differences among sites and no pattern of IBD. The COI data did not reject a single genetic-stock model for orange roughy in New Zealand waters. However, there was one exception; the Chatham Rise sample (east of central New Zealand) was significantly different to the Puysegur sample (south of New Zealand) at the 5\% level $\left(\Phi_{\mathrm{ST}}=0.031\right.$, 
$P=0.027$ ), but not after Bonferroni correction. While additional markers are desirable to determine the extent of differentiation among these sites, the data presented here provide additional genetic support for management of the Puysegur stock as a separate unit to the Chatham Rise stock within ORH3B. It is notable that earlier studies of mtDNA RFLPs's found significant divergence between these sites (Smith et al. 1996; 1997).

\subsubsection{Demographic history}

The pattern of high haplotype diversity versus low nucleotide diversity found in all the sites and for the total pooled sites indicates that there was a drastic reduction in population size in the past followed by sudden expansion (Grant and Bowen 1998). Similar results have been found in other fishes, Helicolenus dactylopterus, Merluccius capensis, and Glyptocephalus stelleri (Aboim et al. 2005; von der Heyden et al. 2007; Xiao et al. 2010).

Taking into account both, mismatch distribution and skyline analyses and the mutation rates of $2 \%$ and $1.2 \% / \mathrm{Myr}$ (Brown et al. 1979; Bermingham et al. 1997), two expansion events were detected for orange roughy. The first was estimated to have occurred between 200,000 to 75,000 years ago during the Middle - Late Pleistocene period and the second of lower magnitude less than 25,000 years ago at the end of the Pleistocene. The timing of the population expansion events largely depends on the mutation rate used, therefore the precise timing of these events is uncertain, but they most likely occurred during the Pleistocene period which span from $\sim 1.6$ Myr to 10,000 years before present. The Pleistocene was punctuated by a series of large glacialinterglacial changes (Imbrie et al. 1992). Over the last $\sim 175,000$ years, marine ecosystems responded to the climatic events, with changes in species distributions and abundances and changes in productivity (Webb and Bartlein 1992). There were also changes in oceanic circulation, for example, Rasmussen et al. (2003) found that during a period 160,000 to 10,000 years ago the Labrador Sea -one of the main areas for deep water formation in the North Atlantic Ocean today- underwent rapid variations in deep and surface water circulation coinciding with ice rafting events. It has been inferred that glaciations-interglaciations events and associated changes in the marine environment may have had great effects in the demographic history of many marine fishes as the 
coastal species Glyptocephalus stelleri and Pennahia argentata (Xiao et al. 2010; Han et al. 2008) and the deep-sea species as Beryx decadactylus (Friess and Sedberry 2011).

\subsection{Conclusion}

Using mitochondrial DNA sequences I found little evidence of genetic differentiation at both global (between Oceans) and local (within New Zealand) scales. Only the Northeast Atlantic sample showed some degree of genetic differentiation from all other regions. This pattern of historical genetic homogeneity may be explained by dispersal of adults under the stepping-stone model. These findings provide new evidence supporting previous studies that have reported high levels of connectivity in deep-sea species. On the other hand, demographic analyses indicated that there were two population expansion events in orange roughy, one during the Middle-Late Pleistocene and the second at the end of the Pleistocene period. 


\section{Chapter 3}

\section{Global and fine-scale population structure in the commercially exploited deep-sea teleost orange roughy (Hoplostethus atlanticus)}

\subsection{Abstract}

The widely distributed teleost orange roughy, Hoplostethus atlanticus, has been one of the main species targeted in deep-sea fisheries. While morphometric, parasite and otolith analyses have generally found differentiation among populations within ocean basins, genetic techniques have shown contradictory results at different geographical scales. Here, I used nine microsatellite DNA loci to study genetic diversity and differentiation in orange roughy at a global scale using samples from New Zealand, Australia, Namibia, Chile, and the Northeast Atlantic Ocean. Additionally, temporal genetic variation was assessed for eight sites in Northern New Zealand sampled in two different years. The expected heterozygosity was high in all the sites, suggesting high levels of genetic diversity in orange roughy. Overall, I detected low but significant differentiation at the global scale: across the Southern hemisphere and between the Southern hemisphere regions and the Northeast Atlantic Ocean. However, genetic homogeneity was found between New Zealand and Australia. The present data does not showed temporal variation in orange roughy from Northern New Zealand. A pattern of isolation by distance at the global scale suggests stepping-stone migration, which is likely the result of active adult dispersal. This study revealed levels of genetic differentiation at the global scale that were undetected with mitochondrial DNA sequences analyses. 


\subsection{Introduction}

The marine environment was once considered a largely "open" system with few boundaries to dispersal of marine organisms. However, increasing research has revealed that many marine species are not panmictic. Despite the potential for widespread dispersal of swimming adults and/or pelagic early life stages, many studies have reported restricted gene flow at different geographic scales in marine fishes. Oceanographic and topographic features, coupled with behavioural characteristics provide barriers for dispersal in marine species. For example, Fauvelot and Borsa (2011) found high levels of genetic divergence in the widely-distributed Spanish mackerel Scomberomorus commerson and suggested that the high migrating ability of this fish may be associated with phylopatric behaviour rather than promoting wide-scale dispersal. In contrast, there are examples of species with genetically homogeneous populations over wide geographical scales; $\mathrm{Wu}$ et al. (2010) found that the yellowfin tuna Thunnus albacares exhibits no genetic differentiation between populations from the Western Pacific and Western Indian Oceans. For commercial marine fishes rates of migration are important to determine the boundaries of a "stock", which is typically considered a population or unit large enough to be self-reproducing (Hilborn and Walters 1992). Stock delineation is of major importance for stock assessment and effective fisheries management, but it is complex and usually requires a multidisciplinary approach (see Begg et al. 1999). One widely used technique to assist in the study of stock structure is the application of neutral molecular markers (e.g. González-Wangüemert et al. 2010; Broderick et al. 2011; Schunter et al. 2011). Genetic studies are particularly useful for deep-sea species for which tag-recapture techniques are difficult to apply. Population genetics studies have been conducted on deep-sea fishes such as the wreckfish Polyprion americanus (Ball et al. 2000), the tusk Brosme brosme (Knutsen et al. 2009) and the alfonsino Beryx decadactylus (Friess and Sedberry 2011) among others. While dispersal by larval stages and swimming adults was related to the finding of a single genetic stock in B. decadactylus in the North Atlantic Ocean (Friess and Sedberry 2011), genetic differentiation among North Atlantic samples of $B$. brosme was related to bathymetric barriers (Knutsen et al. 2009). At a wider scale including samples from the North and South Atlantic Ocean, the Mediterranean Sea, and the South Pacific Ocean, Ball et al. (2000) found three genetic stocks in the wreckfish P. americanus. 
Many deep-sea fishes are $K$-selected: they are long-lived, have late maturation and low fecundity. The increased fishing pressure on deep-sea species over the last three decades (see Pitcher et al. 2010) coupled with their life history characteristics make them vulnerable to over exploitation (reviewed by Baker et al. 2009). One such species is the widely distributed deep-sea teleost orange roughy, Hoplostethus atlanticus, which is found between 450 and 1,800 $\mathrm{m}$ in the Indian Ocean, South Pacific Ocean, and the Northeast Atlantic Ocean (Horn et al. 1998; Branch 2001; Labbé and Arana 2001). Like other deep-sea fish species, orange roughy occur around seamounts especially during spawning and feeding events. It has been suggested that they could migrate hundreds of kilometres to spawn (Bell et al. 1992; Francis and Clark 1998), but they also disperse to flat areas close to seamounts (Clark 1996). Orange roughy have been one of eight major target species in global seamount fisheries (Pitcher 2010). Fisheries for orange roughy started off New Zealand in 1979 and progressively expanded to Australia, Namibia, the Northeast Atlantic Ocean, the Indian Ocean and Chile (reviewed by Branch 2001). Many stocks have been fished down to or below $30 \%$ of initial levels, and some fisheries have been closed or quotas largely reduced (see Clark 2009; Niklitscheck et al. 2010; Foley et al. 2011). Currently, the only remaining large-scale fisheries for orange roughy are around New Zealand (Clark 2009; New Zealand Ministry of Fisheries 2011).

Several studies using parasite, phenotypic traits, and genetic markers have identified population differentiation in orange roughy over a range of geographical scales (Lester et al. 1988; Edmonds et al. 1991; Smolenski et al. 1993; Elliott et al. 1995; Smith et al. 1996; Smith and Benson 1997; Smith et al. 1997; Smith et al. 2002a). Some earlier genetic studies found little differentiation at regional and global scales (Smith 1986; Elliott and Ward 1992; Oke et al. 2002). Using mitochondrial DNA sequences and large sample sizes, I found genetic homogeneity between orange roughy from sites off New Zealand, Australia, Namibia, and Chile, but low levels of genetic differentiation between these regions and the Northeast Atlantic Ocean (Chapter 2). Contrasting levels of genetic differentiation have been detected with microsatellite DNA markers among populations in the Northeast Atlantic Ocean. White et al. (2009a) detected panmixia among five sites between $\sim 40^{\circ} \mathrm{N}$ and $56^{\circ} \mathrm{N}$, some separated by over $2,000 \mathrm{~km}$, while Carlsson et al. (2011) detected low but significant differentiation at a smaller spatial scale within the Porcupine Bank (a complex topographic system $\sim 50^{\circ} \mathrm{N}$ ), mostly in comparisons between one flat site and seamount sites. 
The main goal of the present study was to use microsatellite DNA markers over the same geographic range surveyed with mitochondrial DNA sequences (Chapter 2) to determine levels of nuclear variation and to test for global levels of genetic differentiation that might have been undetected with the mtDNA marker. The second goal was to conduct a fine-scale study around New Zealand to provide new genetic data for local stock discrimination and fisheries management. Samples from a second season for some sites in Northern New Zealand were included to assess temporal variation.

\subsection{Materials and methods}

\subsubsection{Sampling and DNA extraction}

Tissue samples from 812 individuals were available from 22 sites in five regions, New Zealand (16 sites), Australia (2 sites), Namibia (1 site), Chile (1 site) and the Northeast Atlantic Ocean (2 sites) (Fig. 3.1). Around northern New Zealand (fishery management area ORH 1), eight sites were sampled in both 2008 and 2010 (Fig. 3.1). Muscle tissue samples were taken from fresh fish and frozen at $-20^{\circ} \mathrm{C}$, or stored in $95 \%$ ethanol. Samples from ORH 1 were obtained by New Zealand Ministry of Fishery Observers. Samples from all other sites around New Zealand, Australia, and Namibia were made available from a frozen tissue collection held at NIWA (National Institute of Water and Atmospheric Research Ltd., New Zealand). Samples from Chile and the Northeast Atlantic Ocean were provided from tissue collections held at Universidad Austral de Chile, University College Cork, Ireland and University of the Azores, Portugal.

A small piece of tissue $\left(\sim 2 \mathrm{~mm}^{3}\right)$ was used for DNA extractions. Genomic DNA was obtained using a salt extraction protocol with proteinase $\mathrm{K}$ digestion. The remaining pellet was washed two times with ethanol and resuspended in $100 \mu \mathrm{L}$ TE buffer. DNA samples were stored at $4^{\circ} \mathrm{C}$. 


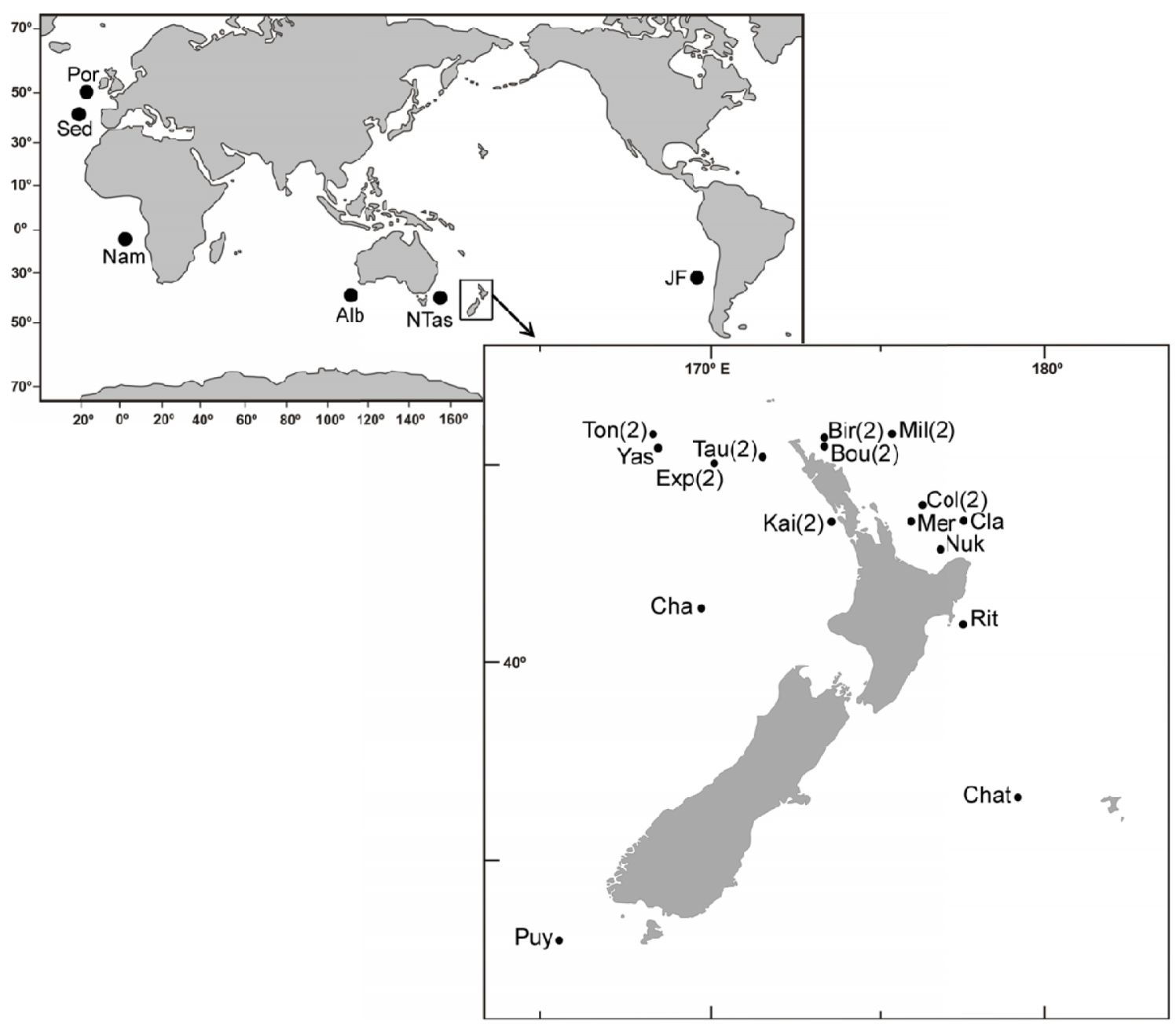

Fig. 3.1 Map showing the 22 sampling sites across the five regions surveyed. Sites sampled in both, 2008 and 2010 are indicated by (2). Codes for New Zealand sites are: Kai = Kaipara Flats, Tau $=$ Tauroa Knoll, Exp $=$ Explorer Hill, Ton $=$ Tony B, Yas $=$ Yasmin's, Bir $=$ Birdflue, Bou $=$ Boulder Ridge, Mil $=$ Milan's, Nuk $=$ Nukuhou Knoll, Col $=$ Colville Knoll, Mer $=$ Mercury Knoll, Cla $=$ Clark, Rit $=$ Ritchie Bank, Chat $=$ Chatham Rise, Puy $=$ Puysegur, Cha $=$ Challenger Plateau. Codes for sites outside New Zealand are as follow: Por = Porcupine Bank, Sed $=$ Sedlo (Northeast Atlantic), Nam $=$ Namibia, Alb $=$ Albany, NTas $=$ North Tasmania (Australia), JF = Juán Fernández Archipelago (Chile). 


\subsubsection{PCR and genotyping}

Fourteen published microsatellite DNA loci (Oke et al. 1999; White et al. 2009b) were assessed in preliminary trials to determine amplification success by polymerase chain reaction (PCR) and genotyping errors. Five loci were discarded due to technical difficulties; four of them showed a consistent presence of null alleles and one locus presented a high proportion of missing data (i.e. alleles were not possible to determine for more than $80 \%$ of the individuals). I used nine loci: Hat2a, Hat3, Hat7, Hat9a, Hat45 (Oke et al. 1999), HopAt2, HopAt4, HopAt5 and HopAt11 (White et al. 2009b) across all 812 samples. Forward primers were synthesised by Applied Biosystems (Foster City, USA) with the 5'-labelled with a florescent tag: VIC, 6FAM, NED or PET. Reverse primers were synthesised by Invitrogen (Auckland, New Zealand). Final PCR reactions of $15 \mu \mathrm{L}$ total volume consisted of $20 \mathrm{ng}$ of DNA, 1X PCR buffer (160mM $\left(\mathrm{NH}_{4}\right)_{2} \mathrm{SO}_{4}, 670 \mathrm{mM}$ Tris- $\mathrm{HCl}, 0.1 \%$ stabilizer), $2 \mathrm{mM} \mathrm{MgCl} 2,0.5 \mu \mathrm{M}$ of each primer, $0.2 \mathrm{mM}$ of each dNTPs, $1.5 \mathrm{U}$ of Taq polymerase and $0.4 \mathrm{mg} \mathrm{mL}^{-1}$ of Bovine Serum Albumin (BSA). PCR cycles were performed in an Eppendorf Mastercycler ep gradient S using 96 well plates. The profile for primers Hat2a, Hat3, Hat7, Hat9a and Hat 45 was: $94^{\circ} \mathrm{C}$ for $3 \mathrm{~min}$, then 10 cycles of denaturing at $94^{\circ} \mathrm{C}$ for $30 \mathrm{~s}$, annealing at $50^{\circ} \mathrm{C}$ for $30 \mathrm{~s}$, extension at $72^{\circ} \mathrm{C}$ for $30 \mathrm{~s}$ followed by 35 cycles of $94^{\circ} \mathrm{C}$ for $30 \mathrm{~s}, 55^{\circ} \mathrm{C}$ for $30 \mathrm{~s}, 72^{\circ} \mathrm{C}$ for $30 \mathrm{~s}$ and a final extension at $72^{\circ} \mathrm{C}$ for $10 \mathrm{~min}$. For primers HopAt2, HopAt4, HopAt5 and HopAt11 the profile was: $95^{\circ} \mathrm{C}$ for $15 \mathrm{~min}$, followed by 35 cycles of $94^{\circ} \mathrm{C}$ for $30 \mathrm{~s}, 63^{\circ} \mathrm{C}$ for $90 \mathrm{~s}, 72^{\circ} \mathrm{C}$ for $1 \mathrm{~min}$ and a final extension at $60^{\circ} \mathrm{C}$ for $10 \mathrm{~min}$. Final PCR products of each locus were pooled together for genotyping (three pool plexes each one with three loci). Samples were analyzed on a capillary ABI3730 Genetic Analyser (Applied Biosystems Inc.) using LIZ 500 (-250) size standard by Massey Genome Service (Palmerston North, New Zealand). Alleles were scored using GENEMAPPER 3.7 (Applied Biosystems).

\subsubsection{Data analyses}

The total data set (812 specimens) was used for spatial and temporal analyses of genetic differentiation. The spatial analyses were performed for 620 individuals collected from the 22 sites (Table 3.1). For the temporal analyses eight sites in northern New Zealand (ORH 1) were sampled in both 2008 and 2010, and 192 individuals were available from 
2010 (Table 3.4). MICROCHECKER 2.2.3 (van Oosterhout et al. 2004) was used to detect possible scoring errors and the presence of null alleles. Pairwise tests of linkage disequilibrium (Slatkin 1994; Slatkin and Excoffier 1996) were performed running 10,000 permutations in ARLEQUIN 3.11 (Excoffier et al. 2005). Deviations from Hardy-Weinberg Equilibrium (HWE) for each locus were tested using GENEPOP 4.0 (Rousset 2008). A Bayesian approach implemented in the program BAYESCAN (Foll and Gaggiotti 2008) was used to detect loci under selection.

\subsubsection{Spatial analyses}

Diversity indices were calculated for each of the 22 sites (including the New Zealand sites sampled on 2008). The average number of alleles per locus $\left(N_{\mathrm{a}}\right)$, allelic richness $\left(A_{\mathrm{r}}\right)$, observed number of private alleles $\left(P_{\mathrm{a}}\right)$ and the inbreeding coefficient $\left(F_{\mathrm{IS}}\right)$ were calculated in FSTAT 2.9.3.2 (Goudet 1995; 2001). Allelic richness calculates the number of alleles independent of sample size. The observed $\left(H_{\mathrm{O}}\right)$ and expected $\left(H_{\mathrm{E}}\right)$ heterozygosities were determined with ARLEQUIN and HWE tests were performed using 100,000 steps in Markov Chain and 10,000 dememorisation steps.

The pairwise genetic divergence between sites using the fixation index $F_{\mathrm{ST}}$ was estimated with ARLEQUIN. The software POWSIM 4.1 (Ryman and Palm 2006) was used to estimate the statistical power of the loci to detect population differentiation at $F_{\text {ST }}$ level of 0.005 using Chi-squared and Fisher's exact tests. Two combinations of settings were used to generate the desired $F_{\mathrm{ST}}$ value, $N_{\mathrm{e}}=2,000, t=20$ and $N_{\mathrm{e}}=10,000$, $t=100$; using 1,000 and 100 replicates, respectively, and the sampling sizes of each of the 22 sites. Estimates of the statistical $\alpha$ (type I) error were generated using samples drawn directly from the base population, omitting the drift steps $(t=0)$ and using 1,000 replicates. Another measure that is able to detect differentiation even when diversity is high is the estimator of actual differentiation, $D_{\text {est }}$ (Jost 2008). $D_{\text {est }}$ was calculated for pairwise comparisons using 1,000 bootstrap replicates in SMOGD 1.2.5 (Crawford 2010). ARLEQUIN was also used to perform AMOVA and Mantel tests. For $F_{\mathrm{ST}}$ and AMOVA 10,000 permutations were implemented. The Mantel tests were performed to determine the occurrence of the isolation by distance (IBD) pattern at a global scale (with sites from ORH 1 pooled together), and at a fine-scale within New Zealand, where all the sites were considered separate. Correlation between genetic differentiation 
$F_{\mathrm{ST}} /\left(1-F_{\mathrm{ST}}\right)$ and geographic distance $(\mathrm{ln} \mathrm{m})$ between sites, was assessed performing 1,000 permutations. The shortest distance between sites was estimated using Google Earth 4.3.

To visualize patterns of population differentiation, a Principal Component Analysis (PCA) was performed in P.C.A.-GEN 1.2 (http://www2.unil.ch/popgen/softwares/ pcagen.htm). The program tests the significance of total inertia as well as individual axes inertia. Population structure was also evaluated with STRUCTURE 2.3.3 (Pritchard et al. 2000). The program CONVERT 1.31 (Glaubitz 2004) was used to obtain the STRUCTURE file. STRUCTURE assigns individuals probabilistically to $K$ groups maximizing HWE and linkage equilibrium. Sample location was used as a prior as this improves the performance of the analysis when the $F_{\mathrm{ST}}$ values are low (Hubisz et al. 2009). The no admixture model and correlated allele frequencies (Falush et al. 2003) were implemented. Ten independent runs were performed for each $K$ ( $K=$ two to 22$)$ with 100,000 iterations and a burn-in length of 100,000. The program STRUCTURE HARVESTER (Earl and vonHoldt 2011) was used to apply the Evanno method (Evanno et al. 2005) to detect the value of $K$ (number of genetic groups) that best fit the data.

\subsubsection{Temporal analyses}

Temporal analyses were conducted for the eight sampling sites around Northern New Zealand (ORH 1) sampled in 2008 and 2010 (see Fig. 3.1). The diversity indices, average number of alleles per locus $\left(N_{\mathrm{a}}\right)$, allelic richness $\left(A_{\mathrm{r}}\right)$, observed number of private alleles $\left(P_{\mathrm{a}}\right)$, inbreeding coefficient $\left(F_{\mathrm{IS}}\right)$, and observed $\left(H_{\mathrm{O}}\right)$ and expected $\left(H_{\mathrm{E}}\right)$ heterozygosities were calculated for each of the eight sites sampled in 2010. An AMOVA was conducted to compare samples nested from both seasons within sampling sites to evaluate the variation among sampling sites relative to variation among seasons within sampling sites. To further explore the data, variability among temporal samples was assessed with pairwise $F_{\mathrm{ST}}$ and $D_{\text {est }}$ analyses. Pairwise $F_{\mathrm{ST}}$ values were calculated in ARLEQUIN using 10,000 permutations and $D_{\text {est }}$ pairwise comparisons were calculated in SMOGD using 1,000 bootstrap replicates. POWSIM 4.1 was used to evaluate the statistical power of the loci to detect population differentiation at $F_{\mathrm{ST}}$ level of 0.005 for the temporal data set. The settings were the same as with the spatial analysis, two 
combinations of settings were used, $N_{\mathrm{e}}=2,000, t=20$ and $N_{\mathrm{e}}=10,000, t=100$; with 1,000 and 100 replicates, respectively, and the sampling sizes of each of the 16 samples (eight sites per season).

\subsection{Results}

The genotypes of each individual for the spatial and temporal analyses are found in Appendixes C and D. MICROCHECKER analyses found no scoring errors. Five loci showed an excess of homozygotes suggesting the presence of null alleles, but none were consistent across sites (i.e. in two to four sites from the total 22). No tests for linkage disequilibrium were significant after Bonferroni correction $(\alpha=0.001)$. According to GENEPOP, two loci (Hat2a and Hat7) showed deviations from Hardy-Weinberg expectations but only at single sites. No loci were identified as outliers under selection, although locus Hat3 showed higher $F_{\text {ST }}$ values in comparison with the other eight loci. Statistics per locus for each sampling site are found in Appendix E.

\subsubsection{Spatial analyses}

Summary statistics for each site across all loci are reported in Table 3.1. The largest number of samples was obtained from New Zealand (430), with 16 sites surveyed with 22 to 37 samples per site. The sample sizes for the other four regions, Australia, Namibia, Chile, and the Northeast Atlantic, ranged from 46 to 49 . The average number of alleles per locus $\left(N_{\mathrm{a}}\right)$ ranged from 10.8 to 16.9 and allelic richness $\left(A_{\mathrm{r}}\right)$ from 9.2 to 11.2. The Porcupine Bank in the Northeast Atlantic had the lowest allelic diversity as indicated by both, $N_{\mathrm{a}}$ and $A_{\mathrm{r}}$. The highest allelic diversity was obtained for two sites in New Zealand, where Milan's presented the highest $N_{\mathrm{a}}$ and $A_{\mathrm{r}}$. The $A_{\mathrm{r}}$ was equally high in the Challenger Plateau. A few private alleles (between 1 and 3) were detected at 12 sites. The observed and expected heterozygosities were similar across all sites, ranging from 0.79 to 0.88 and from 0.85 to 0.88 , respectively. There were no significant departures from Hardy-Weinberg equilibrium in any of the sites and concordantly, none of the $F_{\text {IS }}$ values were significantly different from zero after Bonferroni correction $(\alpha=$ $0.00025, P>0.01)$. 
Table 3.1 Summary statistics for the levels of genetic variation across all loci for 22 sampling sites grouped in five regions. ORH 1 sites (see note below table) were sampled on 2008. Sample size $(n)$, average number of alleles per locus $\left(N_{\mathrm{a}}\right)$, allelic richness $\left(A_{\mathrm{r}}\right)$, observed number of private alleles $\left(P_{\mathrm{a}}\right)$, observed heterozygosity $\left(H_{\mathrm{O}}\right)$, expected heterozygosity $\left(H_{\mathrm{E}}\right)$, HardyWeinberg probability $\left(P_{\mathrm{HWE}}\right)$ and the inbreeding coefficient $\left(F_{\mathrm{IS}}\right) . P>0.01$ for all $F_{\mathrm{IS}}$ values (Bonferroni correction $\alpha=0.00025$ ). Total $n=620$

\begin{tabular}{llcccccccccc}
\hline Region & \multicolumn{1}{c}{ Sampling sites* } & Code & $N$ & $N_{\mathrm{a}}$ & $A_{\mathrm{r}}$ & $P_{\mathrm{a}}$ & $H_{\mathrm{O}}$ & $H_{\mathrm{E}}$ & $P_{\text {HWE }}$ & $F_{\mathrm{IS}}$ \\
\hline \multirow{2}{*}{ New Zealand } & Kaipara Flats & 1A & Kai & 37 & 15.3 & 10.4 & - & 0.85 & 0.86 & 0.446 & 0.013 \\
& Tauroa Knoll & 1B & Tau & 24 & 12.6 & 10.1 & 1 & 0.79 & 0.85 & 0.329 & 0.075 \\
& Explorer Hill & 1B & Exp & 24 & 13.8 & 10.8 & 1 & 0.81 & 0.86 & 0.412 & 0.059 \\
& Tony B & 1B & Ton & 24 & 12.7 & 10.3 & - & 0.87 & 0.86 & 0.550 & -0.019 \\
& Yasmin's & 1B & Yas & 24 & 13.7 & 10.6 & 1 & 0.81 & 0.86 & 0.469 & 0.060 \\
& Birdflue & 1C & Bir & 36 & 16.0 & 10.9 & 3 & 0.83 & 0.87 & 0.412 & 0.038 \\
& Boulder Ridge & 1C & Bou & 22 & 12.7 & 10.4 & - & 0.85 & 0.87 & 0.529 & 0.022 \\
& Milan's & 1C & Mil & 36 & 16.9 & 11.2 & - & 0.84 & 0.86 & 0.458 & 0.030 \\
& Nukuhou Knoll & 1D & Nuk & 22 & 13.7 & 11.0 & 2 & 0.83 & 0.86 & 0.365 & 0.040 \\
& Colville Knoll & 1D & Col & 24 & 13.8 & 11.1 & 1 & 0.85 & 0.86 & 0.560 & 0.018 \\
& Mercury Knoll & 1D & Mer & 24 & 14.1 & 11.0 & - & 0.88 & 0.87 & 0.615 & -0.013 \\
& Clark & 1D & Cla & 24 & 14.0 & 10.9 & - & 0.84 & 0.88 & 0.344 & 0.046 \\
& Ritchie Bank & 2A & Rit & 24 & 13.4 & 10.6 & - & 0.86 & 0.86 & 0.467 & 0.006 \\
& Chatham Rise & 3B & Chat & 24 & 13.0 & 10.6 & 1 & 0.84 & 0.86 & 0.464 & 0.013 \\
& Puysegur & 3B & Puy & 36 & 15.7 & 10.9 & 1 & 0.83 & 0.85 & 0.578 & 0.018 \\
& Challenger Plateau & 7A & Cha & 25 & 14.9 & 11.2 & 1 & 0.87 & 0.87 & 0.497 & 0.000 \\
Australia & North Tasmania & & NTas & 22 & 11.4 & 9.8 & - & 0.84 & 0.87 & 0.478 & 0.033 \\
& Albany & & Alb & 25 & 13.8 & 10.8 & 1 & 0.86 & 0.86 & 0.498 & 0.000 \\
Namibia & Namibia & & Nam & 48 & 14.7 & 10.0 & 3 & 0.82 & 0.86 & 0.436 & 0.037 \\
Chile & Juan Fernández & & JF & 46 & 14.7 & 10.2 & 1 & 0.83 & 0.86 & 0.371 & 0.039 \\
Atlantic & Porcupine Bank & & Por & 23 & 10.8 & 9.2 & - & 0.81 & 0.86 & 0.460 & 0.054 \\
& Sedlo & & Sed & 26 & 12.0 & 9.7 & - & 0.83 & 0.85 & 0.359 & 0.028 \\
\hline
\end{tabular}

*For New Zealand sampling sites, reference to main management areas for orange roughy as defined by the Ministry of Fisheries is indicated by: $1 \mathrm{~A}-1 \mathrm{D}=$ subareas within ORH 1, $2 \mathrm{~A}=$ $\mathrm{ORH} 2 \mathrm{~A}, 3 \mathrm{~B}=\mathrm{ORH} 3 \mathrm{~B}$ and $7 \mathrm{~A}=\mathrm{ORH} 7 \mathrm{~A}$ 
At a global scale, the $F_{\mathrm{ST}}$ analysis revealed a lack of differentiation in most comparisons between New Zealand and Australian sites. A few $F_{\mathrm{ST}}$ values were significant $(P<0.05)$, and $D_{\text {est }}$ values between sites in these two regions ranged from 0.000 to 0.039 (Table 3.2). In general, comparisons of New Zealand sites with North Tasmania resulted in higher $F_{\mathrm{ST}}$ and $D_{\text {est }}$ values than comparisons with Albany; and the $F_{\text {ST }}$ value between North Tasmania and Albany was low but significant $(P<0.05$, Table 3.2). On the other hand, most $F_{\mathrm{ST}}$ values showed significant differentiation $(P<0.05)$ between the New Zealand/Australian sites and those from Namibia, Chile, and the Northeast Atlantic (Table 3.2). The results of the POWSIM analysis for the two combinations of settings showed that the power to detect population differentiation at $F_{\mathrm{ST}} 0.005$ was 1.0 (100\% of the tests with both, Chi-squared and Fisher's exact tests) suggesting that the number of loci and sample sizes were sufficient to detect differentiation with a high degree of confidence. The estimates of the statistical $\alpha$ (type I) error were 0.062 and 0.090 with the Chi-squared and Fisher's exact test, respectively. Some comparisons were also significant after correction for multiple tests $(P<0.0002)$. $D_{\text {est }}$ values between sites in the different regions ranged from 0.000 to 0.114 (Table 3.2). Sites were pooled by region to perform new $F_{\mathrm{ST}}$ and $D_{\text {est }}$ analyses. The revised analyses on pooled samples showed significant $F_{\mathrm{ST}}$ values $(P<0.005)$ between regions, but not between New Zealand and Australia (Table 3.3). Similarly, $D_{\text {est }}$ values of pooled samples ranged from 0.0125 to 0.1031 between regions, but was 0.0016 between New Zealand and Australia (Table 3.3). The $F_{\mathrm{ST}}$ analysis showed a lack of genetic differentiation at a fine-scale around New Zealand (Table 3.2) with only eight comparisons (out of 120$)$ showing significant differentiation $\left(F_{\mathrm{ST}}=0.006-0.010, P<\right.$ 0.05 ), and most of these corresponded to comparisons between the Northern sites and the Chatham Rise or Puysegur sites (see Fig. 3.1). Similarly, $D_{\text {est }}$ values were low within New Zealand, ranging from 0.000 to 0.024 , with a mean value of 0.002 . The highest $D_{\text {est }}$ values $(0.012-0.024)$ were obtained in comparisons with the Chatham Rise or Puysegur sites. 


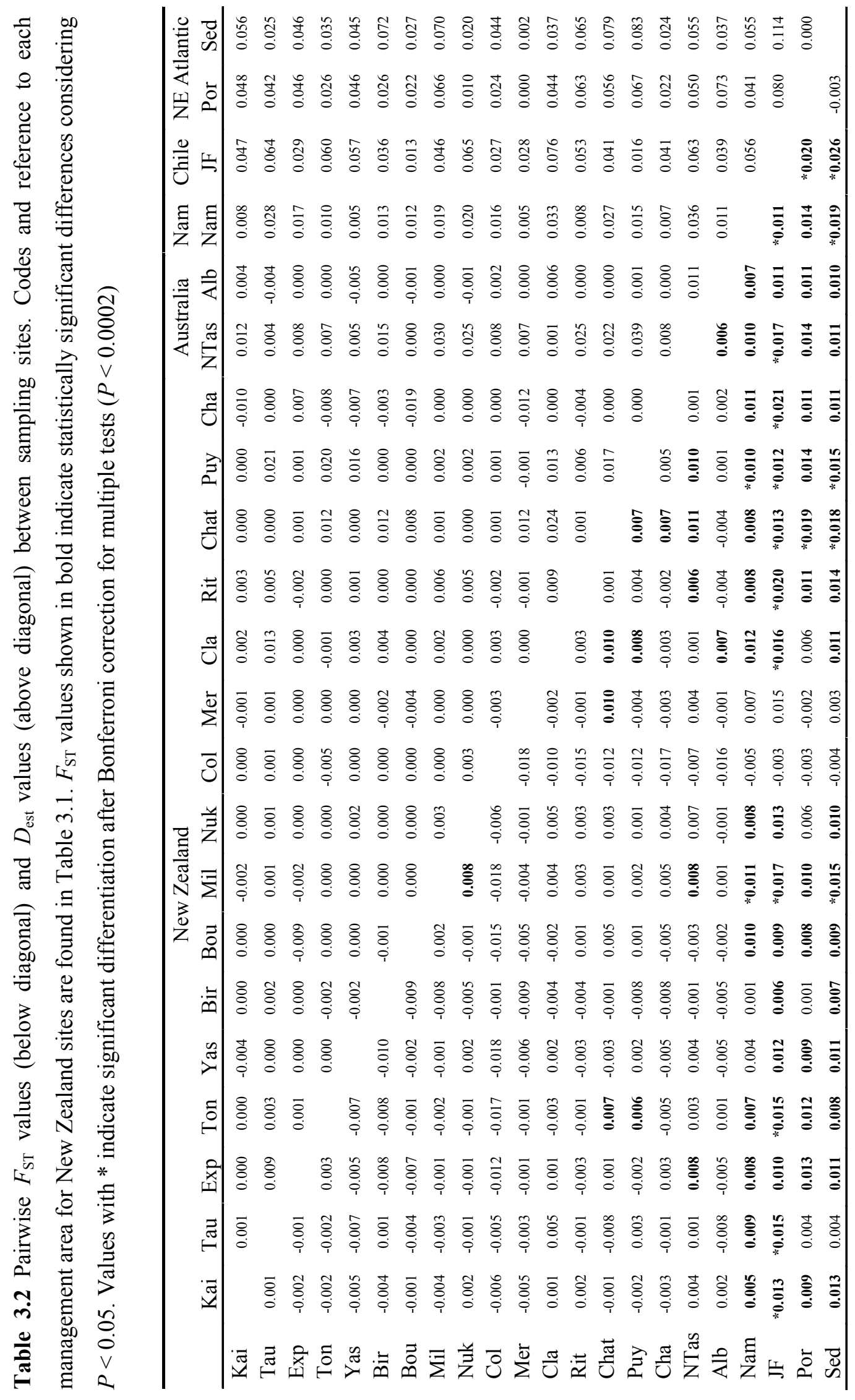


Table 3.3 Pairwise $F_{\mathrm{ST}}$ values (below diagonal) and $D_{\text {est }}$ values (above diagonal) between the five regions. Values shown in bold indicate statistically significant differences considering Bonferroni correction $(P<0.005)$

\begin{tabular}{lccccc}
\hline & New Zealand & Australia & Namibia & Chile & Northeast Atlantic \\
\hline New Zealand & & 0.0016 & 0.0125 & 0.0418 & 0.0667 \\
Australia & 0.0002 & & 0.0135 & 0.0461 & 0.0574 \\
Namibia & $\mathbf{0 . 0 0 8 2}$ & $\mathbf{0 . 0 0 6 4}$ & & 0.0559 & 0.0487 \\
Chile & $\mathbf{0 . 0 1 4 0}$ & $\mathbf{0 . 0 1 1 9}$ & $\mathbf{0 . 0 1 0 9}$ & & 0.1031 \\
Northeast Atlantic & $\mathbf{0 . 0 1 1 1}$ & $\mathbf{0 . 0 1 0 3}$ & $\mathbf{0 . 0 1 7 4}$ & $\mathbf{0 . 0 2 3 6}$ & \\
\hline
\end{tabular}

An AMOVA over all sites showed that most of the variation (99\%) was within sites. A significant but weak pattern of IBD was detected within New Zealand (Mantel test, $r$ $=0.25, P=0.02)$, driven by the consistent differentiation of the Chatham Rise and Puysegur sites from the Northern sites. A clear pattern of IBD was detected at the global scale (Mantel test, $r=0.62, P=0.001$ ). In the PCA most of the variation was explained by axis PC1 (Fig. 3.2). In the plot, Australian sites were next to New Zealand sites and sites from Namibia, Chile and the Northeast Atlantic appeared distant from New Zealand/Australia, with the site from Chile being the most distant.

Interestingly, STRUCTURE revealed three genetic groups ( $K=3$ was the best $K$ obtained with STRUCTURE HARVESTER, Fig. 3.3). In concordance with the analyses above, one group included all the New Zealand and Australian sites, and a second group corresponded to the Northeast Atlantic sites. However, despite the significant differentiation detected between Namibia and Chile $\left(F_{\mathrm{ST}}=0.011 P<0.0002, D_{\text {est }}\right.$ $=0.056$ ), the third group included the sites from Namibia and Chile (Fig. 3.4). In the PCA plot the closest site to the Chilean site was Namibia. 


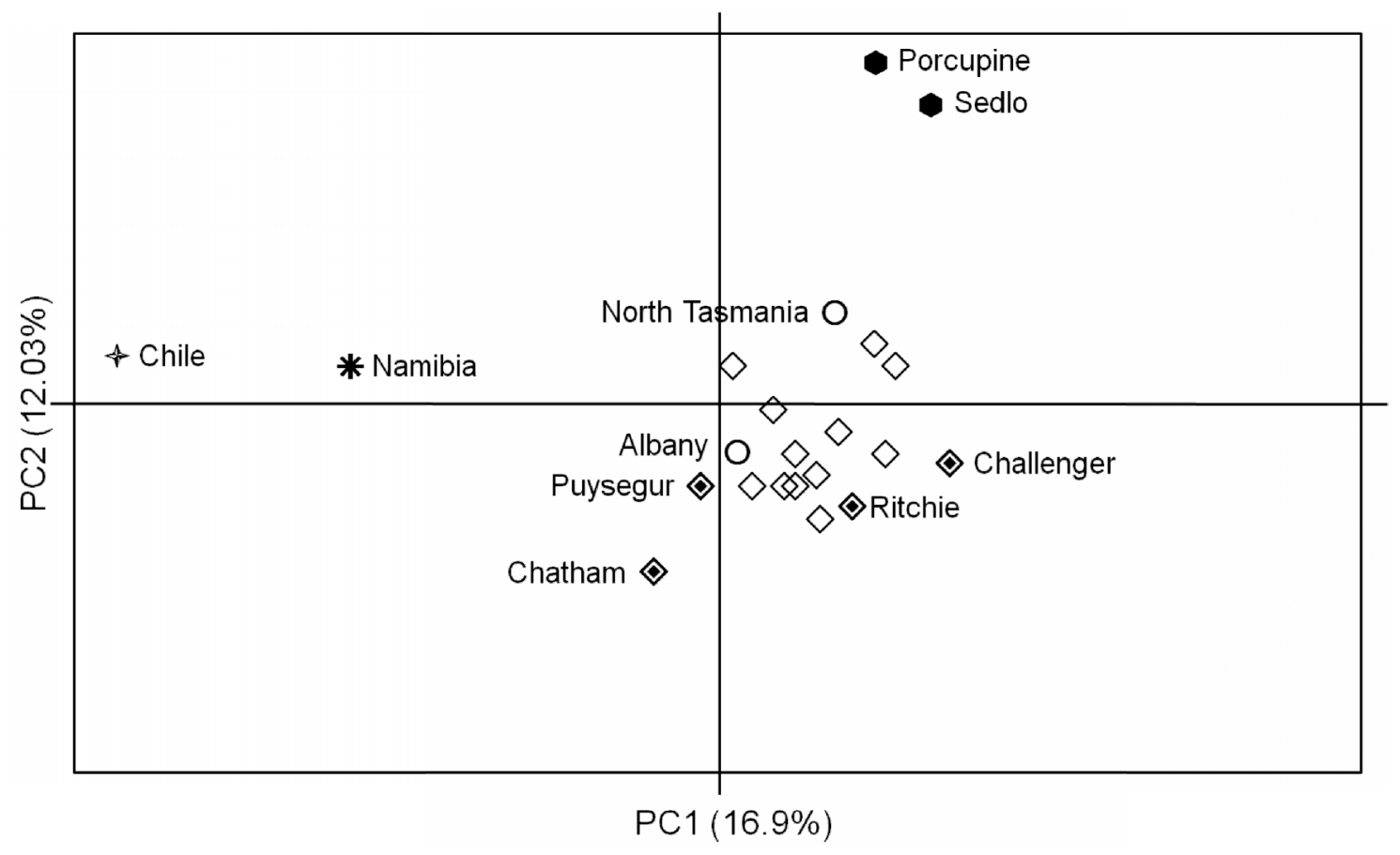

Fig. 3.2 Plot of the first two principal components axes of microsatellite DNA variation. Each symbol corresponds to one of the 22 sampling sites. $\diamond:$ sites from the ORH 1 area in New Zealand (see Table 3.1) sampled on 2008, $\diamond$ : other sites around New Zealand, $\bigcirc$ : Australian sites, *: Namibia, $\&$ : Chile, $:$ Northeast Atlantic sites. The axe PC1 explains most of the variation. $P=0.01$ 


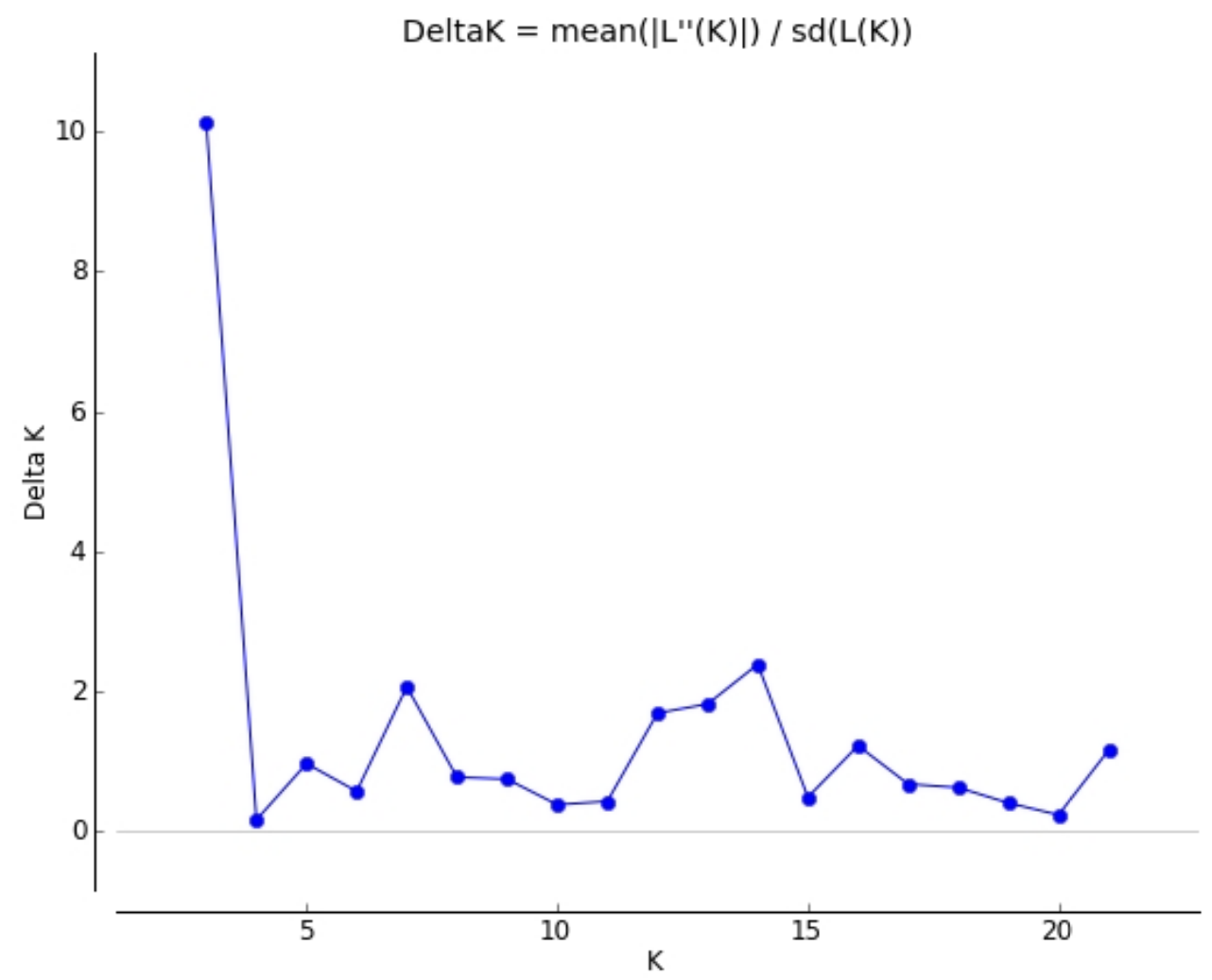

Fig. 3.3 Evanno et al. (2005) plot obtained from STRUCTURE HARVESTER. The modal value of this distribution is the best number of $K$ groups for the data 

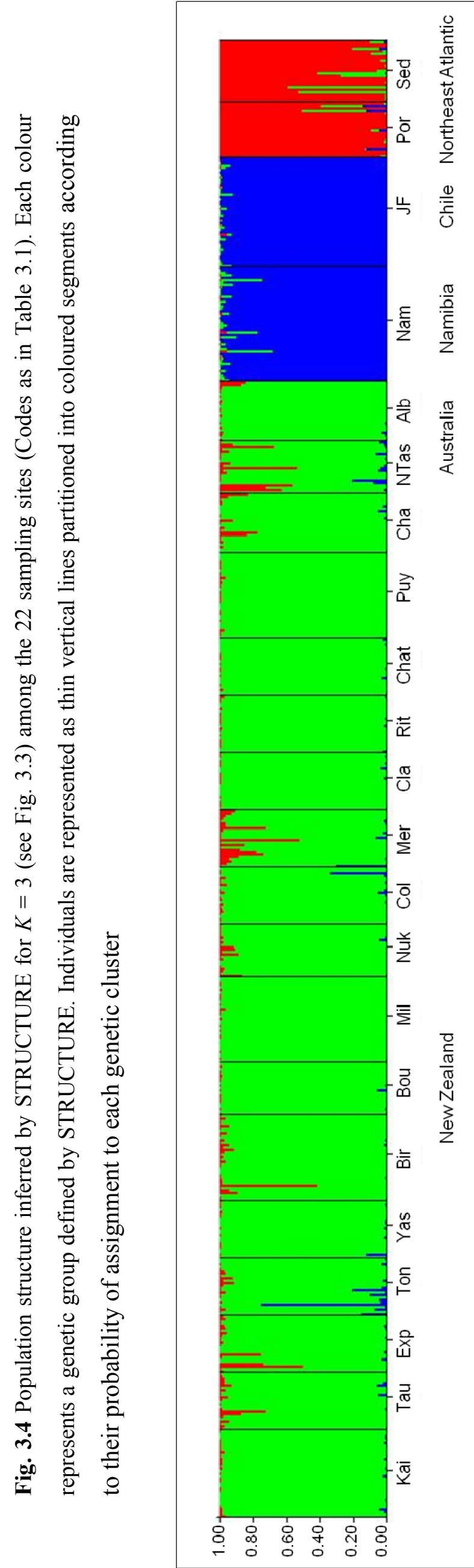


\subsubsection{Temporal analyses}

Analyses were conducted for eight sites in ORH 1 that were sampled in both 2008 and 2010 (see Fig. 3.1). A summary of the genetic indexes per site surveyed on 2010 are shown in Table 3.4 (genetic indexes for sites surveyed on 2008 are shown in Table 3.1). The mean number of alleles per locus $\left(N_{\mathrm{a}}\right)$ and the allelic richness $\left(A_{\mathrm{r}}\right)$ for each site were similar between years, particularly for the allelic richness that is independent of the sample size. The observed and expected heterozygosities were also very similar between the two years, ranging from 0.80 to 0.87 and from 0.85 to 0.87 , respectively for the sites sampled on 2010. All the sites were in Hardy-Weinberg equilibrium in both years and none of the $F_{\text {IS }}$ values were significant after Bonferroni correction (sites sampled on 2010: $\alpha=0.00069, P$ values $>0.01$ ).

The AMOVA revealed a lack of spatial and temporal differentiation, since no variation was found among sites nor between seasons within each site sampled in 2008 and 2010. Similarly, most pairwise $F_{\mathrm{ST}}$ and $D_{\text {est }}$ values were low and not significant $(P>$ 0.05 ) (Table 3.5). None of the $F_{\mathrm{ST}}$ values were significant after Bonferroni correction ( $P$ $>0.0004)$. POWSIM result for the temporal data set was the same as for the spatial data set: the power to detect population differentiation at $F_{\mathrm{ST}} 0.005$ was also $1.0(100 \%$ of the tests with both, Chi-squared and Fisher's exact tests). The four $F_{\mathrm{ST}}$ comparisons that were significant at $P<0.05$, also showed some of the highest $D_{\text {est }}$ values (0.012-0.031) and six other comparisons showed $D_{\text {est }}$ values $\geq 0.010$ (see Table 3.5). It is worth noting that two sites, Milan's and Colville Knoll, showed $D_{\text {est }}$ values $\geq 0.010$ between years. 
Table 3.4 Summary statistics for the levels of genetic variation across all loci for eight sampling sites from the ORH 1 area sampled in 2010. Sample size $(n)$, average number of alleles per locus $\left(N_{\mathrm{a}}\right)$, allelic richness $\left(A_{\mathrm{r}}\right)$, observed number of private alleles $\left(P_{\mathrm{a}}\right)$, observed heterozygosity $\left(H_{\mathrm{O}}\right)$, expected heterozygosity $\left(H_{\mathrm{E}}\right)$, Hardy-Weinberg probability $\left(P_{\mathrm{HWE}}\right)$ and the inbreeding coefficient $\left(F_{\mathrm{IS}}\right) . P>0.01$ for all $F_{\mathrm{IS}}$ values (Bonferroni correction $\alpha=0.00069$ ). Total $n=192$

\begin{tabular}{lccccccc}
\hline Sampling sites & $n$ & $N_{\mathrm{a}}$ & $A_{\mathrm{r}}$ & $H_{\mathrm{O}}$ & $H_{\mathrm{E}}$ & $P_{\mathrm{HWE}}$ & $F_{\mathrm{IS}}$ \\
\hline Kaipara Flats & 24 & 13.9 & 11.4 & 0.85 & 0.87 & 0.568 & 0.017 \\
Tauroa Knoll & 24 & 12.4 & 10.6 & 0.87 & 0.86 & 0.644 & -0.006 \\
Explorer Hill & 24 & 13.1 & 10.9 & 0.82 & 0.85 & 0.460 & 0.035 \\
Tony B & 24 & 13.9 & 11.1 & 0.85 & 0.87 & 0.564 & 0.020 \\
Birdflue & 24 & 13.1 & 10.6 & 0.80 & 0.85 & 0.374 & 0.057 \\
Boulder Ridge & 24 & 13.8 & 11.3 & 0.82 & 0.85 & 0.471 & 0.035 \\
Milan's & 24 & 12.8 & 10.8 & 0.87 & 0.87 & 0.336 & 0.005 \\
Colville Knoll & 24 & 13.8 & 11.1 & 0.84 & 0.86 & 0.582 & 0.027 \\
\hline
\end{tabular}




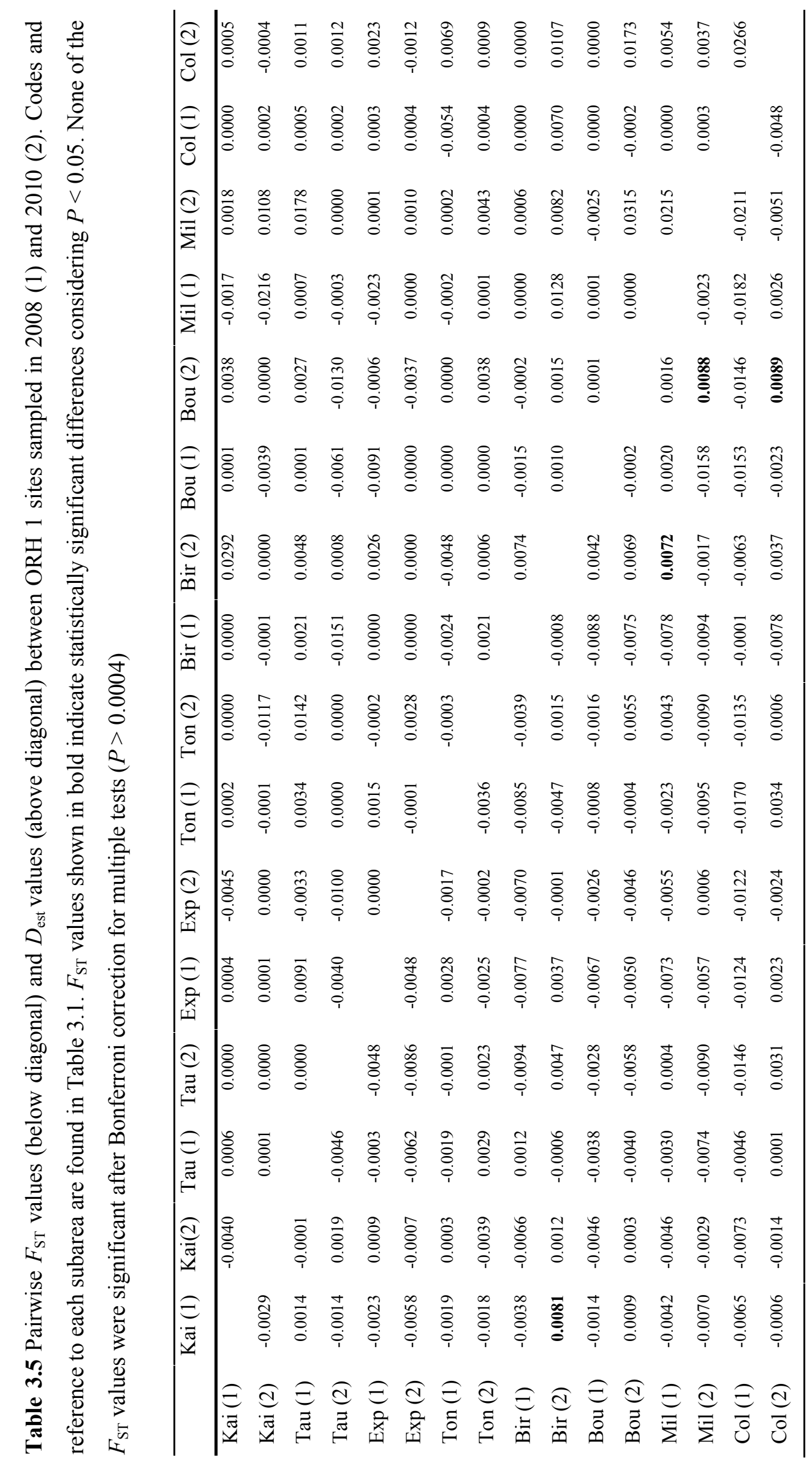




\subsection{Discussion}

\subsubsection{Microsatellite DNA diversity}

Levels of genetic variation were high and similar among all the sites, with a mean expected heterozygosity $\left(H_{\mathrm{E}}\right)$ of 0.86 ; similar, but slightly lower mean values were reported for orange roughy by White et al. $(2009 a)\left(H_{\mathrm{E}}=0.72\right)$ and Carlsson et al. (2011) $\left(H_{\mathrm{E}}=0.77\right)$. Considerably lower diversity was reported by Oke et al. (2002) (mean $H_{\mathrm{E}}=0.40$ ), which is probably related to the fact that of the six loci used by Oke et al. (2002) three have low heterozygosities and were not used in this study. High levels of genetic diversity for microsatellite DNA markers are typical of commercially exploited deep-sea teleosts, such as the redfish Sebastes mentella (Roques et al. 2002, $H_{\mathrm{E}}=0.87$ ), the roundnose grenadier Coryphaenoides rupestris (White et al. 2010, $H_{\mathrm{E}}=$ 0.77), and the blue hake Antimora rostrata (White et al. 2011, $H_{\mathrm{E}}=0.83$ ). A positive relationship between genetic diversity and abundance in fishes has been determined by McCusker and Bentzen (2010), especially for microsatellite DNA markers. However, the high levels of genetic diversity in orange roughy detected here and in other studies with microsatellite DNA markers (White et al. 2009a; Carlsson et al. 2011) and mtDNA markers (Chapter 2), does not rule out the possibility that commercial exploitation has impacted on the genetic composition and abundance of orange roughy populations. Fisheries for the species begun just $\sim 30$ years ago, and because of the long-life span of orange roughy (more than 100 years, Mace et al. 1990; Fenton et al. 1991) and late maturity ( 30 years, Fenton et al. 1991; Francis and Horn 1997) it is unlikely that reduction in levels of genetic diversity would be detected at this early stage with selectively neutral markers, as inferred previously for orange roughy (Baker et al. 1995; Carlsson et al. 2011).

\subsubsection{Global scale population structure}

Overall, I detected low but significant levels of differentiation at the global scale, within the Southern hemisphere, and between the Southern hemisphere sites and the Northeast Atlantic Ocean. Genetic homogeneity prevailed between orange roughy samples from around New Zealand and Australia, although there was some differentiation between 
few sites. The general lack of differentiation among sites around New Zealand and Australia was reported with allozymes, microsatellite DNA, and mitochondrial DNA sequence analyses (Elliott and Ward 1992; Oke et al. 2002; Chapter 2). However, using mtDNA RFLP's Smolenski et al. (1993) found evidence of genetic differentiation between Southeastern Australian and New Zealand samples. In another deep-sea fish, microsatellite DNA analyses showed no differentiation between New Zealand and Australian samples of the wreckfish Polyprion americanus (Ball et al. 2000). Significant differentiation between orange roughy sites in the Northeast Atlantic Ocean and the Southern hemisphere was also detected with mitochondrial DNA COI gene sequences (Chapter 2), and here the highest values of differentiation were between pooled sites in the Northeast Atlantic Ocean and Southern hemisphere regions $\left(F_{\mathrm{ST}}=\right.$ $0.010-0.023$ and $\left.D_{\text {est }}=0.049-0.103\right)$. It is possible that oceanographic characteristics at $41^{\circ} \mathrm{N}$ restrict the north-south dispersal of orange roughy (see Discussion section in Chapter 2). The present study revealed levels of genetic differentiation within the Southern hemisphere (Australia/New Zealand, Namibia, and Chile) that were undetected with the COI gene sequences (Chapter 2). Similarly, in the deep-sea wreckfish P. americanus a clear pattern of differentiation between sites in the Northern and Southern hemisphere was detected with microsatellite DNA markers (Ball et al. 2000), but little evidence of genetic divergence was found with mtDNA markers (Sedberry et al. 1996).

Low, but significant values of microsatellite DNA differentiation at the global scale (pooled sites, $F_{\mathrm{ST}}=0.006-0.023$ and $D_{\text {est }}=0.012-0.103$ ) indicate a lack of panmixia, as might be expected given the large geographic distances between the regions $(\sim 8,000$ to $\sim 20,000 \mathrm{~km}$ ). Genetic distance was correlated with geographic distance (Mantel test, $r$ $=0.62, P=0.001)$. These findings suggest a restriction to gene flow at the global scale and some fidelity to specific regions. However, it is probable that some degree of dispersal occurs, particularly, within the Southern hemisphere. Long distance dispersal is unlikely to occur during the early life-history stages because eggs and larvae are probably retained around seamounts (Rogers 1994), and the pelagic larval period is extremely short ( 10 days, Zeldis et al. 1998). The predominant lack of differentiation found between New Zealand and Australia, and the low levels of differentiation within the Southern hemisphere, most likely result from active stepping-stone dispersal of long-lived adults that are able to spawn many times during their life (Elliott et al. 1994; White et al. 2009a). 
3.5.3 Fine-scale population structure and implications for fisheries management in New Zealand

In New Zealand orange roughy fisheries have been divided into different areas (code ORH) for assessment and management. This is the first genetic study to include samples from sites around Northern New Zealand (ORH 1, 12 sites); and considering the other 4 sites sampled around New Zealand, this study included samples from most of the orange roughy fishing grounds inside the New Zealand Economic Exclusive Zone (see Table 3.1), except for the area ORH 7B (off the west coast of the South Island). In general, I found a lack of differentiation within New Zealand as revealed by STRUCTURE and PCA analyses. The spatial $F_{\mathrm{ST}}$ analysis showed that only $6.7 \%$ of the comparisons were significant $(P<0.05)$ among New Zealand sites. Similarly, in the spatial $D_{\text {est }}$ analysis only $10 \%$ of the comparisons showed values higher than 0.01 . Significant differentiation was found between the Chatham Rise and Puysegur sites $\left(F_{\mathrm{ST}}\right.$ $\left.=0.007, P=0.02, D_{\text {est }}=0.017\right)$, and most other examples of significant differentiation involved these two sites (see Table 3.2). Previous studies using mtDNA RFLPs's (Smith et al. 1996; 1997), and mitochondrial DNA sequences (Chapter 2) found significant divergence between Chatham Rise and Puysegur; while an allozyme study detected significant differentiation between samples from the east coast of New Zealand and samples of the Chatham Rise (Smith and Benson 1997). Together these combined studies indicate that there is a restriction to dispersal among these sites supporting the current management of the Chatham Rise and Puysegur as separate stocks within ORH 3B. In the spatial $F_{\mathrm{ST}}$ analysis only one comparison showed significant differentiation $(P<0.05)$ that did not include the Chatham Rise or Puysegur sites, this was the comparison between Milan's from ORH 1C and Nukuhou Knoll from ORH 1D.

The temporal analyses conducted for eight sites within ORH 1 showed a lack of significant differentiation between sites and years, suggesting temporal stability in genetic variation and panmixia for orange roughy at this fine-scale. Genetic homogeneity in orange roughy has been also found at a fine-scale in the Northeast Atlantic Ocean (White et al. 2009a). However, the present findings should be treated carefully because it may be the result of highly variable loci and sample sizes of less than 50 specimens per site. Temporal differentiation in orange roughy has been detected in previous studies. Smith and Benson (1997) found spatial and temporal differentiation at one allozyme locus among multiple samples from the Chatman Rise surveyed in 
winter and summer seasons in the same year. Some degree of temporal differentiation was also detected at one site off South Australia with mtDNA RFLP's, that corresponded with biological, reproductive and catch-rate data (Smolenski et al. 1993). The subtle temporal differentiation detected by Smith and Benson (1997) and Smolenski et al. (1993) may be related with the inference that mature females are able to spawn many times in their life time, but they do not spawn every year, and may not participate in annual migrations to spawning sites (Bell et al. 1992; Zeldis et al. 1997). A pattern of temporal variation in orange roughy cannot be ruled out by the present data and should be further explored in studies including larger sample sizes.

There is some uncertainty about the current levels of dispersal among sites and the general lack of genetic differentiation that I have detected among New Zealand sites and between New Zealand and Australian sites. These findings could be explained by high levels of gene flow by adults actively dispersing around New Zealand and across the Tasman Sea. However, they could also be explained by low levels of dispersal, since genetic connectivity can be maintained by the dispersal of only a few individuals, but populations are not considered demographically coupled until about $10 \%$ of the individuals are regularly exchanged (see Lowe and Allendorf 2010). Another possibility is that distinct populations have recently diverged, and it is too early to detect the lack of gene flow with microsatellite DNA markers, particularly considering that genetic drift has probably been very weak in orange roughy populations due to their historically large sizes, and because of the species' longevity and late maturation. Future research applying higher resolution markers such as single nucleotide polymorphisms (SNPs) and/or studies investigating genes under selection may help to disentangle the degree of population connectivity at a fine-scale (around New Zealand) and at a regional scale (between New Zealand and Australia). 


\subsection{Conclusion}

In the present study I found high levels of microsatellite DNA diversity in orange roughy populations, which likely reflect large historical population sizes. Low, but significant differentiation was detected at the global scale, with the highest values of differentiation between the Northeast Atlantic Ocean and the Southern hemisphere sites. No significant divergence was found in most comparisons between New Zealand and Australia. At a fine-scale within New Zealand, there was a lack of spatial divergence, but low levels of differentiation were detected between few sites off Northern New Zealand and two sites off the east and south coast of the South Island. Temporal analyses also revealed a predominant pattern of genetic homogeneity. Overall, the high levels of diversity and the low levels of genetic differentiation detected in this study simile findings for other deep-sea fishes. 


\section{Chapter 4}

\section{Genetic divergence and phylogenetic relationships of six species of the genus Hoplostethus based on Cytochrome $c$ Oxidase I (COI) sequences}

\subsection{Abstract}

The genetic divergence and the molecular phylogenetic relationships among Hoplostethus species have not been proposed yet. Using available COI sequences within the barcode region, I conducted a phylogenetic study including $H$. atlanticus, $H$. crassispinus, $H$. gigas, $H$. japonicus $H$. latus, and H. mediterraneus. Representatives of other three genera, Aulotrachichthys prosthemius, Gephyroberyx darwinni and Paratrachichthys macleayi were added to the analysis to place the phylogenetic position of the genus Hoplostethus within the family Trachichthyidae. The inter species divergence (7.37 - 13.57\%) was much higher than the intra species divergence (0.0 0.65\%). Kimura 2-Parameter (K2P) distance, Maximum Likelihood (ML) and Bayesian analyses showed that $H$. latus, $H$. crassispinus, $H$. japonicus, and $H$. mediterraneus form a separate clade from $H$. atlanticus and $H$. gigas. The position of $H$. gigas was not well defined with the nucleotide data. With K2P distance $H$. gigas was sister to $H$. atlanticus, but not with ML and Bayesian analyses. At the amino acid level, nonsynonymous substitutions clearly differentiated $H$. atlanticus from all the other species. This was correlated with morphological characteristics presented elsewhere. The genus Hoplostethus was monophyletic. According to ML and Bayesian analyses, the Hoplostethus clade was a derived group respect to the other three genera considered here. 


\subsection{Introduction}

The marine fishes within the family Trachichthyidae are represented by eight genera, Aulotrachichthys, Gephyroberyx, Hoplostethus, Optivus, Parinoberix, Paratrachichthys, Sorosichthys and Trachichthys (www.fishbase.org), with most of the species belonging to the genus Hoplostethus. Currently, there are 28 valid species of Hoplostethus (Moore and Dodd 2010), which are commonly called roughies or slimeheads. They mainly inhabit the continental slope and seamounts in tropical, subtropical, and temperate waters of the Atlantic, Indian, and Pacific oceans (Kotlyar 1996 in Kotlyar 2010; Table 4.1). Some of the main characteristics of the species in the genus Hoplostethus are a high body (1/3 - 1/2 standard body length), a large head with bony crests covered with fine spines, large eyes, large transverse mouth, fine seta-like teeth in the jaws and presence or absence of a keel on the abdomen, among others (Kotlyar 1986). The pigmentation of the body is either light (red, orange or brownish) or dark (black and grey) (Kotlyar 1986). Hoplostethus specimens are of relatively small size, the maximum length recorded among the species range from $7.5 \mathrm{~cm}$ (H. rifti) to 75 cm (H. atlanticus) (Table 4.1). All Hoplostethus are deep-sea species (i.e. maximum depth recorded $>300 \mathrm{~m}$, Table 4.1).

The amount of scientific research on each Hoplostethus species typically corresponds to their commercial value. As stated in the previous chapters, many studies have been conducted in the highly valuable species $H$. atlanticus (orange roughy) and a few others on $H$. mediterraneus (silver roughy) which has lower commercial value. Published studies are generally lacking for the other Hoplostethus species. Moreover, there are no studies on the genetic divergence among Hoplostethus species; and phylogenetic relationships within the genus Hoplostethus or the family Trachichthyidae have not been proposed yet (Moore and Dodd 2010). Kotlyar (1986) considered that Hoplostethus species were grouped in four subgenera and proposed a phylogenetic tree for the subgenera based in geographic distribution and a few morphological characters (Kotlyar 1986).

A suitable molecular marker to determine genetic divergence and phylogenetic relationship among species is the Cytochrome $c$ Oxidase I (COI) gene. In a specific region of the COI gene, the inter species variation is much greater than the intra species variation and is the marker most often used for species identification ("DNA barcoding") in fish (e.g. Ward et al. 2005; Cawthorn et al. 2011; Lakra et al. 2011; 
Zhang 2011; Zhang and Hanner 2011) and in many other animal groups (see Bucklin et al. 2011).

The first goal of the present study was to determine intra and inter species genetic divergence and to propose phylogenetic relationships for some of the Hoplostethus species using available Cytochrome $c$ Oxidase I (COI) sequences. The species included in the analyses were H. atlanticus, H. crassispinus, H. gigas, H. japonicus H. latus, and $H$. mediterraneus. The second goal was to place the phylogenetic position of the genus Hoplostethus within the Trachichthyidae family using available COI sequences. Representatives from three other genera were included, Aulotrachichthys prosthemius, Gephyroberyx darwinni and Paratrachichthys macleayi. 


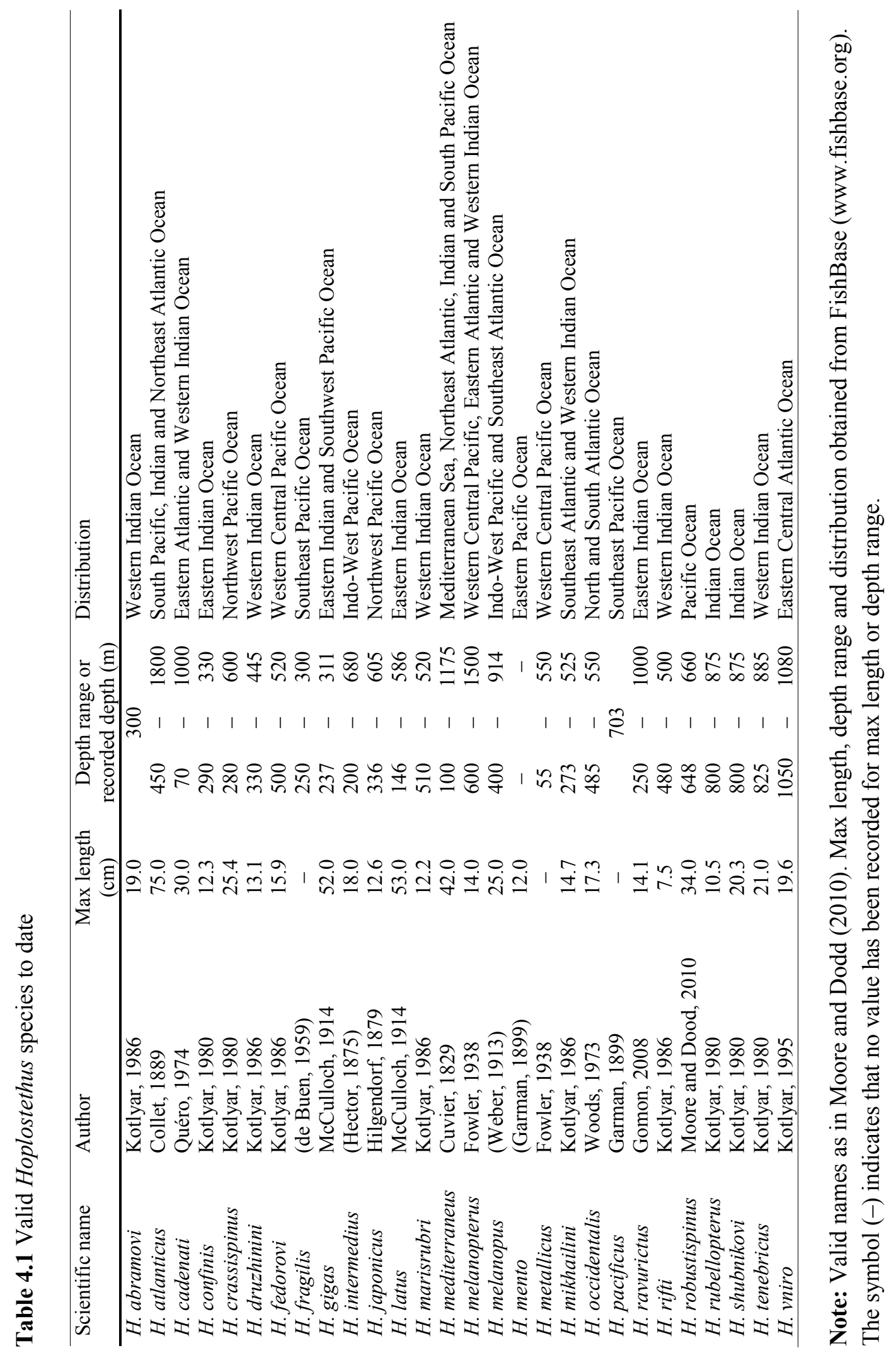




\subsection{Materials and methods}

\subsubsection{Data collection}

The 114 COI haplotypes produced by 546 orange roughy specimens (see Chapter 2) were included in the phylogenetic analyses.

Tissue samples of $H$. mediterraneus were obtained from a total of 45 specimens from New Zealand (21), Portugal (8), France (8) and Italy (8). Samples were from a frozen tissue collection held at NIWA. DNA extractions were performed using proteinase K digestion followed by salt extraction. The remaining pellet was washed twice with ethanol and resuspended in $100 \mu \mathrm{L}$ TE buffer. DNA samples were stored at $4^{\circ} \mathrm{C}$. COI sequences of $H$. mediterraneus were obtained following the same primers and protocol used for $H$. atlanticus (see subsection 2.3.2 PCR amplification, sequencing and alignment of Materials and methods, Chapter 2). The 45 samples produced 12 haplotypes (GenBank Accession Numbers: JX049153-JX049164).

Five COI sequences of $H$. crassispinus were available (supplied by PJ Smith) and resulted in two haplotypes. A GenBank search on March 2012 was conducted to obtain all the available COI sequences of Hoplostethus species. Sequences of other three Hoplostethus species were found on GenBank. The used haplotypes were two of $H$. gigas (DQ108107.1, DQ108106.1), two of H. latus (DQ108099.1, DQ108097.1) and one of $H$. japonicus obtained from the complete mitochondrial sequence (NC_003187.1). In total, 133 COI haplotypes of $H$. atlanticus, $H$. mediterraneus, $H$. crassispinus, H. gigas, $H$. latus and $H$. japonicus were aligned using the software Geneious 5.1.7 and the Geneious alignment option (Drummond et al. 2010). COI sequences of Aulotrachichthys prosthemius (DQ648438), Gephyroberyx darwinni (DQ108114) and Paratrachichthys macleayi (EF609430) were added to the alignment to place the phylogenetic position of the genus Hoplostethus within Trachichthyidae. The alignment was truncated at each extreme to generate equal length sequences. Geneious was also used to translate the nucleotide sequences into amino acid sequences using the vertebrate mitochondrial genetic code. The translation was performed to determine synonymous and non-synonymous changes and the percentages of variation at each codon position. The amino acid sites were numbered according to the bovine sequence (Bos taurus, AAQ06595.1). 


\subsubsection{DNA sequence analyses}

Pairwise distance among haplotypes was determined by the Kimura 2-Parameter (K2P) method (Kimura 1980) using the software MEGA 5.05 (Tamura et al. 2011).

A neighbour-joining ( $\mathrm{NJ}$ ) phylogram was constructed in MEGA using the K2P method to compute the evolutionary distances. The robustness of the topology was evaluated with 10,000 bootstrap replications. Phylograms were also constructed using Maximum Likelihood (ML) and Bayesian criterions in MEGA and MrBayes3.1.2 (Ronquist and Huelsenbeck 2003), respectively. The software jModelTest (Posada 2008) was used to obtain the model of molecular substitution that best fit the data. The selected model under the Akaike information criterion (AIC) was TVM+G. The Hasegawa-Kishino-Yano model with a proportion of invariable sites and a gamma distribution $(\mathrm{HKY}+\mathrm{I}+\mathrm{G})$ was used in the $\mathrm{ML}$ and Bayesian analyses since it was ranked $3^{\text {rd }}$ among the 88 models compared with the AIC criterion and was available in MEGA and MrBayes. For ML analyses, support for the nodes was obtained from 1,000 bootstrap replications. Bayesians analyses were performed using 1,000,000 iterations and sampling every 10 generations ensuring that the average standard deviation of split frequencies was $<0.01$. The first $25 \%$ of the saved trees were discarded as burn-in.

\subsection{Results}

\subsubsection{Genetic divergence}

The proportion of A, C, G, and T bases over all 133 Hoplostethus COI sequences was $23.5 \%, 30.0 \%, 17.8 \%$ and $28.7 \%$, respectively. The GC content of the sequences was $47.8 \%$. The total length of the nucleotide sequences was 609 bp (within the barcode region of $\sim 655 \mathrm{bp}$ ) and this region codes for 203 amino acids. Considering the bovine sequence as reference, the Hoplostethus amino acid sequences obtained started at site 32 and ended at site 234 .

The total length of the nucleotide sequences contained 151 variable sites. From the total of variable sites, $93.38 \%$ were synonymous changes at the third codon positions and $6.62 \%$ of the changes occurred at the first codon positions. No changes were 
observed in the second codon positions. From the total of 10 changes at the first codon positions, three were non-synonymous. At one of those nucleotide sites, $H$. atlanticus had guanine giving the codon GTT and the amino acid Valine at the amino acid site 83. All the other species had adenine giving the codon ATT and the amino acid Isoleucine at site 83. In the two other first codon positions that were variable, $H$. atlanticus presented timine resulting in the codon TCC and in the amino acid Serine at sites 114 and 187. All the other species instead had guanine which resulted in the codon GCC and the amino acid Alanine in sites 114 and 187.

The K2P distance within species ranged from zero to $0.65 \%$ and among species ranged from $7.37 \%$ (between $H$. japonicus and $H$. crassispinus) to $13.57 \%$ between $(H$. crassispinus and H. gigas) (Table 4.2).

Table 4.2 K2P (\%) distances within species (diagonal) and among species (below diagonal)

\begin{tabular}{lcccccc}
\hline & H. gig. & H. atla. & H. lat. & H. cras. & H. jap. & H. med. \\
\hline H. gigas & 0.00 & & & & & \\
H. atlanticus & 7.74 & 0.65 & & & & \\
H. latus & 9.29 & 12.89 & 0.33 & & & \\
H. crassispinus & 13.57 & 14.48 & 7.94 & 0.30 & & \\
H. japonicas & 11.20 & 10.10 & 7.73 & 7.37 & -- & \\
H. mediterraneus & 10.26 & 12.55 & 9.77 & 10.45 & 9.19 & 0.40 \\
\hline
\end{tabular}

\subsubsection{Phylogenetic relationships}

The phylogenetic analyses performed using K2P distance, ML and Bayesian criterions resulted in similar topologies (Fig. 4.1 and 4.2). The NJ phylogram obtained with K2P distance showed that $H$. atlanticus and $H$. gigas form a separate clade, which was well supported by bootstrap analysis (81\%). A good supported clade (92\%) was composed by the other four Hoplostethus species. Within this clade, H. latus and H. crassispinus 
grouped together with $H$. japonicus closer to $H$. latus/H. crassispinus than to $H$. mediterraneus. The representative species of other three genera, A. prosthemius, $G$. darwinni and P. macleayi, grouped together and where clearly separated from Hoplostethus species, with A. prosthemius sister to G. darwinni (Fig. 4.1).

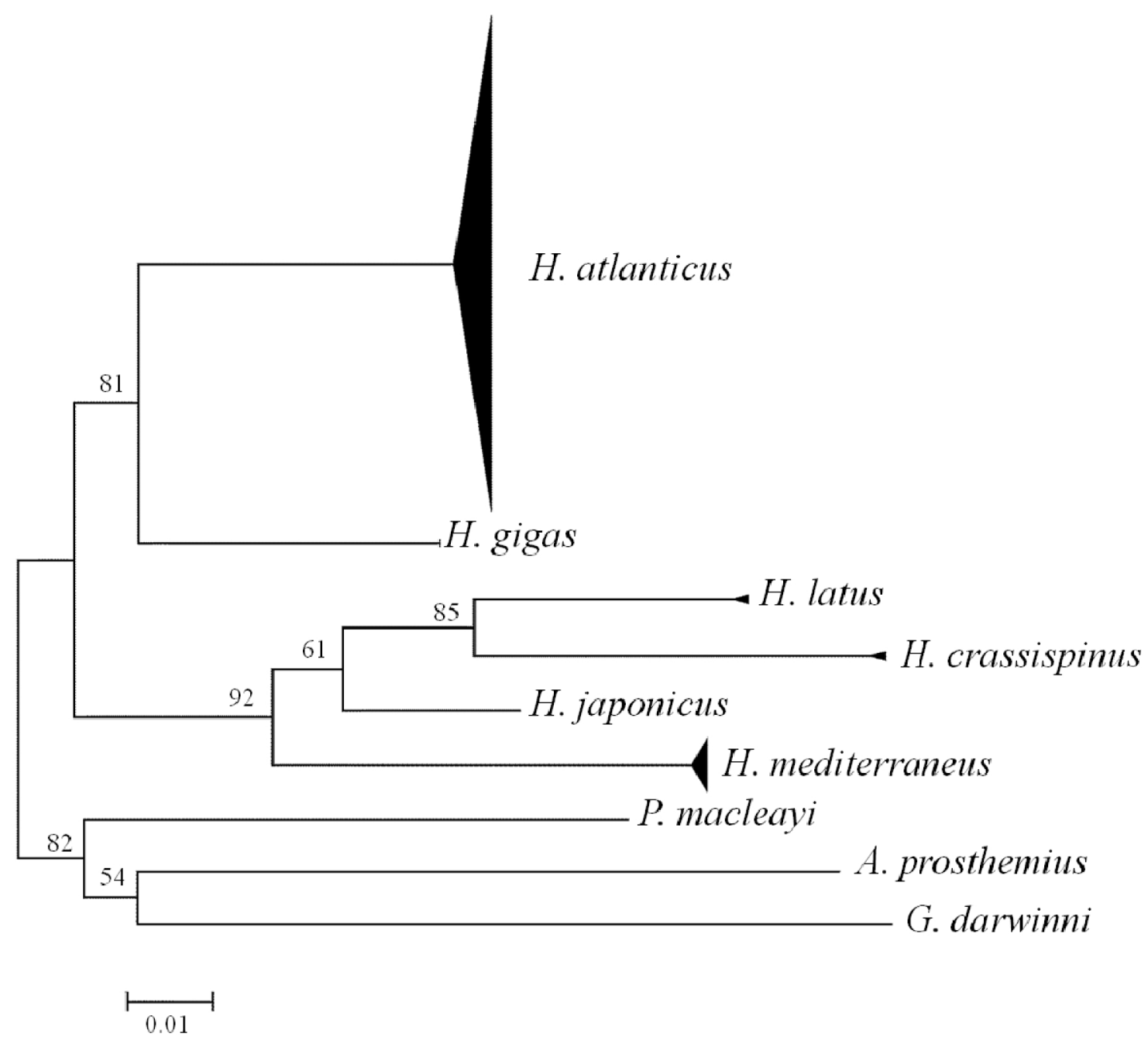

Fig. 4.1 Kimura 2-Parameter distance neighbour-joining phylogram of COI sequences from six Hoplostethus species and representatives from other three genera, Paratrachichthys macleayi, Aulotrachichthys prosthemius, Gephyroberyx darwinni. Numbers at nodes indicate bootstrap values $(\%)$ 
The phylograms obtained with ML and Bayesian criterions resulted in a similar topology (only the ML tree is shown with Bayesian posterior probabilities [PP] included in the corresponding nodes). The only difference between ML and Bayesian phylograms was that $A$. prosthemius and $P$. macleayi were grouped as sister taxa in the ML tree (Fig. 4.2); however, the phylogenetic relationship between these species was not resolved with the Bayesian analysis (Bayesian tree not shown).

There were few differences between ML/Bayesian phylograms (Fig. 4.2), compared to the K2P phylogram (Fig. 4.1). First, in the ML/Bayesian trees G. darwinni appeared in a basal position separated from all the other species; in the K2P tree instead, $G$. darwinni was a sister taxa to A. prosthemius. The second difference is related with the relationship between Hoplostethus species. In the K2P tree H. atlanticus and H. gigas were sister taxa (bootstrap $=81 \%$ ), but in the ML/Bayesian trees, $H$. atlanticus and $H$. gigas were not grouped together, which had a medium-low support value (bootstrap = $38 \%$, PP $=0.78)$. In the ML/Bayesian trees $H$. gigas appeared closer to the other Hoplostethus species, however, this relationship had a low support value (bootstrap = $22 \%, \mathrm{PP}=0.52$ ). The phylogenetic relationships among $H$. latus, $H$. crassispinus, $H$. japonicus, and $H$. mediterraneus were the same in K2P, ML and Bayesian analyses (Fig. 4.1 and 4.2). 


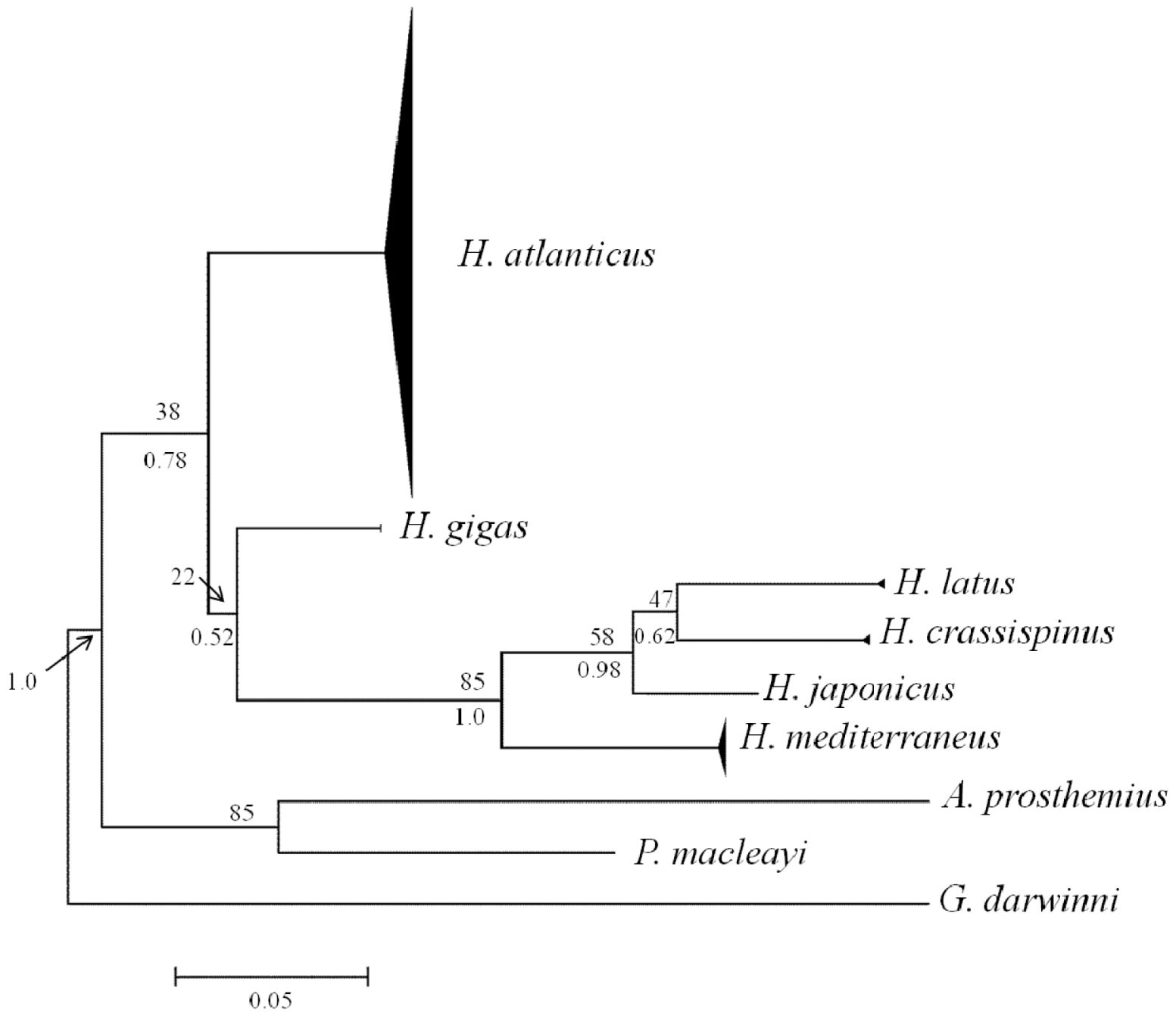

Fig. 4.2 Maximum Likelihood phylogram of COI sequences from six Hoplostethus species and representatives from other three genera, Paratrachichthys macleayi, Aulotrachichthys prosthemius, Gephyroberyx darwinni. Numbers above and below the branches indicate bootstrap values (\%) and Bayesian posterior probabilities (PP), respectively 


\subsection{Discussion}

\subsubsection{Genetic divergence}

Most of the variation across the COI sequences occurred in third codon positions, which is consistent with the expectation of a degenerated genetic code. Few variable sites occurred at first codon positions and none at second codon positions. This pattern was also reported by Ward and Holmes (2007) for many species of marine fishes. Considering the three non-synonymous changes at first codon positions, it is notable that only $H$. atlanticus presented different amino acids respect to the other five Hoplostethus species. The amino acidic site 83 was reported as a high variable site by Ward and Holmes (2007). In that study, it was also determined that site 83 have valine or isoleucine, both aliphatic amino acids. In the present study, the two other nonsynonymous sites produced the amino acids Serine or Alanine at sites 114 and 187, which are hydroxyl and aliphatic amino acids, respectively. As pointed out by Ward and Holmes (2007), amino acid substitutions are most common among physicochemical similar amino acids than among dissimilar amino acids. As only H. atlanticus had amino acids of different physicochemical characteristics at sites 114 and 187 compared to the other species, there may be a particular adaptation in the expression of the COI gene in $H$. atlanticus. This could be related to a unique characteristic in $H$. atlanticus in respect to the other Hoplostethus species considered here, for example, H. atlanticus is the only one able to occur deeper than 1,200 m.

The analysis of the genetic distance as measured by the K2P method among the COI haplotypes of Hoplostethus species showed that the intra-species divergence was much lower than the inter-species divergence (intra-species divergence was not possible to estimate for $H$. japonicus as there was only one haplotype available). The marked difference between intra and inter-species divergence is widely recognized for a specific region of COI gene making this of one the main characteristics for the generalized use of the COI gene as the molecular marker for DNA barcoding (Hebert et al. 2003). Although only two haplotypes per species were available to estimate intra-specific divergence in $H$. gigas, $H$. latus and $H$. crassispinus, the marked difference between intra-species divergence respect to inter-species divergence was also found in $H$. mediterraneus (12 haplotypes) and H. atlanticus (114 haplotypes). The intra-species divergence in $H$. mediterraneus was $0.40 \%$ and the divergence respect to the other 
species ranged from 9.19 to $12.55 \%$. Similarly, the intra-species divergence in $H$. atlanticus was $0.65 \%$, diverging from the other species in 7.74 to $14.48 \%$. The average intra (five species) and inter (six species) divergence among Hoplostethus species were $0.34 \%$ and $10.30 \%$, respectively. These values are within the ranges reported for marine fishes: $0.10-0.39 \%$ and $4.58-17.6 \%$ for the intra and inter-species divergence, respectively (Ward et al. 2005; Cawthorn et al. 2011; Lakra et al. 2011; Zhang 2011; Zhang and Hanner 2011).

\subsubsection{Phylogenetic relationships}

All the phylogenetic analyses based on K2P distance, Maximum Likelihood and Bayesian criterions showed that $H$. latus, $H$. crassispinus, $H$. japonicus, and $H$. mediterraneus form a separate clade from $H$. atlanticus and $H$. gigas. Within the former, $H$. latus and $H$. crassispinus were sister taxa and $H$. japonicus was close to $H$. latus and $H$. crassispinus with $H$. mediterraneus being the most divergent species in the clade. The position of $H$. gigas was not well defined with the nucleotide data. With the $\mathrm{K} 2 \mathrm{P}$ distance criterion this species was sister to $H$. atlanticus with a good support value. Instead Maximum Likelihood and Bayesian analyses showed that $H$. gigas was a separate taxa from $H$. atlanticus. On the other hand, and as stated before, at the amino acid level, non-synonymous substitutions at three sites in first codon positions clearly differentiated $H$. atlanticus from all the other species with $H$. gigas presenting the same amino acids at those positions than $H$. latus, $H$. crassispinus $H$. japonicus and $H$. mediterraneus. The differentiation of $H$. atlanticus from all the other five species at the amino acid level and the clear differentiation $H$. atlanticus from $H$. latus, $H$. crassispinus, $H$. japonicus, and $H$. mediterraneus at the nucleotide level could be correlated with morphological characteristics. Kotlyar (1986) considered that $H$. atlanticus was part of the subgenus Macrohoplostethus and that $H$. gigas, $H$. crassispinus $H$. japonicus, and $H$. mediterraneus were part of the subgenus Hoplostethus (H. latus was not recognized in that study). According to Kotlyar (1986) these two subgenera were morphological differentiated by the size and thickness of the scales in the ventral keel, the number of soft rays in the dorsal fin, the number of vertebrae, the morphology of the pyloric caeca, and the number of terminal appendages. 
Therefore, I found a correlation between the results of the phylogenetic analyses presented here for six Hoplostethus species and general morphologic characteristics presented elsewhere.

The analyses conducted here support the monophyly of the genus Hoplostethus. Also, Maximum Likelihood and Bayesian analyses showed that the Hoplostethus clade seems to be a derived group respect to the phylogenetic positions of other three genera, Aulotrachichthys, Gephyroberyx and Paratrachichthys.

\subsection{Conclusions}

A specific region of the COI gene is widely used to differentiate species (reviewed by Bucklin et al. 2011) even congeneric species (Hebert et al. 2003). In this study I found that this COI region is highly effective in differentiate species of the genus Hoplostethus given the marked difference between intra and inter-species divergence. The COI marker was also useful to determine the phylogenetic relationships of the species under study. Overall, taking into account the different methods employed, the phylogenetic relationship among $H$. atlanticus, $H$. latus, $H$. crassispinus $H$. japonicus, and $H$. mediterraneus was well defined. However, the phylogenetic position of $H$. gigas respect to the others species was uncertain. Future studies using nuclear molecular markers may help to determine the phylogenetic position of $H$. gigas.

This is the first study conducted to determine the genetic divergence and the molecular phylogenetic relationship among species of the genus Hoplostethus. Nevertheless, the un-availability of samples of other congeners resulted in the inclusion of only six out of 28 valid Hoplostethus species. A further study using the barcode region of the COI gene in combination with nuclear markers and including all the species within the genus is needed to resolve the evolutionary relationship among these deep-sea congeners. 


\section{Chapter 5}

\section{Critical amino acid replacements in the rhodopsin gene of the deep-sea teleost orange roughy (Hoplostethus atlanticus): comparison with other teleost species occupying different light environments}

\subsection{Abstract}

Critical amino acid replacements in opsin proteins shift the maximal absorbance of visual pigments to perceive different photic environments (spectral tuning). Here I studied the molecular basis for spectral tuning of the rhodopsin (RH1) pigment in the deep-sea fish orange roughy, which is important to understand how deep-sea species have adapted to the dim-light available in the bathypelagic environment. To compare and identify critical amino acid changes I also obtained partial rhodopsin sequences of 18 species of marine teleost habiting different light environments. I identified replacements at four critical amino acid sites that have been numbered according to the bovine RH1 pigment: 194, 195, 292 and 299. All the species had the substitutions P194R and H195A. The combination 292S/299A was only found in the deep-sea congeners silver roughy and orange roughy. This likely reflects an adaptation of these species to the bathypelagic light environment. All the epipelagic species studied and the epi-mesopelgic species blue cod, had the combination 292A/299S, except the red gurnard (292A/299A) and the spotty (292S/299S). It is possible that the combination $292 \mathrm{~A} / 299 \mathrm{~S}$ is an adaptation to longer wavelengths of light in comparison with the deeper species. This is the first study in determine partial rhodopsin in all the species under study, except by the hoki and silver roughy. Further studies are needed to determine all the critical amino acid replacements in the rhodopsin gene of these species and to measure the maximal absorbance $\left(\lambda_{\max }\right)$ of the corresponding RH1 pigments. 


\subsection{Introduction}

Many animal groups have evolved visual pigments that are often specialized and enable them to perceive their surrounding environment. A diverse range of visual pigments have arisen, which indicate the adaptive significance that light sensitive molecules have for organisms living in different photic environments (see Yokoyama 2008). Visual pigments consist of an opsin protein attached to a chromophore via a Schiff base linkage and a conserved lysine residue. The opsin protein in vertebrates is composed of a single polypeptide chain of 340 - 370 amino acids that forms seven $\alpha$-helical transmembrane (TM) regions connected by cytoplasmic and luminal loops (Dratz and Hargrave 1983). Each pigment shows a characteristic peak of maximal absorbance $\left(\lambda_{\max }\right)$; the location of this peak depends on the chromophore (11-cis-retinal or 11-cis3,4-dehydroretinal) and the interactions between the chromophore and the specific amino acid sequence of the opsin protein (Bowmaker 1995). In most vertebrates, rod photoreceptors are highly sensitive to dim-light and cone photoreceptors mediate vision at higher light intensities (reviewed by Yokoyama 2008).

In terrestrial environments and in the surface of the Oceans the sun radiation is dominated by photons of the visual spectrum from ultraviolet with wavelengths of $~$ $300 \mathrm{~nm}$, to infrared with wavelengths of 1,100 $\mathrm{nm}$ (Levine and MacNichol 1982; Bowmaker 1995). In the Oceans, the intensity and spectral composition of the light decreases with depth due to absorption by water molecules and suspended particles; the light becomes monochromatic towards blue $(\sim 470 \mathrm{~nm})$, while ultraviolet and infrared light are reduced (Bowmaker 1995; Warrant and Locket 2004). The epipelagic zone up to $\sim 150-200 \mathrm{~m}$ receives bright sunlight, further down to about $1,000 \mathrm{~m}$ the mesopelagic zone is characterized by dim-light bioluminescence (Douglas et al. 1998). After $1,000 \mathrm{~m}$, in the dark bathypelagic zone, the light comes from point-source bioluminescent flashes (Warrant and Locket 2004). Over $80 \%$ of the marine species living deeper than $200 \mathrm{~m}$ produce bioluminescence for diverse functions such as intra and inter-specific communication, camouflage, startling predators and attracting prey (Douglas et al. 1998). Organisms usually produce blue/green bioluminescence; however, some produce far-red illumination (Douglas et al. 1998; Turner et al. 2009). Deep-sea fishes (i.e. $>200 \mathrm{~m}$ ) have visual systems adapted to perceive the limited spectrum of light; one typical feature is the loss of cone photoreceptors resulting in rodonly retina (see Hunt et al. 2001). 
The opsin genes were first isolated and characterized in bovines and later in humans (Nathans and Hogness 1983, 1984). Since then, many opsin genes from a variety of vertebrate species have been studied including the measure of the $\lambda_{\max } \mathrm{s}$ of the corresponding visual pigments (see Yokoyama 2008). Modifications of the $\lambda_{\max }$ s values have allowed organism to adapt to diverse light environments. These pigments are divided into five groups: rhodopsins $\left(\mathrm{RH} 1, \lambda_{\max }=\sim 500 \mathrm{~nm}\right)$, RH1-like $\left(\mathrm{RH} 2, \lambda_{\max }=\right.$ $470-510 \mathrm{~nm}$ ), short wavelength-sensitive type 1 (SWS1, $\lambda_{\max }=360-420 \mathrm{~nm}$ ), SWS type 2 (SWS2, $\lambda_{\max }=440-455 \mathrm{~nm}$ ), and middle and long wavelength-sensitive $\left(\mathrm{M} / \mathrm{LWS}, \lambda_{\max }=510-570 \mathrm{~nm}\right.$ ) (Yokoyama 1999 and references therein). RH1 pigments are usually expressed in rods and the four other classes of pigments in cones (Yokoyama et al. 1999). Certain amino acid changes in the opsin protein shift the $\lambda_{\max }$ values of the visual pigments making possible a phenomenon known as "spectral tuning" in which a chromophore attains different absorption spectra when attached to different opsins (Yokoyama 2008). The critical amino acid sites (tuning sites) that shift $\lambda_{\max }$ values have been identified according to the site numbers of the bovine RH1 pigments and specific replacements in many marine fishes shift the $\lambda_{\max }$ values of the RH1 pigments towards the blue (e.g. Yokoyama 1999; Yokoyama et al. 1999; Hunt et al. 2001; Yokoyama and Takenaka 2004; Yokoyama 2008). Hunt et al. (2001) studied the rhodopsin gene sequence of 28 deep-sea fish species; most of the $\lambda_{\max }$ values of the rod pigments of those species vary from 490 to $477 \mathrm{~nm}$.

The molecular basis for spectral tuning of rod pigments has never been studied in the teleost orange roughy, Hoplostethus atlanticus. This deep-sea fish inhabit depths of 450 $-1,800 \mathrm{~m}$ between the mesopelagic and the bathypelagic zones. It is likely that orange roughy exhibits visual adaptations to dim-light and bioluminescence. Studying retinal morphology of mesopelagic and demersal teleost, Pankhurst (1987) found that orange roughy have retinal adaptations that maximise visual sensitivity. Hunt et al. (2001) identified tuning sites in the congener species H. mediterraneus that occurs at $100-$ $1,175 \mathrm{~m}$ and reported that the rod visual pigment of this species have a $\lambda_{\max }$ value of 479 $\mathrm{nm}$, likely an adaptation to the blue-light environment and blue luminescence.

The first goal of this study was to determine whether orange roughy have critical amino acid replacements that are known to cause a shift in the $\lambda_{\max }$ value of RH1 pigments. To achieve this, I sequenced a partial sequence of the rhodopsin gene of orange roughy. To compare and identify critical amino acid changes I also sequenced the rhodopsin sequence of 18 species of marine teleost habiting at different depths (1 - 
$1,175 \mathrm{~m})$ and, therefore, different light environments. The second goal was to conduct a phylogenetic analysis of partial sequences of the rhodopsin gene among all the species under study. I hypothesized that, 1) the species would have amino acid replacement that are known to be implicated in shift the $\lambda_{\max }$ of RH1 pigments towards the blue; 2) orange roughy would have particular set of amino acid replacements that is not found in the shallower species due to an adaptation to the bathypelagic light environment; and 3) the arrangement of the phylogenetic tree would correspond with the depths occupied by species.

\subsection{Materials and methods}

\subsubsection{Sampling and DNA extractions}

Tissue samples from a total of 127 specimens were obtained from 19 teleost species belonging to 16 families (Table 5.1). Sample size per species ranged from two to 19 and sampling areas included New Zealand, Australia, Namibia, Chile, the Mediterranean Sea and the Northeast Atlantic Ocean (Table 5.1). Muscle samples were collected from fresh fish and frozen at $-20^{\circ} \mathrm{C}$ or stored in $95 \%$ ethanol.

DNA extractions were performed using proteinase $\mathrm{K}$ digestion followed by salt extraction. The remaining pellet was washed twice with ethanol and resuspended in 100 $\mu \mathrm{L}$ TE buffer. DNA samples were stored at $4^{\circ} \mathrm{C}$. 
Table 5.1 Sample size (n) and sampling area of 19 teleots species used for partial amplification of the rhodopsin gene. The common names of each species are those used in New Zealand. Total $n=127$

\begin{tabular}{|c|c|c|c|}
\hline Common names & $\begin{array}{l}\text { Scientific name } \\
\text { (Family) }\end{array}$ & $n$ & Sampling area \\
\hline Butterfish & $\begin{array}{l}\text { Odax pullus } \\
\text { (Odacidae) }\end{array}$ & 5 & New Zealand \\
\hline Kahawai & $\begin{array}{l}\text { Arripis trutta } \\
\text { (Arripidae) }\end{array}$ & 2 & New Zealand \\
\hline $\begin{array}{l}\text { Yellowbelly } \\
\text { flounder }\end{array}$ & $\begin{array}{l}\text { Rhombosolea leporina } \\
\text { (Pleuronectidae) }\end{array}$ & 3 & New Zealand \\
\hline Sand flounder & $\begin{array}{l}\text { Rhombosolea plebeia } \\
\text { (Pleuronectidae) }\end{array}$ & 3 & New Zealand \\
\hline Sole & $\begin{array}{l}\text { Peltorhamphus latus } \\
\text { (Pleuronectidae) }\end{array}$ & 3 & New Zealand \\
\hline Blue moki & $\begin{array}{l}\text { Latridopsis ciliaris } \\
\text { (Latridae) }\end{array}$ & 5 & New Zealand \\
\hline Spotty & $\begin{array}{l}\text { Notolabrus celidotus } \\
\text { (Labridae) }\end{array}$ & 10 & New Zealand \\
\hline Red gurnard & $\begin{array}{l}\text { Chelidonichthys kumu } \\
\text { (Triglidae) }\end{array}$ & 4 & New Zealand \\
\hline Snapper & $\begin{array}{l}\text { Pagrus auratus } \\
\text { (Sparidae) }\end{array}$ & 10 & New Zealand \\
\hline Jack mackerel & $\begin{array}{l}\text { Trachurus murphyi } \\
\text { (Carangidae) }\end{array}$ & 10 & Chile \\
\hline Blue cod & $\begin{array}{l}\text { Parapercis colias } \\
\text { (Pinguipedidae) }\end{array}$ & 13 & New Zealand \\
\hline Tarakihi & $\begin{array}{l}\text { Nemadactylus macropterus } \\
\text { (Cheilodactylidae) }\end{array}$ & 4 & New Zealand \\
\hline Blue warehou & $\begin{array}{l}\text { Seriolella brama } \\
\text { (Centrolophidae) }\end{array}$ & 4 & New Zealand \\
\hline Hapuku & $\begin{array}{l}\text { Polyprion oxygeneios } \\
\text { (Polyprionidae) }\end{array}$ & 5 & New Zealand \\
\hline Hoki & $\begin{array}{l}\text { Macruronus novaezelandiae } \\
\text { (Merlucciidae) }\end{array}$ & 12 & New Zealand, Australia, Chile \\
\hline Giant stargazer & $\begin{array}{l}\text { Kathetostoma giganteum } \\
\text { (Uranoscopidae) }\end{array}$ & 5 & New Zealand \\
\hline Red cod & $\begin{array}{l}\text { Pseudophycis bachus } \\
\text { (Moridae) }\end{array}$ & 5 & New Zealand \\
\hline Silver roughy & $\begin{array}{l}\text { Hoplostethus mediterraneus } \\
\text { (Trachichthyidae) }\end{array}$ & 5 & $\begin{array}{l}\text { New Zealand, Mediterranean Sea, } \\
\text { Northeast Atlantic }\end{array}$ \\
\hline Orange roughy & $\begin{array}{l}\text { Hoplostethus atlanticus } \\
\text { (Trachichthyidae) }\end{array}$ & 19 & $\begin{array}{l}\text { New Zealand, Australia, Namibia, } \\
\text { Chile, Northeast Atlantic }\end{array}$ \\
\hline
\end{tabular}


5.3.2 PCR amplification, sequencing and alignment

Six primers pairs developed for teleost species (Chen et al. 2003) were tested for partial amplification of the rhodopsin gene. Un-specific DNA fragments were observed in gel electrophoresis for all primer pairs. Successful optimization was obtained for one primer pair. The primers used were: Rh545 -5'- GCAAGCCCATCAGCAACTTCCG3' and Rh1073r -5'- CCRCAGCACARCGTGGTGATCATG-3' (Chen et al. 2003).

Final PCR reactions of $10 \mu \mathrm{L}$ total volume consisted of $\sim 20 \mathrm{ng}$ of DNA, 1X PCR buffer (160mM (NH4)2SO4, 670mM Tris-HCl, 0.1\% stabilizer), $1.5 \mathrm{mM} \mathrm{MgCl}, 0.6$ $\mu \mathrm{M}$ of each primer, $0.2 \mathrm{mM}$ of each dNTPs, $1.5 \mathrm{U}$ of Taq polymerase and $0.4 \mathrm{mg} \mathrm{mL}^{-1}$ of Bovine Serum Albumin (BSA). PCR cycles were performed on a Eppendorf Mastercycler ep gradient $\mathrm{S}$, as follow: initial denaturing at $95^{\circ} \mathrm{C}$ for $2 \mathrm{~min}$, followed by 35 cycles of denaturing at $95^{\circ} \mathrm{C}$ for $30 \mathrm{~s}$, annealing at $58^{\circ} \mathrm{C}$ for $1 \mathrm{~min}$, extension at $72^{\circ} \mathrm{C}$ for $1 \mathrm{~min}$ and a final extension at $72^{\circ} \mathrm{C}$ for $5 \mathrm{~min}$. PCR products were purified with ExoSAP-IT following manufacturer's instructions. The nucleotide sequences were determined using an ABI3730 Genetic Analyzer. The software Geneious 5.1.7 (Biomatters Ltd.) was used to align the sequences using the Geneious alignment option (Drumond et al. 2010). Each species had a unique nucleotide sequence (except for within orange roughy), with few heterozygotes sites (see results). The nucleotide sequence of each species was translated into amino acid sequences in Geneious using the standard genetic code. The amino acid sequences of the 19 species were aligned to the bovine rhodopsin sequence (Bos taurus, GenBank accession number: NP_001014890) to determine potential sites for spectral tuning.

\subsubsection{Data analyses}

A phylogenetic analysis was performed to determine if the phylogeny of the partial sequences of the rhodopsin gene was related with the depth range of the species (Table 5.2). A Bayesian analysis was conducted with MrBayes 3.1 .2 (Ronquist and Huelsenbeck 2003) using the bovine sequence as the outgroup. The program was set to determine the best fixed-rate model for the amino acid sequences during the analysis. The analysis was performed using 5,000,000 iterations and sampling every 10 
generations. The standard deviation of split frequencies index fall to 0.004 . The $25 \%$ of the trees were discarded as burn-in.

Table 5.2 Depth range and geographic distribution of the 19 teleost species. The information was obtained from FishBase (www.fishbase.org) and the literature as indicated. Scientific names of the species can be found in Table 5.1

\begin{tabular}{|c|c|c|c|}
\hline Species & Depth range $(\mathrm{m})$ & Distribution & References \\
\hline Butterfish & $0-40$ & New Zealand & $\begin{array}{l}\text { Trip et al. (2011) } \\
\text { Ministry of Fisheries (2011) }\end{array}$ \\
\hline Kahawai & $30-40$ & $\begin{array}{l}\text { New Zealand and southern } \\
\text { Australia }\end{array}$ & $\begin{array}{l}\text { Duffy and Patherick (1999) } \\
\text { Francis et al. (2002) }\end{array}$ \\
\hline $\begin{array}{l}\text { Yellowbelly } \\
\text { flounder }\end{array}$ & $1-50$ & New Zealand & $\begin{array}{l}\text { Ayling and Cox (1982) } \\
\text { Glova and Sagar (2000) }\end{array}$ \\
\hline Sand flounder & $22-100$ & New Zealand & $\begin{array}{l}\text { Ayling and Cox (1982) } \\
\text { Glova and Sagar (2000) }\end{array}$ \\
\hline Sole & $1-100$ & New Zealand & Ayling and Cox (1982) \\
\hline Blue moki & $10-120$ & $\begin{array}{l}\text { New Zealand and southern } \\
\text { Australia }\end{array}$ & Smith et al. (2001) \\
\hline Spotty & $10-145$ & New Zealand & Anderson and Millar (2004) \\
\hline Red gurnard & $1-200$ & New Zealand and Australia & Francis et al. (2002) \\
\hline Snapper & $3-200$ & New Zealand, Australia, Japan & $\begin{array}{l}\text { Francis et al. (2002) } \\
\text { Stewart (2008) }\end{array}$ \\
\hline Jack mackerel & $20-300$ & $\begin{array}{l}\text { Ecuador, Peru, Chile and New } \\
\text { Zealand }\end{array}$ & $\begin{array}{l}\text { Francis et al. (2002) } \\
\text { Bertrand et al. (2004) }\end{array}$ \\
\hline Blue cod & $5-360$ & New Zealand & $\begin{array}{l}\text { Francis et al. (2002) } \\
\text { Carbines (2003) }\end{array}$ \\
\hline Tarakihi & $40-400$ & $\begin{array}{l}\text { New Zealand, southern } \\
\text { Australia and south America }\end{array}$ & $\begin{array}{l}\text { Jordan (2001) } \\
\text { Threscher et al. (2007) }\end{array}$ \\
\hline Blue warehou & $100-600$ & New Zealand and Australia & $\begin{array}{l}\text { Francis et al. (2002) } \\
\text { Robinson et al. (2008) }\end{array}$ \\
\hline Hapuku & $50-850$ & $\begin{array}{l}\text { Southern Oceans, New Zealand } \\
\text { and Australia, off Chile }\end{array}$ & $\begin{array}{l}\text { Francis et al. (2002) } \\
\text { Wakefield et al. (2010) }\end{array}$ \\
\hline Hoki & $10-900$ & $\begin{array}{l}\text { New Zealand, Australia and } \\
\text { Chile }\end{array}$ & $\begin{array}{l}\text { Connell et al. (2010) } \\
\text { Olavarria et al. (2006) }\end{array}$ \\
\hline Giant stargazer & $12-1000$ & New Zealand & Smith et al. (2006) \\
\hline Red cod & $26-1000$ & New Zealand and Australia & $\begin{array}{l}\text { Beentjes and Renwick } \\
(2001)\end{array}$ \\
\hline Silver roughy & $100-1175$ & $\begin{array}{l}\text { Northeast Atlantic, } \\
\text { Mediterranean Sea, Indian and } \\
\text { South Pacific Oceans }\end{array}$ & $\begin{array}{l}\text { Francis et al. (2002) } \\
\text { Madurell and Carter (2005) }\end{array}$ \\
\hline Orange roughy & $450-1800$ & $\begin{array}{l}\text { South Pacific, Indian and } \\
\text { Northeast Atlantic Ocean }\end{array}$ & Branch (2001) \\
\hline
\end{tabular}




\subsection{Results}

A 477-bp nucleotide fragment was obtained for all 127 individuals analyzed (Table 5.1). Sequences were deposited in GenBank under Accession Numbers: JX049165JX049193. There were 177 variable sites among all the samples, but intra-specific variation was low. Aside of few heterozygote positions in seven species (Table 5.3), there was not nucleotide variation within each species, except by the orange roughy at site 190. From the total number of orange roughy samples, at site 190 two individuals had cytosine, 11 had thymine (homozygotes) and six were heterozygotes (see Table 5.3). The translation of the nucleotide sequences into amino acids resulted in a unique amino acid sequence for each species, with a total length of 158 amino acids. An alignment with the bovine amino acidic sequence as a reference to identified potential sites for spectral tuning, showed that the amino acid sequences obtained started at site 161 and ended at site 318 , from the $\alpha$-helix IV to the luminal loop after $\alpha$-helix VII. In the total length of the amino acid sequences, 60 sites were variable (Table 5.4). Among these variable sites, four are known to be involved in shift the $\lambda_{\max }$ value of RH1 pigments. The potential sites for spectral tuning were P194R, H195A, A292S and A299S (the letters represent the code of the amino acid in the bovine/teleost species sequences and the number indicates the site according to the site number of the bovine RH1 pigment). The critical amino acid changes P194R and H195A were determined for all the teleost species. The change A292S occurred only in spotty, silver roughy and orange roughy. The replacement A299S was identified in nine species: butterfish, kahawai, yellowbelly flounder, sand flounder, sole, blue moki, spotty, snapper and blue cod (Table 5.4).

Table 5.3 Heterozygote positions in the 477-bp nucleotide fragment identified in 14 individuals of seven species. The number of individuals with heterozygote position per species is indicated by $(n)$. Scientific names of the species can be found in Table 5.1

\begin{tabular}{lcc}
\hline Species $(n)$ & Positions & Bases \\
\hline Yellowbelly flounder (1) & 166 & $\mathrm{~A} / \mathrm{G}$ \\
Sand flounder (2) & $130-307$ & $\mathrm{C} / \mathrm{T}-\mathrm{G} / \mathrm{T}$ \\
Jack mackerel (1) & 37 & $\mathrm{C} / \mathrm{T}$ \\
Blue cod (2) & $97-208$ & $\mathrm{C} / \mathrm{T}-\mathrm{C} / \mathrm{T}$ \\
Hoki (1) & 121 & $\mathrm{C} / \mathrm{T}$ \\
Red cod (1) & 205 & $\mathrm{C} / \mathrm{T}$ \\
Orange roughy (6) & 190 & $\mathrm{C} / \mathrm{T}$ \\
\hline
\end{tabular}




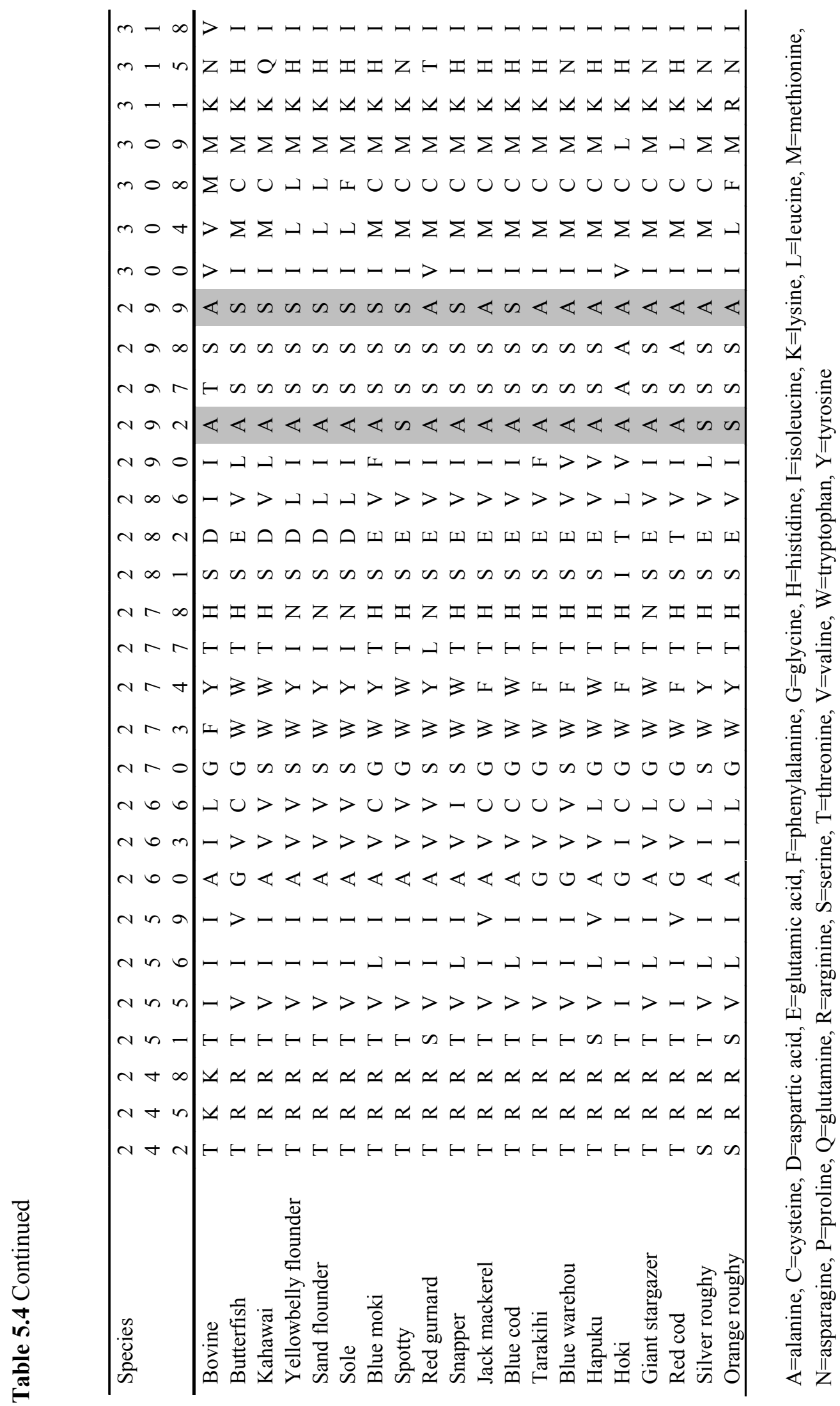


The Bayesian phylogeny of the rhodopsin sequences of 19 teleost species using the bovine sequence as outgroup resulted in four clades, here after referred as Clade A - D (Fig. 5.1). There was a weak relationship between clades composition and the maximum depths reported for the species (see Table 5.2 for depth range of each species). The sequences of butterfish, hapuku and giant stargazer were not part of any clade and their divergence from the rest of the species was supported by high posterior probabilities $(\mathrm{PP})$ values $(\mathrm{PP}=0.87-0.99)$. Clades $\mathrm{B}, \mathrm{C}$ and $\mathrm{D}$ were well supported $(\mathrm{PP}=0.78-$ $1.0)$; clade $\mathrm{A}$ had a lower support $(\mathrm{PP}=0.65)$. Clade $\mathrm{A}$ was composed by epipelagic species that habitat at a maximum depth of $40-200 \mathrm{~m}$. Clade B was formed by species occupying epipelagic and mesopelagic environments, with a maximum depth of $300-$ 1,000 m. Clade C was formed by only two species, the epipelagic species blue moki (maximum depth $120 \mathrm{~m}$ ) and by Blue cod that is able to occupy epi and mesopelagic environments (maximum depth $360 \mathrm{~m}$ ). Finally, clade D was composed by the two species able to occur in bathypelagic environments, the silver roughy (maximum depth $1,175 \mathrm{~m}$ ) and the orange roughy (maximum depth 1,800 m). The species within clades B, C and D presented a unique combination at the critical sites 292 and 299. All the species in clade B had 292A/299A, the two species in clade C had 292A/299S, and the roughies, the only species in clade D, had the combination 292S/299A, which was not found in any other species. Instead, clade A was composed by species presenting the combinations 292A/299S, 292A/299A and 292S/299S (Fig. 5.1).

On the other hand, the grouping of the species according to the combination of the critical sites 292 and 299 shows a better relationship between the maximum depth of the species and the amino acids at these two sites (Table 5.5). However, the relationship is not clear for the species that have a maximum depth of 145-360 m (spotty, snapper, red gurnard, jack mackerel and blue cod). 


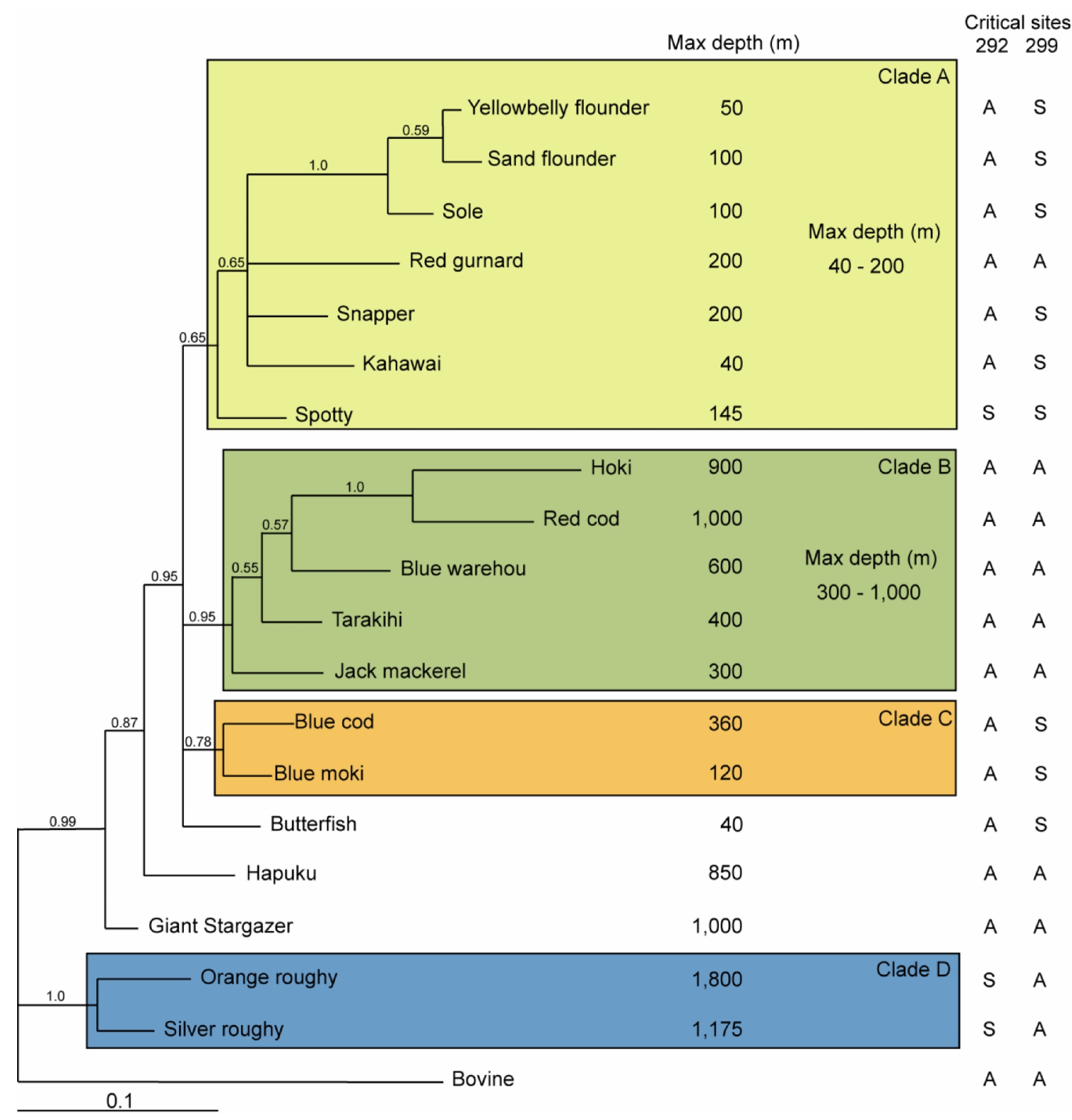

Fig. 5.1 Bayesian phylogram of 19 teleost species using amino acidic data and the bovine sequence as outgroup (accession number: NP_001014890). The numbers above branches correspond to posterior probabilities (PP). The maximum (Max) depth range of each species is found in Table 5.2. The amino acids at the critical sites 292 and 299 are indicated for each species in the right side of the phylogram. 
Table 5.5 Grouping of the 19 teleost species according to the combination at the critical sites 292 and 299. Scientific names of the species can be found in Table 5.1

\begin{tabular}{llc}
\hline Critical sites & Species & Max depth $(\mathrm{m})$ \\
\hline 292A/299S & Butterfish & 40 \\
& Kahawai & 40 \\
& Yellowbelly flounder & 50 \\
& Sand flounder & 100 \\
& Sole & 100 \\
& Blue moki & 120 \\
& Snapper & 200 \\
& Blue cod & 360 \\
292S/299S & Spotty & 145 \\
& Red Gurnard & 200 \\
& Jack mackerel & 300 \\
& Tarakihi & 400 \\
& Blue warehou & 600 \\
& Hapuku & 850 \\
& Hoki & 900 \\
& Giant stargazer & 1,000 \\
& Red cod & 1,000 \\
& Silver roughy & 1,175 \\
& Orange roughy & 1,800 \\
\hline
\end{tabular}




\subsection{Discussion}

As hypothesized, I detected amino acid replacement in the rhodopsin sequences of 19 marine teleost that are known to be involved in shift the $\lambda_{\max }$ of RH1 pigments towards the blue light. Hunt et al. (2001), Yokoyama and Takenaka (2004) and Yokoyama (2008) summarized critical amino acid changes in marine fishes. I also detected conserved and functionally important amino acids identified by previous studies (data not shown): K296, C187 and W265 (reviewed by Hope et al. 1997 and by Hunt et al. 2001).

Hunt et al. (2001) determined that a specific $\lambda_{\max }$ value is not always explained by a particular set of amino acid substitutions; rather, the same $\lambda_{\max }$ value results from different combinations of amino acid at specific sites. In the present study, all the species had the substitution P194R, H195A; however, the combination of the replacements P194R, H195A and A292S was only found in three species: spotty, silver roughy and orange rough (but the spotty differed from the roughies in the critical amino acid site 299, which is discussed further below). The combination P194R, H195A, A292S decrease the $\lambda_{\max }$ value of the RH1 pigment by $14-20 \mathrm{~nm}$ (Yokoyama 2008); and for a conger species this combination resulted in a $\lambda_{\max }$ value of $486 \mathrm{~nm}$ (Yokoyama 2008). The same decrease in the $\lambda_{\max }$ value could be achieved by the combination D83N/A292S and by a unique replacement at site 122 (E122Q) (Yokoyama 2008). Because the sequences that I obtained started at site 161, it could not been ruled out that the same functional change is presented by some of the other species studied. The replacement A292S was already detected in silver roughy by Hope et al. (1997). Others marine fishes living at depths of more than $200 \mathrm{~m}$ had the substitution A292S, such as the coelacanth, Latimeria chalumnae (Yokoyama et al. 1999). Also, Hunt et al. (2001) detected this replacement in 18 deep-sea teleost from six different orders: Beryciformes,

Ophidiiformes, Gadiformes, Aulopiformes, Stomiiformes and Osmeriformes. The same replacement has been also detected in shallower species. Yokoyama and Takenaka (2004) found the A292S change in three species of squirrelfishes habiting depths of less than $70 \mathrm{~m}$, and it was also detected in the bottlenose dolphin, Tursiops truncatus (Fasick and Robinson 1998). Mutation experiments in the bovine rod pigment performed by Fasick and Robinson (1998) indicated that the change A292S alone is capable of shift the $\lambda_{\max }$ value by $10 \mathrm{~nm}$ towards the blue. Another site involved in shortwave shifts is the site 299 (Fasick and Robinson 1998; Hunt et al. 2001). Hunt et al. (2001) noted that 
the combination $292 \mathrm{~S} / 299 \mathrm{~A}$ in the silver roughy was related to a $\lambda_{\max }$ value of $479 \mathrm{~nm}$, but a larger $\lambda_{\max }$ value of $485 \mathrm{~nm}$ was detected in Anoplogaster cornuta, which has the combination $292 \mathrm{~S} / 299 \mathrm{~S}$. In this study, I found that orange roughy has the same 292S/299A combination than silver roughy; instead, the spotty has 292S/299S. Considering the findings of Hunt et al. (2001), it is possible that the amino acids found at the critical sites 292 and 299 result in a shorter $\lambda_{\max }$ value of the RH1 pigments in the orange roughy in comparison with the spotty; supporting the hypothesis that orange roughy would present a set of amino acid changes that is not found in the shallower species, related to an adaptation to the bathypelagic light environment. Nonetheless, and as stated before, other un-detected critical amino acid sites may influence the $\lambda_{\max }$ value of the rhodopsin pigment in these species.

Interestingly, I found that all the epipelagic species and the epi-mesopelgic species blue cod, had the combination 292A/299S. The exceptions were the red gurnard (292A/299A), and, as stated, the spotty (292S/299S). The combination 292A/299S plus the site $83 \mathrm{D}$ was detected in the rhodopsin sequence of the sheep and the freshwater eel; with a $\lambda_{\max }$ value of $502 \mathrm{~nm}$ in the later species (see Table 2 in Fasick and Robinson 1998). Since the epipelagic species under study inhabit at minimum depth of $0-30 \mathrm{~m}$ (see Table 5.2), where green light (wavelength of $\sim 500 \mathrm{~nm}$ ) is available, it is likely that the combination $292 \mathrm{~A} / 299 \mathrm{~S}$ detected here in most of the epipelagic species is related with an adaptation to longer wavelengths of light in comparison with the deeper species.

I found a weak relationship between the phylogeny of the partial rhodopsin sequences and the maximum depth of the species, giving a low support for the third hypothesis. The composition of the clades was not completely explained by depth. The species blue moki and blue cod formed a separated clade even though they occupy the same depths that the species in clades A and B, respectively. Similarly, butterfish, hapuku, and giant stargazer did not grouped with other species according to their depth range. It is possible that a better defined phylogeny would be achieved by using the complete rhodopsin sequence of the species included in this study. On the other hand, it is likely that not all the amino acid sites in the sequences under study are correlated with an adaptation to light conditions. Some sites must be neutral to selection and inherited by ancestry. Therefore, phylogenetic relationships of rhodopsin sequences would reflect selectively neutral and non-neutral changes. On the other hand, the pooling of the species according to the combination at the critical sites 292 and 299 showed a better, but still not complete, relationship with the maximum depth of the species. 
To the best of my knowledge, this is the first study in determine partial rhodopsin sequences in all the species under study, except by the hoki (Prado et al., unpublished data, GenBank number: FR832604) and the silver roughy (Hope et al. 1997; Chen et al. 2003). Further studies about the molecular basis of rod pigments in these species should attempt to obtain a larger or complete rhodopsin sequence to identify if there are other replacements at critical sites that have been shown to be involved in spectral tuning in marine fishes (e.g. sites 83, 122, 124, 132). These kinds of studies will also allow to investigate if the combination at different critical sites can be completely related with depth distribution.

To better understand how these and potentially other critical amino acid replacements are involved in the visual adaptations of these species, it is also necessary to determine the $\lambda_{\max }$ value of their rod pigments.

\subsection{Conclusion}

In summary, I identified four critical amino acid changes in partial rhodopsin sequences of 19 teleost species that have been involved in the spectral tuning of rod pigments. Orange roughy presented the same amino acid combination in two sites already reported for silver roughy, which was not found in any of the other species. This likely reflects an adaptation to the dim-light available in the bathypelagic environment. I found that the phylogeny of the partial rhodopsin sequences of these species was weakly related to depth distribution. 


\section{Chapter 6}

\section{General Discussion}

\subsection{Genetic diversity in orange roughy}

The DNA sequence and microsatellite DNA analyses presented in Chapters 2 and 3, respectively, showed a high genetic diversity in orange roughy as indicated by the values of the haplotype diversity of the COI and Cyt $b$ sequences and by the expected heterozygosity of the microsatellite data. This pattern has been reported before for orange roughy using DNA sequences (Baker et al. 1995) and microsatellite loci (White et al. 2009a; Carlsson et al. 2011). High levels of genetic diversity for both types of molecular markers are common among marine fishes including deep-sea fishes (Stepien et al. 2000; Roques et al. 2002; von der Heyden et al. 2007; Nielsen et al. 2010; White et al. 2010; Friess and Sedberry 2011; White et al. 2011), and the most common explanation for this pattern has been related to large historical effective population sizes (McCusker and Bentzen 2010). As discussed in Chapter 3, these estimates probably do not reflect current population sizes and do not rule out the possibility the fisheries have reduced the population sizes of exploited marine fishes. This would be particularly difficult to detect with molecular markers in $K$-selected species, as orange roughy, because they have late maturity and long-life span and, therefore, only a few generations and overlapped generations may have elapsed since the beginning of commercial exploitation (Baker et al. 1995; Carlsson et al. 2011; Chapman et al. 2011).

\subsection{Population structure in orange roughy}

The levels of migration (gene flow) are often suggested to be higher in the marine realm than in terrestrial and freshwater habitats because of the lack of obvious barriers in the sea and the high potential for dispersal of marine species. Genetic panmixia has been found in marine species at a range of geographic scales. For example, in the gastropod Crepipatella fecunda (Guzmán et al. 2011), the crustacean Panulirus argus (Naro- 
Maciel et al. 2011), the mammal Cephalorhynchus heavisidii (van Vuuren et al. 2002), the fish Caffrogobius caffer (Neethling et al. 2008), and also in deep-sea fish species (e.g. Pseudopentaceros wheeleri, Martin et al. 1992; Beryx splendens, Hoarau and Borsa 2000; Antimora rostrata, White et al. 2011) among others. However, there are barriers for dispersal in the oceans such as oceanographic discontinuities, bathymetric features, and behavioural characteristics (e.g. homing), that effectively limit the levels of gene flow among populations; even for marine fishes with high potential for passive (larval transport) and/or active (swimming adults) dispersal (e.g. Serranus cabrilla, Schunter et al. 2011; Brosme brosme, Knutsen et al. 2009; Scomberomorus commerson, Fauvelot and Borsa 2011). The life-history of the species plays a key role in determining the levels of differentiation among populations; however, simple assumptions as a direct correlation between pelagic larval duration (PLD) and levels of connectivity have been largely challenged. For example, Riginos et al. (2011) reviewed the effects of geography and life history traits on genetic differentiation in benthic marine fishes and found that PLD does not often explain genetic population structure. They found that transitions between biogeographic regions and egg type significantly affect genetic population structure in benthic marine fishes. It seems that there are no general rules regarding levels of connectivity in marine species and, on the contrary, this may be highly depend on the species being considered and on the type of molecular marker used. For example, using mtDNA markers, Sedberry et al. (1996) found genetic homogeneity among samples of the deep-sea wreckfish Polyprion americanus collected in Brazil, Australia and New Zealand. However, using microsatellite DNA markers, Ball et al. (2000) found two genetic groups among samples of P. americanus, one from Brazil and the other one in Australia and New Zealand.

In this thesis, using two types of neutral molecular markers, I studied the population genetic structure of orange roughy, one of the most heavily exploited deep-sea fishes in the world (Pitcher 2010). Using DNA sequence data (Chapter 2), I found that orange roughy exhibit high-historical levels of connectivity at a global scale. Low but significant differentiation was only detected between sites in the Northeast Atlantic Ocean and all the sites in the Southern hemisphere and between the Chatham Rise and Puysegur off New Zealand. On the other hand, at an ecological/more recent time scale given by the higher mutation rate of the microsatellite DNA markers (Chapter 3), low but significant levels of differentiation were also detected within the Southern hemisphere. The pattern of differentiation between the Northeast Atlantic and the 
Southern hemisphere revealed by the DNA sequence analyses was supported by the highest values of differentiation between sites of the two hemispheres with the microsatellite DNA data. The clear genetic differentiation between New Zealand and the Northeast Atlantic Ocean samples found in this study differs from the findings of Smith (1986), who reported genetic homogeneity between samples of these two regions using allozyme loci. This is probably explained by the higher resolution power of mtDNA sequences and microsatellite DNA loci compared to allozymes. On the other hand, using microsatellite DNA loci, Oke et al. (2002) reported a lack of differentiation between New Zealand/Australia and the Northeast Atlantic Ocean samples, which also differs from the results of the present study. This discrepancy may be due to the fact that of the six loci used by Oke et al. (2002) three had low heterozygosities and were not used in this study. Instead, all the nine loci used here had high heterozygosities, likely resulting in a higher resolution power of the present data. Regarding the prevalent lack of differentiation between New Zealand and Australia reported here, similar results have been found with allozymes (Elliott and Ward 1992), but disagree with the results of restriction enzyme analysis of mtDNA (Smolenski et al. 1993) and with parasite analyses (Lester et al. 1988). At a fine-scale around New Zealand, a panmictic pattern was revealed with both mtDNA sequences and microsatellite DNA loci. Significant differentiation was detected in only a few comparisons mostly involving the Chatham Rise and/or Puysegur. In contrast, previous studies using RFLPs, allozymes, otolith shape, fish size, and restriction digest of the whole mitochondrial genome have reported significant genetic structure around New Zealand (Smith et al. 1996; Smith and Benson 1997; Smith et al. 2002a). However, mitochondrial DNA polymorphism of the control region and two microsatellite loci revealed lack of differentiation among New Zealand sites (Smith et al. 2002a). As stated before, contrasting results at a fine-scale have been also reported within the Northeast Atlantic Ocean using microsatellite DNA loci (White et al. 2009a; Carlsson et al. 2011). The marked contradictions among population differentiation studies in orange roughy are most likely explained by different signals revealed by the different molecular markers/techniques that have been used. Moreover, each study has used a particular set of sampling sites and they have also differed in the number of individuals sampled in each location. On the other hand, techniques that are highly influenced by recent environmental conditions such as parasite, otolith and morphometrics analyses have showed population differentiation in orange roughy at regional and fine-scales (e.g. Lester et al. 1988; Edmonds et al. 1991; Elliott et al. 
1995). However, the genome is not immediately affected by environmental conditions, since a number of generations are necessary to accumulate genetic differences that can be detected with molecular markers. The main advantage of the present study in comparison with previous studies is the high geographical coverage of the sampling squeme and the use of two neutral molecular markers, which revealed signals at different time scales. While the present data is not conclusive about levels of genetic differentiation at a fine-scale (i.e. around New Zealand) and across the Tasman Sea (between New Zealand and Australia), the main conclusion of this study is that orange roughy exhibits a significant genetic structure at a global scale.

The lack of differentiation (mtDNA) and low differentiation (microsatellite DNA) found across the Southern hemisphere (i.e. New Zealand, Australia, Chile, and Namibia) is likely the result of active adult dispersal under a stepping-stone model combined with long-life span and multiple spawning events (White et al. 2009a). However, the clear differentiation of the Northeast Atlantic from the Southern hemisphere and the consistent differentiation between the Chatham Rise and Puysegur off New Zealand with both markers, suggest that there might be oceanographic conditions that limit the dispersal of orange roughy at large and short spatial scales. As discussed in Chapter 2, an abrupt water-mass boundary at $41^{\circ} \mathrm{N}$ may be related with the differentiation of the Northeast Atlantic sites from all the other sites. As suggested by Smith et al. (1996), the differentiation of orange roughy samples from the Chatham Rise and Puysegur may be related with a major hydrological barrier between these sites. The Subtropical Convergence zone along the Chatham Rise marks the transition between the Subtropical Water (STW) and the Subantarctic Water (SAW). The STW has its origin in the central Pacific Ocean and is characterized by high temperature and salinity. In contrast, the SAW is cooler and less saline (Heath 1985). Another main water mass around New Zealand is called Antarctic Intermediate Water (AAIW) which sinks at the Convergence zone and travel northwards. The salinity minimum of the AAIW occurs at $700 \mathrm{~m}$ south of the Convergence zone and 1,000 m north of the Convergence (Heath 1985). There are pronounced changes in temperature at the surface and mid-depth waters at the Convergence zone, but the influence of these water masses over the temperature at depths inhabited by orange roughy is less documented (Smith et al. 1996). However, differences in temperature have been registered at $500 \mathrm{~m}$ depth (see Hadfield et al. 2007), showing a temperature of $8^{\circ} \mathrm{C}$ at the Convergence zone, $9-10^{\circ} \mathrm{C}$ north of the Convergence, and $6-7^{\circ} \mathrm{C}$ to the south. Thus, it is possible that different 
water-masses limit the dispersal of orange roughy between the Chatham Rise and Puysegur, and may also explain the low but significant differentiation between few sites in Northern New Zealand and Chatham Rise and/or Puysegur.

Regarding the three types of genetic structure defined by Laikre et al. (2005) that were highlighted in the general introduction of this thesis, the present study suggests that a global scale orange roughy is within category 2: genetic composition change over space (IBD pattern). At a finer scale (around New Zealand), orange roughy may be better represented by category 3: there is extensive gene flow. However, it is likely that oceanographic discontinuities and migratory behaviour (probably not all individuals join the annual migrations to spawning sites, Bell et al. 1992; Zeldis et al. 1997), limits the dispersal of orange roughy preventing the formation of a single panmictic unit.

\subsection{Implications for fisheries management in New Zealand}

Similar to other deep-sea fisheries, orange roughy fisheries have shown the typical pattern of "boom-and-bust" (reviewed by Pitcher et al. 2010), and most fisheries have been closed or quotas largely reduced (see Clark 2009; Niklitscheck et al. 2010; Foley et al. 2011). However, large-scale fisheries still operate off New Zealand (Clark 2009; New Zealand Ministry of Fisheries 2011) and an effective management is needed to prevent overfishing of stocks. Determining levels of connectivity among populations or stocks (stock structure) of exploited species is crucial for developing sustainable management and conservation plans (Begg et al. 1999; Grant and Waples 2000; Laikre et al. 2005). It has been suggested that the better approach to determine the stock structure of marine resources is to follow and holistic approach (Begg and Waldman 1999; Cadrin et al. 2005). The genetic data generated by this study should be considered in assessments studies as part of a multidisciplinary approach to determine the levels of connectivity among stocks in this species. The main results to consider are: 1) the high levels of genetic diversity in orange roughy found with both molecular markers indicate large past population sizes and do not reflect current population sizes that could have been impacted by fisheries activities; 2) there may be some levels of interchange by adult dispersal between New Zealand and Australian populations; however, levels of differentiation were detected in few comparisons; 3) significant differentiation was 
detected between the Chatham Rise and Puysegur with both markers and between few Northern sites and Chatham Rise and/or Puysegur with the microsatellite DNA marker. Smith et al. (1996) and Smith et al. (1997) also found differentiation between the Chatham Rise and Puysegur. Considering all these studies, there is support from genetic data for the current management of these sites as two different stocks; and 4) temporal variation in orange roughy populations cannot be ruled out by the present data due to the high variability of the loci coupled with a low sample size for the temporal analyses and, therefore, this should be assessed in the future (about temporal variation see Smith and Benson 1997; Smolenski et al. 1993).

\subsection{Demographic history of orange roughy}

Different combinations of small and large levels of haplotype and nucleotide diversities have been used to define groups of species in relation to their demographic history (Grant and Bowen 1998). As reviewed by Grant and Waples (2000) (see Fig. 6.1 reconstructed following Grant and Waples 2000), most marine fishes are within category 2; these species have rapidly recovered from severe population reductions. Some species have not yet recovered from bottleneck events and are within category 1. Others, those in the category 3 , have had large and stable population sizes for long periods of time. None of the marine species considered by Grant and Waples (2000) or by some other studies (see legend in Fig 6.1) are in category 4, which is most common in inshore or freshwater species (Grant and Waples 2000).

In figure 6.1, orange roughy appears in the category 1 and 2 considering the values reported by Smolenski et al. (1993) using restriction enzyme analysis of mtDNA and by Baker et al. (1995) using Cyt $b$ sequences, respectively (dot numbers 48 and 49 in Fig. 6.1). The demographic analyses conducted in Chapter 2 with COI sequences support that orange roughy is within the category 2 (dot number 51 in Fig. 6.1): there is a pattern of high haplotype diversity and low nucleotide diversity that can be related with a drastic reduction in population size in the past followed by sudden expansion. The analyses presented in Chapter 2 inferred two expansion events during the Pleistocene period, likely related with glaciations events. Taking into account the values of haplotype and nucleotide diversities for the Cyt $b$ sequences shown in Chapter 2, orange 
roughy falls into category 3 (dot number 50 in Fig. 6.1). The discrepancy between the COI and Cyt $b$ signals may be because the Cyt $b$ is generally more variable than the COI gene. However, using Cyt $b$ sequences Baker et al. (1995) also found that orange roughy is within category 2 . On the other hand, the average nucleotide diversity in the Cyt $b$ sequences was $0.86 \%$, which is very close to the limit of $0.8 \%$ between low and high nucleotide diversity (see Fig. 6.1) as defined by Grant and Bowen (1998). Furthermore, the demographic analyses conducted with the COI sequences (mismatch distribution, Bayesian skyline analyses and the start-like shape of the haplotype genealogy) indicated the occurrence of expansion events. Thus, it is more likely that orange roughy is within category 2 defined by Grant and Bowen (1998). 


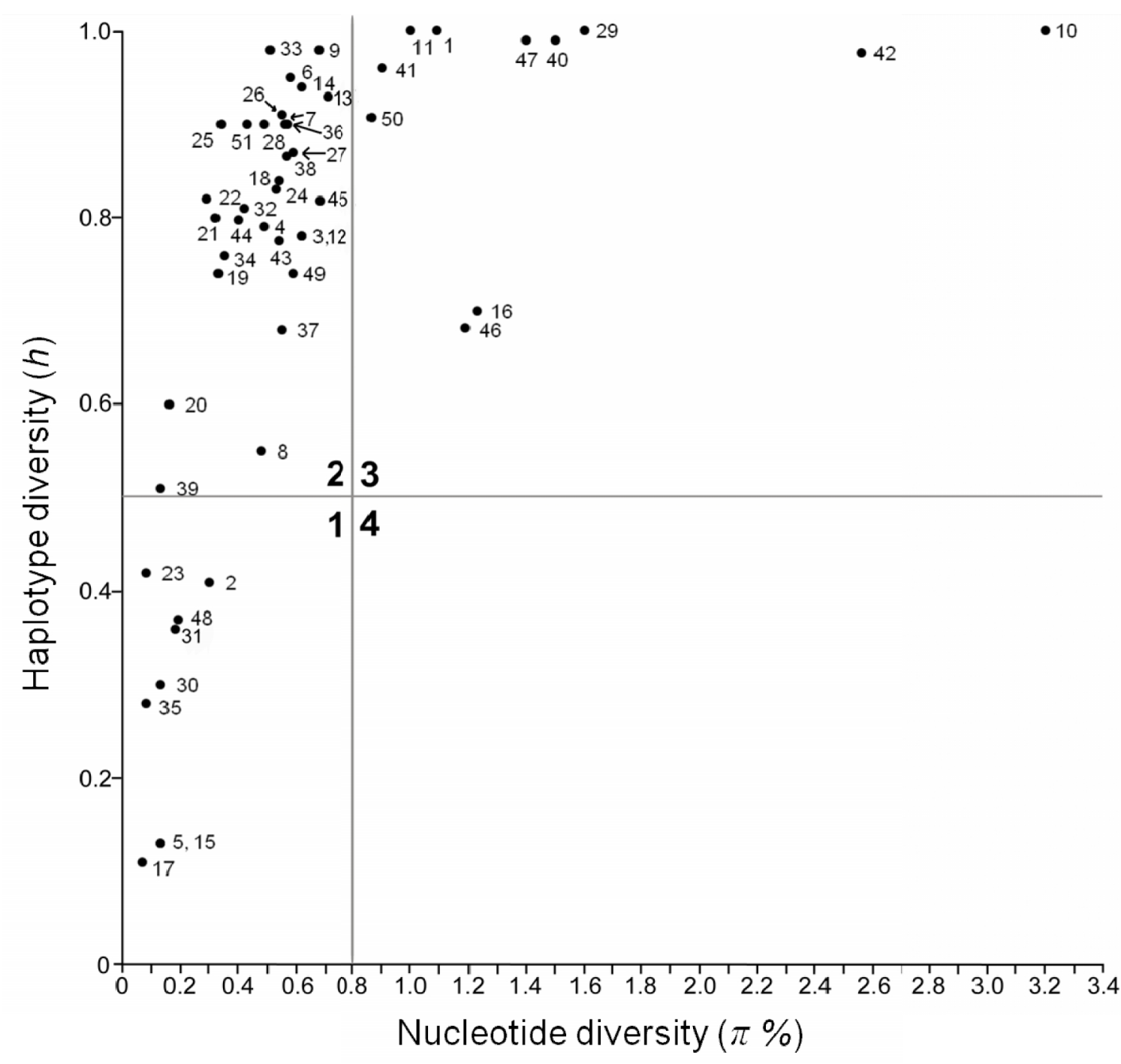

Fig. 6.1 Relationship between haplotype diversity $(h)$ and nucleotide diversity $(\pi)$ for marine fishes. Reconstructed following Grant and Waples (2000). Values are from Grant and Bowen (1998) unless stated. Numbers represent species. 1-22: shallow-sea species (i.e. max. depth $\leq$ $200 \mathrm{~m}$ ), 23-51: deep-sea species (i.e. max. depth $>200 \mathrm{~m}$ ). 1, redlip blenny; 2, beaugregory damselfish; 3, slippery dick; 4, sergeant major; 5, weakfish; 6, red drum (Gulf of Mexico); 7, red drum (Atlantic); 8, bluehead; 9, goldspot goby; 10, menhaden (Atlantic); 11, menhaden (Gulf of Mexico); 12, french grunt; 13, stickleback; 14, longjaw squirrelfish; 15, red snapper; 16, bluefish (Atlantic); 17, bluefish (Australia); 18, blue marlin (Atlantic-Indo-Pacific); 19, blue marlin (Atlantic); 20, blue marlin (Pacific); 21, sailfish; 22, white/striped marlin; 23, red grouper; 24, spanish sardine; 25, greater amberjack; 26, atlantic herring; 27, haddock; 28, pacific herring; 29, broadbanded thornyhead (Stepien et al. 2000); 30, atlantic cod (N Atlantic); 31, atlantic cod (NW Atlantic); 32, capelin (NW Atlantic); 33, capelin (NE Atlantic); 34, shortfin mako; 35, hoki; 36, cape hake; 37, deepwater hake; 38, cape hake (von der Heyden et al. 2007); 39, deepwater hake (von der Heyden et al. 2007); 40, shortspine thornyhead (Stepien et al. 2000); 41, longspine thornyhead (Stepien et al. 2000); 42, bluemouth (control region, Aboim et al. 2005); 43, bluemouth (cyt b, Aboim et al. 2005); 44, alfonsino (Friess and Sedberry 2011); 45, alaskan pacific halibut (Nielsen et al. 2010); 46, spikey oreo (Elliott et al. 1998); 47, blackfin flounder (Xiao et al. 2010); 48, orange roughy (Smolenski et al. 1993); 49, orange roughy (Baker et al. 1995); 50, orange roughy (cyt $b$, present study, Chapter 2); 51, orange roughy (COI, present study, Chapter 2) 


\subsection{Genetic divergence and phylogenetic relationships of Hoplostethus spp.}

The analyses conducted using COI sequences of six Hoplostethus species in Chapter 4, showed the typical pattern found in the barcode DNA region, there is a marked difference between intra and inter-species divergence (Hebert et al. 2003).

The analyses of the nucleotide data clearly showed that $H$. atlanticus is a separate taxon from the clade formed by $H$. latus, $H$. crassispinus, $H$. japonicus, and $H$. mediterraneus. The phylogenetic relationship between $H$. atlanticus and $H$. gigas was not resolved at the nucleotide level. However, the amino acid data differentiated $H$. atlanticus from all the other species including $H$. gigas. This was evident by the presence of three non-synonymous substitutions in $H$. atlanticus. Even more, two of these substitutions were among different physicochemical amino acids. These results are correlated with morphological differences. Hoplostethus atlanticus have different morphological characteristics respect to $H$. gigas, $H$. crassispinus $H$. japonicus, and $H$. mediterraneus Kotlyar (1986).

Considering the species used here, the analyses indicated that the genus Hoplostethus is monophyletic and derived (Maximum Likelihood and Bayesian analyses) respect to the genera Aulotrachichthys, Gephyroberyx and Paratrachichthys within the family Trachichthyidae. Further studies including all the Hoplostethus species and representatives of all the genera within Trachichthyidae would be needed to propose a complete molecular phylogeny for the genus Hoplostethus, and for clearly place the phylogenetic position of this genus within the family.

\subsection{Visual adaptations of orange roughy to the bathypelagic light environment}

It is well known that certain amino acid replacements (critical sites) in the opsin protein of vertebrates' visual pigments shift the maximal absorbance $\left(\lambda_{\max }\right)$ of the pigments to adapt to different light environments (reviewed by Yokoyama 2008). The diversity of marine fish species inhabiting a wide range of depths and photic conditions (e.g. turbidity, color of the water and brightness of the downwelling light) provide an ideal model to study the evolution of visual systems (Bowmaker 1995; Yokoyama 2000). The visual pigments of many fish species are shifted towards the blue light when compared with terrestrial species (e.g. the bovine Bos taurus) (reviewed by Yokoyama 2008). 
In Chapter 5, using partial rhodopsin sequences of 19 marine fish species inhabiting different depths $(1-1,800 \mathrm{~m})$, I identified 60 variable amino acid sites; four of them are known to be involved in spectral tuning in marine fish species: P194R, H195A, A292S and A299S (Hunt et al. 2001; Yokoyama and Takenaka 2004; Yokoyama 2008). The comparisons of the amino acid sequences of the species under study, revealed that orange roughy have a particular set of amino acids at two critical sites (292S/299A), which has been previously reported for silver roughy and was related with a $\lambda_{\max }$ value of $479 \mathrm{~nm}$ (Hunt et al. 2001). This combination was not found in any of the other species and, therefore, may represent an adaptation to the light available in bathypelagic environments (i.e. blue bioluminescence).

The study of rhodopsin gene sequences conducted here included very divergent species (belonging to16 families). The species used were available since they are common in New Zealand (although the samples of Trachurus murphyi were obtained from Chile). The diversity of species used allowed the identification of potential sites for spectral tuning for species covering a wide range of depth distribution, and thus, different light environments. Nonetheless, the use of rhodopsin gene sequences to identify critical amino acid sites has an enormous potential to study intra-specific adaptive evolution in many and diverse organisms (Yokoyama 2000). For example, a recent study reported a correlation between critical sites in the rhodopsin gene and the photic environments of different populations of the sand goby, Pomatoschistus minutus (Larmuseau et al. 2009b). Similarly, the influence of natural selection in visual systems has been related with diversification of marine fishes flocks in sand goby and sevenspined gobies species (Teleostei: Gobiidae) (Larmuseau et al. 2010; Larmuseau et al. 2011). Future studies aiming to study functional variation in the rhodopsin gene at intra and inter-species levels would be highly valuable to continue the research about the influence of natural selection (operating over visual systems) in the evolution and diversification of fishes. These kinds of studies are part of three steps needed to determine the molecular basis of adaptive changes in visual systems. The two other steps involve cloning and characterization of the retinal opsin genes and determination of the actual effects of critical amino acid sites on shifts in the $\lambda_{\max }$ of visual pigments using in vitro assay (Yokoyama 2000). 


\subsection{Concluding remarks and future research}

This thesis covered several different aspects of genetic research on the deep-sea fish orange roughy. The main goal was to add knowledge into the already extensive research field of population connectivity in this heavily exploited fish. This is the first study to use large sample sizes, two types of neutral molecular markers and samples from New Zealand, Australia, Namibia, Chile, and the Northeast Atlantic Ocean; including multiple locations around New Zealand within the EEZ and in the high seas. Future studies should also include markers under selection to evaluate if adaptive variation plays a role in the levels of connectivity among orange roughy populations. The rapid advance in molecular technology (i.e. genome-wide studies) combined with continuos reductions in costs could facilitate the research into adaptive vs. neutral divergence in non-model species and will likely influence fisheries sciences (Hauser and Seeb 2008).

I also aimed to study the intra/inter genetic divergence and phylogenetic relationships of orange roughy respect to other congeners using a portion of the DNA barcode region. The lack of access to samples of other congeners limited the proposition of a molecular phylogeny for the genus Hoplostethus, and, therefore, constitutes a future area of research.

A third topic of study was about the molecular basis for visual adaptations of orange roughy to the bathypelagic light environment. The inclusion of other fish species inhabiting different depths allowed to gain insights into a particular feature not found in any of the other species, except by the congener silver roughy, which also occur in bathypelagic environments. Further studies about this aspect should aim to obtain the complete rhodopsin gene sequence in orange roughy to identify other potential tuning sites. 


\section{References}

Abaunza P, Murta AG, Campbell N, Cimmaruta R, Comesaña AS, Dahle G, García Santamaría MT, Gordo LS, Iversen SA, MacKenzie K, Magoulas A, Mattiucci S, Molloy J, Nascetti G, Pinto AL, Quinta R, Ramos P, Sanjuan A, Santos AT, Stransky C, Zimmermann C (2008) Stock identity of horse mackerel (Trachurus trachurus) in the Northeast Atlantic and Mediterranean Sea: Integrating the results from different stock identification approaches. Fisheries Research 89:196-209

Aboim MA, Menezes GM, Schlitt T, Rogers AD (2005) Genetic structure and history of populations of the deep-sea fish Helicolenus dactylopterus (Delaroche, 1809) inferred from mtDNA sequence analysis. Molecular Ecology 14:1343-1354

Anderson MJ, Millar RB (2004) Spatial variation and effects of habitat on temperate reef fish assemblages in northeastern New Zealand. Journal of Experimental Marine Biology and Ecology 305:191-221

André C, Larsson LC, Laikre L, Bekkevold D, Brigham J, Carvalho GR, Dahlgren TG, Hutchinson WF, Mariani S, Mudde K, Ruzzante DE, Ryman N (2011) Detecting population structure in a high gene-flow species, Atlantic herring (Clupea harengus): direct, simultaneous evaluation of neutral vs putatively selected loci. Heredity $106: 270-280$

Avise JC (1998a) The history and purview of phylogeography: a personal reflection. Molecular Ecology 7:371-379

Avise JC (1998b) Conservation genetics in the marine realm. Journal of Heredity $89: 377-382$

Ayling T, Cox GJ (1982) Collins guide to the sea fishes of New Zealand. Collins Publishers Auckland, $343 \mathrm{pp}$

Baker CS, Perry A, Chambers GK, Smith PJ (1995) Population variation in the mitochondrial cytochrome $b$ gene of the orange roughy Hoplostethus atlanticus and the hoki Macruronus novaezelandiae. Marine Biology 122:503-509

Baker KD, Devine JA, Haedrich RL (2009) Deep-sea fishes in Canada's Atlantic: population declines and predicted recovery time. Environmental Biology of Fishes $85: 79-88$ 
Ball AO, Sedberry GR, Zatcoff MS, Chapman RW, Carlin JL (2000) Population structure of the wreckfish Polyprion americanus determined with microsatellite genetic markers. Marine Biology 137:1077-1090

Bandelt HJ, Forster P, Röhl A (1999) Median-joining networks for inferring intraspecific phylogenies. Molecular Biology and Evolution 16:37-48

Begg GA, Waldman JR (1999) An holistic approach to fish stock identification. Fisheries Research 43:35-44

Begg GA, Friedland KD, Pearce JB (1999) Stock identification and its role in stock assessment and fisheries management: an overview. Fisheries Research 43:1-8

Bell JD, Lyle JM, Bulman CM, Graham KJ, Newton GM, Smith DC (1992) Spatial variation in reproduction, and occurrence of non-reproductive adults, in orange roughy, Hoplostethus atlanticus Collett (Trachichthyidae), from south-eastern Australia. Journal of Fish Biology 40:107-122

Bermingham E, McCafferty SS, Martin AP (1997) Fish biogeography and molecular clocks: perspectives from the Panamanian isthmus. In: Kocher T, Stepien C (Eds.) Molecular Systematics of Fishes. Academic Press, San Diego, pp 113-128

Bertrand A, Barbieri MA, Córdova J, Hernández C, Gómez F, Leiva F (2004). Diel vertical behaviour, predator-prey relationships, and occupation of space by jack mackerel (Trachurus murphyi) off Chile. ICES Journal of Marine Sciences 61:11051112

Boehlert GW, Sasaki T (1988) Pelagic biogeography of the armorhead, Pseudopentaceros wheeleri, and recruitment to isolated seamounts in the North Pacific Ocean. Fishery Bulletin 86:453-465

Bowmaker JK (1995) The visual pigments of fish. In: Osborne NN, Chader GJ, editors. Progress in retinal and eye research, vol 15. Oxford: Pergamon Press, 1-31

Branch TA (2001) A review of orange roughy Hoplostethus atlanticus fisheries, estimation methods, biology and stock structure. South African Journal of Marine Science 23:181-203

Broderick D, Ovenden JR, Buckworth RC, Newman SJ, Lester RJG, Welch DJ (2011) Genetic population structure of grey mackerel Scomberomorus semifasciatus in northern Australia. Journal of Fish Biology 79:633-661

Brown WM, George M, Wilson AC (1979) Rapid evolution of animal mitochondrial DNA. Proceedings of the National Academy of Sciences of the United States of America 76:1967-1971 
Bucklin A, Steinke D, Blanco-Bercial L (2011) DNA Barcoding of marine metazoa. Annual Review of Marine Science 3:471-508

Bulman CM, Koslow JA (1992) Diet and food consumption of a deep-sea fish, orange roughy Hoplostethus atlanticus (Pisces: Trachichthyidae), off southeastern Australia. Marine Ecology Progress Series 82:115-129

Cadrin SX, Friedland KD, Waldman J (2005) Stock identification methods: applications in Fishery Science. Elsevier Academic Press, Amsterdam.

Carbines G (2003) Age, growth, movement and reproductive biology of blue cod (Parapercis colias - Pinguipedidae): Implications for fisheries management in the south island of New Zealand. PhD Thesis, University of Otago, Dunedin, New Zealand, $225 \mathrm{pp}$

Carlsson J, Shephard S, Coughlan J, Trueman CN, Rogan E, Cross TF (2011) Finescale population structure in a deep-sea teleost (orange roughy, Hoplostethus atlanticus). Deep-Sea Research I 58:627-636

Cawthorn DM, Steinman HA, Witthuhn RC (2011) Establishment of a mitochondrial DNA sequence database for the identification of fish species commercially available in South Africa. Molecular Ecology 11:979-991

Chapman DD, Simpfendorfer CA, Wiley TR, Poulakis GR, Curtis C, Tringali M, Carlson JK, Feldheim (2011) Genetic diversity despite population collapse in a critically endangered marine fish: The smalltooth sawfish (Pristis pectinata). Journal of Heredity 102:643-652

Chen WJ, Bonillo C, Lecointre G (2003) Repeatability of clades as a criterion of reliability: a case study for molecular phylogeny of Acanthomorpha (Teleostei) with larger number of taxa. Molecular Phylogenetics and Evolution 26:262-288

Clark MR (1996) Biomass estimation of orange roughy: a summary and evaluation of techniques for measuring stock size of a deep-water fish species in New Zealand. Journal of Fish Biology 49(Supplement A):114-131

Clark MR (2009) Deep-sea seamount fisheries: a review of global status and future prospects. Latin American Journal of Aquatic Research 37:501-512

Clark MR (2010) Box 9: Effects of trawling on seamounts. Oceanography 23:132-133

Clark MR, Anderson OF, Francis RIC, Tracey DM (2000) The effects of commercial exploitation on orange roughy (Hoplostethus atlanticus) from the continental slope of the Chatham Rise, New Zealand, from 1979 to 1997. Fisheries Research 45:217238 
Correia AT, Pipa T, Gonçalves JMS, Erzini K, Hamer PA (2011) Insights into population structure of Diplodus vulgaris along the SW Portuguese coast from otolith elemental signatures. Fisheries Research 111:82-91

Crandall KA, Templeton AR (1993) Empirical test of some predictions from coalescent theory with applications to intraspecific phylogeny reconstruction. Genetics 134:959969

Crawford NG (2010) SMOGD: Software for the measurement of genetic diversity. Molecular Ecology Resources 10:556-557

Crescitelli F (1991) Adaptations of visual pigments to the photic environment of the deep sea. The Journal of Experimental Zoology (Supplement 5):66-75

DeWoody JA, Avise JC (2000) Microsatellite variation in marine, freshwater and anadromous fishes compared with other animals. Journal of Fish Biology 56:461-473

Dower JF, Brodeur RD (2004) The role of biophysical coupling in concentrating marine organism around shallow topographies. Journal of Marine Systems 50:1-2

Dratz EA, Hargrave PA (1983) The structure of rhodopsin and the rod outer segment disc membrane. Trends in Biochemical Sciences 8:128-131

Drummond AJ, Rambaut A (2007) BEAST: Bayesian evolutionary analysis by sampling trees. BMC Evolutionary Biology 7:214. doi:10.1186/147-2148-7-214

Drummond AJ, Rambaut A, Shapiro B, Pybus OG (2005) Bayesian coalescent inference of past population dynamics from molecular sequences. Molecular Biology and Evolution 22:1185-1192

Drummond AJ, Ho SYW, Phillips MJ, Rambaut A (2006) Relaxed phylogenetics and dating with confidence. PLoS Biology 4:699-710

Drummond AJ, Ashton B, Buxton S, Cheung M, Cooper A, Heled J, Kearse M, Moir R, Stones-Havas S, Sturrock S, Thierer T, Wilson A (2010) Geneious v5.1, Available from http://www.geneious.com

Duffy CAJ, Petherick C (1999) A new size record for kahawai (Arripis trutta) from New Zealand. New Zealand Journal of Marine and Freshwater Research 33:565-569

Dunn MR, Devine JA (2010) An holistic approach to determining stock structure of orange roughy on the Chatham Rise. New Zealand Fisheries Assessment Report 2010/17

Dunn MR, Forman JS (2011) Hypotheses of spatial stock structure in orange roughy Hoplostethus atlanticus inferred from diet, feeding, condition, and reproductive activity. PLoS ONE 6(11): e26704 
Earl DA, vonHoldt BM (2011) STRUCTURE HARVESTER: a website and program for visualizing STRUCTURE output and implementing the Evanno method. Conservation Genetic Resources (In press). doi:10.1007/s12686-011-9548-7

Edmonds JS, Caputi N, Morita M (1991) Stock discrimination by trace-element analysis of otoliths of orange roughy (Hoplostethus atlanticus), a deep-water marine teleost. Australian Journal of Marine and Freshwater Research 42:383-389

Elliott NG, Ward RD (1992) Enzyme variation in orange roughy, Hoplostethus atlanticus (Teleostei: Trachichthyidae), from Southern Australian and New Zealand waters. Australian Journal of Marine and Freshwater Research 43:1561-1571

Elliott NG, Smolenski AL, Ward RD (1994) Allozyme and mitochondrial DNA variation in orange roughy, Hoplostethus atlanticus (Teleostei, Trachichthyidae): little differentiation between Australian and North Atlantic populations. Marine Biology 119:621-627

Elliott NG, Haskard K, Koslow JA (1995) Morphometric analyses of orange roughy (Hoplostethus atlanticus) off the continental slope of southern Australia. Journal of Fish Biology 46:202-220

Elliott NG, Lowry PS, Grewe PM, Innes BH, Yearsley GK, Ward RD (1998) Genetic evidence for depth- and spatially separated stocks of the deep-water spikey oreo in Australasian waters. Journal of Fish Biology 52:796-816

Evanno G, Regnaut S, Goudet J (2005) Detecting the number of clusters of individuals using the software STRUCTURE: a simulation study. Molecular Ecology 14:26112620

Excoffier L, Laval G, Schneider S (2005) Arlequin (version 3.0): An integrated software package for population genetics data analysis. Evolutionary Bioinformatics Online 1:47-50

Falush D, Stephens M, Pritchard JK (2003) Inference of population structure using multilocus genotype data: linked loci and correlated allele frequencies. Genetics $164: 1567-1587$

Fanelli E, Cartes JE (2010) Temporal variations in the feeding habits and trophic levels of three deep-sea demersal fishes from the western Mediterranean Sea, based on stomach contents and stable isotope analyses. Marine Ecology Progress Series 402:213-232

Fasick JI, Robinson PR (1998) Mechanism of spectral tuning in the dolphin visual pigments. Biochemistry 37:433-438 
Fauvelot C, Borsa P (2011) Patterns of genetic isolation in a widely distributed pelagic fish, the narrow-barred Spanish mackerel (Scomberomorus commerson). Biological Journal of the Linnean Society 104:886-902

Felsenstein J (1989) PHYLIP - Phylogeny inference package (version 3.2). Cladistics 5:164-166

Fenton GE, Short SA, Ritz DA (1991) Age determination of orange roughy, Hoplostethus atlanticus (Pisces: Trachichthyidae) using 210Pb: 226Ra disequilibria. Marine Biology 109:197-202

Fevolden SE, Pogson GH (1997) Genetic divergence at the synaptophysin (Syp I) locus among Norwegian coastal and north-east Arctic populations of Atlantic cod. Journal of Fish Biology 51:895-908

Foley NS, van Rensburg TM, Armstrong CW (2011) The rise and fall of the Irish orange roughy fishery: An economic analysis. Marine Policy 35:756-763

Foll M, Gaggiotti O (2008) A genome-scan method to identify selected loci appropriate for both dominant and codominant markers: A Bayesian perspective. Genetics $180: 977-993$

Francis RICC, Horn PL (1997) Transition zone in otoliths of orange roughy (Hoplostethus atlanticus) and its relationship to the onset of maturity. Marine Biology 129:681-687

Francis RICC, Clark MR (1998) Inferring spawning migrations of orange roughy (Hoplostethus atlanticus) from spawning ogives. Marine and Freshwater Research 49:103-108

Francis MP, Hurst RJ, McArdle BH, Bagley NW, Anderson OF (2002) New Zealand demersal fish assemblages. Environmental Biology of Fishes 65:215-234

Friess C, Sedberry GR (2011) Genetic evidence for a single stock of the deep-sea teleost Beryx decadactylus in the North Atlantic Ocean as inferred from mtDNA control region analysis. Journal of Fish Biology 78:466-478

Fu YX (1997) Statistical tests of neutrality of mutations against population growth, hitchhiking and background selection. Genetics 147:915-925

Glaubitz JC (2004) CONVERT: A user-friendly program to reformat diploid genotypic data for commonly used population genetic software packages. Molecular Ecology Notes 4:309-310 
Glova GJ, Sagar PM (2000) Summer spatial patterns of the fish community in a large, shallow, turbid coastal lake. New Zealand Journal of Marine and Freshwater Research 34:507-522

González-Wangüemert M, Cánovas F, Pérez-Ruzafa A, Marcos C, Alexandrino P (2010) Connectivity patterns inferred from the genetic structure of white seabream (Diplodus sargus L.). Journal of Experimental Marine Biology and Ecology 383:2331

Goudet J (1995) FSTAT (version 1.2): A computer program to calculate $F$-statistics. Journal of Heredity 86:485-486

Goudet J (2001) FSTAT, a program to estimate and test gene diversities and fixation indices, version 2.9.3. Available from http://www2.unil.ch/ popgen/ softwares/fstat. htm.

Grant WS, Bowen BW (1998) Shallow population histories in deep evolutionary lineages of marine fishes: insights from sardines and anchovies and lessons for conservation. Journal of Heredity 89:415-426

Grant WS, Waples RS (2000) Spatial and temporal scales of genetic variability in marine and anadromous species: implications for fisheries oceanography. In: Harrison PJ, Parsons TR (ed) Fisheries Oceanography: an integrative approach to fisheries ecology and management, pp 61-93

Guindon S, Dufayard JF, Lefort V, Anisimova M, Hordijk W, Gascuel O (2010) New algorithms and methods to estimate Maximum-Likelihood phylogenies: Assessing the performance of PhyML 3.0. Systematic Biology 59:307-321

Guzmán BE, Nuñez JJ, Vejar A, Barriga EH, Gallardo CS (2011) Genetic diversity and population structure of two South American marine gastropods, Crepipatella dilatata and C. fecunda (Gastropoda: Calyptraeidae): distinct patterns based on developmental mode. Italian Journal of Zoology 78:444-454

Hadfield MG, Rickard GJ, Uddstrom MJ (2007) A hydrodynamic model of Chatham Rise, New Zealand. New Zealand Journal of Marine and Freshwater Research 41:239-264

Han ZQ, Gao TX, Yanagimoto T, Sakurai Y (2008) Deep phylogeographic break among white croaker Pennahia argentata (Sciaenidae, Perciformes) populations in north-western pacific. Fisheries Science 74:770-780

Harpending RC (1994) Signature of ancient population growth in a low-resolution mitochondrial DNA mismatch distribution. Human Biology 66:591-600 
Hauser L, Seeb JE (2008) Advances in molecular technology and their impact on fisheries genetics. Fish and Fisheries 9:473-486

Heath RA (1985) A review of the physical oceanography of the seas around New Zealand - 1982. New Zealand Journal of Marine and Freshwater Research 19:79-124

Hebert PDN, Ratnasingham S, de Waard JR (2003) Barcoding animal life: cytochrome $c$ oxidase subunit 1 divergences among closely related species. Proceedings of the Royal Society of London B 270(Supplement):96-99

Hellberg ME (2009) Gene flow and isolation among populations of marine animals. Annual Review of Ecology. Evolution and Systematics 40:291-310

Hemmer-Hansen J, Nielsen EE, Frydenberg J, Loeschcke V (2007) Adaptive divergence in a high gene flow environment: Hsc70 variation in the European flounder (Platichthys flesus L.). Heredity 99:592-600

Hilborn R, Walters CJ (1992) Quantitative Fisheries Stock Assessment. Choice, Dynamics and Uncertainty. Chapman \& Hall, New York, 570 pp

Hoarau G, Borsa P (2000) Extensive gene flow within sibling species in the deep-sea fish Beryx splendens. Comptes Rendus de l'Academie des Sciences/Life Sciences $323: 315-325$

Holderegger R, Kamm U, Gugerli F (2006) Adaptive vs. neutral genetic diversity: implications for landscape genetics. Landscape Ecology 21:797-807

Hope AJ, Partridge JC, Dulai KS, Hunt DM (1997) Mechanism of wavelength tuning in the rod opsins of deep-sea fishes. Proceedings of the Royal Society B 264:155-163

Horn PL, Tracey DM, Clark MR (1998) Between-area differences in age and length at first maturity of the orange roughy Hoplostethus atlanticus. Marine Biology 132:187-194

Hubisz MJ, Falush D, Stephens M, Pritchard JK (2009) Inferring weak population structure with the assistance of sample group information. Molecular Ecology Resources 9:1322-1332

Hunt DM, Dulai KS, Partridge JC, Cottrill P, Bowmaker JK (2001) The molecular basis for spectral tuning of rod visual pigments in deep-sea fish. The Journal of Experimental Biology 204:3333-3344

Hurst RJ, Baglet NW, McGregor GA, Francis MP (1999) Movement of the New Zealand school shark, Galeorhinus galeus, from tag returns. New Zealand Journal of Marine and Freshwater Research 33:29-48 
Imbrie J, Boyle EA, Clemens SC, Duffy A, Howard WR, Kukla G, Kutzbach J, Martinson DG, McIntyre A, Mix AC, Molfino B, Morley JJ, Peterson LC, Pisias NG, Prell WL, Raymo ME, Shackleton NJ, Toggweiler JR (1992) On the structure and origin of major glaciations cycles 1. Linear responses to Milankovitch forcing. Paleoceanography 7:701-738

Jones MRL (2009) Diets of eight fish species from the upper slope off the Wairarapa coast, North Island, New Zealand, with notes on the diets of others. New Zealand Journal of Marine and Freshwater Research 43:929-939

Jordan AR (2001) Spatial and temporal variations in abundance and distribution of juvenile and adult jackass morwong, Nemadactylus macropterus, in south-eastern Tasmania. Marine and freshwater Research 52:661-670

Jost L (2008) $G_{\mathrm{ST}}$ and its relatives do not measure differentiation. Molecular Ecology 17: $4015-4026$

Katsanevakis S, Maravelias CD (2009) Bathymetric distribution of demersal fish in the Aegean and Ionian Seas based on generalized additive modelling. Fisheries Science $75: 13-23$

Kimura M (1980) A simple method for estimating evolutionary rates of base substitutions through comparative studies of nucleotide sequences. Journal of Molecular Evolution 16:111-120

Knutsen H, Jorde PE, Sannaes H, Hoelzel AR, Bergstad OA, Stefanni S, Johansen T, Stenseth NC (2009) Bathymetric barriers promoting genetic structure in the deepwater demersal fish tusk (Brosme brosme). Molecular Ecology 18:3151-3162

Kocher TD, Thomas WK, Meyer A, Edwards SV, Pääbo S, Villablanca FX, Wilson AC (1989) Dynamics of mitochondrial DNA evolution in animals: amplification and sequencing with conserved primers. Proceedings of the National Academy of Sciences of the United States of America 86:6196-6200

Koslow JA (1996) Energetic and life-history patterns of deep-sea benthic, benthopelagic and seamount-associated fish. Journal of Fish Biology 49(Supplement A):54-74

Koslow JA (1997) Seamounts and the ecology of deep-sea fisheries. American Scientist $85: 168-176$

Koslow JA, Boehlert GW, Gordon JDM, Haedrich RL, Lorance P, Parin N (2000) Continental slope and deep-sea fisheries: implications for a fragile ecosystem. ICES Journal of Marine Sciences 57:548-557 
Kotlyar AN (1986) Taxonomy and distribution of species of the genus Cuvier (Beryciformes, Trachichthyidae). Trudy Instituta Okeanologii Akademi Nauk SSSR 121:97-140

Kotlyar AN (2010) Fry of pacific slimehead Hoplostethus pacificus - a rare species of the Family of slimeheads (Trachichthyidae, Beryciformes). Journal of Ichthyology 50:197-200

Labbé J, Arana PM (2001) Alimentación de orange roughy, Hoplostethus atlanticus (Pisces: Trachichthyidae), en el archipiélago de Juan Fernández, Chile. Revista de Biología Marina y Oceanografía 36:75-82

Laikre L, Palm S, Ryman N (2005) Genetic population structure of fishes: Implications for coastal zone management. Ambio 34:111-119

Lakra WS, Verma MS, Goswami M, Lal KK, Mohindra V, Punia P, Gopalakrishnan A, Singh KV, Ward RD, Hebert P (2011) DNA barcoding Indian marine fishes. Molecular Ecology Resources 11:60-71

Larmuseau MHD, Van Houdt JKJ, Guelinckx J, Hellemans B, Volckaert FAM (2009a) Distributional and demographic consequences of Pleistocene climate fluctuations for a marine demersal fish in the north-eastern Atlantic. Journal of Biogeography $36: 1138-1151$

Larmuseau MHD, Raeymaekers JAM, Ruddick KG, van Houdt JKJ, Volckaert FAM (2009b) To see indifferent seas: spatial variation in the rhodopsin gene of the sand goby (Pomatoschistus minutus) Molecular Ecology 18:4227-4239

Larmuseau MHD, Huyse T, Vancampenhout K, van Houdt JKJ, Volckaert FAM (2010) High molecular diversity in the rhodopsin gene in closely related goby fishes: a role for visual pigments in adaptive speciation? Molecular Phylogenetics and Evolution 55:689-698

Larmuseau MHD, Vanhove MPM, Huyse T, Volckaert FAM, Decorte R (2011) Signature of selection on the rhodopsin gene in the marine radiation of American seven-spined gobies (Gobiidae, Gobiosomatini). Journal of Evolutionary Biology 24:1618-1625

Lester RJG, Sewell KB, Barnes A, Evanks K (1988) Stock discrimination of orange roughy, Hoplostethus atlanticus, by parasite analysis. Marine Biology 99:137-143

Levine JS, MacNichol EF (1982) Color vision in fishes. Scientific American 246:140149 
Levin LA, Etter RJ, Rex MA, Gooday AJ, Smith CR, Pineda J, Stuart CT, Hessler RR, Pawson D (2001) Environmental influences on regional deep-sea species diversity. Annual Review of Ecology and Systematics 32:51-93

Librado P, Rozas J (2009) DNAsp v5: A software for comprehensive analysis of DNA polymorphism data. Bioinformatics 25:1451-1452

Lorance P, Uiblein F, Latrouite D (2002) Habitat, behaviour and colour patterns of orange roughy Hoplostethus atlanticus (Pisces: Trachichthyidae) in the Bay of Biscay. Journal of the Marine Biological Association of the United Kingdom 82:321 331

Lowe WH, Allendorf FW (2010) What can genetics tell us about population connectivity? Molecular Ecology 19:3038-3051

Mace PM, Fenaughty JM, Coburn RP, Doonan IJ (1990) Growth and productivity of orange roughy (Hoplostethus atlanticus) on the north Chatham Rise. New Zealand Journal of Marine and Freshwater Research 24:105-119

Madurell T, Cartes JE (2005) Temporal changes in feeding habits and daily rations of Hoplostethus mediterraneus in the bathyal Ionian Sea (eastern Mediterranean). Marine Biology 146:951-962

Mamuris Z, Apostolidis AP, Panagiotaki P, Theodorou AJ, Triantaphyllidis C (1998) Morphological variation between red mullet populations in Greece. Journal of Fish Biology 52:107-117

Martin AP, Humphreys R, Palumbi SR (1992) Population genetic structure of the Armorhead, Pseudopentaceros wheeleri, in the North Pacific Ocean: application of the polymerase chain reaction to fisheries problems. Canadian Journal of Fisheries and Aquatic Sciences 49:2368-2391

McCusker MR, Bentzen P (2010) Positive relationships between genetic diversity and abundance in fishes. Molecular Ecology 19:4852-4862

Ministry of Fisheries (2011) Report from the Fisheries Assessment Plenary, May 2011: stock assessment and yield estimates. Ministry of Fisheries, Wellington, New Zealand. 1178 p. Available: http://www.fish.govt.nz via the Internet. Accessed 2011 Oct 21

Ministry of Fisheries (2011) Report from the Ministry of Fisheries 144-150. Available: http://fs.fish.govt.nz/Doc/22715/12_BUT_2011.pdf.ashx. Accessed 2012 Feb 15 
Moore BR, Stapley J, Allsop Q, Newman SJ, Ballagh A, Welch DJ, Lester RJG (2011) Stock structure of blue threadfin Eleutheronema tetradactylum across northern Australia, as indicated by parasites. Journal of Fish Biology 78:923-936

Moore JA, Dodd KA (2010) A new species of the roughy genus Hoplostethus (Teleostei: Trachichthyidae) from the Philippines. Bulletin of the Peabody Museum of Natural History 51:137-144

Morato T, Watson R, Pitcher TJ, Pauly D (2006) Fishing down the deep. Fish and Fisheries 7:24-34

Mundy BC, Moser HG (1997) Development of early stages of pelagic armorhead Pseudopentaceros wheeleri with notes on juvenile Ps. richardsoni and larval Histiopterus typus (Pisces, Percoidei, Pentacerotidae). Bulletin of Marine Sciences 61:241-269

Naro-Maciel E, Reid B, Holmes KE, Brumbaugh DR, Martin M, DeSalle R (2011) Mitochondrial DNA sequence variation in spiny lobsters: population expansion, panmixia, and divergence. Marine Biology 158:2027-2041

Nathans J, Hogness DS (1983) Isolation, sequence analysis, and intron-exon arrangement of the gene encoding bovine rhodopsin. Cell 34:807-841

Nathans J, Hogness DS (1984) Isolation and nucleotide sequence of the gene encoding human rhodopsin. Proceedings of the National Academy of Sciences of the United States of America 81:4851-4855

Neethling M, Matthee CA, Bowie RCK, von der Heyden S (2008) Evidence for panmixia despite barriers to gene flow in the southern African endemic, Caffrogobius caffer (Teleostei: Gobiidae). BMC Evolutionary Biology 8:325, doi:10.1186/1471-2148-8-325

Nielsen JL, Graziano SL, Seitz AC (2010) Fine-scale population genetic structure in Alaskan Pacific halibut (Hippoglossus stenolepis). Conservation Genetics 11:9991012

Niklitschek EJ, Cornejo-Donoso J, Oyarzún C, Hernández E, Toledo P (2010) Developing seamount fishery produces localized reductions in abundance and changes in species composition of bycatch. Marine Ecology-An Evolutionary Perspective 31(Supplement 1):168-182

Oke CS, Crozier YC, Crozier RH, Ward RD (1999) Microsatellites from a teleost, orange roughy (Hoplostethus atlanticus), and their potential for determining population structure. Molecular Ecology Primer Notes 8:2145-2147 
Oke CS, Crozier RH, Ward RD (2002) Stock structure of Australian populations of orange roughy analysed using microsatellites. Published by James Cook University. Fisheries Research and Development Corporation, James Cook University, La Trobe University and the Commonwealth Scientific and Industrial Research Organization. $44 \mathrm{p}$.

Palumbi SR, Martin A, Romano S, McMillan WO, Stice L, Grabowski G (1991) The simple fool's guide to PCR. Honolulu, Department of Zoology, University of Hawaii

Pankhurst NW (1987) Intra- and interspecific changes in the retinal morphology among mesopelagic and demersal teleosts from the slope waters of New Zealand. Environmental Biology of Fishes 19:269-280

Pankhurst NW, Conroy AM (1987) Size-fecundity relationships in orange roughy, Hoplostethus atlanticus. New Zealand Journal of Marine and Freshwater Resarch 21:295-300

Paulin CD (1979) New Zealand roughies (Pisces: Berycomorphi: Trachichthyidae). New Zealand Journal of Zoology 6:69-76

Pitcher TJ (2010) Box 8: Eight major target species in world seamount fisheries. Oceanography 23:130-131

Pitcher TJ, Clark MR, Morato T, Watson R (2010) Seamount fisheries: Do they have a future? Oceanography 23:134-144

Pogson GH, Fevolden SE (2003) Natural selection and the genetic differentiation of coastal and Artic populations of the Atlantic cod in northern Norway: a test involving nucleotide sequence variation at the pantophysin (PanI) locus. Molecular Ecology $12: 63-74$

Posada D (2008) jModelTest: Phylogenetic model averaging. Molecular Biology and Evolution 25:1253-1256

Pritchard JK, Stephens M, Donnelly P (2000) Inference of population structure using multilocus genotype data. Genetics 155:945-959

Rambaut A, Drummond AJ (2007) Tracer v1.4. Available from http://beast.bio.ed.ac.uk/Tracer

Ramirez-Llodra E, Brandt A, Danovaro R, De Mol B, Escobar E, German CR, Levin LA, Arbizu PM, Menot L, Buhl-Mortensen P, Narayanaswamy BE, Smith CR, Tittensor DP, Tyler PA, Vanreusel A, Vecchione M (2010) Deep, diverse and definitely different: unique attributes of the world's largest ecosystem. Biogeosciences 7:2851-2899 
Ramirez-Llodra E, Tyler PA, Baker MC, Bergstad OA, Clark MR, Escobar E, Levin LA, Menot L, Rowden AA, Smith CR, Van Dover CL (2011) Man and the last great wilderness: Human impact on the deep sea. PLoS ONE 6(7): e22588.

Rasmussen TL, Oppo DW, Thomsen E, Lehman SJ (2003) Deep sea records from the southeast Labrador Sea: Ocean circulation changes and ice-rafting events during the last 160,000 years. Paleoceanography 18(1):1018 doi:10.1029/2001PA000736

Rex MA, Stuart CT, Hessler RR, Allen JA, Sanders HL, Wilson GDF (1993) Globalscale latitudinal patterns of species diversity in the deep-sea benthos. Nature 365:636-639

Riginos C, Douglas KE, Jin Y, Shanahan DF, Treml EA (2011) Effects of geography and life history traits on genetic differentiation in benthic marine fishes. Ecography 34:566-575

Robinson N, Skinner A, Sethuraman L, McPartlan H, Murray N, Knuckey I, Smith DC, Hindell J, Talman S (2008) Genetic stock structure of blue-eye trevalla (Hyperoglyphe antarctica) and warehous (Seriolella brama and Seriolella punctata) in south-eastern Australian waters). Marine and Freshwater Research 59:502-514

Rogers AD (1994) The biology of seamounts. Advances in Marine Biology 30:305-350

Rogers AD, Morley S, Fitzcharles E, Jarvis K, Belchier M (2006) Genetic structure of Patagonian toothfish (Dissostichus eleginoides) populations on the Patagonian Shelf and Atlantic and western Indian Ocean Sectors of the Southern Ocean. Marine Biology 149:915-924

Rogers AR, Harpending H (1992) Population growth makes waves in the distribution of pairwise genetic differences. Molecular Biology and Evolution 9:552-569

Ronquist F, Huelsenbeck JP (2003) MrBayes 3: Bayesian phylogenetic inference under mixed models. Bioinformatics 19:1572-1574

Roques S, Sévigny JM, Bernatchez L (2002) Genetic structure of deep-water redfish, Sebastes mentella, populations across the North Atlantic. Marine Biology 140:297307

Rousset F (2008) GENEPOP'007: a complete reimplementation of the GENEPOP software for Windows and Linux. Molecular Ecology Resources 8:103-106

Ryman N, Palm S (2006) POWSIM: a computer program for assessing statistical power when testing for genetic differentiation. Molecular Ecology Notes 6:600-602 
Salzburger W, Ewing GB, von Haeseler A (2011) The performance of phylogenetic algorithms in estimating haplotype genealogies with migration. Molecular Ecology 20:1952-1963

Sanders HL (1968) Marine benthic diversity: a comparative study. The American Naturalist 102:243-282

Sanders HL, Hessler RR, Hampson GR (1965) An introduction to the study of deep-sea benthic faunal assemblages along the Gay Head-Bermuda transect. Deep-sea Research 12:845-867

Schunter C, Carreras-Carbonell J, Macpherson E, Tintoré J, Vidal-Vijande E, Pascual A, Guidetti P, Pascual M (2011) Matching genetics with oceanography: directional gene flow in a Mediterranean fish species. Molecular Ecology 20:5167-5181

Sedberry GR, Carlin JL, Chapman RW, Eleby B (1996) Population structure in the panoceanic wreckfish, Polyprion americanus (Teleostei: Polyprionidae), as indicated by mtDNA variation. Journal of Fish Biology 49(Supplement A):318-329

Selkoe KA, Toonen RJ (2006) Microsatellites for ecologists: a practical guide to using and evaluating microsatellite markers. Ecology Letters 9:615-629

Slatkin M (1994) Linkage disequilibrium in growing and stable populations. Genetics 137: $331-336$

Slatkin M, Excoffier L (1996) Testing for linkage disequilibrium in genotypic data using the expectation-maximization algorithm. Heredity 76:377-383

Smith PJ (1986) Genetic similarity between samples of the orange roughy Hoplostethus atlanticus from the Tasman Sea, South-west Pacific Ocean and North-east Atlantic Ocean. Marine Biology 91:173-180

Smith PJ (2007) Issues, status and trends in deep-sea fishery genetic resources. FAO Fisheries Proceedings 5:81-108

Smith PJ, Benson PG (1997) Genetic diversity in orange roughy from the east of New Zealand. Fisheries Research 31:197-213

Smith PJ, McVeagh SM (2000) Allozyme and microsatellite DNA markers of toothfish population structure in the Southern Ocean. Journal of Fish Biology $57: 72-83$

Smith PJ, McVeagh SM, Ede A (1996) Genetically isolated stocks of orange roughy (Hoplostethus atlanticus) but not hoki (Macruronus novaezelandiae) in the Tasman Sea and Southwest Pacific Ocean around New Zealand. Marine Biology 125:783-793 
Smith PJ, Benson PG, McVeagh SM (1997) A comparison of three genetic methods for stock discrimination of orange roughy, Hoplostethus atlanticus: allozymes, mitochondrial DNA, and random amplified polymorphic DNA. Fishery Bulletin 95:800-811

Smith PJ, Roberts CD, Benson PG (2001) Biochemical-genetic and meristic evidence that blue and cooper moki (Teleostei: Latridae: Latridopsis) are discrete species. New Zealand Journal of Marine and Freshwater Research 35:387-395

Smith PJ, Robertson SG, Horn PL, Bull B, Anderson OF, Stanton BR, Oke CS (2002a). Multiple techniques for determining stock relationships between orange roughy, Hoplostethus atlanticus, fisheries in the eastern Tasman Sea. Fisheries Research 58:119-140

Smith PJ, McMillan PJ, Bull B, McVeagh SM, Gaffney PM, Chow S (2002b) Genetic and meristic variation in black and smooth oreos in the New Zealand Exclusive Economic Zone. New Zealand Jornal of Marine and Freshwater Research 36:737750

Smolenski AJ, Ovenden JR, White RWG (1993) Evidence of stock separation in southern hemisphere orange roughy (Hoplostethus atlanticus, Trachichthyidae) from restriction-enzyme analysis of mitochondrial DNA. Marine Biology 116:219-230

Stepien CA, Dillon AK, Patterson AK (2000) Population genetics, phylogeography, and systematic of the thornyhead rockfishes (Sebastolobus) along the deep continental slopes of the North Pacific Ocean. Canadian Journal of Fisheries and Aquatic Sciences 57:1701-1717

Stewart J (2008) Capture depth related mortality of discarded snapper (Pagrus auratus) and implications for management. Fisheries Research 90:289-295

Stuart CT, Rex MA, Etter RJ (2003) Large-scale spatial and temporal patterns of deepsea benthic species diversity. In: Tyler PA, ed. Ecosystems of the Deep Oceans, Ecosystems of the World Elsevier, Amsterdam. pp 295-311

Stockley B, Menezes G, Pinho MR, Rogers AD (2005) Genetic population structure in the black-spot sea bream (Pagellus bogaraveo Brünnich, 1768) from the NE Atlantic. Marine Biology 146:793-804

Sverdrup HU, Johnson MW, Fleming RH (1942) The Oceans: their physics, chemistry, and general biology. Prentice-Hall

Tajima F (1989) Statistical-method for testing the neutral mutation hypothesis by DNA polymorphism. Genetics 123:585-595 
Tamura K, Peterson D, Peterson N, Stecher G, Nei M, Kumar S (2011) MEGA5: Molecular Evolutionary Genetics Analysis using Maximum Likelihood, Evolutionary Distance, and Maximum Parsimony methods. Molecular Biology and Evolution 28:2731-2739

Thistle D (2003) The deep sea floor: an overview, in: Ecosystems of the World, Vol. 28, Ecosystems of the Deep Oceans, edited by: Tyler, PA, Elsevier, Amsterdam, 5-39

Thresher RE, Koslow JA, Morison AK, Smith DC (2007) Depth-mediated reversal of the effects of climate change on long-term growth rates of exploited marine fish. Proceedings of the National Academy of Sciences of the United States of America 18:7461-7465

Trip EDL, Clements KD, Raubenheimer D, Choat JH (2011) Reproductive biology of an odacine labrid, Odax pullus. Journal of Fish Biology 78:741-761

Tsuchiya M, Talley LD, McCartney MS (1992) An eastern Atlantic section from Iceland southward across the equator. Deep-Sea Research 39:1885-1917

van Oosterhout C, Hutchinson WF, Wills DPM, Shipley P (2004) MICRO-CHECKER: software for identifying and correcting genotyping errors in microsatellite data. Molecular Ecology Notes 4:535-538

van Vuuren BJ, Best PB, Roux JP, Robinson TJ (2002) Phylogeographic population structure in the Heaviside's dolphin (Cephalorhynchus heavisidii): conservation implications. Animal Conservation 5:303-307

von der Heyden S, Lipinski MR, Matthee CA (2007) Mitochondrial DNA analyses of the Cape hakes reveal an expanding, panmictic population for Merluccius capensis and population structuring for mature fish in Merluccius paradoxus. Molecular Phylogenetics and Evolution 42:517-527

Wakefield CB, Newman SJ, Molony BW (2010) Age-based demography and reproduction of hapuku, Polyprion oxygeneios, from the south coast of Western Australia: implications for management. ICES Journal of Marine Sciences 67:11641174

Ward RD, Holmes BH (2007) An analysis of nucleotide and amino acid variability in the barcode region of cytochrome $c$ oxidase I ( $\operatorname{cox} 1)$ in fishes. Molecular Ecology Notes 7:899-907

Ward RD, Woodwark M, Skibinski DOF (1994) A comparison of genetic diversity levels in marine, freshwater, and anadromous fishes. Journal of Fish Biology 44:213232 
Ward RD, Zemlak TS, Innes BH, Last PR, Hebert PDN (2005) DNA barcoding Australia's fish species. Philosophical Transactions of the Royal Society B 360:1847-1857

Ward RD, Hanner R, Hebert PDN (2009) The campaign to DNA barcode all fishes, FISH-BOL. Journal of Fish Biology 74:329-356

Warrant EJ and Locket NA (2004) Vision in the deep-sea. Biological Reviews 79:671712

Watson R, Morato T (2004) Exploitation patterns in seamount fisheries: a preliminary analysis. In Seamounts: Biodiversity and Fisheries (ed) T. Morato and D. Pauly Fisheries Centre Research Report: 61-65

Webb T, Bartlein PJ (1992) Global changes during the last 3 million years: Climatic controls and biotic responses. Annual Review of Ecology and Systematics 23:141173

White TA, Stefanni S, Stamford J, Hoelzel AR (2009a) Unexpected panmixia in a longlived, deep-sea fish with well-defined spawning habitat and relatively low fecundity. Molecular Ecology 18:2563-2573

White TA, Stamford J, Hoelzel AR (2009b) Nine new microsatellite loci for the orange roughy (Hoplostethus atlanticus). Conservation Genetics 10:601-603

White TA, Stamford J, Hoelzel AR (2010) Local selection and population structure in a deep-sea fish, the roundnose grenadier (Coryphaenoides rupestris). Molecular Ecology 19:216-226

White TA, Fotherby HA, Stephens PA, Hoelzel AR (2011) Genetic panmixia and demographic dependence across the North Atlantic in the deep-sea fish, blue hake (Antimora rostrata). Heredity 106:690-699

Wu G C-C, Chiang H-C, Chou Y-W, Wong Z-R, Hsu C-C, Chen C-Y, Yang H-Y (2010) Phylogeography of yellowfin tuna (Thunnus albacares) in the Western Pacific and Western Indian Oceans inferred from mitochondrial DNA. Fisheries Research 105:248-253

Xiao Y, Gao T, Zhang Y, Yanagimoto T (2010) Demographic history and population structure of blackfin flounder (Glyptocephalus stelleri) in Japan revealed by mitochondrial control region sequences. Biochemical Genetics 48:402-417

Yanagimoto T, Kitamura T, Kobayashi T (2008) Population structure of the pelagic armorhead Pseudopentaceros wheeleri, inferred from PCR-RFLP analysis of the mtDNA variation. Nippon Suisan Gakk 74:412-420 
Yokoyama S (1999) Molecular bases of color vision in vertebrates. Genes and Genetic Systems 74:189-199

Yokoyama S (2000) Molecular evolution of vertebrate visual pigments. Progress in Retinal and Eye Research 19:385-419

Yokoyama S (2008) Evolution of dim-light and color vision pigments. Annual Review of Genomics and Human Genetics 9:259-282

Yokoyama S, Takenaka N (2004) The molecular basis of adaptive evolution of squirrelfish rhodopsins. Molecular Biology and Evolution 21:2071-2078

Yokoyama S, Zhang H, Radlwimmer FB, Blow NS (1999) Adaptive evolution of color vision of the Comoran coelacanth (Latimeria chalumnae). Proceedings of the National Academy of Sciences of the United States of America 96:6279-6284

Zhang J (2011) Species identification of marine fishes in China with DNA barcoding. Evidence-Based Complementary and Alternative Medicine. doi:10.1155/2011/ 978253

Zhang J, Hanner R (2011) DNA barcoding is a useful tool for the identification of marine fishes from Japan. Biochemical Systematics and Ecology 39:31-42

Zeldis JR, Grimes PJ, Ingerson JKV (1995) Ascent rates, vertical distribution, and a thermal history model of development of orange roughy, Hoplostethus atlanticus, eggs in the water column. Fishery Bulletin 93:373-385

Zeldis JR, Francis RICC, Clark MR, Ingerson JKV, Grimes PJ, Vignaux M (1997) An estimate of orange roughy, Hoplostethus atlanticus, biomass using the daily fecundity reduction method. Fishery Bulletin 95:576-597

Zeldis JR, Grimes PJ, Hart AC (1998) Embryology and early larval development of orange roughy (Hoplostethus atlanticus Collet). New Zealand Journal of Marine and Freshwater Research 32:159-174 


\section{Appendix A}

COI haplotype frequencies in each sampling site. GenBank Accession Numbers are indicated for each haplotype

\begin{tabular}{|c|c|c|c|c|c|c|c|c|c|c|c|c|c|}
\hline $\begin{array}{c}\text { Accession } \\
\text { number }\end{array}$ & ORH1 & Rit & Chat & Puy & Cha & LHR & Lou & NTas & Alb & Nam & JF & Por & Sed \\
\hline JN580075 & 0 & 0 & 0 & 0 & 0 & 1 & 0 & 0 & 2 & 0 & 0 & 0 & 0 \\
\hline JN580076 & 9 & 8 & 10 & 12 & 7 & 8 & 7 & 8 & 8 & 12 & 16 & 7 & 0 \\
\hline JN580077 & 7 & 7 & 4 & 10 & 5 & 4 & 6 & 8 & 9 & 10 & 13 & 18 & 12 \\
\hline JN580078 & 1 & 2 & 7 & 4 & 1 & 5 & 5 & 0 & 7 & 5 & 3 & 2 & 12 \\
\hline JN580079 & 0 & 0 & 0 & 0 & 0 & 0 & 0 & 0 & 1 & 3 & 0 & 0 & 0 \\
\hline JN580080 & 0 & 1 & 0 & 0 & 1 & 0 & 0 & 0 & 1 & 0 & 0 & 1 & 2 \\
\hline JN580081 & 0 & 0 & 1 & 0 & 0 & 0 & 0 & 0 & 2 & 0 & 0 & 0 & 0 \\
\hline JN580082 & 2 & 0 & 0 & 0 & 1 & 0 & 1 & 0 & 1 & 1 & 1 & 0 & 0 \\
\hline JN580083 & 0 & 0 & 0 & 0 & 0 & 0 & 0 & 0 & 1 & 0 & 0 & 0 & 0 \\
\hline JN580084 & 1 & 0 & 3 & 0 & 2 & 1 & 0 & 0 & 1 & 0 & 0 & 2 & 0 \\
\hline JN580085 & 0 & 0 & 0 & 0 & 0 & 0 & 0 & 0 & 1 & 0 & 0 & 0 & 0 \\
\hline JN580086 & 0 & 1 & 2 & 0 & 1 & 2 & 4 & 0 & 1 & 2 & 0 & 0 & 0 \\
\hline JN580087 & 0 & 0 & 1 & 0 & 1 & 1 & 0 & 0 & 1 & 0 & 0 & 0 & 0 \\
\hline JN580088 & 0 & 0 & 0 & 0 & 0 & 0 & 0 & 0 & 1 & 0 & 0 & 0 & 0 \\
\hline JN580089 & 2 & 2 & 2 & 4 & 0 & 2 & 1 & 2 & 1 & 1 & 0 & 0 & 0 \\
\hline JN580090 & 0 & 1 & 0 & 0 & 0 & 0 & 0 & 0 & 1 & 0 & 0 & 0 & 0 \\
\hline JN580091 & 0 & 0 & 0 & 0 & 0 & 0 & 0 & 0 & 1 & 0 & 3 & 0 & 0 \\
\hline JN580092 & 0 & 0 & 0 & 0 & 0 & 0 & 0 & 0 & 1 & 0 & 2 & 0 & 0 \\
\hline JN580093 & 2 & 1 & 1 & 1 & 1 & 0 & 0 & 0 & 1 & 0 & 0 & 1 & 1 \\
\hline JN580094 & 0 & 0 & 0 & 1 & 0 & 2 & 0 & 0 & 1 & 0 & 0 & 0 & 0 \\
\hline JN580095 & 0 & 0 & 0 & 0 & 0 & 0 & 1 & 0 & 1 & 0 & 0 & 0 & 0 \\
\hline JN580096 & 0 & 0 & 1 & 0 & 0 & 1 & 0 & 0 & 1 & 0 & 0 & 0 & 0 \\
\hline JN580097 & 1 & 0 & 0 & 1 & 0 & 1 & 0 & 0 & 1 & 0 & 0 & 0 & 0 \\
\hline JN580098 & 1 & 0 & 0 & 0 & 0 & 0 & 0 & 0 & 0 & 0 & 0 & 0 & 0 \\
\hline JN580099 & 1 & 0 & 0 & 0 & 0 & 0 & 0 & 0 & 0 & 0 & 0 & 0 & 0 \\
\hline JN580100 & 0 & 0 & 1 & 0 & 0 & 0 & 0 & 0 & 0 & 0 & 0 & 0 & 0 \\
\hline JN580101 & 0 & 1 & 1 & 1 & 1 & 1 & 0 & 0 & 0 & 0 & 0 & 0 & 0 \\
\hline JN580102 & 0 & 0 & 1 & 0 & 0 & 0 & 0 & 0 & 0 & 0 & 0 & 0 & 0 \\
\hline JN580103 & 0 & 0 & 1 & 0 & 0 & 0 & 0 & 0 & 0 & 0 & 0 & 0 & 0 \\
\hline JN580104 & 0 & 0 & 1 & 0 & 0 & 0 & 0 & 0 & 0 & 0 & 0 & 0 & 0 \\
\hline JN580105 & 1 & 0 & 1 & 0 & 0 & 1 & 0 & 1 & 0 & 0 & 0 & 0 & 0 \\
\hline JN580106 & 0 & 0 & 1 & 0 & 0 & 0 & 0 & 0 & 0 & 1 & 0 & 0 & 0 \\
\hline JN580107 & 0 & 0 & 1 & 0 & 0 & 0 & 0 & 0 & 0 & 0 & 0 & 0 & 0 \\
\hline JN580108 & 0 & 0 & 1 & 0 & 0 & 0 & 0 & 0 & 0 & 0 & 0 & 0 & 0 \\
\hline JN580109 & 0 & 0 & 1 & 0 & 0 & 0 & 0 & 0 & 0 & 0 & 0 & 0 & 0 \\
\hline JN580110 & 0 & 1 & 1 & 2 & 0 & 1 & 0 & 0 & 0 & 0 & 0 & 0 & 0 \\
\hline JN580111 & 0 & 0 & 1 & 0 & 0 & 0 & 0 & 0 & 0 & 0 & 0 & 0 & 0 \\
\hline JN580112 & 0 & 0 & 1 & 0 & 0 & 0 & 0 & 0 & 0 & 0 & 0 & 0 & 0 \\
\hline JN580113 & 0 & 0 & 1 & 0 & 0 & 1 & 0 & 0 & 0 & 0 & 0 & 0 & 0 \\
\hline JN580114 & 0 & 0 & 0 & 0 & 1 & 0 & 0 & 0 & 0 & 0 & 0 & 0 & 0 \\
\hline
\end{tabular}


Appendix A continued

\begin{tabular}{|c|c|c|c|c|c|c|c|c|c|c|c|c|c|}
\hline $\begin{array}{l}\text { Accession } \\
\text { number }\end{array}$ & ORH1 & Rit & Chat & Puy & Cha & LHR & Lou & NTas & Alb & Nam & $\mathrm{JF}$ & Por & Sed \\
\hline JN580115 & 0 & 1 & 0 & 1 & 1 & 0 & 0 & 0 & 0 & 2 & 0 & 0 & 0 \\
\hline JN580116 & 0 & 0 & 0 & 0 & 1 & 0 & 0 & 0 & 0 & 0 & 0 & 0 & 0 \\
\hline JN580117 & 0 & 0 & 0 & 0 & 1 & 0 & 0 & 0 & 0 & 0 & 0 & 0 & 0 \\
\hline JN580118 & 0 & 0 & 0 & 0 & 1 & 0 & 0 & 0 & 0 & 0 & 0 & 0 & 0 \\
\hline JN580119 & 1 & 2 & 0 & 0 & 1 & 1 & 1 & 0 & 0 & 0 & 0 & 7 & 2 \\
\hline JN580120 & 0 & 0 & 0 & 0 & 1 & 0 & 0 & 0 & 0 & 0 & 0 & 0 & 0 \\
\hline JN580121 & 0 & 0 & 0 & 0 & 1 & 0 & 0 & 0 & 0 & 0 & 0 & 0 & 0 \\
\hline JN580122 & 0 & 0 & 0 & 0 & 1 & 0 & 0 & 0 & 0 & 0 & 0 & 0 & 0 \\
\hline JN580123 & 0 & 0 & 0 & 0 & 0 & 0 & 0 & 0 & 0 & 1 & 2 & 0 & 0 \\
\hline JN580124 & 0 & 0 & 0 & 0 & 0 & 0 & 0 & 0 & 0 & 0 & 1 & 0 & 0 \\
\hline JN580125 & 0 & 2 & 0 & 0 & 0 & 1 & 0 & 0 & 0 & 0 & 1 & 0 & 0 \\
\hline JN580126 & 0 & 0 & 0 & 0 & 0 & 0 & 1 & 0 & 0 & 0 & 3 & 0 & 0 \\
\hline JN580127 & 0 & 0 & 0 & 0 & 0 & 0 & 0 & 1 & 0 & 0 & 3 & 0 & 0 \\
\hline JN580128 & 0 & 0 & 0 & 0 & 0 & 0 & 0 & 0 & 0 & 0 & 1 & 0 & 0 \\
\hline JN580129 & 0 & 0 & 0 & 0 & 0 & 0 & 0 & 0 & 0 & 0 & 2 & 0 & 0 \\
\hline JN580130 & 0 & 0 & 0 & 0 & 0 & 0 & 1 & 0 & 0 & 0 & 1 & 0 & 0 \\
\hline JN580131 & 2 & 1 & 0 & 0 & 0 & 0 & 0 & 1 & 0 & 0 & 0 & 0 & 0 \\
\hline JN580132 & 1 & 0 & 0 & 0 & 0 & 0 & 0 & 0 & 0 & 0 & 0 & 0 & 0 \\
\hline JN580133 & 1 & 0 & 0 & 0 & 0 & 0 & 0 & 0 & 0 & 0 & 0 & 0 & 0 \\
\hline JN580134 & 1 & 0 & 0 & 0 & 0 & 0 & 0 & 0 & 0 & 0 & 0 & 0 & 0 \\
\hline JN580135 & 1 & 0 & 0 & 0 & 0 & 0 & 0 & 0 & 0 & 0 & 0 & 0 & 0 \\
\hline JN580136 & 0 & 0 & 0 & 0 & 0 & 0 & 0 & 0 & 0 & 0 & 0 & 2 & 2 \\
\hline JN580137 & 0 & 0 & 0 & 0 & 0 & 0 & 0 & 0 & 0 & 0 & 0 & 2 & 2 \\
\hline JN580138 & 0 & 0 & 0 & 0 & 0 & 0 & 0 & 0 & 0 & 0 & 0 & 6 & 2 \\
\hline JN580139 & 0 & 0 & 0 & 0 & 0 & 0 & 0 & 0 & 0 & 0 & 0 & 2 & 3 \\
\hline JN580140 & 1 & 0 & 0 & 0 & 0 & 0 & 1 & 1 & 0 & 0 & 0 & 0 & 0 \\
\hline JN580141 & 1 & 0 & 0 & 0 & 0 & 0 & 0 & 0 & 0 & 0 & 0 & 0 & 0 \\
\hline JN580142 & 0 & 0 & 0 & 0 & 0 & 1 & 0 & 0 & 0 & 0 & 0 & 0 & 0 \\
\hline JN580143 & 1 & 0 & 0 & 1 & 0 & 1 & 1 & 0 & 0 & 0 & 0 & 0 & 0 \\
\hline JN580144 & 0 & 0 & 0 & 0 & 0 & 1 & 0 & 0 & 0 & 0 & 0 & 0 & 0 \\
\hline JN580145 & 0 & 0 & 0 & 0 & 0 & 1 & 0 & 0 & 0 & 0 & 0 & 0 & 0 \\
\hline JN580146 & 0 & 0 & 0 & 0 & 0 & 1 & 0 & 0 & 0 & 0 & 0 & 0 & 0 \\
\hline JN580147 & 0 & 0 & 0 & 0 & 0 & 0 & 1 & 0 & 0 & 0 & 0 & 0 & 0 \\
\hline JN580148 & 0 & 0 & 0 & 0 & 0 & 0 & 1 & 0 & 0 & 0 & 0 & 0 & 0 \\
\hline JN580149 & 0 & 0 & 0 & 0 & 0 & 0 & 1 & 0 & 0 & 0 & 0 & 0 & 0 \\
\hline JN580150 & 0 & 0 & 0 & 0 & 0 & 0 & 1 & 0 & 0 & 0 & 0 & 0 & 0 \\
\hline JN580151 & 0 & 0 & 0 & 0 & 0 & 0 & 1 & 0 & 0 & 0 & 0 & 0 & 0 \\
\hline JN580152 & 0 & 0 & 0 & 0 & 0 & 0 & 1 & 0 & 0 & 0 & 0 & 0 & 0 \\
\hline JN580153 & 0 & 0 & 0 & 0 & 0 & 0 & 1 & 0 & 0 & 0 & 0 & 0 & 0 \\
\hline JN580154 & 0 & 2 & 0 & 1 & 0 & 0 & 1 & 0 & 0 & 0 & 0 & 0 & 0 \\
\hline
\end{tabular}


Appendix A continued

\begin{tabular}{|c|c|c|c|c|c|c|c|c|c|c|c|c|c|}
\hline $\begin{array}{c}\text { Accession } \\
\text { number }\end{array}$ & ORH1 & Rit & Chat & Puy & Cha & LHR & Lou & NTas & $\mathrm{Alb}$ & Nam & $\mathrm{JF}$ & Por & Sed \\
\hline JN580155 & 0 & 0 & 0 & 0 & 0 & 0 & 1 & 0 & 0 & 0 & 0 & 0 & 0 \\
\hline JN580156 & 1 & 0 & 0 & 0 & 0 & 0 & 1 & 0 & 0 & 1 & 0 & 0 & 0 \\
\hline JN580157 & 0 & 0 & 0 & 0 & 0 & 0 & 0 & 0 & 0 & 0 & 0 & 0 & 1 \\
\hline JN580158 & 0 & 0 & 0 & 0 & 0 & 0 & 0 & 0 & 0 & 1 & 0 & 0 & 0 \\
\hline JN580159 & 0 & 0 & 0 & 0 & 0 & 0 & 0 & 0 & 0 & 2 & 0 & 0 & 0 \\
\hline JN580160 & 0 & 0 & 0 & 0 & 0 & 0 & 0 & 0 & 0 & 1 & 0 & 0 & 0 \\
\hline JN580161 & 0 & 0 & 0 & 0 & 0 & 0 & 0 & 0 & 0 & 1 & 0 & 0 & 0 \\
\hline JN580162 & 0 & 0 & 0 & 0 & 0 & 0 & 0 & 0 & 0 & 1 & 0 & 0 & 0 \\
\hline JN580163 & 0 & 0 & 0 & 0 & 0 & 0 & 0 & 1 & 0 & 0 & 0 & 0 & 0 \\
\hline JN580164 & 0 & 0 & 0 & 0 & 0 & 0 & 0 & 1 & 0 & 0 & 0 & 0 & 0 \\
\hline JN580165 & 0 & 0 & 0 & 0 & 0 & 0 & 0 & 1 & 0 & 0 & 0 & 0 & 0 \\
\hline JN580166 & 1 & 0 & 0 & 0 & 0 & 0 & 0 & 0 & 0 & 0 & 0 & 0 & 0 \\
\hline JN580167 & 0 & 0 & 0 & 0 & 0 & 0 & 0 & 0 & 0 & 0 & 0 & 1 & 0 \\
\hline JN580168 & 0 & 0 & 0 & 1 & 0 & 0 & 0 & 0 & 0 & 0 & 0 & 0 & 0 \\
\hline JN580169 & 0 & 0 & 0 & 1 & 0 & 0 & 0 & 0 & 0 & 0 & 0 & 0 & 0 \\
\hline JN580170 & 0 & 0 & 0 & 1 & 0 & 0 & 0 & 0 & 0 & 0 & 0 & 0 & 0 \\
\hline JN580171 & 0 & 0 & 0 & 1 & 0 & 0 & 0 & 0 & 0 & 0 & 0 & 0 & 0 \\
\hline JN580172 & 0 & 0 & 0 & 1 & 0 & 0 & 0 & 0 & 0 & 0 & 0 & 0 & 0 \\
\hline JN580173 & 0 & 0 & 0 & 1 & 0 & 0 & 0 & 0 & 0 & 0 & 0 & 0 & 0 \\
\hline JN580174 & 0 & 0 & 0 & 1 & 0 & 0 & 0 & 0 & 0 & 0 & 0 & 0 & 0 \\
\hline JN580175 & 0 & 0 & 0 & 1 & 0 & 0 & 0 & 0 & 0 & 0 & 0 & 0 & 0 \\
\hline JN580176 & 0 & 0 & 0 & 1 & 0 & 0 & 0 & 0 & 0 & 0 & 0 & 0 & 0 \\
\hline JN580177 & 0 & 1 & 0 & 0 & 0 & 0 & 0 & 0 & 0 & 0 & 0 & 0 & 0 \\
\hline JN580178 & 0 & 1 & 0 & 0 & 0 & 0 & 0 & 0 & 0 & 0 & 0 & 0 & 0 \\
\hline JN580179 & 0 & 1 & 0 & 0 & 0 & 0 & 0 & 0 & 0 & 0 & 0 & 0 & 0 \\
\hline JN580180 & 0 & 1 & 0 & 0 & 0 & 0 & 0 & 0 & 0 & 0 & 0 & 0 & 0 \\
\hline JN580181 & 0 & 1 & 0 & 0 & 0 & 0 & 0 & 0 & 0 & 0 & 0 & 0 & 0 \\
\hline JN580182 & 0 & 1 & 0 & 0 & 0 & 0 & 0 & 0 & 0 & 0 & 0 & 0 & 0 \\
\hline JN580183 & 0 & 1 & 0 & 0 & 0 & 0 & 0 & 0 & 0 & 0 & 0 & 0 & 0 \\
\hline JN580184 & 1 & 0 & 0 & 0 & 0 & 0 & 0 & 0 & 0 & 0 & 0 & 0 & 0 \\
\hline JN580185 & 0 & 0 & 0 & 0 & 0 & 0 & 0 & 0 & 0 & 0 & 0 & 0 & 1 \\
\hline JN580186 & 0 & 0 & 0 & 0 & 0 & 0 & 0 & 0 & 0 & 0 & 0 & 0 & 1 \\
\hline JN580187 & 0 & 0 & 0 & 0 & 0 & 0 & 0 & 0 & 0 & 0 & 0 & 0 & 1 \\
\hline JN580188 & 0 & 0 & 0 & 0 & 0 & 1 & 0 & 0 & 0 & 0 & 0 & 0 & 0 \\
\hline
\end{tabular}




\section{Appendix B}

Cyt $b$ haplotype frequencies in each area. GenBank Accession Numbers are indicated for each haplotype

\begin{tabular}{|c|c|c|c|c|c|}
\hline $\begin{array}{c}\text { Accession } \\
\text { number }\end{array}$ & New Zealand & Australia & Namibia & Chile & NE Atlantic \\
\hline JN580189 & 0 & 2 & 0 & 0 & 0 \\
\hline JN580190 & 0 & 1 & 0 & 0 & 0 \\
\hline JN580191 & 1 & 3 & 5 & 2 & 8 \\
\hline JN580192 & 0 & 2 & 0 & 2 & 0 \\
\hline JN580193 & 8 & 2 & 5 & 4 & 2 \\
\hline JN580194 & 0 & 1 & 1 & 1 & 0 \\
\hline JN580195 & 0 & 1 & 0 & 0 & 0 \\
\hline JN580196 & 0 & 1 & 0 & 0 & 0 \\
\hline JN580197 & 1 & 0 & 0 & 0 & 0 \\
\hline JN580198 & 3 & 0 & 1 & 1 & 0 \\
\hline JN580199 & 1 & 0 & 0 & 0 & 0 \\
\hline JN580200 & 0 & 0 & 0 & 1 & 0 \\
\hline JN580201 & 0 & 0 & 0 & 3 & 0 \\
\hline JN580202 & 0 & 0 & 0 & 1 & 0 \\
\hline JN580203 & 0 & 0 & 0 & 1 & 0 \\
\hline JN580204 & 0 & 1 & 0 & 1 & 0 \\
\hline JN580205 & 0 & 0 & 0 & 1 & 0 \\
\hline JN580206 & 0 & 0 & 1 & 1 & 0 \\
\hline JN580207 & 0 & 0 & 0 & 0 & 2 \\
\hline JN580208 & 1 & 0 & 0 & 0 & 3 \\
\hline JN580209 & 0 & 0 & 0 & 0 & 1 \\
\hline JN580210 & 1 & 0 & 0 & 0 & 0 \\
\hline JN580211 & 0 & 0 & 2 & 0 & 0 \\
\hline JN580212 & 0 & 0 & 1 & 0 & 0 \\
\hline JN580213 & 0 & 0 & 1 & 0 & 0 \\
\hline JN580214 & 0 & 0 & 1 & 0 & 0 \\
\hline JN580215 & 0 & 1 & 0 & 0 & 0 \\
\hline JN580216 & 0 & 1 & 0 & 0 & 0 \\
\hline JN580217 & 0 & 1 & 0 & 0 & 0 \\
\hline JN580218 & 0 & 1 & 0 & 0 & 0 \\
\hline JN580219 & 0 & 1 & 0 & 0 & 0 \\
\hline JN580220 & 0 & 0 & 0 & 0 & 2 \\
\hline JN580221 & 1 & 0 & 0 & 0 & 0 \\
\hline JN580222 & 0 & 0 & 0 & 0 & 1 \\
\hline JN580223 & 0 & 0 & 0 & 0 & 1 \\
\hline JN580224 & 1 & 0 & 0 & 0 & 0 \\
\hline JN580225 & 1 & 0 & 0 & 0 & 0 \\
\hline
\end{tabular}




\section{Appendix C}

Genotypes of each individual in GENEPOP format for the spatial analyses. Sampling sites codes as in Table 3.1 .

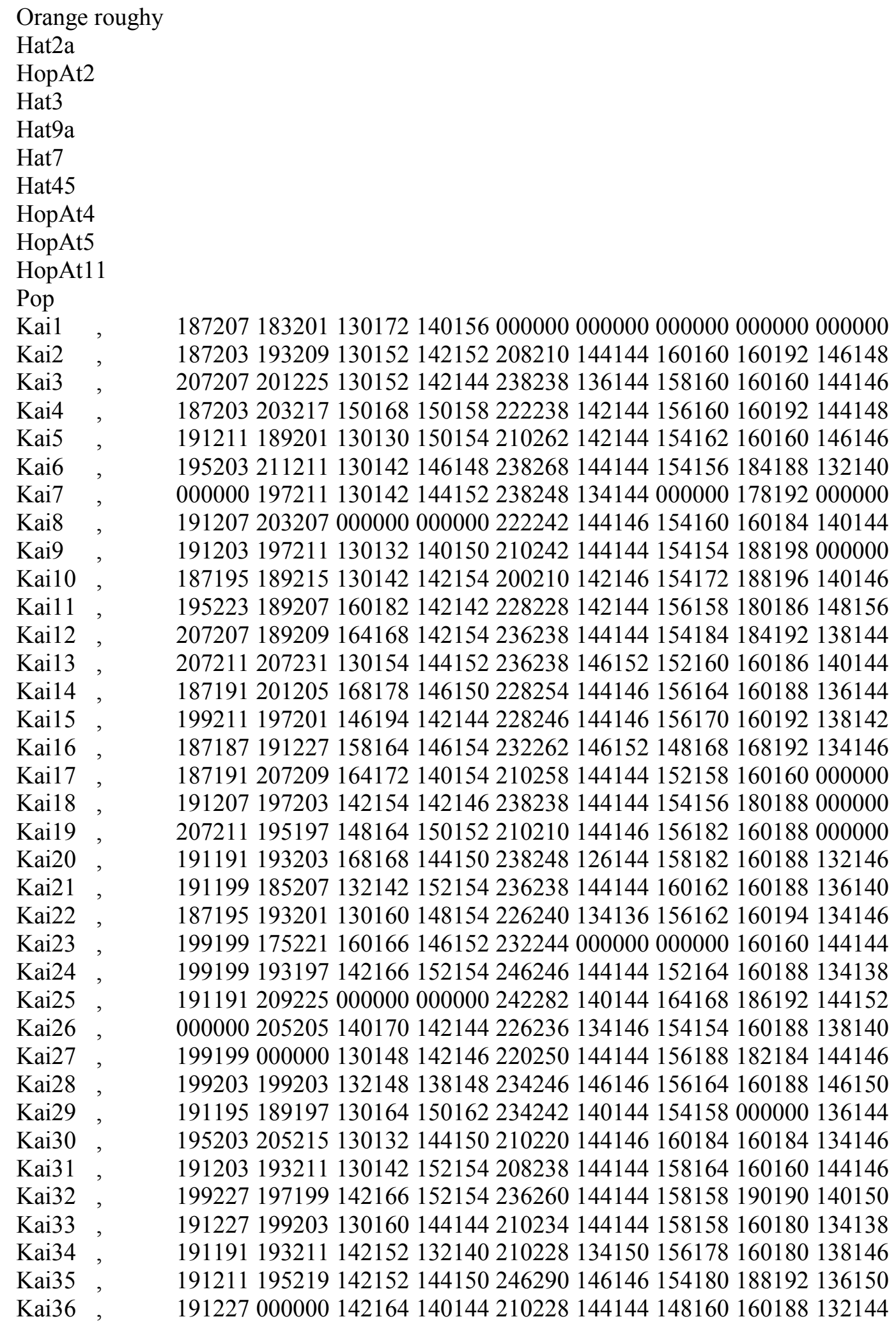




\begin{tabular}{|c|c|c|}
\hline \multirow{2}{*}{\multicolumn{3}{|c|}{195199195197130148142154240262144146148156160188128146}} \\
\hline & & \\
\hline Tau1 & & 191207177193164180144152210210144146156160160188146160 \\
\hline Tau2 & & 187187189193132182152152210274000000152152160160134160 \\
\hline Tau3 & & 187187185201148162148152212260000000158160188192140152 \\
\hline Tau4 & & 187199181211164172144150210226142144154158190196142142 \\
\hline Tau5 & & 199207201211130130142152224256144144154156180192140144 \\
\hline Tau6 & & 199207000000158166144148212224144144154158160192146146 \\
\hline Tau7 & & 199207199199130168140142210238144144156164160180138144 \\
\hline Tau8 & & 195207189189130166144148226238144146156160180180146146 \\
\hline Tau9 & & 187203205205130156126150000000144146160160160196000000 \\
\hline Tau10 & & 187191193197156160144154210234144144152180160192000000 \\
\hline Tau11 & & 187191201213130160146158236268144144154158160180144144 \\
\hline Tau12 & & 187219201201138164142152218236134146156160184198140140 \\
\hline Tau13 & & 195195187205142176142152208274144146154160160192146146 \\
\hline Tau14 & & 187207193195130130142148236244000000000000000000140146 \\
\hline Tau15 & & 195227191239130146142148234236142144154162180184134148 \\
\hline Tau16 & & 187203199211174188144158228234144150158158188190000000 \\
\hline Tau17 & & 187219181201130142144148210236142144162182160192000000 \\
\hline Tau18 & & 191191183209130140134142000000144144164172192198144144 \\
\hline Tau19 & & 191199189213140148142154236236134140156160160190134142 \\
\hline Tau20 & & 187195201213130154144148228228144144148162160160150150 \\
\hline Tau21 & & 187187211223164168150154228244140152158160160160142150 \\
\hline Tau22 & & 207207199205130130154154210242144146162188160160134150 \\
\hline Tau23 & & 187195195199158182140152230246134144154156160188144152 \\
\hline Tau24 & & 000000193199130172134158234238144144156164184188000000 \\
\hline \multicolumn{3}{|r|}{ 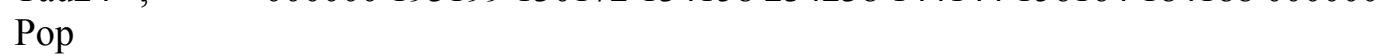 } \\
\hline Exp1 & & \\
\hline Exp2 & & 1992111 \\
\hline Exp3 & & 1871911992111 \\
\hline Exp4 & & 19519 \\
\hline Exp5 & & 0120313013014215224825415215815415416016012814 ( \\
\hline Exp6 & & 191199175187142148140150234258144144158160160160140140 \\
\hline Exp7 & & 191207195195130154154154226250144154148154160188000000 \\
\hline Exp8 & & 187191187205130176146156000000142146154162160188144146 \\
\hline Exp9 & & 191227203215130174142146236254144144158158160192136146 \\
\hline Exp10 & & 187191189201164170148148234248134144154158160188140154 \\
\hline Exp11 & & 191211187197130160148156222266144154152158180188128144 \\
\hline Exp12 & & 18719118520316016214214423424014414400000016018414615 \\
\hline Exp13 & & 00000020121115816813214823823814414415415816019014615 \\
\hline Exp14 & & 18719119720316216414014221022614414414816018819213814 \\
\hline Exp15 & & 19920319720114215800000022024013413415815816018414014 \\
\hline Exp16 & & 18718718521114214213215023424014414600000000000014414 \\
\hline Exp17 & & 20721100000016817614015425026214414400000019219213814 \\
\hline Exp18 & & 18718719920513817413614222825214415214815616019814414 \\
\hline Exp19 & & 18720700000000000015015400000013414215615816019213814 \\
\hline Exp20 & & 199207000000148174146156000000140144156156196196138170 \\
\hline Exp21 & & 18719119519913414215617022223014615214615618819215415 \\
\hline Exp22 & & 19519519520513014213814221223814414400000016017813014 \\
\hline Exp23 & & 18720718920913016814615624024014414615618416016014815 \\
\hline Exp24 & & 19120320520715817614215023423414414415616016016015215 \\
\hline \multicolumn{3}{|r|}{ ( } \\
\hline Ton1 & & \\
\hline Ton2 & & 18719918921513016014015222623414214400000016016013614 \\
\hline Ton3 & & 20722319520513814814414421022613414015415616019214415 \\
\hline
\end{tabular}




\begin{tabular}{|c|c|c|}
\hline Ton4 & & \\
\hline Ton5 & & 87195197205144148150156218230134140154158160188146148 \\
\hline Ton6 & & 1219195195148158144154212214144146160164160192144146 \\
\hline Ton7 & & 87191195213148166146148222234144146164184000000140148 \\
\hline Ton8 & & 00000017720714216414215222625014414614815417818013214 \\
\hline Ton9 & & 19121120320913814814214422426013414414815418620013814 \\
\hline Ton10 & & 18721119319500000000000000000014414600000000000015216 \\
\hline Ton11 & & 00000019319713014415015421422814415214815216018814414 \\
\hline Ton12 & & 18720718321113815213814823023815215215215618419214414 \\
\hline Ton13 & & 19119119921713017214814822623814615215216016018814614 \\
\hline Ton14 & & 203207199207130130146150228232144146000000176192138 \\
\hline Ton15 & & 187191183193148164142148000000134144154154182192136 \\
\hline Ton16 & & 207223187203130172142144210212144156000000160192146 \\
\hline Ton17 & & 199199000000000000000000210226144150170182180188140 \\
\hline Ton18 & & 18720700000013016813614822622814414615416016019214 \\
\hline Ton19 & & 187223193199130158142150228230144146158158160180140 \\
\hline Ton20 & & 199207195207130168138142234242144144156160160160144 \\
\hline Ton21 & & 191199199211162172144152000000134150154154188192140 \\
\hline Ton22 & & 187191185215130152142152228246144144158158160188144 \\
\hline Ton23 & & 191199197205130142136146234234134146154154160160144 \\
\hline Ton24 & & 19119917920113016814815023624214414415416416019213814 \\
\hline \multicolumn{3}{|r|}{ 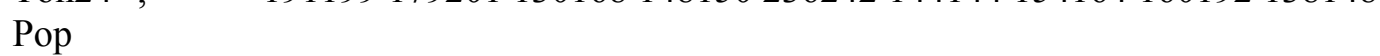 } \\
\hline Yas1 & & 313014214014423624613814616618216016014014 \\
\hline Yas2 & & 187187195197152152142150222246144146156 \\
\hline Yas3 & & 187203175213130170142148200200142144154190160198144 \\
\hline Yas4 & & 19119900000013016813815224627614415014815219219214014 \\
\hline Yas5 & & 199207191201142168144150218228144144158158160160000000 \\
\hline Yas6 & & 18718700000013014814815824225214214415215618018813214 \\
\hline Yas7 & & 19519919920113016214415022823813414415618816019214414 \\
\hline Yas8 & & 20513017014414823623614014415216016018012814 \\
\hline Yas9 & & 19119919 \\
\hline Yas10 & & 0000002 \\
\hline Yas11 & & 1872111 \\
\hline Yas12 & & 1871991 \\
\hline Yas13 & & 1992071 \\
\hline Yas14 & & 0000016416813614822423014414416016016016012814 \\
\hline Yas15 & & 1720314616814214221023414414415217016018814414 \\
\hline Yas16 & & 721515820015215623223614414615616016018813213 \\
\hline Yas17 & & 19514219014615220821014415215215218019613613 \\
\hline Yas18 & & 720913016614014222422414414615615618419214014 \\
\hline Yas19 & & 19120720922913015814815821021014415015617018018014014 \\
\hline Yas20 & & 18721119519516018015415821023614014416016218819213014 \\
\hline Yas21 & & 19119118720113019014415421223414415215815816019214414 \\
\hline Yas22 & & 19120718720514818614214223823814414415216416018813414 \\
\hline Yas23 & & 18719100000014816814415021024214614615616016018612815 \\
\hline Yas24 & & 18721119119515217213415022623614614615816416018413814 \\
\hline \multicolumn{3}{|r|}{ ( } \\
\hline Bir1 & & \\
\hline Bir2 & & 19119519320314216815015223426414414415016218819214614 \\
\hline Bir3 & & 19120319323115817214214422423414414615218019219815015 \\
\hline Bir4 & & 20721119320713015012814223624413414615415416019213414 \\
\hline Bir5 & & 20723118721316218415015221023414415214816016016014014 \\
\hline Bir6 & & 18719519122313018014215223023814414415616016018814015 \\
\hline Bir7 & & 19921120522913013015415622624613414214815616018014414 \\
\hline Bir8 & & 19519518319514816615015023626014414415416416016014414 \\
\hline
\end{tabular}




\begin{tabular}{|c|c|c|}
\hline Bir9 & & 191191203203130190144152210252134142156182192194138144 \\
\hline Bir10 & & 191195189197130156144148222234144154156156160160146146 \\
\hline Bir11 & & 199227193199158160140142228244144144154160160188146148 \\
\hline Bir12 & & 207207177193158162142154236242144146152186180188144144 \\
\hline Bir13 & , & 187199197201142166146148208224146164156168160160000000 \\
\hline Bir14 & , & 187207195201160196142152254266144144164186160190000000 \\
\hline Bir15 & , & 187199187193130142150154000000134144158192160198000000 \\
\hline Bir16 & , & 191195195209132162138140210224146152158158160194140146 \\
\hline Bir17 & , & 191199191205148158144154238286144146158158160180142162 \\
\hline Bir18 & , & 187187195205130168142150214242144144154154160192000000 \\
\hline Bir19 & & 000000205223148152142152232232144146182182184192136140 \\
\hline Bir20 & , & 187199187195162172138156230234144144156166188192000000 \\
\hline Bir21 & , & 203211189213130148146150236242144144160164188190000000 \\
\hline Bir22 & , & 199207000000130172152156234238144146000000160192000000 \\
\hline Bir23 & , & 000000181197142170128162222250142146160160160160000000 \\
\hline Bir24 & & 199203197213148152142152222230146146148160160176134142 \\
\hline Bir25 & , & 195199191205162164142154230240146146152168160186000000 \\
\hline Bir26 & , & 207211191199152158146150230238144144000000186200144146 \\
\hline Bir27 & , & 187191195197130142146146256258144152158176160182144144 \\
\hline Bir28 & & 191199215231130130140148226230144144148152180188140144 \\
\hline Bir29 & , & 187191187205000000000000000000000000156164184188134152 \\
\hline Bir30 & & 191207197203142172140156000000146154184194160182128140 \\
\hline Bir31 & & 207215189195130142146160000000144144154158160184000000 \\
\hline Bir32 & & 199207199205130142152152232236144146154160160192134146 \\
\hline Bir33 & & 199203000000130142142152218230144152152158160188140144 \\
\hline Bir34 & & 191211199203154166150158236236144144152158172180128140 \\
\hline Bir35 & & 187187207207148158136142228228144144000000160192000000 \\
\hline Bir36 & & 191195197199148168142148220242142144156164190194134140 \\
\hline \multicolumn{3}{|r|}{ 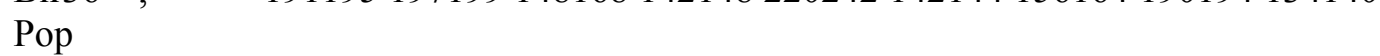 } \\
\hline Bou1 & & 187199193209130154152154234270144150158172160180140140 \\
\hline Bou2 & & 187187205215158160142160230264144144172176160180128146 \\
\hline Bou3 & & 199199207213130188148152236240140150160176160190138146 \\
\hline Bou4 & & 207207197201160168142156230238144146154188000000138144 \\
\hline Bou5 & & 187191177195158164144148210234144144156182160184144158 \\
\hline Bou6 & & 187191195203158164150152236240144146156156160188144148 \\
\hline Bou7 & & 199203205211158164140144236238144144154184160160130136 \\
\hline Bou8 & & 199203193197130130142146216244134146154162160160140144 \\
\hline Bou9 & & 191207185185130140146150210226144146158170160184130140 \\
\hline Bou10 & & 199211199201140168000000210230146158152156160188144146 \\
\hline Bou11 & & 191195191197000000000000230244146146154158184190138140 \\
\hline Bou12 & & 191207187209130158152156232234144144154184160194140144 \\
\hline Bou13 & & 203219203205152158148156238262142152156160160160138154 \\
\hline Bou14 & & 191195203215130134128148212236142144156160160160140146 \\
\hline Bou15 & & 203207193217130186144150234234134146156158192198138146 \\
\hline Bou16 & & 191195199205168186140142244244144144158158160188132134 \\
\hline Bou17 & & 000000213215130166142148226254152152148154190196144144 \\
\hline Bou18 & & 191191203211130168144152212236132144148158180192144144 \\
\hline Bou19 & & 187195193201142142148154212226146158154156184186134152 \\
\hline Bou 20 & & 207207185187158168144152236238144144160160184188140166 \\
\hline Bou21 & & 203207199209138172142148226238144146156160160192134164 \\
\hline Bou22 & & 195195195203130164138144000000142146154156160190138140 \\
\hline \multicolumn{3}{|r|}{ - } \\
\hline Mill & & 203223197199000000000000000000144152152160196198138156 \\
\hline Mil2 & & 187195000000164168150152228240144150148158160188138144 \\
\hline Mil3 & & 191203197207162172148154228234142144152192160188136148 \\
\hline
\end{tabular}




\begin{tabular}{|c|c|c|}
\hline Mil4 & & 191191187187160172152154236254144144156170160160146146 \\
\hline Mil5 & & 199203193205142158140154222232138144156156160182136150 \\
\hline Mil6 & & 1191191203130182150154226248144152154156160188138138 \\
\hline Mil7 & & 99219189215162162142144246288144146158158192196140146 \\
\hline Mil8 & & 187191197215142142138154238242142144156162188192146166 \\
\hline Mil9 & & 191199217223130130144152210228144144158158188192132140 \\
\hline Mil10 & & 191203199201130142152152210222144158158186160192138146 \\
\hline Mil11 & & 191199000000158162136142234238144144156158190192148154 \\
\hline Mil12 & & 187191187197148148148152228228144146174180160192134140 \\
\hline Mil13 & & 203207215225132162142154254260144144152160180188140150 \\
\hline Mil14 & & 187207199207130172144158206228144152160160186192140146 \\
\hline Mil15 & & 187199193197138198150156210228134136154160172188138146 \\
\hline Mil16 & & 187195187199142148132154234246134144154156190192140146 \\
\hline Mil17 & & 187199189201130130148160234234144144152158160184128144 \\
\hline Mil18 & & 195199211217154172144154234234144144154168160192140140 \\
\hline Mil19 & & 199211193193130166142148242248144146156156160192144164 \\
\hline Mil20 & & 207211187201130136136150228244144146156162160188140140 \\
\hline Mil21 & & 191199181205130166144150208210144144156166160160146148 \\
\hline Mil22 & & 191211189225130148144150236238144144154170190196136138 \\
\hline Mil23 & & 203207191199130168142158238244144152158160160184150160 \\
\hline Mil24 & & 191191193203130180142142228236140 \\
\hline Mil25 & & 187199193195186194148168222234146152154154186192134150 \\
\hline Mil26 & & 187195203211142168140150238244136142160188160190144148 \\
\hline Mil27 & & 191199199209146176142146218228144144154158186196128138 \\
\hline Mil28 & & 187191183205130142136158226256144144154158192192138146 \\
\hline Mil29 & & 187219187199158176142150246248144152160192190192140146 \\
\hline Mil30 & & 191195197205170174140142216238134146148184160160134138 \\
\hline Mil31 & & 191191203207000000156156236288142144158158178180140144 \\
\hline Mil32 & & 5197201152160142142222246144144154172160178144146 \\
\hline Mil33 & & 191195000000130130148152236 \\
\hline Mil34 & & 187207207223000000000000212 \\
\hline Mil35 & & 1992072 \\
\hline Mil36 & & 19921519921113015815216822423614215015415618419014616 \\
\hline & & \\
\hline Nuk1 & & 4414 \\
\hline Nuk2 & & 19520 \\
\hline Nuk3 & & $2072071911951301521421<$ \\
\hline Nuk4 & & 4414414415615616016014815 \\
\hline Nuk5 & & 015816416019214414 \\
\hline Nuk6 & & 5214615216016014615 \\
\hline Nuk7 & & 7614415415215216016012815 \\
\hline Nuk8 & & 422823414214415615618419214014 \\
\hline Nuk9 & & 19920719920916616814615823625014414418619416018614014 \\
\hline Nuk10 & & 19920719319300000014415021023214414614814816018814414 \\
\hline Nuk11 & & 18719500000013016214615222223014615015815816016014414 \\
\hline Nuk12 & & 19519518719314818014815022024014615615815816019613814 \\
\hline Nuk13 & & 19120718919517618015015621022614414414815818019613414 \\
\hline Nuk14 & & 18722319921513819214214421023014214215415816019814014 \\
\hline Nuk15 & & 19119919520714216614215222828614414416016016018813415 \\
\hline Nuk16 & & 19120718918914615414215022823414414615415616019213613 \\
\hline Nuk17 & & 19120700000014617614214421025414414416016216016014414 \\
\hline Nuk18 & & 18719121121513014214815222625813414616019416019613815 \\
\hline Nuk19 & & 20721119722513016414614821822813415415415616018013814 \\
\hline Nuk20 & & 19922720120516817615215222824414414413415416019214014 \\
\hline Nuk21 & & 19119120521113014815215223826213414215816216019612612 \\
\hline
\end{tabular}




\begin{tabular}{|c|c|c|}
\hline Nuk22 & & 187207195203130188146148232248144144148148160160148154 \\
\hline Pop & & \\
\hline Coll & & 187191193203130186140158000000126144152156000000146156 \\
\hline $\mathrm{Col} 2$ & & 187207179193130130154160238246144150164166180196138146 \\
\hline Col3 & & 187199195195130148152156228234144144160186192198146146 \\
\hline Col4 & & 187199197207142168150150220262144146154156160188134140 \\
\hline Col5 & , & 187207197197130168142152212232144144000000192196144146 \\
\hline Col6 & & 187211203229130160146152224244144152148164160192134140 \\
\hline Col7 & , & 191199207207130176146158232234146146150172160192138138 \\
\hline Col8 & , & 187199201215162182144150238260144144156160160192140152 \\
\hline Col9 & , & 187187181205164164140144000000144146156162160160144154 \\
\hline Col10 & & 191199211211146190142146212236134144160164160176000000 \\
\hline Col11 & , & 203223193215130180144152210238000000000000000000000000 \\
\hline Col12 & , & 187207203203130142148154228232000000158160188194000000 \\
\hline Col13 & , & 191199000000160164140148232234140140144152000000140146 \\
\hline Col14 & & 187191193195140148132154000000000000154162160196146166 \\
\hline Col15 & & 187199193197142158144152000000144146154156160190000000 \\
\hline Col16 & & 187191000000130150148152230238142144176190188198148154 \\
\hline Col17 & , & 191191207207130130144144226252146152154160160160000000 \\
\hline Col18 & & 191199195205142160146150234246142144156156180192000000 \\
\hline Col19 & & 000000195201130154150154210250144146154172190192000000 \\
\hline Col20 & & 187199195223132148142146000000144144154156180190000000 \\
\hline Col21 & , & 187191185199138182144150240242142152156170160184000000 \\
\hline Col22 & & 191191197199152152142156214218144144154184180196146152 \\
\hline Col23 & & 187195189203130186142148236244144158156188160188000000 \\
\hline Col24 & & 187187195199130160144144220234134146000000160188000000 \\
\hline Pop & & \\
\hline Mer1 & & 191195197199130144142154216218140144154160176186134140 \\
\hline Mer2 & , & 191199207229130142144146222240146150000000160194132144 \\
\hline Mer3 & , & 187203193209180186144144000000144144156168188200138144 \\
\hline Mer4 & , & 191207181195160176140146238252144152148160160182146146 \\
\hline Mer5 & , & 203211201205130168144154212226134146156164160182134146 \\
\hline Mer6 & & 191199209209130160148156210240142146158158190196144146 \\
\hline Mer7 & & 199203193201150164144148210226146146160166180200140152 \\
\hline Mer8 & & 187203203213130142156166238248144152154158160182134154 \\
\hline Mer9 & & 191207195205130164140146224236132144156162160192134140 \\
\hline Mer10 & & 199203193193158172142152000000144144158168160198138146 \\
\hline Mer11 & & 199207203205130154144150234258144144156158180192128146 \\
\hline Mer12 & & 199211183187130176132142214236144144000000160160134140 \\
\hline Mer13 & & 000000177193000000142144232232136144152160160190144164 \\
\hline Mer14 & & 191191183195130158150156236262144144152154160188134150 \\
\hline Mer15 & & 187191197207146160142144226242144144000000160160134144 \\
\hline Mer16 & & 187191185199146170138146222244142144160182160180144154 \\
\hline Mer17 & & 000000193197130152144146226238146152156158180196138144 \\
\hline Mer18 & & 199199203223130146162168232236132144154194160192144154 \\
\hline Mer19 & & 199203197205130166148150240240144144148186190192140146 \\
\hline Mer20 & & 195207191197130188142152210222146150154156160160144150 \\
\hline Mer21 & & 187191207217130176150152236252154158156188188192134144 \\
\hline Mer22 & & 199207197211130172152156210228144146154186180192144150 \\
\hline Mer23 & & 187199195207170176152152000000144144156158160180140146 \\
\hline Mer24 & & 191191187205166176142144242248144144000000192192146146 \\
\hline Pop & & \\
\hline Cla1 & & 191195189193174198142142226234144154156158160160134140 \\
\hline Cla2 & & 191207175207130164140148226226144150158158160192144156 \\
\hline Cla3 & & 191191191209162184142142238238144154160180184198140144 \\
\hline
\end{tabular}




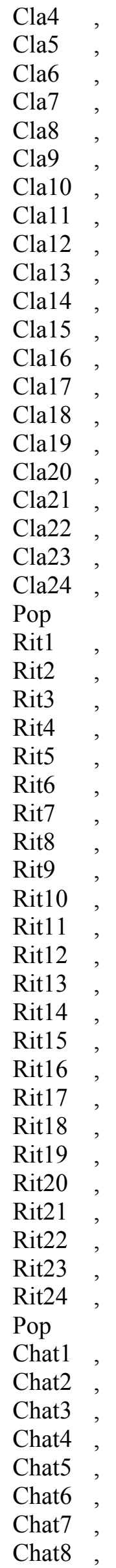

195199203211170176142144218240144144158158180192140144 207211197205130142000000228234146152154156160188144150 195199000000148172144148238258144144148156160184144166 211211181201142160128140230250134146148158188192138148 203211195195160180144154224260142146156180186190136138 187207207207138148142144232268144146152168160192128144 199203207213130164144144216238136146156160160184144170 000000205207168176142148226226134158172188180184132150 187195199211160176152158226268142144158162160192138140 199215191199130164140144236238144146154156000000140148 187191187207130152142148218218144146156168180188138146 191211189211130130140144212228142142160172160192138146 195207201207130158146150208234146146154164160194138146 207211213215174176134148210210144146154160188190140156 191191201209150154142146234288144144162172000000144150 187191187203130170138154214228142158156156160192144144 207211189217148158142158248260142144148154160188144146 191207199199130166140140236248144144154154160194146146 199203195207178188140142248274146146000000000000144146 191191187203148164144156218234146146148156160192134144 199207195207130162142146210236152154152152000000146146

187187177205142154150152232238144146154160194196140146 191191197213130176128150262266144158156164188192132140 187191203207130130128146240244134144152168192198140144 191207191207160172140142222232146152154160188194134144 195207187187130164140154238242144144154162160194134164 191199197203148166142150226232158158158160160194144146 191199195211168174142144208210144144168190196196138140 187195199205130142142148238238144144154160160180140146 199207209223160190148152234240144150164172160192146154 187191197205132164140168222234142146154156180180140146 187203185195130176140144222282144156148176160160144144 187187175195000000144150234240146146152188160180132144 187187187197174174152158232238142144154156160192146146 187199193197142174142154244250144146154154160178144154 195203211211130140150156228234144146162184160200000000 187203199211000000000000000000144144152158188192144144 207207203213130164148148220240144150154158176180140144 191219197199142154148152000000144144154160192200140148 187199197213130176138152246258142142156162160180140144 195223179197130130138142000000144144158190160188144150 187195197217148164142152210222144144000000160188128170 207207195215130176140142236248134142156160000000138148 203207203209152164148160222232144158000000160180144146 187191189195130148144148228240144146154162160192144146

187207207233160174142144236240144146154160160188140150 187199197197148168138142234234134150162172160192134136 187187000000164176150156208208144152000000160180144146 187187205211130146148154214248144158156158160188140140 195207189189130162152158230244144144148154160160136146 187211199211130166144148252272140144154160188196136148 000000189199148158140166232246144144154188160196140150 187207185191000000000000000000144158156166160160136146 
Chat9, Chat10, Chat11, Chat12, Chat13, Chat14, Chat15, Chat16, Chat17, Chat18, Chat19, Chat20, Chat21, Chat22, Chat23, Chat24, Pop

Puyl , Puy2, Puy3 , Puy4, Puy5 , Puy6 , Puy7 , Puy8 , Puy9, Puy10, Puy11, Puy12, Puy13, Puy14, Puy15, Puy16, Puy17, Puy18, Puy19, Puy20, Puy21, Puy22, Puy23, Puy24, Puy25, Puy26, Puy27, Puy28, Puy29, Puy30, Puy31, Puy32, Puy33, Puy34, Puy35, Puy36 , Pop

Chal ,
187187193209168176142148000000144146166166160184138146 191207207223158160142154210216134142152162160160134148 195195201219130148152168238250142154000000180196138146 187203185213000000152152210236144146154160184192132146 000000197201164168142158208222144146160190160188146148 191191201205142158134140226246144144156164160192136138 207211175189142142000000210238144144156194160186136148 195195187201142176142150210266144146152168180192136146 187219193207130148150154232248144144148160160160146146 187207189205130142154154226236152152156160184194140144 187191191203130160142144210246144144154156160184136140 187199205211130152144148216246142144154154180188138140 207207189203142186140148236270144144154156182192144156 187191205211140142152168238248144144000000160192144150 207211201203166174140152210228144152154160180188134140 191203187205142146144148000000144144148152160184138146

191207197199130162152152212242144144152162160182134154 187207203209130132142142240260142146154186160160140156 000000000000000000000000000000144144156166160198000000 187187193209130148146152246272142144156156192196132134 191219189197142166142146210234144146148152160186146152 191203205215156162146152234246146146156166160160144144 191199203213148178146152222222144144162188160196144148 191199199199138142148152214240144152156168184186134146 191207163163130162144150238242136148154168160192140170 199207191211130156148150210240144154154154160180144156 187191195203000000142152240240144144148162160160138148 191203199215130148142148238252142144154160160188140146 199203205211162162140144242246144144154172160160138170 187191201207156174154154208228142142156168160188146148 195195187201158176138152216242144146154160180188144146 191191193197130176150154212238144146162186160188144144 187199203229130182152168236256134146154156160160138140 195215191205130168144146222234144144156160160192138148 191207205207164164144152244250144144156172160200128128 191199203205130166144144222264144158154156160192138158 191191209217174188140152218236144154160170160180138140 191203185203130172144146244260144144154162160200132132 195203195229000000000000000000144146152182160184140144 199199203203160172140152220238140146156158160180138144 195207185213130148142152210246144144156156188188136170 000000000000130148142146210240144152156160160188144150 187187195209130142000000240256000000000000000000140148 199199191229160172150152216230144144158158178190140150 187191177207148168142152216238134144152164160160140144 187211203211130130152158210236134152154188160190144146 195207189193142174140152230242144144156158160188144146 199211197217142174146146232252144146158164160160134150 199199179193000000000000000000142144156174160194136140 191207193209130138000000212236144144158192160182128146 191211203211130174142152232236144144154158160188134140 199207201203130146142150226234144146146186160200138146 191199195227164168138156200250146146148156160188132136 


\begin{tabular}{|c|c|c|}
\hline Cha2 & & 187207203203158164144148234254144146 \\
\hline Cha3 & & 91195203203130148144154210240146146160178160192140144 \\
\hline Cha4 & & 1207197197130142136142210246134144148166160188146150 \\
\hline Cha5 & & 99207189197140168144154210226144146154160160198134138 \\
\hline Cha6 & & 91211193201130130142152256268144144154158160180134146 \\
\hline Cha7 & & 207215197197130166154168244268134146152160160186132134 \\
\hline Cha8 & & 18719919920913014214214223223814214600000016018013814 \\
\hline Cha9 & & 207207191209130130142162210210134146158164180194144 \\
\hline Cha10 & & 20720718721114817214214421023212614415416816018414014 \\
\hline Cha11 & & 19919920521316416815016022624414414614815416018214014 \\
\hline Cha12 & & 18719520721113014812613822825214615015416018418414 \\
\hline Cha13 & & 191199165223148164148152230236144154154160160188136 \\
\hline Cha14 & & 187199191211154166000000210238144146158160160194138 \\
\hline Cha15 & & 191211197215130140146152222234144144186188190200128 \\
\hline Cha16 & & 187203193211130130142144236246144144152192186188140 \\
\hline Cha17 & & 187223189205148190144158248256144146154158160198140 \\
\hline Cha18 & & 191191177191168188146146216242144144160168174188140 \\
\hline Cha19 & & 191195193215154160142144240250146146176194188192140 \\
\hline Cha20 & & 187191181223130152144150234238144144154162174188136 \\
\hline Cha21 & & 18720720521500000000000000000014414615416418819213814 \\
\hline Cha22 & & 187199207219130168148148212218144150154156160180144 \\
\hline Cha23 & & 19119919119513017014015422823613414415619019219614014 \\
\hline Cha24 & & 187199193209164168144150234236144146156160160 \\
\hline Cha25 & & 19920720720713016814815223023200000000000000000014615 \\
\hline \multicolumn{3}{|r|}{ 年 } \\
\hline Ntas1 & & 0000013017014814821 \\
\hline Ntas2 & & 1991991952071 \\
\hline Ntas3 & & 19920718 \\
\hline Ntas4 & & 119513016614215422623814214600000016018213414 \\
\hline Ntas5 & & 1911911 \\
\hline Ntas6 & & 1911992 \\
\hline Ntas7 & & 1911991 \\
\hline Ntas8 & & 2032071 \\
\hline Ntas9 & & 1872072 \\
\hline Ntas 10 & & 0000001 \\
\hline & & 199207000000148166000000214 \\
\hline Ntas 12 & & 90000001421581501522342 \\
\hline Ntas 13 & & 19919900000016817014014222623413414615415818019014414 \\
\hline Ntas14 & & 18720721121116417014415023424013614615415416016014614 \\
\hline Ntas 15 & & 120113014214415022223613415815416216016014815 \\
\hline Ntas 16 & & 1520116017014815600000000000015215616018813614 \\
\hline Ntas 17 & & 19520719920114217400000021024014614815415816018614414 \\
\hline Ntas 18 & & 18719920120715816815215422623613814616416418819215015 \\
\hline Ntas 19 & & 18718719920913016014414821024213413615615816018814414 \\
\hline Ntas 20 & & 19920719520313013015615623623613414415616016016014415 \\
\hline Ntas21 & & 18719521321717618214015023625214415416016018419213415 \\
\hline Ntas22 & & 20720719720114815015415423425813414415415818019214017 \\
\hline \multicolumn{3}{|r|}{ ( } \\
\hline Alb1 & & 18719117319513017614215621023214414615216216016014014 \\
\hline Alb2 & & 18719521521513016413814021025214415015616818819014015 \\
\hline Alb3 & & 18719118519914217215215623624214214215616216018813614 \\
\hline Alb4 & & 18720719520714214614414421024614414414816018019213613 \\
\hline Alb5 & & 18718719720315819014414821024214415015215816018414014 \\
\hline Alb6 & & 18720718719913016214215223023814215015415816019214014 \\
\hline Alb7 & ' & 19519918720513016014416022223614414415616016019014014 \\
\hline
\end{tabular}


Alb8 ,

Alb9

Alb10 ,

Alb11,

Alb12,

Alb13,

Alb14,

Alb15,

Alb16,

Alb17,

Alb18,

Alb19,

Alb20,

Alb21,

Alb22,

Alb23,

Alb24,

Alb25,

Pop

Nam1 ,

Nam2 ,

Nam3,

Nam4,

Nam5 ,

Nam6 ,

Nam7 ,

Nam8,

Nam9,

Nam10,

Nam11,

Nam12,

Nam13 ,

Nam14,

Nam15,

Nam16,

Nam17,

Nam18,

Nam19,

Nam20 ,

Nam21,

Nam22,

Nam23,

Nam24,

Nam25,

Nam26 ,

Nam27,

Nam28,

Nam29,

Nam30,

Nam31,

Nam32,

Nam33,

Nam34,

Nam35,

Nam36 ,
187211191199154164150156222246144146154160160160128134 195199195219130174138148230238144144152154160186146154 000000175221130130144148218238144150164184194196144150 191207199205130148152168206210144144152158160160138152 195207193195142182144150238242142142152156160188138140 195203199201130162148152224238138144156158192194144144 199207211213148172128148222222144144154156184186130140 187191193193130134132148210234144146168170184188144146 187191185197146162152168210246142152154160160180140160 191207191199136160142148226236144144164164160160138152 187211189209130168150152234234144144162186160198150156 187191197211170176144148210234144146154158180190134140 191191187195148170140142236290144146156160160186140140 191211211215168172144148212236142144154168160160136144 187199000000182190152154210282140140158158000000146150 187203201211130176142148228228144144148194160192152154 187211203203162176140156210226134146154158160180144146 187207199229158176148154232240132144148168160192144146

191199199207142148142148222238144144160160160192138146 191203197209000000142152240258144146158192160186140144 191191179215142146142146000000144144158192188192144174 187199175185152152152152212240144144154154174190134140 187199187199148150148150226234144144156160160184132150 187191207213140150142150234238144144154192180192136144 187187000000144146144146226240144144168184188196144146 187203179205000000150152212260144146148164000000138138 191203187207148152148152234260144144162162160188140150 187211197205000000144152230240144146160184160192134146 199203187195150154150154210230144150000000160192144148 187207191217144144144144210234144150152162160192134138 187191189207000000138152240246144144154158184192146152 191207193203142148144148210248144150158160160188150164 191199189203140152142152240248130146158158160186136146 187207207209000000152164228238144144156168160186140140 191195207213146156146156210236144152162162160160146150 203207199203144156144156232232134140154160160192140146 187187193207148150148150232242144152156158160188150170 195199195215140144142144240240142144158190160180140144 187199193213000000144150224246144146154160160180136138 191215195197150154150154000000140144156158194200136146 187191175187142150142150228238144154154158186188140148 187191187201138138140140210260144150158164160160138154 187191000000150150150150220230134146148196180184146148 191207209225138150140150210210134158156162160192138150 191199191197144144144144228238142144156162160160144150 195207181193140152142152240254146150152162160184146148 187195197213000000142152238238144146000000160160134144 191199205205150152150152240242142154168192188192136150 187191197201142142142142210240140144162188160160140144 207207193219140150142150216236144144154160160192136136 191191195209144144144144236258142144158186186196146146 199207195195148152148152234234144146152162160190140146 000000000000140156142156238244144146158164192196000000 199207197197148152148152222238146146148160160182140146 


\begin{tabular}{|c|c|c|}
\hline \multicolumn{2}{|l|}{ Nam37, } & 199215000000140150142150000000146150154166160192144154 \\
\hline \multicolumn{2}{|l|}{ Nam38, } & 187195177181140150142150218238144150154156184190130146 \\
\hline \multicolumn{2}{|l|}{ Nam39, } & 187187195197138150140150210252144144160160180188138138 \\
\hline \multicolumn{2}{|c|}{ Nam40, } & 195199187191138148140148240248144144160168160160138144 \\
\hline \multicolumn{2}{|c|}{ Nam41, } & 000000193215142150144150206210146146160166160188128146 \\
\hline \multicolumn{2}{|c|}{ Nam42, } & 199227199213000000144164228242146152158166160186146158 \\
\hline \multicolumn{2}{|c|}{ Nam43, } & 207223197201000000152152236238142158160190160194144146 \\
\hline \multicolumn{2}{|c|}{ Nam44, } & 199207195217140146140146210210144144162188160160138144 \\
\hline \multicolumn{2}{|c|}{ Nam45, } & 191207201209142148144148210240144144148160160192144144 \\
\hline \multicolumn{2}{|c|}{ Nam46, } & 191191000000142142140140212254000000154166160192146164 \\
\hline \multicolumn{2}{|c|}{ Nam47, } & 195207203203142150144150236236142158154162160186138144 \\
\hline \multicolumn{2}{|c|}{ Nam48, } & 187203195199140144142144246246140144154158160160136144 \\
\hline JF1 & & 191191189231142142142142230230134144156168174190140144 \\
\hline JF2 & & 191203203217146148146148212228142144160160188188144144 \\
\hline JF3 & & 191211197199140152142152234244144154152156160194136146 \\
\hline JF4 & & 203207197215140156140156214252140140000000160160140146 \\
\hline JF5 & & 187227197203138150140150236236140144000000160160146146 \\
\hline JF6 & & 187191189197146154146154234256140144158182160160144150 \\
\hline JF7 & & 187195183197146156146156222256148148154168180188132150 \\
\hline JF8 & & 191195177195000000000000234236136144156184180192140140 \\
\hline JF9 & & 187215177191000000140142236236144144156160160192138146 \\
\hline JF10 & , & 191195197203150158150158210244136140154156160160146150 \\
\hline JF11 & , & 187195203205140146142146218240142144168168160192140150 \\
\hline JF12 & , & 187199191211146160146160212260140144148158160192140146 \\
\hline JF13 & , & 191191191193140148140148218234142150156160160190138144 \\
\hline JF14 & , & 199199193199000000152164244256000000154154160176148152 \\
\hline JF15 & , & 191211197203152156152156210244144144160160160160136144 \\
\hline JF16 & , & 191195191203144148144148226252134144152160160190134146 \\
\hline JF17 & , & 187207201203142142142142234244146154168172160186138150 \\
\hline JF18 & , & 187187201203152158152158236236144146156162160160140146 \\
\hline JF19 & & 187187199205144156144156214238144152164166160186140144 \\
\hline JF20 & & 191195195217000000156156214234144144148186160190134146 \\
\hline JF21 & & 195195193203144152144152242252144146160162168188134140 \\
\hline JF22 & & 000000203215000000000000222230134146152160160160138138 \\
\hline JF23 & & 191207185195146156146156000000142142154156160180132132 \\
\hline $\mathrm{JF} 24$ & & 191191177211148154148154238240140154148160184192146146 \\
\hline JF25 & & 195207189201156158156158236236144152154156192192138156 \\
\hline JF26 & & 191203177191142142142142214242144146154156160192136138 \\
\hline JF27 & & 000000177191146154146154240254140144148158160160134134 \\
\hline JF28 & & 187195191203140152140152240244144144156158160160136162 \\
\hline JF29 & & 187195181203146158146158238246140146154154160192138140 \\
\hline JF30 & & 187191000000144148144148000000144152158160160160134162 \\
\hline JF31 & & 191191177199000000140152228228144146160188172192132158 \\
\hline $\mathrm{JF} 32$ & & 207211195197146148146148232236144146162190160184134140 \\
\hline JF33 & & 187211205215146146146156000000142154162170160160146148 \\
\hline JF34 & & 187207183191148152148152246252142146160160160160128156 \\
\hline JF35 & & 195199195209152154152154240240144144156160160188138140 \\
\hline JF36 & & 195203189197000000146150214252136152154158180190136138 \\
\hline JF37 & & 187203199203140144142144236238114146154164160184146146 \\
\hline JF38 & & 211227195197000000160162222230144146000000160160134146 \\
\hline JF39 & & 191203199225142144142144210222136150148156160160138148 \\
\hline JF40 & & 191203183203144152144152240240140142154156160192138138 \\
\hline JF41 & & 191211203205148152148152242252144152156164160192138148 \\
\hline JF42 & & 191227201205132144132144210222144144154156160192134152 \\
\hline
\end{tabular}




\begin{tabular}{|c|c|c|}
\hline JF43 & & \\
\hline JF44 & & 91227197203152154152154214246144150154158160180140144 \\
\hline JF45 & & 77207191203000000148162236256140150156160160196144150 \\
\hline JF46 & & 87191181213140148142148214240134140156160160188146150 \\
\hline \multicolumn{3}{|r|}{ 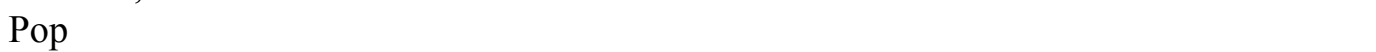 } \\
\hline Por1 & & 199199000000158172142156212248142142156164000000134146 \\
\hline Por2 & & 187187199205130176140142240246144146158158186192152154 \\
\hline Por3 & & 199207193199166176148162232250144156160160192196134140 \\
\hline Por4 & & 199207191203150166156156236236144144162162160160146146 \\
\hline Por5 & & 187187000000132176148154226246144144000000180192134146 \\
\hline Por6 & & 195211193205132172146154210238144156156182160192138144 \\
\hline Por7 & & 191215195199168184142154226246140146158182160192138144 \\
\hline Por8 & & 000000000000130176000000000000140144156160160192134144 \\
\hline Por9 & & 187187193209132166152156210240142144158158180200136144 \\
\hline Por10 & & 191195193199132148150162226226142144156160160160134144 \\
\hline Por11 & & 199199199213164176162168232236144146148156190192144152 \\
\hline Por12 & & 199211185207132150142142228230144152160182176188146150 \\
\hline Por13 & & 187207189193148184142144214238142144148158188190144146 \\
\hline Por14 & & 195207195203132184154156240252142146156156160180144144 \\
\hline Por15 & & 203203187189130176144146210226146152162164160160138146 \\
\hline Por16 & & 191195207207130172152154232236146146158160180192144152 \\
\hline Por17 & & 199207189207148176144144230240142144156162160160138146 \\
\hline Por18 & & 199199000000142172144152244244144156162162160180134146 \\
\hline Por19 & & 191203203205176184152156228246144146160160182192138146 \\
\hline Por20 & & 199207181195130166144150234242140144000000160192138146 \\
\hline Por21 & & $203211187193130130152162210244134144156162 \quad 160192144144$ \\
\hline Por22 & & 187211193197130152142152238244144146000000160160150156 \\
\hline Por23 & & 000000193193130142000000000000142144000000180192144144 \\
\hline \multicolumn{3}{|r|}{ 然 } \\
\hline Sed1 & & 815 \\
\hline Sed2 & & 313017614415800000014414415416016018013815 \\
\hline Sed3 & & 6020014416 \\
\hline Sed4 & & 187195193195132148140162210 \\
\hline Sed5 & & 187195000000130176144150210 \\
\hline Sed6 & & 5816017618013015 \\
\hline Sed7 & & 14414620825014214400000016018613414 \\
\hline Sed 8 & & 19919918320713013213214421026614414415815816019214614 \\
\hline Sed9 & & 18720721721713016815415822624414414615816416018014414 \\
\hline Sed10 & & 19919922522913014815616222224014214215615816019214414 \\
\hline Sed11 & & 9921314816814214221023014415215416016019215215 \\
\hline Sed12 & & 19120319920914816612815424026414214215415418619413813 \\
\hline Sed13 & & 19519520921514817214414623624414415015818016018813415 \\
\hline Sed14 & & 19920319920913015814415021024414415215415419219214415 \\
\hline Sed15 & & 18718718720713018414414823824014615215616200000014415 \\
\hline Sed16 & & 18719922522913014814214422624414414615616816018413614 \\
\hline Sed17 & & 18720322522916418414815624424614414616216216019213615 \\
\hline Sed 18 & & 18718718318713016214214422623614414615615816016014615 \\
\hline Sed19 & & 19919918322913215414015223823814414415815816018014616 \\
\hline Sed 20 & & 18720720322913217214414623824614414614815416018014414 \\
\hline $\operatorname{Sed} 21$ & & 19120320320514817614614822822814414614815616019614615 \\
\hline Sed 22 & & 19920319319915816614415222623614415416416416016014414 \\
\hline $\operatorname{Sed} 23$ & & 18718721321713014014615423623814414415816016019213414 \\
\hline Sed24 & & 18719918320714816614215624024414214416016016016014415 \\
\hline Sed 25 & & 19519918921715817613213223223814215615415816019213415 \\
\hline Sed26 & & 20721100000015216214415623624414414615615816019213615 \\
\hline
\end{tabular}




\section{Appendix D}

Genotypes of each individual in GENEPOP format for eight sampling sites from the ORH 1 area sampled in 2010. Sampling sites codes as in Table 3.1.

Orange roughy

Hat2a

HopAt2

Hat3

Hat9a

Hat7

Hat45

HopAt4

HopAt5

HopAt11

Pop

Kai_2.1,

187191211213130168138142226248142144152154188188136138

Kai 2.2 , 191191193195142194132158226264144146156188160186144152

Kai 2.3 ,

Kai 2.4 , 203203205209130166138144212238144152154162190194138152

Kai 2.5 , 195199197197130162142142232276142144160160160192144156

Kai_2.6, 203211179183158170148152238242144144158160160192000000

Kai_2.7,

Kai 2.8,

Kai_2.9,

Kai-2.10,

Kai_2.11,

Kai_2.12,

Kai_2.13,

Kai_2.14,

Kai 2.15,

Kai-2.16,

Kai 2.17,

Kai_2.18,

Kai_2.19,

Kai_2.20,

Kai_2.21,

Kai_2.22,

Kai-2.23,

Kai_2.24, Pop

Tau_2.1, 191195199205168180152168228236144152152152160180130146 195207191193130148142150220226144146158190160196132144 187203207215130146128152238238144146158180188196128146 191203197201158174140148210234144144152158188192150156 207207000000130180142144212236144146152154160192134146 187191193229130166142154236240144144000000160160138144 191203193209142158150150222268142146158158160180138140 191211183193130142140148244248146152152164190196140150 195199187207130130148162238248134152154160188192146146 195195195215132160150150232238144150000000160160140146 207207201211136158144152234236144144160164160192146156 191199203223130188138162210210144146158194180190146148 191207205209176176144148228236144152156160180192136160 199203189207130160134142228240144144156160160160134138 191199199205146176142146256258134146154158160160146156 191223195199130154142144238246144146158158160160154160 203211187187154164142154222254142144154158188190144150 191195193205130158146152214260146158154156160190146150 000000000000000000000000000000000000000000000000134140

Tau_2.2, 187199000000142160150152210240144146152162160188146148 Tau_2.3, Tau 2.4 , Tau 2.5 , Tau_2.6, Tau_2.7, Tau_2.8, Tau_2.9, Tau_2.10, Tau_2.11, Tau 2.12 , Tau 2.13 , 187207185203130142140152228234144144148160180194136140 191199209211130152154160238244144144158162160160128146 187207185199150176148154234246134142154158160194140144 187187189195130176152160222248144146156160160180138140 195199183197130142144148224226144144156160196196144146 203211203223170192128160240248134144158162160192144152 191203191195000000000000000000142144154160186190144144 191195195205188188144154240250144144152156000000140146 191199191205158164000000228256144146156158160188144146 191199205209130130142162236236142152158160160180144150 207207191207130186152162222226144144162164160190144144 187199189203154174152158230238144146156158192196134144 
Tau 2.14, Tau 2.15, Tau_2.16, Tau_2.17, Tau 2.18, Tau_2.19, Tau_2.20, Tau 2.21, Tau 2.22, Tau 2.23, Tau_2.24, Pop

Exp 2.1, Exp 2.2, Exp 2.3 , Exp 2.4, Exp_2.5, Exp_2.6, Exp_2.7, Exp_2.8, Exp_2.9, Exp_2.10, Exp_2.11, Exp_2.12, Exp_2.13, Exp 2.14, Exp 2.15, Exp 2.16, Exp_2.17, Exp_2.18, Exp_2.19, Exp_2.20, Exp_2.21, Exp_2.22, Exp_2.23, Exp 2.24, Pop

Ton_2.1, Ton 2.2, Ton 2.3 , Ton_2.4, Ton_2.5, Ton_2.6, Ton 2.7 , Ton_2.8, Ton 2.9 , Ton_2.10, Ton 2.11, Ton 2.12 , Ton_2.13, Ton_2.14, Ton 2.15 , Ton 2.16, Ton_2.17, Ton_2.18,
187199197203142142140146236288144146154160180190138138 191199189211130154142142234242142158148160160184136146 191195195199162162142142210244134144160168160198134136 187203177215164172150152228236142146158160160188136144 187191199207144154148152234246146152154154160160146148 187191199211130168148152238248142144000000160196144144 207211185211132170150154230230144152186188160192136144 187187177197130168142150210236144144160184160192140144 203203207213130172144152228234134144160188180192140144 199203199201130162146150226252134146156156160184136140 191207187211142144144146222226144144156162186194128144

187203185189142188140154228240144158156160160190146152 187207207213164174142156208224144158156158160160140140 187187195209130158154162210210144146154160196200134134 187207201221130130140152244248144146154162160180134144 187187000000130144148148226240144144156160188192140146 191199209211140154140154208240134146154158188192136138 191207207215150160154162240246144146154176180192128132 199199179209130174148154210238000000000000000000150164 207207000000152168144150216228140144158168160194144146 195199201217130142152154210236142152160168188192144148 187187191193130138150150240242144154160184188192136140 191199199199130158148150210248134146154162160192140146 191203189193130160142152226226144144152156160186138148 203207189197164174150150222246144144162174160160146148 191191195195142148140144210222142154154188160160128138 000000185209142168138152000000144144154158160184140144 187199193201142176142152228234144146160190160188140150 000000000000170190142152230264144144160160160160000000 191195179207142142142144252256144144156172180192144152 191191201207130144144152234236144146156186184192136148 187191181193130142142144210226144146154192184194140146 191203193203130142142142000000144144154168160160144144 000000000000000000000000000000144144162194160184000000 187199195213130166138150236242144144152158180192138144

187191203215142170142168226246142144156188160160136140 187191195209130154144158242248146154152180160160146148 191195199205142162140166214216144146156188180192138156 191199199203154172146152222244146146154158180188144146 191195199221130130140142226256144144154164184190136146 211211193211158164128154210246144146158170160186132138 187195199213130142144150226234144144158170160188134144 207211197211146176142144210238142144152154160192140144 199207213215168180140152212276134146158168160184140144 187207195195130148142150234242142144148154184188144156 187191183203130148140146208234142144158158160196140146 187187197205130158148148238248144144154174174188130140 207223193211174190148154238246134158152158160160132134 191191203207148148132156228238140146154158160188140146 187191205213168174152154240248144146154158160188138144 187187199219130130138154210210134144152158188194144144 191191189203130130146148236242144146154160160160146154 187203181185172176148154226250146152158166190192140140 
Ton 2.19, Ton 2.20 , Ton_2.21, Ton_2.22, Ton_2.23, Ton_2.24, Pop

Bir 2.1, Bir 2.2, Bir 2.3, Bir 2.4, Bir 2.5, Bir 2.6, Bir 2.7, Bir 2.8, Bir_2.9, Bir 2.10, Bir 2.11, Bir_2.12, Bir 2.13, Bir_2.14, Bir 2.15, Bir 2.16, Bir_2.17, Bir 2.18, Bir 2.19, Bir 2.20, Bir 2.21, Bir_2.22, Bir 2.23, Bir_2.24, Pop

Bou 2.1, Bou 2.2, Bou 2.3, Bou 2.4, Bou_2.5, Bou_2.6, Bou 2.7, Bou 2.8, Bou 2.9, Bou_2.10, Bou_2.11, Bou_2.12, Bou_2.13, Bou 2.14, Bou_2.15, Bou 2.16, Bou 2.17, Bou_2.18, Bou 2.19 Bou 2.20, Bou 2.21, Bou 2.22, Bou_2.23,
195207197203152176142154246268146154156158160184146146 203203209211136160148164212240146146152154160188136136 191207197205130150144146234234146152158180188194140150 187187191211148150142142244246144144152160160192144146 191195207209000000144152238238144146000000186188138156 195207195205136142144150238246144164158160160194138146

187207187193130142142144226226144146152154192194144146 187207193199130168142148210212144154158158178192144144 199219189193130132132154228254144146148154188192144144 191227199205130164142148244244144146152158160192134146 187187195195130162142148226234144144156158160180144148 195195199207130182148152236244146146148154160190146146 195195195197130168152154210226134144158158190200146146 199207189203130138150152240240142144154184160196146150 187207000000158158136146216242144144152160160200132136 187195209211130160142148242242144146158162180198144150 191195193223152158138148232240142144154160160192140146 191211197197168176148154232234144144152174188192146146 207207193203158168138148210226134144154154160192150152 187211189193130152142150224234144144154170192194138138 187187179189148176140148214240144146154158160160140144 183187183201142152152156000000146146160164180180144150 191207185203148182142148222236146154154158160196148152 191207185199130174154164218240140144154166160190140144 187191207209138138144150246250144144152154160192144144 187191193207130130148150248248144144154160160184144150 191199193197130130144146236248142142158158190192144150 187211179209152176148152230234146154158158160180128144 199203201203130148140152236238152156166190160188150150 195195179205160182138146222234144144154160168188138144

187191000000136166142150232238134144156188160192136146 187207187207130174154154210236138140152190160160140146 195195187195142148140142226254142142148160160180126152 191207207207142168140144234234134144158186160160140146 187199199207130190148154240250142144152176180192144146 191191211239130130146150216226144144156160160188144144 187187197209130158152162222232144146160172160180140174 191203181185000000000000000000144146148156188196128136 199199000000130142142150232232140144160168160160140144 187187205211130168142150238250144146156160192196140148 191199189193148180150152234240144146154160160160128144 000000000000130164150156228228144144160190160174000000 199207000000130160150152226256144144148162160188134146 191207000000158162140154230260142144160160160192144146 199199215225138158148154232244136144156160160160138140 187207201217154168146154246248144146160160188192144150 187207199209160168148162236242140144152156160160146146 191203193201146166132156226244138146160160160194132134 187215207207130154136152210246144144152182160192146146 203207181203130142148150224234144144152186190192134138 187199187191130168136162212230142146158164160160144144 187195199213160164142152236242144152158192192192130138 199203181195164168146156234244144144158158188190150156 
Bou_2.24,

Pop

Mil 2.1,

Mil_2.2,

Mil_2.3,

Mil_2.4,

Mil 2.5,

Mil 2.6,

Mil 2.7,

Mil 2.8,

Mil_2.9,

Mil_2.10,

Mil 2.11,

Mil 2.12,

Mil 2.13,

Mil_2.14,

Mil_2.15,

Mil 2.16,

Mil_2.17,

Mil 2.18,

Mil_2.19,

Mil_2.20,

Mil_2.21,

Mil_2.22,

Mil_2.23,

Mil_2.24,

Pop

Col 2.1,

Col 2.2,

Col 2.3,

Col 2.4,

Col_2.5,

Col_2.6,

Col_2.7,

Col 2.8 ,

Col 2.9,

Col_2.10,

Col 2.11,

Col 2.12,

Col 2.13,

Col_2.14,

Col_2.15,

Col_2.16,

Col_2.17,

Col 2.18,

Col 2.19,

Col_2.20,

Col 2.21,

Col_2.22,

Col_2.23,

Col_2.24,
187207179209130154140152234238144144152158160180132138

187199000000154164132144234236134136156186188192136136 191199000000130174140152222234144144162168160190136146 187207185203130160140148234240144144152154160188140144 000000000000146168156158210242144152160170160180146148 191207197207130174142144238240144150148154160188138148 187207193223130164142144218236140146156170160192140146 191211201205168168152152220230144146156162160190144144 187199195195154164132144234236134136156186188192136136 207211000000148164142142236242146150156172188200136150 187211191211168172144150210240126146154158184188136150 187207185203130160140148234240144144152154160188140144 000000000000150178148160228236132154154156192196000000 000000000000130192142156222236000000160160160160140150 000000000000130160144154210238136144154156192194128150 191191000000160178142144210264144146152154180188140144 000000197199142168142148234254142152150158160184144150 187191000000130154140148218234142146158160160160132140 191195189231130166152156212236126136152158160176144144 191207195197162164142142234246144152148160160188144170 199207000000168174138142244244140144154156160190138156 000000203205130188142142226238144144148156160160146146 191207191201000000150162218236134146156192160184144144 187199193209130160144144252252136136154170190192144166 191191165195160178142144210264144146154154180188140144

191207000000142146140152210210144146158162180192132146 191191211213130142140146234244144154152154192192128140 191195000000154174142148210238134146152158160180134144 203211189193164166142158210218144144158182160196144144 203207213215168182144144226256144150152156180180134140 191199199201130162140140232232144146158174000000140140 195199179195148158134152240248144146152158160168144144 207207189213132168142166242256144144152156160178136150 191207193205130130142168226230146150152158160188150156 191231193195000000000000000000134144154154190192140158 195199175203130154000000210228140144154158160160140146 000000187205130164144150230238144150156172160160138140 187199199209130130148164216222144144154158160196144148 187211193205142142140152222240144144156156160190140146 195207191205144174136144210236134146154158180192128136 195195189207130168146156238242146146158160160176140152 199207185189136172152152208210144144000000186192138146 191211191201130144144152222230144144148164160180144166 191199189215148160144148222238144152152154160184138156 195215187201130194142150222248144146152154160180140146 187211201203160182142146224230144144000000160160138144 191191193201142152144152218218134146156170188194144152 187207203209130168140152210216134158154158000000144144 191191191195144148152154228236144146154156160160128138 


\section{Appendix E}

Summary of genetic statistics for each locus for 22 sampling sites considering the samples from both seasons (Total $n=812$ ). Total number of alleles $(A)$, allelic richness $\left(A_{\mathrm{r}}\right)$, expected heterozygosity $\left(H_{\mathrm{E}}\right)$ and the inbreeding coefficient $\left(F_{\mathrm{IS}}\right) . P>0.002$ for all $F_{\text {IS }}$ values (Bonferroni correction $\alpha=0.00025$ ). Codes as in Table 3.1

\section{Hat2a HopAt2 Hat3}

\begin{tabular}{|c|c|c|c|c|c|c|c|c|c|c|c|c|}
\hline Sites & $A$ & $A_{\mathrm{r}}$ & $H_{\mathrm{E}}$ & $F_{\text {IS }}$ & $A$ & $A_{\mathrm{r}}$ & $H_{\mathrm{E}}$ & $F_{\mathrm{IS}}$ & $A$ & $A_{\mathrm{r}}$ & $H_{\mathrm{E}}$ & $F_{\text {IS }}$ \\
\hline Kai & 9 & 8.1 & 0.85 & 0.111 & 27 & 17.1 & 0.95 & 0.016 & 25 & 15.7 & 0.90 & -0.037 \\
\hline Tau & 9 & 7.6 & 0.83 & 0.051 & 21 & 16.8 & 0.95 & 0.034 & 27 & 17.7 & 0.90 & 0.054 \\
\hline Exp & 8 & 7.1 & 0.82 & 0.052 & 21 & 16.8 & 0.95 & 0.022 & 24 & 15.4 & 0.89 & 0.002 \\
\hline Ton & 9 & 8.0 & 0.83 & 0.032 & 23 & 16.3 & 0.94 & 0.007 & 22 & 15.7 & 0.89 & 0.006 \\
\hline Yas & 7 & 6.8 & 0.82 & -0.064 & 19 & 18.1 & 0.94 & -0.007 & 18 & 15.6 & 0.91 & -0.055 \\
\hline Bir & 12 & 8.6 & 0.86 & 0.055 & 23 & 16.2 & 0.94 & 0.011 & 24 & 14.8 & 0.89 & -0.006 \\
\hline Bou & 9 & 7.2 & 0.84 & 0.138 & 22 & 17.5 & 0.95 & 0.029 & 22 & 14.3 & 0.89 & -0.052 \\
\hline Mil & 10 & 8.2 & 0.83 & -0.068 & 22 & 16.9 & 0.95 & 0.012 & 28 & 16.5 & 0.90 & 0.051 \\
\hline Nuk & 8 & 7.6 & 0.82 & -0.053 & 17 & 16.2 & 0.94 & 0.154 & 18 & 16.9 & 0.93 & -0.077 \\
\hline Col & 10 & 7.9 & 0.83 & 0.025 & 21 & 16.2 & 0.94 & 0.084 & 26 & 16.5 & 0.89 & 0.049 \\
\hline Mer & 7 & 6.9 & 0.83 & -0.045 & 20 & 17.5 & 0.95 & 0.031 & 18 & 15.9 & 0.88 & -0.144 \\
\hline $\mathrm{Cla}$ & 8 & 7.8 & 0.86 & 0.036 & 18 & 16.5 & 0.94 & 0.072 & 22 & 18.7 & 0.93 & -0.033 \\
\hline Rit & 8 & 7.5 & 0.83 & 0.095 & 20 & 17.3 & 0.94 & 0.021 & 15 & 13.7 & 0.88 & 0.022 \\
\hline Chat & 8 & 7.6 & 0.80 & 0.154 & 18 & 16.5 & 0.94 & 0.031 & 15 & 14.1 & 0.92 & -0.041 \\
\hline Puy & 9 & 7.9 & 0.84 & 0.088 & 21 & 17.6 & 0.95 & 0.036 & 19 & 15.0 & 0.89 & -0.022 \\
\hline Cha & 9 & 8.1 & 0.83 & -0.008 & 21 & 18.2 & 0.95 & 0.164 & 15 & 13.0 & 0.85 & -0.025 \\
\hline NTas & 6 & 5.9 & 0.77 & 0.117 & 14 & 14.0 & 0.91 & 0.088 & 16 & 15.2 & 0.94 & -0.016 \\
\hline Alb & 7 & 6.9 & 0.81 & -0.128 & 21 & 18.4 & 0.95 & 0.081 & 18 & 16.2 & 0.92 & -0.045 \\
\hline Nam & 10 & 7.7 & 0.83 & -0.023 & 22 & 17.1 & 0.95 & 0.042 & 10 & 9.4 & 0.88 & 0.102 \\
\hline $\mathrm{JF}$ & 9 & 8.1 & 0.84 & 0.051 & 20 & 15.1 & 0.92 & -0.089 & 13 & 11.1 & 0.91 & 0.020 \\
\hline Por & 8 & 7.9 & 0.86 & 0.228 & 14 & 13.7 & 0.91 & 0.014 & 13 & 12.0 & 0.90 & 0.063 \\
\hline Sed & 7 & 6.9 & 0.80 & 0.237 & 16 & 14.9 & 0.94 & 0.029 & 15 & 13.0 & 0.88 & -0.142 \\
\hline Total/Ave. & 13 & 7.8 & 0.83 & 0.049 & 34 & 16.9 & 0.94 & 0.040 & 36 & 16.7 & 0.90 & -0.015 \\
\hline
\end{tabular}


Appendix E continued

Hat9a Hat7

Hat45

\begin{tabular}{llllllllllllll} 
Sites & $A$ & $A_{\mathrm{r}}$ & $H_{\mathrm{E}}$ & $F_{\mathrm{IS}}$ & $A$ & $A_{\mathrm{r}}$ & $H_{\mathrm{E}}$ & $F_{\mathrm{IS}}$ & $A$ & $A_{\mathrm{r}}$ & $H_{\mathrm{E}}$ & $F_{\mathrm{IS}}$ \\
\hline
\end{tabular}

\begin{tabular}{|c|c|c|c|c|c|c|c|c|c|c|c|c|}
\hline Kai & 16 & 11.6 & 0.90 & -0.017 & 29 & 17.9 & 0.94 & 0.061 & 10 & 6.9 & 0.66 & 0.001 \\
\hline Tau & 14 & 11.4 & 0.90 & -0.019 & 24 & 16.9 & 0.94 & 0.054 & 8 & 6.3 & 0.64 & -0.040 \\
\hline Exp & 15 & 12.1 & 0.91 & 0.041 & 28 & 18.8 & 0.95 & 0.071 & 9 & 7.4 & 0.63 & 0.092 \\
\hline Ton & 17 & 12.5 & 0.91 & -0.005 & 27 & 17.8 & 0.94 & 0.036 & 11 & 8.1 & 0.75 & -0.053 \\
\hline Yas & 13 & 12.3 & 0.91 & -0.006 & 21 & 17.9 & 0.93 & 0.200 & 9 & 8.3 & 0.66 & -0.014 \\
\hline Bir & 17 & 12.0 & 0.90 & -0.053 & 30 & 18.9 & 0.95 & 0.105 & 9 & 6.4 & 0.65 & 0.112 \\
\hline Bou & 15 & 11.9 & 0.91 & -0.073 & 24 & 16.8 & 0.94 & 0.059 & 11 & 8.3 & 0.70 & 0.075 \\
\hline Mil & 16 & 12.1 & 0.90 & 0.058 & 28 & 17.4 & 0.94 & 0.045 & 13 & 9.2 & 0.72 & 0.038 \\
\hline Nuk & 12 & 11.2 & 0.89 & -0.017 & 25 & 21.9 & 0.96 & -0.041 & 9 & 8.6 & 0.75 & 0.150 \\
\hline Col & 17 & 12.2 & 0.90 & 0.037 & 26 & 19.1 & 0.95 & 0.027 & 10 & 7.7 & 0.69 & 0.033 \\
\hline Mer & 14 & 12.6 & 0.90 & -0.014 & 20 & 18.5 & 0.95 & 0.052 & 11 & 9.6 & 0.68 & 0.147 \\
\hline Cla & 13 & 11.6 & 0.87 & 0.048 & 22 & 18.8 & 0.95 & 0.171 & 9 & 8.3 & 0.78 & 0.148 \\
\hline Rit & 14 & 12.8 & 0.91 & -0.052 & 20 & 18.2 & 0.94 & -0.010 & 8 & 7.4 & 0.69 & 0.161 \\
\hline Chat & 13 & 12.2 & 0.91 & 0.005 & 21 & 19.4 & 0.95 & 0.052 & 9 & 8.1 & 0.62 & 0.063 \\
\hline Puy & 11 & 9.6 & 0.85 & 0.018 & 25 & 19.3 & 0.96 & 0.019 & 10 & 7.6 & 0.63 & 0.092 \\
\hline Cha & 16 & 14.2 & 0.91 & 0.046 & 23 & 20.2 & 0.96 & -0.001 & 7 & 6.2 & 0.67 & 0.003 \\
\hline NTas & 8 & 7.9 & 0.89 & 0.101 & 15 & 14.4 & 0.92 & -0.033 & 10 & 9.5 & 0.81 & 0.057 \\
\hline Alb & 13 & 11.9 & 0.89 & -0.075 & 19 & 16.4 & 0.93 & 0.054 & 9 & 7.8 & 0.68 & 0.177 \\
\hline Nam & 11 & 9.2 & 0.87 & 0.064 & 24 & 16.8 & 0.93 & 0.118 & 10 & 8.1 & 0.69 & 0.047 \\
\hline $\mathrm{JF}$ & 15 & 12.1 & 0.91 & 0.002 & 20 & 15.8 & 0.94 & 0.159 & 11 & 9.5 & 0.82 & 0.024 \\
\hline Por & 11 & 10.7 & 0.90 & 0.050 & 17 & 15.9 & 0.94 & 0.094 & 7 & 6.7 & 0.75 & 0.107 \\
\hline Sed & 13 & 12.3 & 0.91 & -0.020 & 17 & 14.6 & 0.92 & 0.005 & 7 & 6.5 & 0.75 & 0.031 \\
\hline Total/Ave. & 22 & 11.9 & 0.90 & 0.005 & 41 & 18.0 & 0.94 & 0.059 & 18 & 8.1 & 0.70 & 0.066 \\
\hline
\end{tabular}


Appendix E continued

HopAt4

HopAt5

HopAt11

$\begin{array}{llllllllllllll}\text { Sites } & A & A_{\mathrm{r}} & H_{\mathrm{E}} & F_{\mathrm{IS}} & A & A_{\mathrm{r}} & H_{\mathrm{E}} & F_{\mathrm{IS}} & A & A_{\mathrm{r}} & H_{\mathrm{E}} & F_{\mathrm{IS}}\end{array}$

\begin{tabular}{|c|c|c|c|c|c|c|c|c|c|c|c|c|}
\hline Kai & 18 & 11.8 & 0.88 & 0.055 & 13 & 9.1 & 0.78 & -0.013 & 16 & 12.1 & 0.89 & -0.061 \\
\hline Tau & 15 & 10.7 & 0.87 & -0.019 & 10 & 9.0 & 0.80 & -0.030 & 12 & 10.6 & 0.86 & 0.165 \\
\hline Exp & 20 & 12.9 & 0.89 & 0.007 & 12 & 8.8 & 0.77 & 0.067 & 18 & 12.8 & 0.89 & 0.057 \\
\hline Ton & 15 & 11.2 & 0.87 & 0.006 & 14 & 9.4 & 0.78 & -0.066 & 14 & 10.5 & 0.85 & 0.023 \\
\hline Yas & 14 & 12.4 & 0.90 & 0.216 & 11 & 9.4 & 0.78 & 0.035 & 11 & 10.3 & 0.87 & 0.204 \\
\hline Bir & 21 & 12.8 & 0.89 & 0.113 & 16 & 10.6 & 0.82 & -0.078 & 14 & 10.4 & 0.85 & 0.181 \\
\hline Bou & 18 & 12.8 & 0.89 & 0.046 & 11 & 8.5 & 0.74 & 0.004 & 19 & 12.8 & 0.89 & 0.048 \\
\hline Mil & 20 & 12.1 & 0.88 & 0.054 & 15 & 9.8 & 0.82 & -0.055 & 17 & 11.4 & 0.89 & 0.066 \\
\hline Nuk & 13 & 12.1 & 0.90 & 0.297 & 8 & 7.6 & 0.66 & -0.038 & 13 & 12.3 & 0.88 & -0.028 \\
\hline Col & 20 & 12.9 & 0.89 & -0.049 & 13 & 9.8 & 0.81 & -0.011 & 15 & 12.3 & 0.89 & 0.059 \\
\hline Mer & 14 & 13.4 & 0.90 & -0.057 & 12 & 10.8 & 0.83 & -0.002 & 11 & 9.9 & 0.87 & -0.061 \\
\hline Cla & 12 & 11.4 & 0.90 & 0.129 & 9 & 8.8 & 0.82 & -0.163 & 13 & 11.6 & 0.87 & -0.009 \\
\hline Rit & 14 & 12.9 & 0.90 & -0.067 & 10 & 9.3 & 0.84 & -0.038 & 12 & 10.9 & 0.84 & -0.039 \\
\hline Chat & 14 & 12.9 & 0.89 & -0.020 & 9 & 8.2 & 0.78 & -0.064 & 10 & 9.5 & 0.88 & -0.047 \\
\hline Puy & 18 & 14.1 & 0.90 & 0.015 & 13 & 10.2 & 0.70 & -0.102 & 15 & 12.6 & 0.90 & 0.021 \\
\hline Cha & 17 & 14.9 & 0.91 & -0.106 & 13 & 11.9 & 0.86 & -0.116 & 13 & 11.5 & 0.87 & 0.033 \\
\hline NTas & 11 & 10.6 & 0.88 & 0.091 & 9 & 8.8 & 0.81 & 0.006 & 14 & 12.7 & 0.86 & -0.107 \\
\hline Alb & 13 & 11.8 & 0.91 & -0.013 & 10 & 9.4 & 0.77 & -0.033 & 14 & 12.4 & 0.88 & 0.003 \\
\hline Nam & 16 & 12.7 & 0.90 & 0.037 & 12 & 9.1 & 0.76 & -0.093 & 17 & 11.6 & 0.89 & 0.016 \\
\hline $\mathrm{JF}$ & 17 & 11.7 & 0.87 & 0.014 & 13 & 8.6 & 0.68 & 0.069 & 14 & 11.3 & 0.89 & 0.102 \\
\hline Por & 7 & 6.9 & 0.84 & 0.255 & 10 & 9.0 & 0.77 & 0.006 & 10 & 9.1 & 0.83 & 0.000 \\
\hline Sed & 10 & 9.3 & 0.85 & 0.159 & 12 & 9.9 & 0.75 & -0.125 & 11 & 10.4 & 0.88 & 0.080 \\
\hline Total/Ave. & 28 & 12.2 & 0.89 & 0.053 & 17 & 9.3 & 0.78 & -0.038 & 23 & 11.6 & 0.87 & 0.032 \\
\hline
\end{tabular}




\section{Appendix F}

Varela AI, Ritchie PA, Smith PJ (2012) Low levels of global genetic differentiation and population expansion in the deep-sea teleost Hoplostethus atlanticus revealed by mitochondrial DNA sequences. Marine Biology 159:1049-1060

Varela AI, Ritchie PA, Smith PJ (2013) Global genetic population structure in the commercially exploited deep-sea teleost orange roughy (Hoplostethus atlanticus) based on microsatellite DNA analyses. Fisheries Research 140:83-90 


\title{
Low levels of global genetic differentiation and population expansion in the deep-sea teleost Hoplostethus atlanticus revealed by mitochondrial DNA sequences
}

\author{
Andrea I. Varela $\cdot$ Peter A. Ritchie $\cdot$ Peter J. Smith
}

Received: 25 October 2011/Accepted: 12 January 2012/Published online: 1 February 2012

(C) Springer-Verlag 2012

\begin{abstract}
The orange roughy Hoplostethus atlanticus is a well-known commercial species with a global distribution. There is no consensus about levels of connectivity among populations despite a range of techniques having been applied. We used cytochrome $c$ oxidase subunit I (COI) and cytochrome $b$ sequences to study genetic connectivity at a global scale. Pairwise $\Phi_{\mathrm{ST}}$ analyses revealed a lack of significant differentiation among samples from New Zealand, Australia, Namibia, and Chile. However, low but significant differentiation $\left(\Phi_{\mathrm{ST}}=0.02-0.13, \quad P<0.05\right)$ was found between two Northeast Atlantic sites and all the other sites with COI. AMOVA and the haplotype genealogy confirmed these results. The prevalent lack of genetic differentiation is probably due to active adult dispersal under the stepping-stone model. Demographic analyses suggested the occurrence of two expansion events during the Pleistocene period.
\end{abstract}

\section{Introduction}

Deep-sea fishes (i.e. $>200 \mathrm{~m}$ ) live in the largest habitat on Earth. Many deep-sea fishes are widely distributed and have a circumglobal distribution, for example the alfonsino

Communicated by T. Reusch.

A. I. Varela $(\bowtie)$ · P. A. Ritchie

School of Biological Sciences,

Victoria University of Wellington,

P.O. Box 600, Wellington, New Zealand

e-mail: andrea.varela@vuw.ac.nz

P. J. Smith

Museum Victoria, GPO Box 666,

Melbourne, VIC 3001, Australia
Beryx decadactylus. Some bathyal fishes inhabit continental slopes, the slopes of oceanic islands, and seamounts that are separated by extensive areas of deep ocean. The dispersal of deep-sea fishes may be less constrained by their habitat than that of coastal fishes. However, while there are few obvious barriers in the deep sea, migration of individuals could be limited by ocean currents and bathymetric features, as reported for the demersal fish Brosme brosme (Knutsen et al. 2009). There are several examples of genetic differentiation among deep-sea fish populations at different geographical scales, including the spikey oreo Neocyttus rhomboidalis (Elliott et al. 1998), the bluemouth Helicolenus dactylopterus (Aboim et al. 2005), the Patagonian toothfish Dissostichus eleginoides (Smith and McVeagh 2000; Rogers et al. 2006), and the Cape hake Merluccius paradoxus (von der Heyden et al. 2007). However, there are also species that exhibit panmixia at regional, oceanic, and inter-oceanic scales such as the armorhead Pseudopentaceros wheeleri, the wreckfish Polyprion americanus, the alfonsino Beryx splendens, and the oreos Allocytus niger and Pseudocyttus maculatus (Martin et al. 1992; Sedberry et al. 1996; Hoarau and Borsa 2000; Smith et al. 2002a).

The orange roughy, $H$. atlanticus, has a cosmopolitan distribution (Paulin 1979). It occurs at depths of $450-1,800 \mathrm{~m}$ and is locally abundant off the coasts of New Zealand, Australia, Namibia, and in the Northeast Atlantic Ocean (Horn et al. 1998; Branch 2001) and off Chile (Labbé and Arana 2001). Orange roughy aggregate near prominent topographic features such as seamounts, plateaus, and canyons, especially during spawning and feeding periods (Clark et al. 2000). It is thought that adults migrate hundreds of kilometers to spawn, as mature fish are widespread, but spawning occurs in just a few specific areas (Francis and Clark 1998). Orange roughy fisheries 


\title{
Global genetic population structure in the commercially exploited deep-sea teleost orange roughy (Hoplostethus atlanticus) based on microsatellite DNA analyses
}

\author{
Andrea I. Varela ${ }^{\mathrm{a}, *, 1}$, Peter A. Ritchie ${ }^{\mathrm{a}}$, Peter J. Smith ${ }^{\mathrm{b}}$ \\ a School of Biological Sciences, Victoria University of Wellington, Wellington 6140, New Zealand \\ ${ }^{\mathrm{b}}$ Museum Victoria, Melbourne, Victoria 3001, Australia
}

\section{A R T I C L E I N F O}

\section{Article history:}

Received 22 May 2012

Received in revised form

13 December 2012

Accepted 23 December 2012

\section{Keywords:}

Genetic divergence

Deep-sea fish

Global distribution

Microsatellite DNA

\begin{abstract}
A B S T R A C T
The widely distributed teleost orange roughy, Hoplostethus atlanticus, has been one of the main species targeted in deep-sea fisheries. While morphometric, parasite and otolith analyses have generally found differentiation among populations within ocean basins, genetic techniques have shown contradictory results at different geographical scales. Here, we used nine microsatellite DNA loci to study genetic diversity and differentiation in orange roughy at a global scale using samples from New Zealand, Australia, Namibia, Chile, and the Northeast Atlantic Ocean. Additionally, temporal genetic variation was assessed for eight sites in Northern New Zealand sampled in two different years. The expected heterozygosity was high in all the sites, suggesting high levels of genetic diversity in orange roughy. Overall, we detected low but significant differentiation at the global scale: across the Southern hemisphere and between the Southern hemisphere regions and the Northeast Atlantic Ocean. However, genetic homogeneity was found between New Zealand and Australia. The present data does not showed temporal variation in orange roughy from Northern New Zealand. A pattern of isolation by distance at the global scale suggests stepping-stone migration, which is likely the result of active adult dispersal. This study revealed levels of genetic differentiation at the global scale that were undetected with mitochondrial DNA sequences analyses.
\end{abstract}

(c) 2013 Elsevier B.V. All rights reserved.

\section{Introduction}

The marine environment was once considered a largely "open" system with few boundaries to dispersal of marine organisms. However, increasing research has revealed that many marine species are not panmictic. Despite the potential for widespread dispersal of swimming adults and/or pelagic early life stages, many studies have reported restricted gene flow at different geographic scales in marine fishes. Oceanographic and topographic features, coupled with behavioural characteristics provide barriers for dispersal in marine species. For example, Fauvelot and Borsa (2011) found high levels of genetic divergence in the widely-distributed Spanish mackerel Scomberomorus commerson and suggested that the high migrating ability of this fish may be associated with phylopatric behaviour rather than promoting wide-scale dispersal. In

\footnotetext{
* Corresponding author. Tel.: +56 51 209943; fax: +56 51209812.

E-mail addresses: and.vrl@gmail.com, andrea.varela@vuw.ac.nz (A.I. Varela), Peter.Ritchie@vuw.ac.nz (P.A. Ritchie), h.p.smithnz@gmail.com (P.J. Smith).

1 Current affiliation: Departamento de Biología Marina, Facultad de Ciencias del Mar, Universidad Católica del Norte, Larrondo 1281, Coquimbo, Chile.
}

contrast, there are examples of species with genetically homogeneous populations over wide geographical scales; Wu et al. (2010) found that the yellowfin tuna Thunnus albacares exhibits no genetic differentiation between populations from the Western Pacific and Western Indian Oceans.

Genetic studies are particularly useful for deep-sea species for which tag-recapture techniques are difficult to apply. Population genetics studies have been conducted on deep-sea fishes such as the wreckfish Polyprion americanus (Ball et al., 2000), the tusk Brosme brosme (Knutsen et al., 2009) and the alfonsino Beryx decadactylus (Friess and Sedberry, 2011), among others. While dispersal by larval stages and swimming adults was related to the finding of a single genetic stock in B. decadactylus in the North Atlantic Ocean (Friess and Sedberry, 2011), genetic differentiation among North Atlantic samples of $B$. brosme was related to bathymetric barriers (Knutsen et al., 2009). At a wider scale including samples from the North and South Atlantic Ocean, the Mediterranean Sea, and the South Pacific Ocean, Ball et al. (2000) found three genetic stocks in the wreckfish P. americanus.

Many deep-sea fishes are $K$-selected: they are long-lived, have late maturation and low fecundity. The increased fishing pressure on deep-sea species over the last three decades (see Pitcher 